\title{
ESTABILIDADE A LONGO PRAZO DO TRATAMENTO SEM EXTRAÇÃO DA MORDIDA ABERTA ANTERIOR, NA FASE DA DENTADURA PERMANENTE
}

\section{FABRÍCIO PINELLI VALARELLI}

Dissertação apresentada à Faculdade de Odontologia de Bauru, da Universidade de São Paulo, como parte dos requisitos para a obtenção do título de Mestre em Odontologia, área de Ortodontia.

(edição revista)

Orientador: Prof. Dr. Guilherme R. P. Janson

BAURU 


Valarelli, Fabrício Pinelli
Estabilidade a longo prazo do tratamento sem
extração da mordida aberta anterior, na fase de
dentadura permanente/ Fabrício Pinelli Valarelli. --
Bauru, 2002.
121 p: il. ; $30 \mathrm{~cm}+$ apêndices
Dissertação. (Mestrado) - Faculdade Odontologia de
Bauru. USP.
Orientador: Prof. Dr. Guilherme Janson

Autorizo, exclusivamente para fins acadêmicos e científicos, a reprodução total ou parcial desta tese, por processos fotocopiadores e outros meios eletrônicos.

Assinatura do autor:

Data:

Projeto de pesquisa aprovado pelo comitê de ética em pesquisa da Faculdade de Odontologia de Bauru, Universidade de São Paulo, na reunião do dia 24 de fevereiro de 2000. 


\section{FABRÍCIO PINELLI VALARELLI}

03 de março de 1975

Nascimento

Bauru - SP

1994-1997

Curso de Graduação na

Faculdade de Odontologia de Bauru - USP

$1998-2000$

Curso de Aperfeiçoamento em Ortodontia na ACOPEN - Bauru - SP

2000-2002

Curso de pós-graduação em Ortodontia ao nível de Mestrado na Faculdade de Odontologia de Bauru - USP

Associações

IADR - International Association of Dental Research APCD - Associação Paulista dos Cirurgiões Dentistas APG - Associação dos Pósgraduandos da FOB-USP. 


\section{DEDICO ESTE TRABALHO}

A DEUS, por me iluminar em mais uma jornada, guiando os meus passos para que todos os obstáculos encontrados fossem superados.

Aos meus queridos pais, IVAN e ARLENE, que sempre estiveram ao meu lado me incentivando na busca do conhecimento, compreendendo meus ideais de vida, fazendo o possível e o impossível para o meu enriquecimento humano e profissional e acima de tudo me dando muito amor e carinho além de me proporcionar uma vida cheia de alegria e felicidade. 


\section{Com muito amor e afeto, agradeco}

Aos meus irmãos, Danilo e Liciane, pelo apoio e incentivo incondicional em todos os momentos da minha vida, e pelo grande amor e carinho demonstrados a cada dia.

Ao meu tio José Fernando, que sempre me incentivou a percorrer os caminhos da Ortodontia, estando sempre presente ao menor sinal de dúvida, me apoiando nas decisões mais difíceis.

A minha tia Arlete e primos, Rafael e Fernanda, pelo carinho e estímulos constantes e pela convivência agradável e muito enriquecedora.

A minha avó, Alzira, que nunca deixou de me incentivar e abençoar em todos os momentos de minha vida.

Ao meu tio Ayres, tia Eliane e primas por todos os bons momentos compartilhados e pela palavra amiga e de companheirismo sempre presentes.

Ao meu tio Ivaldo, tia Lana, e primos Thiago e Thalissa pelo incentivo e amizade.

A minha namorada, Thaís, por todo o amor, carinho, compreensão ao longo desses anos e pelos muitos momentos de alegria proporcionados pela sua presença. 


\section{Meu reconhecimento e admiração}

Ao Professor Doutor Guilherme Janson, meu orientador, pelos ensinamentos transmitidos, rigor científico e apurado senso crítico, que muito contribuíram para o meu enriquecimento cultural e aprimoramento no campo da Ortodontia. 


\section{Agradecimentos especiais}

Ao Prof. Dr. José Fernando Castanha Henriques, professor Titular e Chefe do Departamento de Ortodontia, Odontopediatria e Saúde Coletiva da Faculdade de Odontologia de Bauru, por todos os ensinamentos e orientações transmitidas durante toda a minha trajetória na Odontologia.

Aos professores da disciplina de Ortodontia, Dr. Arnaldo Pinzan, Dr. Décio Rodrigues Martins, Dr. Renato Rodrigues de Almeida e Dr. Marcos Roberto de Freitas, pela valiosa contribuição para a minha formação profissional e pela amizade proporcionada nos últimos anos. 


\section{Agradeco}

Aos colegas e amigos do curso de Mestrado, Adriana, Cláudia, Célia, Dani, Denise, Fábio, Fernanda, José Eduardo, José Norberto, Karina, Maria Fernanda, Rejane e Sandra pela agradável convivência e laços de amizade realizados durante o curso.

Ao grande amigo Walter Lázaro Batista, pela palavra sábia e apoio incessante em todos os momentos.

Ao amigo José Eduardo Prado de Souza, pelos momentos compartilhados e por transmitir seus incontestáveis conhecimentos relacionados à pratica Ortodôntica.

A amiga Denise de Carvalho Caffer pela sua generosidade e solicitude quando requisitada para me ajudar a integrar o Grupo Controle e outros aspectos concernentes à finalização desse trabalho.

Ao amigo José Norberto e sua esposa Tatiana, por todos os momentos agradáveis e amizade e ajuda oferecida em todos os momentos.

Ao técnico de informática e colega Daniel Francisco Rascão Selmo, pelo tempo despendido na resolução dos problemas relacionados ao meu pouco conhecimento no campo da informática. 
Ao amigo Murilo Canellas pela ajuda incontestável na correção dos erros e dúvidas advindas ao longo do tempo em relação ao manejo dos "softwares" do computador.

Ao amigo Rodrigo Cançado pela ajuda, amizade sincera, companheirismo e incentivo durante todo o último ano que convivemos.

Aos amigos Cláudio e Rogério pelo convívio de amizade e companheirismo durante todo o curso.

Aos grandes amigos, Luiz, Victor, Henrique, Murilo, João, Maninho, Celinho, Hiroshi, Marcão e Gustavo pela amizade e momentos agradáveis e descontraídos todos esses anos.

Ao Sr. José Marchini, D ${ }^{\text {na }}$ Marilene, Karina e Thiago, pela amizade, carinho e incentivo durante os últimos anos.

Aos colegas do doutorado, pela amizade e transmissão do conhecimento na área de Ortodontia.

Ao professor José Roberto Lauris, por todos os conhecimentos e explicações transmitidas em relação à realização da análise estatística desse trabalho.

Aos funcionários da SDO, Ana Lúcia, Valéria Barbosa, Silvana, Wagner e Leia, e ainda aos colegas de profissão Rodrigo Maraccini, Rodrigo Cançado, Adriana, Thaís, Luciana e Cláudia pela ajuda doada em todos os momentos da realização desse trabalho. 


\section{Agradeço ainda}

Aos funcionários da Disciplina de Ortodontia pela amizade e colaboração para o desfecho desse trabalho.

Aos funcionários da ACOPEN pelo carinho com que sempre me tiveram.

Aos funcionários da Biblioteca, pela atenção e serviços prestados.

Aos pacientes que muito contribuíram para o meu enriquecimento profissional.

A todas as pessoas que contribuíram direta ou indiretamente para a realização desse trabalho.

\section{Agradecimentos administrativos}

Ao Prof. Dr. Aymar Pavarini, Diretor da Faculdade de Odontologia de Bauru - USP.

Ao Prof. Dr. Luiz Fernando Pegoraro, Presidente da Comissão de Pós-Graduação da Faculdade de Odontologia de Bauru - USP.

À Fundação de Amparo à Pesquisa do Estado de São Paulo (FAPESP), pela concessão da bolsa de estudo durante o período de realização deste trabalho. 


\section{SUMÁRIO}

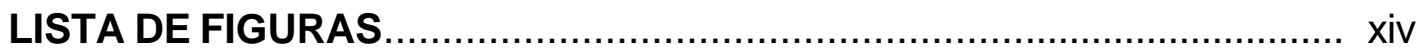

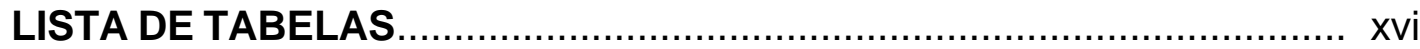

RESUMO

1. INTRODUÇÃO

2. REVISÃO DA LITERATURA..................................................... 4

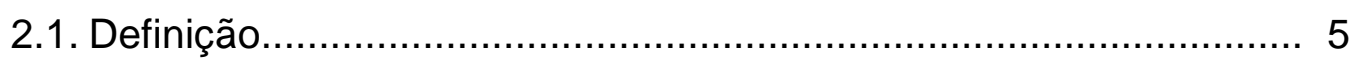

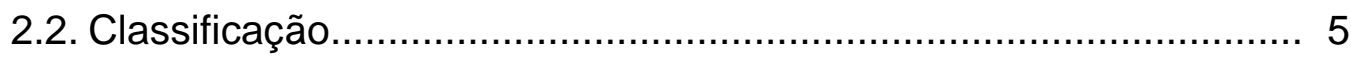

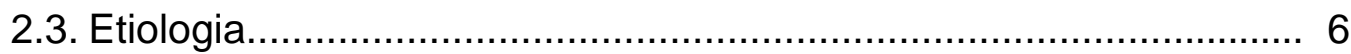

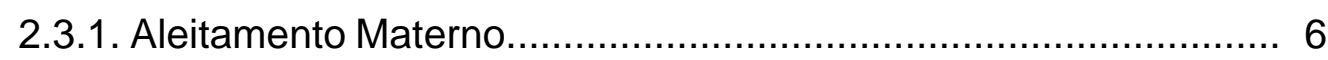

2.3.2. Hábitos de Suç̧ão Digital e Chupeta........................................ 8

2.3.3. Função e Postura Anormal da Língua...................................... 10

2.3.4. Respiração Bucal.............................................................. 12

2.3.5. Hereditariedade .................................................................... 13

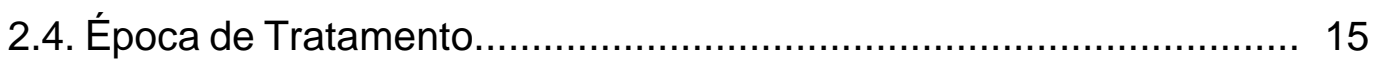

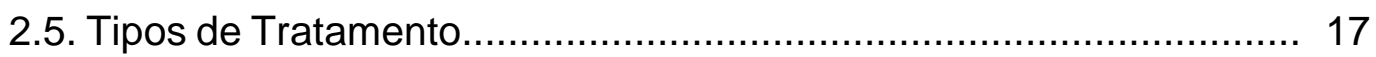

2.5.1. Correção Espontânea.......................................................... 17

2.5.2. Aparelhos Interceptores e Funcionais...................................... 18

2.5.2.1. Grade Palatina................................................................ 19

2.5.2.2. Bionator de Balters fechado............................................... 20

2.5.2.3. Regulador de Função IV .................................................... 21

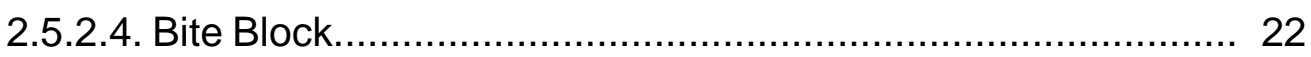

2.5.2.5. Corretor Vertical Ativo.................................................... 23

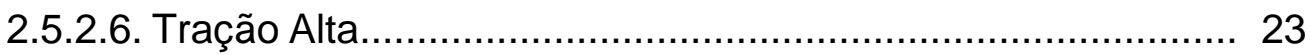

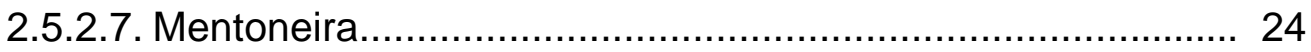

2.5.3. Aparelhos Corretivos.......................................................... 25

2.5.4. Tratamento Ortodôntico-Cirúrgico.......................................... 27

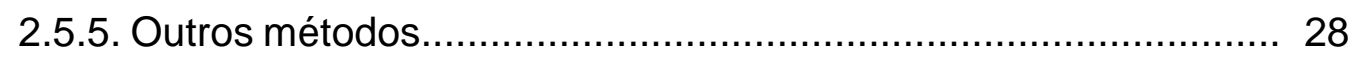

2.6. Estabilidade da Correção da Mordida Aberta Anterior...................... 28 
2.6.1. Dentaduras Decídua e Mista.................................................... 29

2.6.2. Dentadura Permanente.......................................................... 30

2.6.2.1. Tratamento Ortodôntico.................................................. 30

2.6.2.2. Tratamento Ortodôntico-Cirúrgico....................................... 33

2.6.3. Importância do Tratamento Fonoaudiológico............................. 34

3. PROPOSIÇÃO

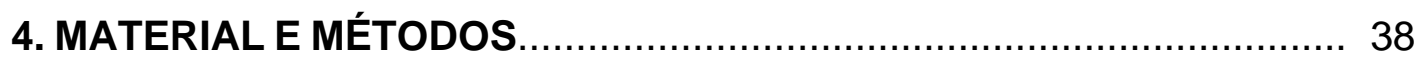

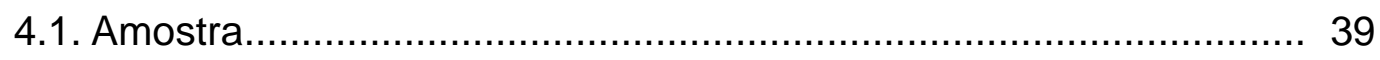

4.1.1. Grupo Experimental........................................................... 39

4.1.2. Grupo Controle 1............................................................ 40

4.1.3. Grupo Controle 2.............................................................. 40

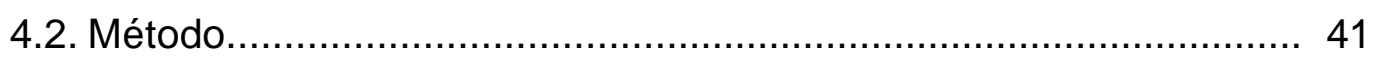

4.3. Traçados e Medição das Radiografias........................................... 42

4.4. Traçado Anatômico.................................................................... 42

4.5. Pontos de Referência................................................................... 43

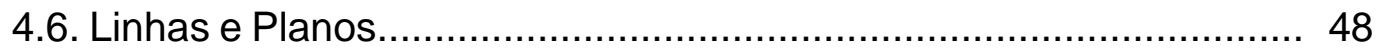

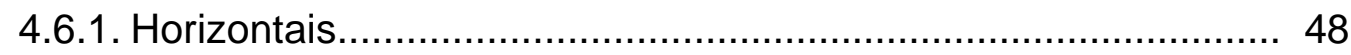

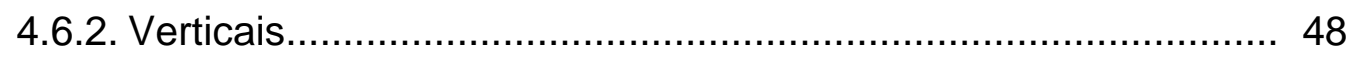

4.7. Grandezas Cefalométricas Esqueléticas.................................... 50

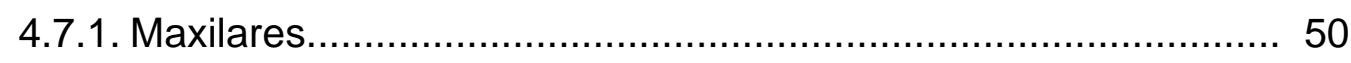

4.7.2. Mandibulares.................................................................... 50

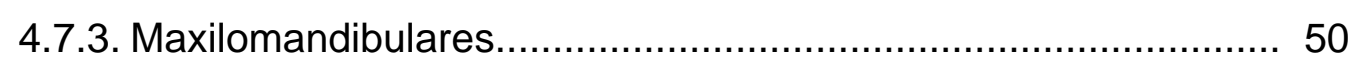

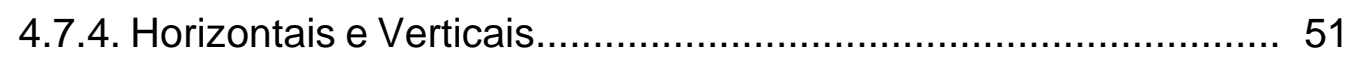

4.8. Grandezas Cefalométricas Dentárias............................................ 53

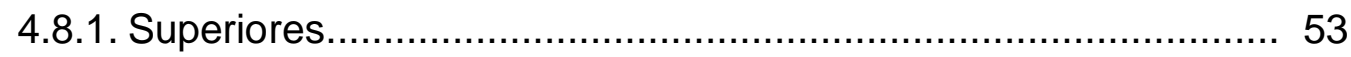

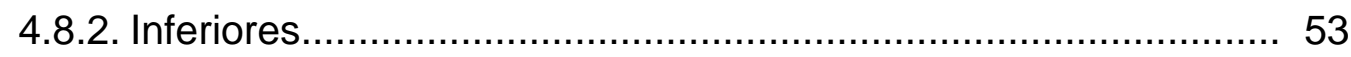

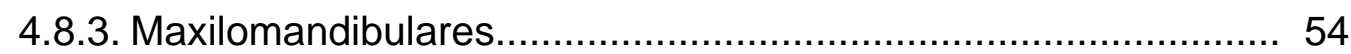

4.9. Medição do Trespasse Vertical................................................. 56

4.10. Protocolo de Tratamento....................................................... 57

4.11. Análise Estatística.............................................................. 57

4.11.1. Erro do Método................................................................... 57 


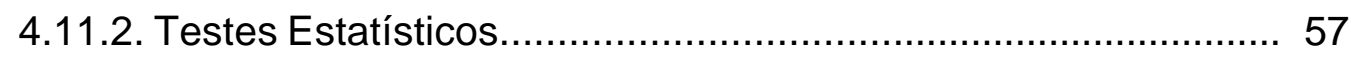

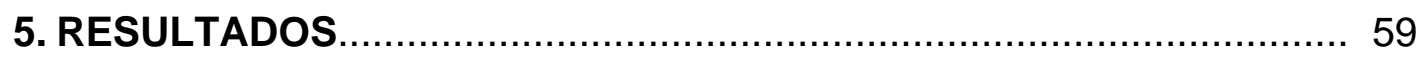

6. DISCUSSÃO

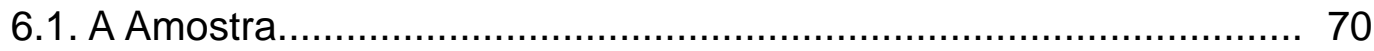

6.1.1. Seleção da Amostra........................................................... 70

6.1.2. Características Cefalométricas................................................ 73

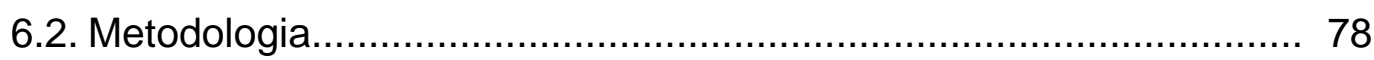

6.2.1. Magnificação das Imagens Radiográficas................................ 79

6.2.2. Mensuração das Grandezas Cefalométricas............................. 79

6.2.3. Medição do Trespasse Vertical.............................................. 80

6.2.4. Precisão da Metodologia...................................................... 82

6.3. Discussão dos Resultados........................................................ 84

6.4. Estabilidade Clínica................................................................ 95

6.5. Considerações Clínicas............................................................. 102

6.6. Sugestões para Futuros Estudos................................................ 102

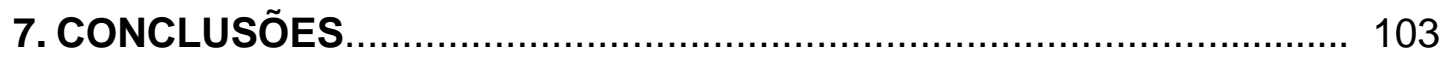

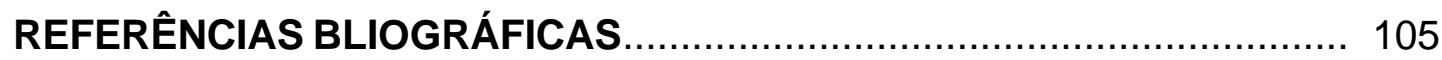

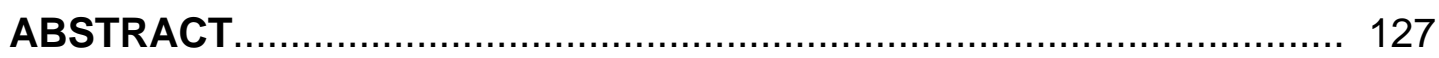

APÊNDICES 


\section{LISTA DE FIGURAS}

FIGURA 1 Pontos de Referência do Traçado Cefalométrico

FIGURA 2 Linhas e Planos

FIGURA 3 Grandezas Cefalométricas Esqueléticas.............................. 52

FIGURA 4 Grandezas Cefalométricas Dentárias................................... 55

FIGURA 5 Representação da forma de medição do trespasse vertical..... 56

FIGURA 6 Representação da forma de medição do trespasse vertical baseando-se no longo eixo dos incisivos inferiores 80

FIGURA 7 Representação da forma de medição do trespasse vertical baseando-se na linha N-Me

FIGURA 8 Representação da forma de medição do trespasse vertical baseando-se no plano oclusal funcional

FIGURA 9 Sobreposição em BaN centrado em CC, dos traçados cefalométricos médios nas fases: antes (T1), final (T2) e após 5 anos do término do tratamento (T3)

FIGURA 10 Sobreposição em $\mathrm{BaN}$ centrado em $\mathrm{CC}$, dos traçados cefalométricos médios nas fases inicial (T1) e final (T2)......... 86

FIGURA 11 Sobreposição em $\mathrm{BaN}$ centrado em CC, dos traçados cefalométricos médios nas fases final (T2) e 5 anos após o tratamento (T3). 
FIGURA 12 Sobreposição em BaN centrado em N, do traçado médio final (vermelho) e 5 anos após o tratamento (verde) do grupo experimental.

FIGURA 13 Sobreposição em BaN centrado em $\mathrm{N}$, do traçado médio inicial (preto) e final (vermelho) do grupo controle 2.

FIGURA 14 Sobreposição (PP em ENA) do traçado médio final (vermelho) e 5 anos após o tratamento (verde) do grupo experimental.

FIGURA 15 Sobreposição (PP em ENA) do traçado médio inicial (preto) e final (vermelho) do grupo controle 2

FIGURA 16 Sobreposição no Plano mandibular do traçado médio final (vermelho) e 5 anos após o tratamento (verde) do grupo experimental.

FIGURA 17 Sobreposição no Plano mandibular do traçado médio inicial (preto) e final (vermelho) do grupo controle 2.

FIGURA 18 Representação dos casos nas fases antes (T1), final (T2) e após 5 anos do tratamento (T3). Primeiramente os casos com estabilidade (de $\mathrm{A}$ à $\mathrm{M}$ ) e em seguida os casos com recidiva "clinicamente significante" ( de $\mathrm{N}$ à $\mathrm{U}$ ). 


\section{LISTA DE TABELAS}

TABELA 1 Médias, desvios-padrão, máximo e mínimo das idades do grupo experimental no início, final e pós tratamento

TABELA 2 Médias, desvios-padrão, máximo e mínimo das idades dos pacientes do Grupo Controle 2, nas fases inicial e final.

TABELA 3 Resultados do teste $t$ independente entre as variáveis do grupo experimental no início do tratamento (T1) e da média da população (grupo controle 1), descrita no Atlas de Crescimento Craniofacial, aos 12 anos.

TABELA 4 Resultados do teste $t$ independente entre as variáveis do grupo experimental no final do tratamento (T2) e da fase inicial do grupo controle 2 (amostra de pacientes com oclusão normal aos 14,6 anos).

TABELA 5 Análise do erro intra-examinador. Apresentação dos erros casuais, das médias, dos desvios-padrão e nível de significância estatística dos erros sistemáticos, entre os traçados repetidos.

TABELA 6 Médias reais e desvios-padrão do trespasse vertical (TRES.V.) nas três fases avaliadas.

TABELA 7 Resultados do teste $t$ pareado e médias reais das variáveis estudadas no período de tratamento (T2-T1).

TABELA 8 Resultado do teste $t$ pareado e médias reais das variáveis estudadas no período médio de 5 anos após o término do tratamento (T3-T2). 
TABELA 9 Resultados do teste $t$ independente entre as alterações das variáveis do grupo experimental no período após o tratamento (T3-T2) e do grupo controle 2 (amostra de pacientes com oclusão normal no período dos 14,6 aos 19,6 anos) 66

TABELA 10 Análise da correlação entre a quantidade de recidiva do trespasse vertical (TRES. V.) e as alterações das variáveis estudadas, entre o final e 5 anos após o término do tratamento (T3-T2).

Tabela 11 Análise da correlação existente da magnitude inicial da mordida aberta anterior (TRES. V. T1) e da quantidade de correção efetuada pelo tratamento (TRES. V. T2-T1) com relação à quantidade de recidiva apresentada após 5 anos do término do tratamento (TRES. V. T3-T2). 68

TABELA 12 Quantidade e porcentagem dos pacientes estudados que apresentaram recidiva "clinicamente significante" após 5 anos do término do tratamento..... 


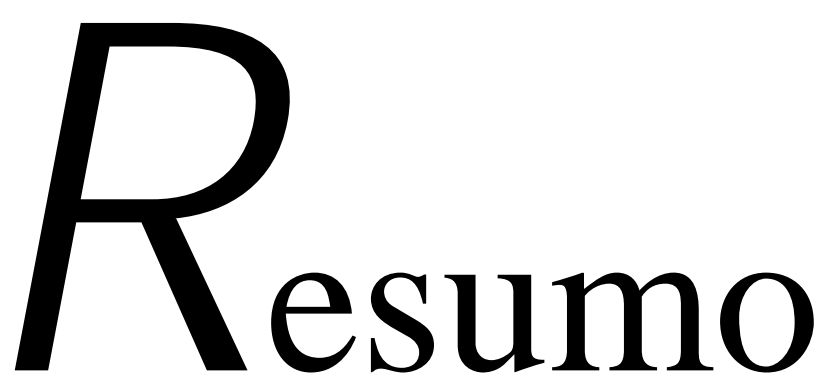




\section{RESUMO}

objetivo desse estudo foi avaliar cefalometricamente a
estabilidade do tratamento sem extração da mordida aberta anterior realizado na dentadura permanente, após um período médio de 5 anos do término do tratamento. O grupo experimental consistiu de 21 pacientes que foram tratados com aparelho fixo, técnica de Edgewise, e que foram radiografados em três períodos: no início do tratamento (T1); imediatamente após o término do tratamento (T2); e após 5 anos, em média, do término do tratamento (T3). Foram utilizados dois grupos controle. O primeiro, em idade compatível ao grupo experimental no início do tratamento, serviu apenas para caracterizá-lo. O segundo grupo controle, de oclusão normal, apresentava um acompanhamento longitudinal, compatível ao período pós-tratamento, que foi utilizado para comparação das alterações entre ambos, nesse intervalo de tempo. As diferenças ocorridas entre as fases intra-grupo experimental foram analisadas pelo teste $t$ pareado $\mathrm{e}$ as alterações pós-tratamento foram comparadas com as alterações do segundo grupo controle pelo teste $t$ independente. Os resultados demonstraram uma recidiva estatisticamente significante da mordida aberta ao final do período pós-tratamento. Os principais fatores que contribuíram para a recidiva foram 0 menor desenvolvimento vertical dos incisivos superiores e inferiores, no período póstratamento. Entretanto, $61,9 \%$ dos casos tratados apresentaram resultados da correção da mordida aberta "clinicamente estáveis". Nem a magnitude inicial da mordida aberta anterior, nem a quantidade total de correção da má oclusão, mostraram-se correlacionadas com a recidiva do tratamento. 


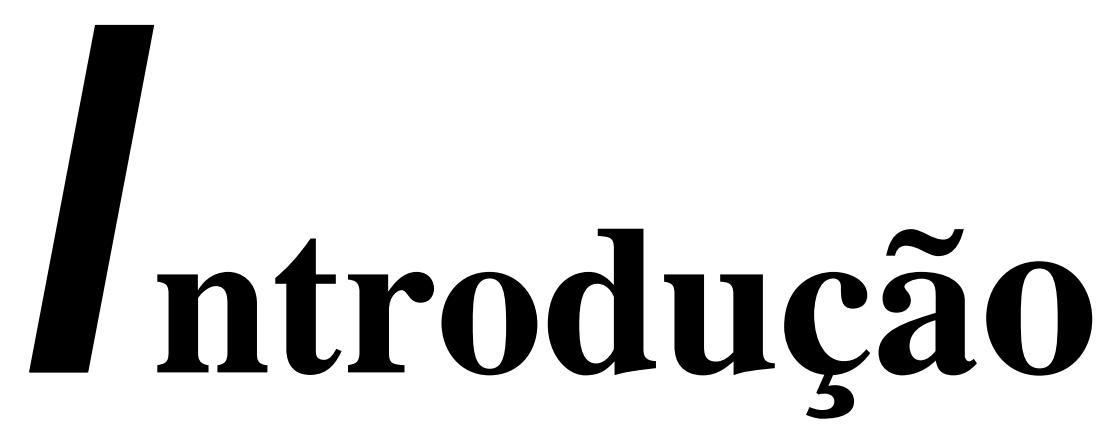




\section{INTRODUÇÃO}

【 nicialmente, as más oclusões no sentido ântero-posterior eram o alvo dos pesquisadores, os quais não atribuíam a devida importância para as discrepâncias verticais e transversais. Nos últimos 20 anos, porém, muitos autores passaram a dar maior valor às displasias verticais, pois perceberam a interdependência entre as proporções faciais nos três planos do espaço $24,62,78,83,139,146,154,155,159,207,225$.

As desarmonias faciais no plano vertical são mais difíceis de serem tratadas e menos estáveis, de acordo com sua gravidade, etiologia e fase em que se introduz o tratamento $49,149,152,156,157,159,225$. Dentre estas, uma que desafia os profissionais é a mordida aberta anterior que pode ser definida como um trespasse vertical negativo na região anterior, estando os dentes posteriores em oclusão. De um modo geral, esta má oclusão acarreta alterações no aspecto estético do indivíduo, dificulta a apreensão e corte dos alimentos e prejudica também os fonemas ${ }^{146,158,213}$.

A mordida aberta anterior deve ser corrigida o mais precocemente possível, proporcionando uma terapêutica mais simples e um prognóstico mais favorável ${ }^{24,33,70,79,83,87,166,201}$. Mas nem sempre o tratamento é realizado na fase ideal e quando isso ocorre, geralmente existe um maior fator esquelético em sua composição, o que sugere, em muitos casos, a associação de um tratamento cirúrgico simultaneamente ao ortodôntico ${ }^{12,14,49,53,63}$.

Atualmente, observa-se que a literatura é escassa em trabalhos sobre mordida aberta anterior, principalmente de estudos direcionados na avaliação da estabilidade e contenção desta má oclusão, depois de tratada ortodonticamente. Os poucos trabalhos que enfocam este tema, ainda assim, apresentam algumas deficiências como o pequeno período de controle do paciente após o tratamento ${ }^{46,110,113,169,191}$ ou uma amostra pequena de casos tratados $^{30,50,68,103,117,121,143,169,191}$ e além disso, trabalhos que não promovem a distinção entre casos com e sem extração ${ }^{87,110,125}$. 
Introducãa 3

Baseando-se nos aspectos acima mencionados decidiu-se realizar um estudo para avaliar a estabilidade dos casos de mordida aberta anterior na fase de dentadura permanente, tratados sem extração, após um período de cinco anos, em média, do término do tratamento (mínimo de 3,2 anos e máximo de 10,4 anos). 

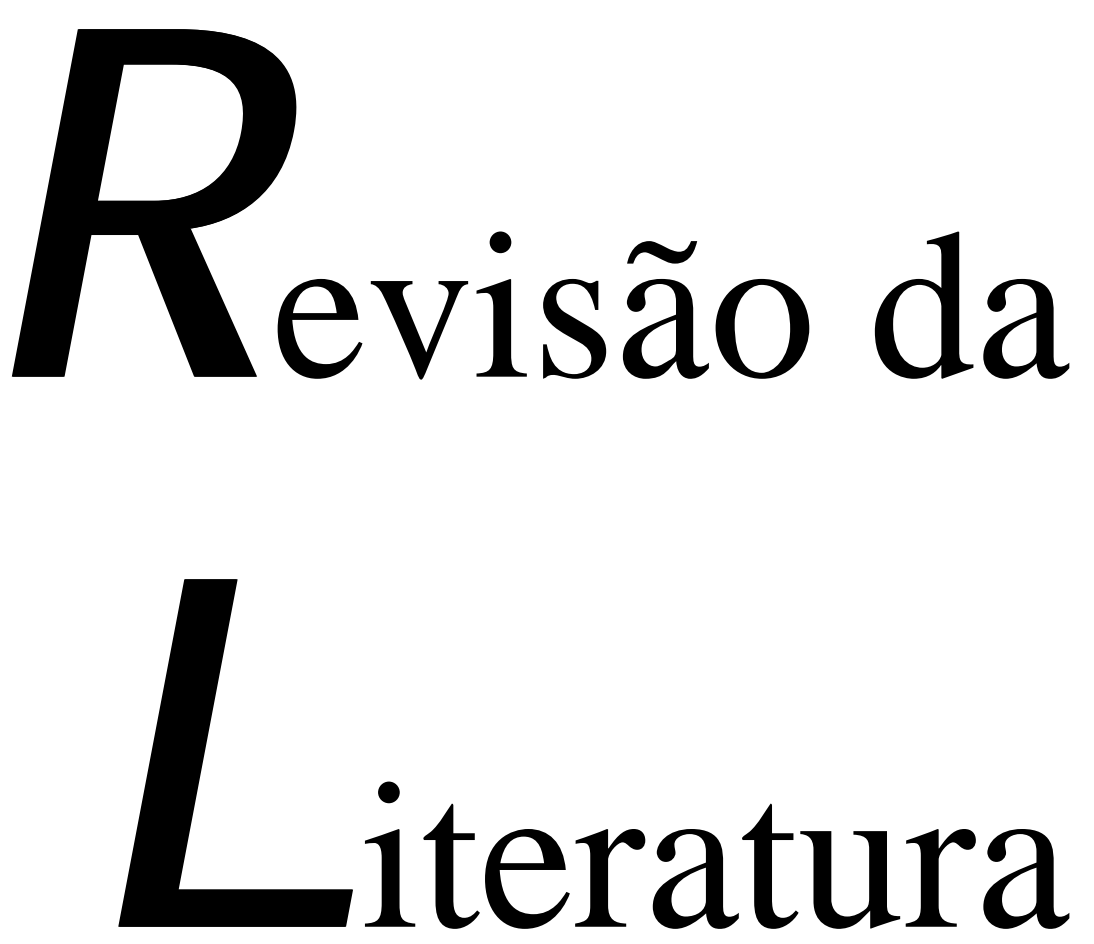


\section{REVISÃO DA LITERATURA}

\subsection{Definição}

mordida aberta anterior é definida como a ausência de contato
entre as bordas dos dentes superiores e inferiores na região anterior, medida verticalmente ${ }^{132,146,158,213,220}$. Consiste principalmente em uma discrepância no sentido vertical que além do envolvimento dos incisivos, algumas vezes se estende aos caninos e com menor freqüência aos prémolares e molares. Essa má oclusão geralmente altera o perfil e acarreta deficiências no aspecto estético do paciente, dificultando a apreensão e corte dos alimentos, além de prejudicar determinados fonemas, expondo o paciente a situações desagradáveis em seu ambiente ${ }^{33}$.

\subsection{Classificação}

Ao longo do tempo, as mordidas abertas têm sido classificadas baseadas tanto na sua etiologia como em sua severidade de expressão. Diversos foram os autores que propuseram uma forma de classificação para esse tipo de má oclusão 40,41,98,127,146,185,213,222,229.

WORMS et $\mathrm{al}^{229}$, em 1971, classificaram essa má oclusão quanto à sua severidade em: simples, compreendida de canino a canino; composta, entre os pré-molares; e infantil, quando atinge os molares. DAWSON ${ }^{40}$, em 1974, classificaram-na mediante a amplitude em: mínima, que se apresenta até $1 \mathrm{~mm}$ de abertura; moderada, cuja abertura está compreendida entre $1 \mathrm{~mm}$ e $5 \mathrm{~mm}$; e severa, que constitui a má oclusão com mais de $5 \mathrm{~mm}$ de abertura.

Em 1981, RICHARDSON ${ }^{185}$, baseando-se na etiologia, propôs a classificação da mordida aberta anterior em: transitória; por hábitos; por patologias bucais; por patologias gerais; por padrão de crescimento; e pela função e morfologia da língua e lábios. Já MOYERS ${ }^{146}$, em 1991, classificou 
as mordidas abertas anteriores em: simples, confinadas aos dentes e processos alveolares; e complexas, dependentes da displasia esquelética vertical.

Porém NAHOUM ${ }^{151}$, em 1975, foi o mais simples e objetivo, dividindo-as em duas categorias distintas: dentária e esquelética. Esse autor acredita que as mordidas abertas dentárias apresentam um desenvolvimento normal de toda a área basal, residindo o problema, exclusivamente, na falta de irrompimento dos dentes anteriores. Já as mordidas abertas esqueléticas apresentam displasias craniofaciais envolvendo a área da base apical com características variadas associadas à má oclusão ${ }^{151}$.

\subsection{Etiologia}

A etiologia da mordida aberta anterior é multifatorial ${ }^{80,87,144,159,225}$, ou seja, diversos fatores que interagindo e operando dentro de um potencial de crescimento inerente a cada indivíduo, promovem essa má oclusão. Portanto, observa-se que esta displasia pode ser muito complexa, não devendo ser considerada morfológica e funcionalmente como uma entidade única, para qual um mecanismo puramente genético é responsável.

Dentre os diversos fatores que estão relacionados, direta ou indiretamente, na etiologia da má oclusão de mordida aberta anterior, alguns merecem destaque como é o caso do aleitamento materno $25,34,37,67,134,199,204,226$, a hereditariedade ${ }^{17,83,131,144,149,159,183,193,194,196,197,225}$, os hábitos deletérios $^{20,70,101,129,153,172}$, a função ou tamanho anormal da língua 5,9,126,174,175,212,216,219,230, a respiração bucal ${ }^{65,78,122,132,148}$, e os traumatismos e patologias congênitas ou adquiridas na região de pré-maxila ${ }^{179}$.

\subsubsection{Aleitamento Materno}

O aleitamento materno desempenha importante papel na saúde do ser humano, abrangendo o desenvolvimento infantil e a saúde da mulher ${ }^{25,37,134}$, 
uma vez que o leite natural é considerado o melhor alimento do ponto de vista nutricional, reforçando a imunidade do bebê contra doenças infecciosas e ainda diminuindo a incidência de câncer mamário ${ }^{3}$.

O ato da sucção, para o recém-nascido, é o maior mecanismo de ligação com o mundo exterior, pois os lábios, nesta fase, constituem-se em um aguçado órgão sensitivo que transmite as percepções exteriores diretamente para o cérebro ${ }^{71}$. Portanto, é durante a amamentação que a criança obtém não só o alimento necessário para suprir a sua demanda fisiológica, como também, as sensações de segurança, aconchego e aceitação, necessárias para o seu bem-estar e desenvolvimento emocional adequado ${ }^{34,67}$.

Ao longo dos anos, diversos autores vêm se preocupando com o estudo da associação entre a forma de aleitamento e a instalação de hábitos bucais deletérios com conseqüente desenvolvimento de más oclusões em crianças. $\mathrm{Na}$ literatura essa associação é muito controversa, com alguns autores relatando não haver essa correlação ${ }^{75,141,161}$ e outros destacando o importante papel da amamentação natural na prevenção da instalação de hábitos deletérios ${ }^{54,118,199,201,204,224}$.

O primeiro livro de odontopediatria publicado, JÓRDON ${ }^{102}$ em 1926, já abordava a importância do aleitamento materno no desenvolvimento do sistema estomatognático descrevendo a maior probabilidade do desenvolvimento de más oclusões em crianças não aleitadas naturalmente.

Em 1977, COMMERFORD et $\mathrm{al}^{35}$ demonstraram que $92 \%$ das crianças que receberam aleitamento materno como forma exclusiva de alimentação nos primeiros 6 meses de vida, não apresentaram hábitos deletérios de sucção. No trabalho realizado por SERRA NEGRA et al $^{199}$ em 1997, o autor relata conclusões similares às de COMMEFORD et $\mathrm{al}^{35}$, onde $86,1 \%$ das crianças que não apresentaram hábitos bucais deletérios receberam aleitamento materno por 6 meses ou mais. Esses autores observam também, a associação existente entre hábitos bucais deletérios e más oclusões e verificam que as 
crianças aleitadas naturalmente até 6 meses de idade possuem menor probabilidade de apresentar más oclusões.

Segundo SANTOS et $\mathrm{al}^{192}$, quando a criança é nutrida com mamadeira, sua demanda fisiológica é satisfeita, mas a necessidade natural que possui de sugar não é suprida nos poucos minutos que permanece no colo da mãe. Assim pode iniciar-se um processo compensatório de sucção digital ou de chupetas, executados nos intervalos das refeições e no momento de dormir.

MARESCA e FERES ${ }^{130}$, em 1992, elaboraram uma teoria para explicar a relação entre aleitamento materno e má oclusão. Segundo os autores, os bebês aleitados de forma natural executam um intenso trabalho muscular ao sugar o seio materno, causando a fadiga da musculatura peribucal. Com isso, a criança dorme sem necessitar da sucção da chupeta, dedos ou outros objetos, os quais são fatores prejudiciais ao desenvolvimento do sistema estomatognático e possibilitam a instalação da mordida aberta anterior.

\subsubsection{Hábitos de sucção digital e chupeta}

A maioria dos autores concorda que os hábitos de sucção digital e chupeta têm uma grande participação na etiologia da mordida aberta anterior $^{20,70,120,129,172,201,205,214}$. Entretanto, o hábito de sucção dos dedos ou chupeta até a idade de 3 anos consiste em um mecanismo de suprimento emocional da criança que não deve sofrer interferência ${ }^{70}$. Isto porque as alterações causadas pela sucção, nesta fase do desenvolvimento da oclusão, restringem-se ao segmento anterior dos arcos dentários e podem ser revertidas espontaneamente com a interrupção do hábito ${ }^{120}$. Além disso, existe uma tendência natural que a própria criança abandone 0 hábito com 0 desenvolvimento de sua maturidade emocional e com 0 início de sua socialização, que normalmente ocorre a partir dos 5 anos de idade ${ }^{200}$.

SWINEHART ${ }^{216}$, já em 1942, relatou em seu trabalho que somente a sucção digital, isolada de outros fatores, não causa mordida aberta anterior. Entretanto, esse hábito deve ser considerado um importante fator etiológico 
dessa má oclusão, pois, quando associado a um potencial genético e permanecendo por longo tempo, pode promover grandes discrepâncias dentoalveolares.

GRABER $^{69}$, em 1958, verificou que a severidade dessa má oclusão varia conforme a intensidade, duração e freqüência com que a criança exerce o hábito de sucção (tríade de GRABER), pois mesmo o tecido ósseo sendo um dos mais duros do organismo, ele se torna muito maleável quando submetido às forças suaves e prolongadas, que podem promover o bloqueio do crescimento do processo alveolar, resultando na mordida aberta anterior ${ }^{200}$.

BOWDEN ${ }^{20}$, em 1966, fez um estudo com 116 pacientes, sendo 58 do gênero masculino e 58 do gênero feminino, os quais foram observados por um período médio de 6 anos, dos 2 aos 8 anos de idade. Nesse trabalho, o autor concluiu que a persistência do hábito de sucção digital ou chupeta leva à acentuação da mordida aberta anterior com maior envolvimento esquelético e, portanto, mais difícil de ser corrigida futuramente.

Em 1975, FERRE ${ }^{57}$ considerou a mordida aberta como uma anomalia provocada, na maioria dos casos, por hábitos anormais de sucção digital ou chupeta e conseqüentemente interposição lingual. O lábio superior torna-se hipotônico e o lábio inferior hiperativo, podendo ser elevado, por contrações do músculo orbicular, para uma posição entre os incisivos durante a deglutição ${ }^{18}$.

$\mathrm{Na}$ revisão de literatura realizada por JOHNSON \& $\operatorname{LARSON}^{101}$, em 1993, conclui-se que a maioria dos autores afirma que a prevalência de pacientes com sucção digital, no início da infância, no gênero feminino é maior do que no gênero masculino. Após essa fase da infância, esses níveis se equiparam e a diferença entre os gêneros passa a ser insignificante $e^{75,84,153}$. O fator sócio-econômico também influencia na sucção digital ou de chupeta, sendo que, pacientes com maiores poderes sócio-econômicos possuem maiores tendências a desenvolverem esse tipo de hábito ${ }^{23}$. 
FERREIRA et $\mathrm{al}^{58}$, em estudo realizado em 2001, avaliaram a prevalência da mordida aberta anterior em crianças até 5 anos, conclíram que $100 \%$ das crianças que apresentavam essa má oclusão, tinham como hábito a utilização da chupeta.

O hábito de sucção digital, ou da chupeta, além de restringir o crescimento do processo alveolar anterior, com o conseqüente bloqueio do irrompimento dos dentes anteriores, propiciará uma condição apta para o desenvolvimento da mordida cruzada posterior ${ }^{31,178}$. Isso acontece porque o posicionamento do polegar no palato mantém a língua numa posição mais inferior, afastando-se do contato com os dentes posteriores, permitindo que haja um rompimento do equilíbrio natural existente entre a língua e a musculatura peribucal ${ }^{200,217}$.

\subsubsection{Função e postura anormal da língua}

Quando existe um padrão morfogenético normal, a língua e a musculatura peribucal promovem a homeostasia local. Porém, qualquer interferência nessa homeostasia, no período ativo de crescimento das estruturas da face, pode alterar a morfologia e função do sistema estomatognático, rompendo 0 equilíbrio dentário e prejudicando 0 desenvolvimento oclusal e esquelético normal ${ }^{32,61,71,170,176,198}$.

A função anormal da língua e sua postura $5,76,117,124,126,146,174,175,195,219,230$, e a obstrução das vias aéreas superiores (buco e nasofaringe) com hipertrofia da adenóide ${ }^{122,123,144}$, também são causas apontadas para o desenvolvimento da mordida aberta anterior.

Observa-se na literatura que, antigamente, a interposição lingual era apontada como uma das principais causas da mordida aberta anterior ${ }^{9,212,216}$. Atualmente, a interposição lingual é considerada como um hábito secundário, pois, origina-se principalmente por uma adaptação do espaço existente causado por sucção digital ou chupeta, portanto, atua mais como um agravante 
da mordida aberta do que propriamente como seu fator causal $^{14,158,174,202,203,206,214}$.

ANDERSEN ${ }^{5}$ em 1963, relatou que a função anormal da língua pode causar mordida aberta anterior, assim como várias outras más oclusões. Concluiu que a natureza da função anormal da língua é muito complexa e que depois do tratamento ortodôntico, a maioria das funções da língua se normalizam. Três anos mais tarde, em 1966, ATKINSON ${ }^{9}$ considerando a língua como um poderoso fator etiológico durante a deglutição, afirmou que esta estimularia o crescimento da pré-maxila e da mandíbula para frente, além de evitar o contato entre os dentes ântero-superiores e inferiores.

Ao analisar a correção das mordidas abertas anteriores, BELL ${ }^{14} \mathrm{em}$ 1971, afirmou que os portadores desse tipo de má oclusão apresentam uma posição crônica da língua para frente, permanecendo, em repouso, entre os dentes anteriores. Essa posição é observada também no ato de deglutição.

SUBTELNY \& SUBTELNY ${ }^{214}$, em 1973, relataram em seu estudo, a necessidade de se realizar primeiramente o tratamento da má oclusão, para que posteriormente a língua apresente condições de função dentro da normalidade ${ }^{206,225}$. Na maioria das vezes, com a correção morfológica, também se obtém a funcional, embora em alguns casos seja necessária a readaptação da língua em seu novo ambiente, para evitar as recidivas ${ }^{212}$.

A deglutição atípica foi destacada por JARABAK \& FIZZEL ${ }^{98}$, em 1975. Os autores afirmam sua origem de duas hipóteses: um hábito, cujo tratamento normaliza a má oclusão; ou, uma consequêencia da própria mordida aberta anterior, que pela forma alterada dos tecidos morfológicos, a língua é pressionada entre os dentes anteriores durante 0 ato de deglutição.

A interposição lingual pode ocorrer também nos casos de hipertrofia das amígdalas palatinas, na região da bucofarínge ${ }^{78}$. Esse aumento que pode ocorrer isolada ou conjuntamente com obstrução das vias aéreas superiores, gera uma alteração postural da língua e mandíbula. $O$ contato da porção 
posterior da língua com as amígdalas aumentadas, promove uma sensação dolorosa e a língua é projetada para frente e para baixo, num movimento reflexo, interpondo-se entre os incisivos e favorecendo o desenvolvimento da mordida aberta anterior.

\subsubsection{Respiração Bucal}

O hábito de respirar pela cavidade bucal está presente em cerca de $83 \%$ dos casos de mordida aberta anterior causada por sucção digital ou de chupeta $^{202}$. A língua, em vez de pressionar o palato, fica numa posição mais abaixada e a mandíbula posiciona-se póstero-inferiormente, liberando os dentes posteriores para uma erupção passiva, proporcionando um aumento da altura facial ântero-inferior e da convexidade facial ${ }^{132}$.

HARVOLD $^{78}$, em 1981, relatou em sua pesquisa envolvendo animais cuja respiração nasal foi bloqueada, que todos desenvolveram respiração bucal e conseqüentemente algumas características comuns como: aumento na altura facial, plano mandibular e ângulo goníaco. O autor ressalta que não se pode correlacionar a respiração bucal como fator causal de uma determinada má oclusão, embora esteja associada à mordida aberta anterior como um fator secundário.

Em 1986, LINDER-ARONSON et al ${ }^{122}$, concluíram que há associação entre a adenoidectomia, realizada para melhorar a respiração do paciente, e a direção de crescimento da mandíbula, que adquire novamente uma direção de crescimento mais horizontal após a cirurgia. Afirmação semelhante foi citada por NAGAHARA et $\mathrm{al}^{148}$, em 1966, que relataram que em pacientes com hipertrofia das amígdalas palatinas e ou adenóides, a língua e o osso hióide estão posicionados anteriormente, gerando uma respiração bucal e propiciando a mordida aberta anterior. Nesse caso, uma tonsilectomia ou adenoidectomia é necessária para a normalização do posicionamento da língua e conseqüente respiração nasal ${ }^{65,78}$. 
MARTINS et al. ${ }^{132}$, em 1994 salientaram que a respiração bucal está presente em grande parte dos pacientes com mordida aberta anterior. Ponderaram que a obstrução das vias aéreas superiores e a conseqüente deficiência na respiração endonasal podem ocorrer por diversos fatores, como: hipertrofia dos cornetos, devido a rinites alérgicas; más formações septais, como desvios de septo; presença de pólipos nos tecidos nasais, principalmente por fatores alérgicos; hipertrofia da adenóide e desenvolvimento de pólipos, cistos e tumores na região nasofaríngea; e hipertrofia das amígdalas palatinas, que pressionam o palato mole contra a parede posterior da nasofaringe, diminuindo a passagem de ar pela cavidade nasal ${ }^{163,200}$.

\subsubsection{Hereditariedade}

Outro fator importante da etiologia dessa má oclusão é a hereditariedade ${ }^{139,149,152,154,157,159,194,195,196,216}$, pois o indivíduo já nasce com os genes que controlam os padrões individuais de crescimento definidos e quanto mais vertical for sua tendência de crescimento, maior é a probabilidade de apresentar mordida aberta anterior ${ }^{17,152,154,159,194,197}$, principalmente se esse fator estiver associado concomitantemente à outros como: hábitos bucais deletérios, deglutição atípica e respiração bucal ${ }^{83,144}$.

A mordida aberta anterior, quando o fator etiológico não é ambiental, geralmente está associada com as faces longas ou adenoideanas, que por envolverem características faciais semelhantes, são denominadas de "síndrome da face longa"139,152,155,196. Os valores cefalométricos citados na literatura para evidenciar o excesso de crescimento vertical apontam tanto para a participação da maxila, como da mandíbula na determinação da face longa. Alguns autores acreditam que existe um excesso vertical maxilar com maior irrompimento dos dentes superiores ${ }^{17,63,90,131,193,194}$. A altura dentoalveolar está aumentada tanto na região dos molares quanto dos incisivos. Esse excesso superior induz a rotação da mandíbula no sentido horário, tornando os planos e linhas faciais divergentes em relação à base do crânio, com aumento dos ângulos SN.GoGn, SN.Gn e AFAI ${ }^{90,131,183,193,195,213}$. 
CASE $^{26}$, em 1921, foi o primeiro autor a relacionar a mordida aberta anterior com um pobre desenvolvimento mandibular e o ângulo formado entre 0 ramo e o corpo muito obtuso. Posteriormente, outros autores confirmaram essa conclusão estudando outras medidas mandibulares ${ }^{82,194,211}$. Esse hipodesenvolvimento ocasiona uma rotação mandibular no sentido horário, o que proporciona uma maior tendência ao desenvolvimento desse tipo de má oclusão $24,91,108,149,194,213$.

SCHUDY ${ }^{197}$, em 1965, avaliou a rotação mandibular resultante do crescimento e afirmou que a variação no crescimento dos côndilos e na área dos molares são responsáveis pela rotação do corpo da mandíbula. Concluiu que o extremo dessa condição leva à instalação da mordida aberta anterior. Também afirmou que o tamanho do ângulo goníaco e o grau de divergência facial têm efeito sobre a rotação mandibular.

Em 1971, analisando as proporções verticais da face NAHOUM ${ }^{149}$ afirmou que muitas mordidas abertas anteriores são deficiências de crescimento da face superior e posterior. Entretanto alguns pacientes apresentavam este tipo de má oclusão com a altura da face posterior dentro dos padrões normais de crescimento. O autor destaca também que ocorre um aumento compensatório na altura facial ântero-inferior.

Em 1978, MIZRAHI ${ }^{144}$ relacionou a hereditariedade com outros fatores não hereditários como: sucção digital ou de chupeta; função anormal da língua; trauma ou patologia no côndilo; distúrbios neurológicos e ainda outros fatores iatrogênicos. O autor chegou a conclusão de que se a hereditariedade estiver associada a um desses fatores, o paciente terá uma grande probabilidade de apresentar mordida aberta anterior.

Estudando as diferenças entre indivíduos com padrão de crescimento vertical e horizontal, LUNDSTROM \& WOODSIDE ${ }^{128}$, em 1981, afirmaram que os primeiros apresentam a altura total da face inferior maior, resultando em faces mais longas. Verificaram também, que nesses mesmos indivíduos há maior retrusão mandibular. 
Analisando pacientes com faces longas que apresentavam má oclusão de mordida aberta anterior, MERVILLE \& DINER ${ }^{139}$, em 1987, verificaram um excesso maxilar no sentido vertical, na região dentoalveolar posterior ocasionada por meio da extrusão de molares e pré-molares. Verificaram também uma deficiência dentoalveolar mandibular no sentido vertical pela extrusão compensatória dos incisivos. O ângulo goníaco se apresentava com valor elevado nesses casos.

DUNG \& $\mathrm{SMITH}^{48}$, em 1988, publicaram um artigo que analisa cefalometricamente as características do paciente com mordida aberta anterior e concluíram que nem todos os pacientes que possuem um padrão vertical excessivo, herdado de seus pais, possuem a má oclusão e também pacientes com o padrão horizontal predominante são passíveis de apresentar mordida aberta anterior, embora raramente. Isso acontece porque existem fatores etiológicos dessa má oclusão que não podem ser mensurados cefalometricamente, como é o caso da sucção digital, interposição lingual e respiração bucal.

STAGGERS ${ }^{207}$, em 1994, relata que os pacientes com crescimento vertical excessivo possuem os piores prognósticos de tratamento. Muitos desses pacientes apresentam deficiência no comprimento do arco, requerendo extrações dentárias.

\section{4. Época de tratamento}

Quando a má oclusão de mordida aberta anterior é diagnosticada, vários fatores devem ser considerados antes de qualquer intervenção. Primeiramente deve-se realizar um exame detalhado do paciente para elucidar as possíveis causas relacionadas ao problema: um distúrbio respiratório, um problema emocional, uma alteração funcional ou uma combinação de todos. Após essas considerações, deve-se observar a faixa etária do paciente para a definição do plano de tratamento e a época em que será instituído. 
A grande maioria dos autores recomenda o início do tratamento da mordida aberta anterior o mais precoce possível, isto é, entre os 4 e 6 anos de idade. Antes dessa idade, o hábito de succionar o dedo ou chupeta pode ser considerado normal ${ }^{70,205}$, já que faz parte do desenvolvimento emocional da criança, e as possíveis conseqüências dentárias prejudiciais não são permanentes para a oclusão ${ }^{120}$. No entanto, nesta fase, mesmo que o problema ortodôntico não seja imediatamente corrigido, é importante que todos os fatores predisponentes da má oclusão sejam eliminados, como distúrbios de função ou respiratórios ${ }^{170}$.

Com a intervenção precoce diante dessa má oclusão, isto é, na dentadura decídua ou mista, as chances de sucesso do tratamento se elevam e há menor propensão à recidiva ${ }^{9,24,71,87,158,166}$. Os autores dessa afirmação estão de acordo com BIEN et al ${ }^{15}$, que em 1955, concluíram em seu estudo que o tratamento da mordida aberta deve ser feito precocemente, pois nesse estágio, essa má oclusão é facilmente corrigida somente com a interrupção do hábito.

SILVA FILHO et al. $^{200}$, em 1986, mencionaram algumas justificativas para o início do tratamento da mordida aberta anterior precocemente: a criança, na idade de 4 a 6 anos, já adquiriu capacidade de compreensão que facilita o seu condicionamento pelo profissional; existe uma grande probabilidade de auto-correção morfológica se a criança interromper o hábito; grande flexibilidade óssea, o que permite um prognóstico de tratamento mais favorável; permite o correto irrompimento dos dentes anteriores; e, proporciona um contato social normal com seus colegas, refletindo um bom desenvolvimento emocional. Quanto mais tarde for instituído o tratamento, maior a participação de fatores esqueléticos e com isso a mordida aberta anterior se torna mais difícil de ser tratada, sendo muitas vezes necessário o auxílio da cirurgia ortognática para sua correção ${ }^{213}$.

Em 1995, SILVA FILHO et al. ${ }^{203}$ relataram que se a má oclusão não se corrigir espontaneamente durante a fase de dentadura decídua, torna-se 
necessária a intervenção do ortodontista para que seja possível uma correção precoce da má oclusão e um desenvolvimento harmonioso dos maxilares com o passar dos anos, concordando com a teoria da matriz funcional de MOSS ${ }^{145}$.

CHASE $^{29}$, em 1993, relatou em seu trabalho que é importante intervir precocemente na má oclusão, pois com o passar do tempo, aumentam as chances de agravamento das alterações dentoalveolares já instaladas, dificultando sua correção. Para tanto, é necessária a eliminação dos hábitos deletérios e dos problemas funcionais associados ao quadro da má oclusão o mais precoce possível.

Entretanto, nada deve ser imposto alheio à vontade da criança, pois, todo hábito tem uma raiz emocional. Muitas vezes, a tranqüilidade da sucção digital ou da chupeta, oculta um imensurável problema emocional, o qual exige um acompanhamento psicológico ${ }^{59,111,218}$. Dessa forma, a frase elaborada por WATSON ${ }^{225}$ se torna de extrema veracidade e importância: "É preferível deixar uma criança alegre com mordida aberta anterior que psicótica com boa relação dos incisivos".

\subsection{Tipos de tratamento}

Por existirem inúmeras teorias sobre os fatores etiológicos da mordida aberta anterior, verifica-se na literatura uma grande variedade de filosofias de tratamento, apoiadas em diferentes mecanismos terapêuticos. Com base nesses autores, podemos citar os principais aparelhos e métodos utilizados para o tratamento dessa má oclusão, os quais serão descritos abaixo em forma de tópicos.

\subsubsection{Correção espontânea}

Quando o hábito deletério é abandonado espontaneamente na dentadura decídua, até aproximadamente os 5 anos de idade, existe uma forte tendência para a auto-correção da má oclusão ${ }^{64,100,111,119,120,142,172}$. No entanto, 
isso nem sempre ocorre, estando na dependência de diversos outros fatores além da época de interrupção do hábito. Dentre os fatores mais relatados estão: padrão dentofacial da criança, gravidade da má oclusão, competência da musculatura peribucal e instalação de outros hábitos como: pressionamento lingual atípico, postura inadequada da língua em repouso, respiração bucal e hábitos labiais ${ }^{200}$.

A maioria dos autores acredita que a mordida aberta anterior pode ser corrigida espontaneamente se removido o fator etiológico, durante a fase de dentadura decídua ou início da dentadura mista. Alguns estudos comprovam essa afirmação, pois concluem que ocorre uma diminuição gradativa da incidência da mordida aberta anterior, devido ao seu próprio desenvolvimento oclusal, a maturação do indivíduo, facilitando a eliminação de hábitos deletérios, a diminuição de tamanho das adenóides e o estabelecimento de uma deglutição normal $\left.\right|^{33,76,225,229}$.

VATTEONE $^{222}$, em 1969, relata no seu estudo que a eliminação do hábito de sucção digital ou chupeta, é um fator necessário para que ocorra a correção espontânea da mordida aberta anterior. O autor ainda cita que quando a criança entra numa fase de maior socialização, o hábito danoso é mais facilmente removido.

\subsubsection{Aparelhos interceptores e funcionais}

No tratamento precoce dessa má oclusão os aparelhos utilizados têm a finalidade de eliminar hábitos deletérios ${ }^{62,87}$, liberando o crescimento das estruturas que compõem o mecanismo de oclusão. Nesse período, os aparelhos mais utilizados são: a grade palatina fixa ou removível ${ }^{87,103}$. Os tecidos morfologicamente alterados, como adenóide e amígdalas também devem ser normalizados a fim de proporcionar condições favoráveis para 0 tratamento da mordida aberta anterior ${ }^{62,65,78,122}$.

\subsubsection{Grade palatina}


A grade palatina é descrita por vários autores como o melhor aparelho para a correção da mordida aberta anterior ${ }^{55,87,103,135}$. Esse aparelho é utilizado no arco superior e pode ser fixo ou removível, dependendo do grau de colaboração do paciente. A grade palatina é um aparelho passivo, ou seja, não exerce nenhum tipo de força sobre as estruturas dentárias, agindo somente como um obstáculo mecânico que não só impede a sucção digital ou da chupeta, como também mantém a língua numa posição mais retruída, impedindo sua interposição nos dentes anteriores ${ }^{87,132,201,213}$. Adicionalmente, o arco vestibular que acompanha o aparelho removível pode ser ativado no intuito de corrigir uma inclinação desfavorável dos dentes ântero-superiores ${ }^{202}$.

ROGERS ${ }^{189}$, em 1927, foi um dos primeiros autores a relatar a utilização da grade palatina para a correção da mordida aberta anterior. $O$ aparelho era fixo e apresentava em sua parte anterior quatro pontas afiadas (esporões) que visavam a reeducação da posição da língua. Em 1950, MASSLER \& CHOPRA $^{135}$ utilizaram o mesmo aparelho modificado apenas por não apresentar os esporões. Esses autores, assim como SUBTELNY \& SAKUDA $^{213}$ em 1964 e HARYETT et al $^{79}$ em 1967, preconizavam que o aparelho não necessitava apresentar formas punitivas ao paciente para promover a correção da mordida aberta anterior.

HARYETT et al ${ }^{79}$, em 1967, concluíram que a utilização da grade palatina com esporões é uma meio muito eficiente para a remoção do hábito de sucção digital e reeducação da função e postura da língua. Descreveram, ainda, que existem alguns fatores desfavoráveis em relação ao uso da grade palatina como: dificuldade na pronúncia, período temporário de ajuste e adaptação e dificuldades na alimentação.

Em 1976, JUSTUS ${ }^{103}$ apresentou o tratamento de 8 casos de mordida aberta anterior, sendo que, somente um paciente era adulto e, portanto, apresentava-se na dentadura permanente. Esses pacientes foram tratados com uma grade palatina fixa que impedia a sucção digital e a interposição lingual por meio de esporões. Associava uma tração extrabucal vertical 
visando a intrusão dos dentes posteriores para o fechamento da mordida aberta anterior e obteve êxito no tratamento de todos os pacientes.

EVERDI et $\mathrm{al}^{55}$, em 1992, avaliando os efeitos da grade palatina em pacientes com dentadura mista, concluíram que essa reeduca a postura da língua e libera o crescimento do processo alveolar superior e inferior. Além disso, a grade palatina altera o equilíbrio existente entre os lábios e a língua, promovendo a lingualização e extrusão dos incisivos superiores e inferiores, uma vez que existia um "déficit" de crescimento do processo alveolar anterior, que se normaliza após a remoção do hábito 201.

\subsubsection{Bionator de Balters fechado}

O Bionator de Balters fechado é indicado por diversos autores para a correção da mordida aberta anterior causada por interposição lingual e sucção digital ou de chupeta $29,73,162,226$. Esse aparelho proporciona função e postura normal para a língua, orientada pela alça palatina. Possui uma porção de acrílico na região oclusal posterior para prevenir a extrusão dentária e estendese até a porção anterior, desde a região palatina dos dentes superiores até a lingual dos inferiores, inibindo a pressão ou interposição lingual e propiciando o vedamento da mordida aberta anterior. Além disso, confecciona-se um arco vestibular para estimular o selamento e estiramento labial, favorecendo o movimento extrusivo dos dentes ${ }^{56,72,132}$.

GRABER et al. ${ }^{72}$, em 1985, explicaram que esse aparelho foi baseado nos ativadores de Robin, Andresen e Haüpl e que segundo o projeto inicial de Balters, o equilíbrio entre os músculos peribucais e a língua é o responsável pela forma dos arcos dentários, sendo, a língua, o centro das atividades reflexas na cavidade bucal.

Para CHASE $^{29}$, em 1993, este aparelho tem maior potencial de ação quando utilizado em pacientes na fase de crescimento. Para seu idealizador, o propósito do Bionator de Balters é estabelecer uma boa coordenação funcional 
e eliminar os fatores que podem restringir o crescimento, adaptando ativamente a musculatura peribucal.

\subsubsection{Regulador de Função IV}

O regulador de função, RF IV, desenvolvido por Frankel, é indicado especialmente para a correção de más oclusões de Classe I com mordida aberta anterior. O pesquisador explica que este aparelho é composto por escudos laterais, escudos labiais inferiores, um arco labial superior, um arco palatino e quatro apoios oclusais ${ }^{62}$.

O tratamento é indicado na fase inicial da dentadura mista, pois sua terapêutica consiste na normalização das funções da língua e da musculatura peribucal, evitando o aparecimento da mordida aberta anterior assim como outras deformidades. Mas também pode ser utilizado na dentadura permanente, após o tratamento com aparelhos fixos, como meio de contenção, evitando a recidiva da má oclusão ${ }^{62}$.

Para FRANKEL ${ }^{61}$, quando publicou seu estudo em 1969, a relação forma-função é muito importante e não existiria influência genética direta na forma, tamanho e posição dos tecidos ósseos, como defendia a Teoria da Matriz Funcional de MOSS ${ }^{145}$, em 1962, e que função neuromuscular influi diretamente sobre a forma dos ossos, principalmente porque os ossos craniofaciais, em sua maioria, são de origem intramembranosa, sendo portanto, mais susceptíveis às influências biomecânicas.

Posteriormente, FRANKEL \& FRANKEL ${ }^{62}$, em 1983, relataram que a teoria do controle epigenético, desenvolvida por Limborgh, em 1970, é uma melhor forma de explicar seus conceitos de crescimento e desenvolvimento craniofacial. Essa teoria se baseia na conciliação da teoria genética com a teoria da matriz funcional, ou seja, a programação genética não contém todas as informações necessárias ao completo desenvolvimento do complexo craniofacial e, portanto, seriam susceptíveis às alterações provocadas pela função das matrizes funcionais ${ }^{62}$. 
HAYDAR \& ENACAR ${ }^{80}$ em 1992, estudaram a performance do regulador de função RF IV na correção das mordidas abertas anteriores e concluíram que: o aparelho RF IV não produz alterações esqueléticas; ocorreram alterações não significantes na porção facial; e o irrompimento vertical dos incisivos superiores e inferiores são responsáveis pelo fechamento da mordida aberta, portanto, esse aparelho altera as estruturas dentárias antes que se tornem esqueléticas, não melhorando o padrão facial, mas mascarando o problema vertical existente.

\subsubsection{Bite Block}

Historicamente, a terapia com "Bite Block" tem demonstrado ser eficaz. Embora a maioria dos estudos realizados com esse tipo de aparelho tenha sido desenvolvida em amostras com animais ${ }^{4,22,136}$, o "Bite Block" é descrito pelos pesquisadores como um aparelho que obtém melhores resultados se utilizado precocemente ${ }^{45,91,163,215}$. Todavia, vários autores afirmam obter resultados satisfatórios no tratamento de pacientes adultos ${ }^{163}$.

A correção ocorre pela inibição da erupção dentária no segmento posterior, denominada de "intrusão relativa"168, e extrusão dos incisivos superiores e inferiores, gerando rotação para cima e para frente da mandíbula ou uma direção de crescimento mandibular mais horizontal ${ }^{4,22,136}$. Segundo KUSTER \& INGERVALL ${ }^{115}$, em 1992, é importante que a espessura desse aparelho exceda o espaço funcional livre em 3 ou $4 \mathrm{~mm}$, para que esse aumento forçado da dimensão vertical, promova a intrusão dos dentes posteriores. Embora, atualmente, preconiza-se 3 a $4 \mathrm{~mm}$ de espessura para 0 aparelho, dimensões maiores foram utilizadas no passado ${ }^{215}$.

ALTUNA \& WOODSIDE ${ }^{4}$, em 1985, relataram que cada $1 \mathrm{~mm}$ de intrusão dos dentes posteriores implica em, aproximadamente, $3 \mathrm{~mm}$ de fechamento da mordida aberta na região anterior. KILIARIDIS et $\mathrm{al}^{106}$, em 1991, estudaram a os resultados do tratamento do "bite block" com e sem magnetos, e verificaram 
que, esses aparelhos associados aos magnetos provocam uma intrusão mais rápida do segmento posterior.

\subsubsection{Corretor Vertical Ativo}

O Corretor Vertical Ativo se apresenta como um "bite block" associado a magnetos repelentes de samário-cobalto nas placas interoclusais superior e inferior, por oclusal dos dentes que sofrerão o movimento de intrusão ${ }^{44}$. Segundo WOODS \& NANDA ${ }^{227}$, em 1991, a grande vantagem na utilização dos magnetos consiste na liberação de uma força contínua de 600 a 700 gramas, diferentemente da força muscular intermitente provocada pelo "bite block" convencional. Essa combinação provou ser um método eficiente de fechamento da mordida aberta anterior ${ }^{11}$. Segundo DELLINGER ${ }^{45}$, em 1997, esse aparelho pode promover o tratamento de mordidas abertas esqueléticas com grande rapidez e estabilidade a longo prazo.

KALRA $^{104}$ et al, em 1989, analisaram os efeitos do tratamento realizado pelos Corretores Verticais Ativos (CVA). Observaram que houve um aumento do comprimento mandibular, intrusão dentária, e uma rotação para cima e para frente da mandíbula. Esses autores também alertam que grande parte dos pacientes submetidos ao tratamento com esse tipo de aparelho desenvolveu assimetrias nos arcos dentários e mordida cruzada posterior. Isso pode ser explicado pela força contínua de cisalhamento liberada pela repelência entre os magnetos, e apresentou caráter reversível em humanos ${ }^{227}$.

\subsubsection{Tração alta}

O aparelho extrabucal (AEB) com tração alta é descrito na literatura como meio de se controlar a extrusão dos dentes pósterosuperiores ${ }^{10,114,132,144,159,168,190}$. Para um efeito ortopédico, esse aparelho pode ser utilizado por um período de 12 a $14 \mathrm{~h} / \mathrm{dia}$, com uma força de aproximadamente 350 a $400 \mathrm{~g}$ de cada lado ${ }^{178}$. 
Alguns fatores desfavoráveis relacionados à utilização desse aparelho descritos por NGAN \& FIELDS ${ }^{158}$, em 1997, é que se torna quase impossível a obtenção da força totalmente no sentido vertical e para resultar em maior eficiência do tratamento da mordida aberta anterior, esse aparelho deve ser utilizado simultaneamente a outras técnicas.

Quando a mordida aberta está associada a outras más oclusões como a Classe II, alguns autores relatam os bons resultados obtidos com um tratamento combinado de tração alta e aparelhos funcionais ${ }^{116,209}$. DERMOUT $^{47}$, em 1992, demonstrou bom controle esquelético e dentoalveolar na utilização do AEB com tração alta e combinado ao "ativador de Van Beek" para minimizar os efeitos do aumento da altura facial ântero-inferior.

\subsubsection{Mentoneira}

Outro aparelho comumente utilizado para o tratamento da mordida aberta anterior e diminuição da tendência de crescimento vertical, similarmente ao AEB com tração alta, é a mentoneira. Alguns autores relatam o sucesso desse aparelho que promove uma diminuição do plano mandibular e um aumento na altura facial posterior, diminuindo assim, a magnitude da mordida aberta anterior ${ }^{108,169}$.

McNAMARA Jr. ${ }^{136}$, em 1977, adverte que a direção da força utilizada com a mentoneira, utilizada em pacientes com tendência a mordida aberta anterior, deve passar anteriormente ao côndilo para não agravar a condição e provocar um efeito contrário ao esperado.

OZAWA et al. ${ }^{163}$, em 1998, relatam que a vantagem da utilização da mentoneira seria a força intrusiva contínua durante o período noturno, em substituição à força intermitente originada da ação muscular isolada proporcionada pela utilização do "Bite Block". 


\subsubsection{Aparelhos corretivos}

Na dentadura permanente é necessário fazer uma avaliação criteriosa do problema instalado para a confecção do plano de tratamento e a escolha do tipo de aparelho empregado na correção da discrepância. A literatura apresenta vários tipos de aparelhos utilizados para o tratamento dessa má oclusão na dentadura permanente, mas o mais relatado é o aparelho fixo com elásticos intermaxilares na região anterior ${ }^{2,68,92,99,109,113,152,169}$. O objetivo desses autores é a intrusão dos dentes posteriores e a extrusão dos dentes anteriores. Outros preconizam que além desse subsídio, o que pode facilitar o tratamento e sua posterior estabilidade são as extrações dentárias, que dependendo da situação, pode consistir dos primeiros ou segundos molares ${ }^{15,213}$.

De MICHELIS \& HERTEL ${ }^{42}$, em 1967, afirmaram que a mordida aberta esquelética representa uma das anomalias mais difíceis de serem corrigidas e, freqüentemente, requerem não só a presença do ortodontista como também a intervenção do cirurgião. Acrescentam que em muitos casos há necessidade de utilizar arcos metálicos flexíveis em direção vertical, ou forças elásticas intermaxilares e, em casos muito severos, até a extração de dentes para a obtenção de resultados positivos.

Em 1969, REIN ${ }^{180}$ apresentou vários métodos para o tratamento da mordida aberta. Afirmou que a seleção do plano de tratamento e os aparelhos a serem empregados são determinados pela idade do paciente, a etiologia, a severidade e o grau de cooperação. Apresentou 4 casos de mordida aberta anterior com idades de 8 a 29 anos tratados com aparelhos fixos e dobras nos fios na região anterior para promover a extrusão dos dentes ântero-inferiores. Acrescentou que é aconselhável provocar uma sobrecorreção em função da tendência de recidiva, a qual era maior conforme o aumento da idade do paciente.

Em 1975, FERRE ${ }^{57}$ apresentou 2 casos com idades de 12 e 16 anos, cujos pacientes foram tratados com arcos metálicos que provocaram a 
extrusão dos dentes anteriores. Associava elásticos verticais intermaxilares para complementar o fechamento da mordida. Concluiu que existia uma grande dificuldade no tratamento das mordidas abertas severas em adultos.

ARVYSTAS $^{8}$ em 1977, apresentou o tratamento de uma paciente de16 anos e 7 meses com extração dos quatro primeiros molares e bandagem de todos os dentes restantes. A técnica utilizada foi Edgewise, com tratamento ativo de 19 meses, sendo então, colocado um posicionador para promover a contenção.

$\mathrm{KIM}^{108}$, em 1987, desenvolveu a técnica do Multiloop Edgewise Archwire (MEAW) que consistia em corrigir a inclinação dos planos oclusais, alinhando os incisivos superiores em relação à linha do lábio superior por meio de extrusão dos dentes anteriores e intrusão dos posteriores. Essa técnica utilizava fios de aço inox com várias alças (loops) confeccionadas em toda área interdental.

A utilização de elásticos intermaxilares é preconizada por VIAZIS ${ }^{223}$ em 1991. Esse autor promovia o tratamento das discrepâncias ântero-posteriores e verticais com a utilização de vários tipos de elásticos. Relata, em seu estudo, a eficiência do tratamento dos casos de mordida aberta anterior com a utilização de fios NiTi inferiores e fios de aço inox superiores, associados a elásticos verticais na região anterior.

Em 1996, ENACAR et al ${ }^{50}$ modificaram a técnica original de $\mathrm{KIM}^{108}$, utilizando fios de níquel-titânio .016" X .022", com curva acentuada no arco superior e reversa no arco inferior, associados aos elásticos intermaxilares aplicados na região de caninos. Desse modo, o plano oclusal era nivelado sem alterações verticais na posição dos incisivos, provocando maior movimento de intrusão dos dentes posteriores. O autor preconiza que a técnica produz resultados similares à técnica do $\mathrm{MEAW}^{108}$ e ainda promove melhores condições de higienização ao paciente e menor tempo clínico ao ortodontista. 
Em 1999, CHANG \& $\mathrm{MOON}^{28}$, estudaram cefalometricamente o tratamento de 16 pacientes adultos com mordida aberta anterior com 0 aparelho fixo, mecânica do MEAW ${ }^{108}$. A amostra controle era de 58 pacientes adultos com oclusão normal. Concluíram que as mudanças ocorreram somente na região dentoalveolar e foram exclusivamente dentárias, promovendo a restrição da extrusão dos dentes posteriores e agindo favoravelmente à correção a mordida aberta pela rotação anti-horária da mandíbula.

\subsubsection{Tratamento ortodôntico-cirúrgico}

Em casos onde há o maior envolvimento de componentes esqueléticos, somente as compensações dentárias realizadas pelo tratamento ortodôntico podem não proporcionar resultados satisfatórios. Nesses casos, geralmente associa-se a cirurgia ortognática ao tratamento ortodôntico ${ }^{63,85,105,181}$. OZAWA $^{163}$, em 1998, expõe que a indicação da cirurgia ortognática depende da severidade da mordida aberta, grau de envolvimento esquelético, estética facial, idade do paciente e bom senso clínico.

A combinação da cirurgia ortognática com o tratamento ortodôntico consiste em três fases: uma fase de tratamento ortodôntico pré-cirúrgico para alinhamento e nivelamento dos arcos dentários, uma fase cirúrgica para correção da mordida aberta anterior e uma fase pós-cirúrgica para a intercuspidação e contenção. Atualmente existem várias técnicas de tratamentos cirúrgicos ${ }^{53,63,85,162,181}$ que podem ser realizadas na mandíbula, na maxila, ou na maxila e mandíbula conjuntamente.

Historicamente, o tratamento cirúrgico da mordida aberta anterior foi proposto por HULLIHEN $^{88}$, em 1849, que preconizava a utilização de osteotomias principalmente no corpo mandibular. Devido ao alto índice de complicações com essa técnica, os locais da cirurgia foram sendo gradativamente modificados até 0 desenvolvimento das técnicas de OBWEGESER ${ }^{160}$, em 1957 e DALPONT ${ }^{39}$, em 1959, que sugerem osteotomias no ramo mandibular. EPKER \& $\mathrm{FISH}^{53}$ em 1977, obtiveram bons resultados 
com a reposição superior da maxila, pois essa conduta permite a rotação antihorária da mandíbula, facilitando a correção da mordida aberta anterior.

\subsubsection{Outros métodos}

Existe uma diversidade muito grande de métodos de tratamentos da mordida aberta anterior que são relatados na literatura. Em 1985, SPYROPOULOS realizou um estudo que visava o tratamento de pacientes com tendência precoce a apresentar mordida aberta anterior, por meio de exercícios musculares com a utilização de goma de mascar. Dividiu 29 pacientes com média de idade de 9 anos e 1 mês em três grupos diferentes: No grupo I, os pacientes eram instruídos a mascar goma durante 45 minutos por dia; no grupo II, os pacientes utilizavam uma mentoneira 14 h/dia; no grupo III, os pacientes foram submetidos a uma combinação de mascar a goma e utilização da mentoneira. O autor relata que houve melhora na extensão da mordida aberta na maioria dos casos que utilizaram a goma de mascar combinada ou não à mentoneira, sendo que em alguns caos a melhora foi impressionante tanto clínica quanto cefalométrica.

\subsection{Estabilidade da correção da mordida aberta anterior}

REIDEL ${ }^{187}$ em 1969, definiu a contenção após tratamento ortodôntico como "a manutenção dos dentes em suas posições estéticas funcionais ideais", e MOYERS ${ }^{147}$ em 1973, como "a manutenção dos dentes em suas posições após a finalização do tratamento ortodôntico, por um período de tempo necessário". STRANG ${ }^{210}$, já em 1952, preconizava que somente há sucesso no tratamento ortodôntico, quando os objetivos iniciais foram alcançados e permaneceram estáveis por tempo ilimitado.

\subsubsection{Dentaduras Decídua e Mista}


A estabilidade do tratamento da mordida aberta é pouco relatada na literatura. Os estudos são unânimes em afirmar que quando se promove o tratamento dessa má oclusão precocemente, ou seja, em crianças na dentadura decídua ou mista, obtém-se os melhores resultados com o mínimo de recidiva ${ }^{62,71,79,83,87,158,166,200,225}$.

BIEN et alli ${ }^{15}$, já em 1955, concluíram que o tratamento da mordida aberta deve ser feito precocemente, pois nesse estágio, essa má oclusão é facilmente corrigida somente com a interrupção do hábito e proporciona ao paciente o desenvolvimento normal das estruturas faciais. Relata que a eliminação dos hábitos deletérios é essencial para a estabilidade da correção.

Em 1971, PARKER ${ }^{166}$ já recomendava o tratamento da mordida aberta anterior precocemente. Esse autor afirmava que o tratamento na fase de dentadura decídua ou mista propiciava resultados estáveis, pois, além de restabelecer as funções musculares, proporcionava o crescimento normal das estruturas da face, contribuindo para a estabilidade do tratamento.

MOYERS $^{147}$, em 1973, relata que no tratamento precoce dessa má oclusão, os fatores etiológicos como mau posicionamento lingual e deglutição atípica, ainda podem persistirem após o completo restabelecimento da forma normal dos arcos dentários. Nesse caso, o autor preconiza a necessidade da instituição de uma terapia funcional de reeducação muscular para aumentar a estabilidade do tratamento.

Em 1991, PEARSON ${ }^{169}$ relatou o tratamento da mordida aberta anterior em um paciente de 7 anos e 10 meses com Classe II e severo padrão de crescimento vertical. A mecanoterapia foi instituída com mentoneira, tração alta, bite block e finalmente, o aparelho fixo. Observou-se êxito no tratamento e a fase de contenção foi avaliada por modelos de gesso 13 meses após o término do tratamento, resultando em estabilidade.

\subsubsection{Dentadura Permanente}


Já na dentadura permanente, dependendo do grau de discrepância esquelética envolvida, somente as compensações dentárias não são suficientes para resolver o problema, então torna-se necessário o auxílio da cirurgia ortognática para o sucesso do tratamento, evitando-se ao máximo, a recidiva ${ }^{39,46,49,52,53,63,85,105,181}$.

\subsubsection{Tratamento Ortodôntico}

Segundo SUBTELNY \& SAKUDA ${ }^{213}$, em 1964, a mordida aberta anterior é considerada como uma má oclusão muito difícil de ser corrigida e principalmente de estabilidade pouco duradoura após o término do período de correção ortodôntica. Esses autores descreveram que o tratamento da mordida aberta anterior com a utilização de elásticos intermaxilares na região anterior é passível de recidiva, pois, provoca a extrusão dos dentes anteriores, um efeito puramente dentário e não estável.

Em 1974, KIM ${ }^{107}$ explica que o tratamento da mordida aberta anterior pode ser bem sucedido e estável. Ilustra a explicação com dois tratamentos dessa má oclusão em dentaduras permanentes com extração de segundos molares e estabilidade da oclusão após 2 anos do término do tratamento. Segundo o autor, o sucesso do tratamento ocorreu por meio de um sistema de forças recíprocas, isto é, intrusão dos dentes posteriores e extrusão dos dentes anteriores.

NEMETH \& ISAACSON ${ }^{157}$, também em 1974, observaram, em 30 pacientes, as alterações ocorridas nos períodos de correção da má oclusão e após o término do tratamento por meio de modelos de gesso e telerradiografias em norma lateral. A média do período estudado após o tratamento foi de 3,7 anos, com um mínimo de 1 e o máximo de 6 anos. Relacionaram a recidiva da mordida aberta anterior com um aumento na altura facial posterior, o que gerou a rotação da mandíbula no sentido horário. Concluíram que a recidiva das más oclusões no sentido vertical depende da idade e potencial de crescimento que o paciente apresenta no final do tratamento ortodôntico. 
Em 1976, JUSTUS ${ }^{103}$ descreve o tratamento de 8 pacientes com grade palatina e esporões, sendo que para haver a total correção da má oclusão de alguns pacientes, necessitou-se associação do aparelho fixo e tração alta. Afirma que esse método de tratamento é muito eficaz e proporciona grande estabilidade. LIEBERMAN \& GAZIT ${ }^{121}$, em 1978 relataram o tratamento ortodôntico da má oclusão de mordida aberta anterior em uma paciente de 14 anos e 6 meses de idade. O tratamento foi realizado com a remoção dos primeiros pré-molares e com terapia muscular aliada à mecanoterapia. Alcançou-se melhora evidente nas relações oclusais e estética facial. Os registros pós-tratamento mostram a má oclusão corrigida, 18 meses após o início da contenção. Os autores concluem que é possível o tratamento dos casos de mordidas abertas anteriores moderadas com grande estabilidade após correção.

FRANKEL \& FRANKEL ${ }^{62}$, em 1983, baseados em sua própria experiência clínica, realizaram um estudo para mostrar que os princípios ortopédicos gerais podem ser aplicados com sucesso no tratamento da mordida aberta anterior. Acreditam que esse tipo de tratamento permite a obtenção de resultados com maior estabilidade a longo-prazo. Os autores utilizaram uma amostra constituída de 41 crianças, sendo que 11 não sofreram tratamento e compuseram o grupo controle. $O$ tratamento foi realizado nas 30 crianças restantes com um aparelho regulador funcional (RF-IV), e após sua finalização, avaliou-se os resultados por meio das análises radiográficas de Naouhm, Jarabak e Frankel. A análise de Frankel apresentou significativas diferenças no desenvolvimento esquelético entre os grupos tratados e não tratados após um período médio de 8 anos após o início do tratamento.

LOPEZ-GAVITO et al ${ }^{125}$, em 1985, avaliaram 41 pacientes com mordida aberta anterior, após mínimo de 9,6 anos do término do tratamento, com mecânica de Edgewise e aparelho extrabucal. Os autores concluíram que a recidiva é muito grande: cerca de $35 \%$ dos pacientes obtiveram uma recidiva de mais de 3 milímetros. 
Em 1994, GOTO et al ${ }^{68}$ realizaram o tratamento da mordida aberta anterior em um paciente do gênero feminino, com 20 anos de idade, cuja etiologia da má oclusão era a sucção digital. Foi utilizado aparelho fixo, com o auxílio de elásticos intermaxilares. Após dois anos do término do tratamento, a análise cefalométrica mostrou mínimas mudanças e uma boa estabilidade da correção da mordida aberta anterior.

Em 1999, ALEXANDER ${ }^{1}$ descreve o tratamento de um paciente com 21 anos que apresenta mordida aberta anterior. No tratamento, foi instituída a utilização do aparelho fixo, AEB com tração alta, extração dos primeiros prémolares e terapia muscular para a reeducação da função da língua. Após 25 meses do término do tratamento, o paciente apresentava boa estabilidade do tratamento, com pequenas alterações dentárias não significantes. Ainda em 1999, KÜÇÜKKELES et $a^{113}$ avaliaram a estabilidade da correção da mordida aberta anterior em 17 pacientes tratados com fios NiTi e elásticos intermaxilares, após 1 ano do término do tratamento. Concluíram que esse essa mecanoterapia proporciona resultados estáveis e similares ao MEAW ${ }^{108}$.

KIM et al. ${ }^{110}$, em 2000, investigaram a estabilidade após 2 anos do término do tratamento ortodôntico em 55 pacientes, que foram divididos em 2 grupos: grupo I composto por 29 pacientes na fase de crescimento; grupo II com 26 pacientes adultos. O tratamento foi realizado com a técnica do $M \mathrm{AW}^{108}$ e verificado em telerradiografias em norma lateral. Os autores não observaram diferença estatisticamente significante quanto às alterações esqueléticas e dentoalveolares, no período após o tratamento, em relação aos grupos I e II. Concluíram que a mecanoterapia utilizada proporcionou a estabilidade do tratamento da mordida aberta anterior, pois não foi observada significância estatística nas alterações das variáveis no período após o tratamento.

Para obter-se uma boa estabilidade, é necessária a utilização de uma boa contenção após o tratamento. COMPOSTELA ${ }^{36}$, já em 1952, destacou que o melhor aparelho para contenção era o mesmo arco metálico utilizado 
para a correção, de forma passiva, ou o uso de uma placa de Hawley com o arco vestibular apoiado nos bráquetes dos dentes anteriores.

\subsubsection{Tratamento Ortodôntico-Cirúrgico}

Atualmente, as técnicas cirúrgicas com procedimentos na mandíbula e na maxila são as mais utilizadas. Segundo ELLIS et al $^{49}$, essa combinação promove melhores resultados e estabilidade após o tratamento. Alguns autores demonstraram que o tratamento ortodôntico da mordida aberta anterior realizado conjuntamente aos procedimentos cirúrgicos pode apresentar grande recidiva ${ }^{46,52,6646,52,66}$.

GILE $^{66}$ em 1972, observou que em sua amostra de 98 pacientes tratados cirurgicamente, 35\% apresentaram recidiva da mordida aberta anterior após 3 anos de tratamento. Em 1977, EPKER \& FISH $^{53}$ relataram que os resultados conseguidos com a associação da ortodontia com a cirurgia em casos severos de mordida aberta anterior são clinicamente gratificantes quanto à estabilidade da correção da má oclusão e a melhora na aparência do paciente.

DENISON et al. $^{46}$, em 1989 , encontraram $42,9 \%$ de recidiva nos pacientes que anteriormente ao tratamento apresentavam mordida aberta anterior e relataram que os resultados obtidos em seu estudo sugerem que a recidiva foi proveniente de alterações dentoalveolares, especialmente a extrusão dos dentes posteriores após a cirurgia ortognática e o término da terapia ortodôntica.

Em 1985, ELLIS et al $^{49}$, concluíram que os casos de mordida aberta anterior apresentam discrepâncias tanto na mandíbula quanto na maxila, e a realização da cirurgia ortognática apenas na mandíbula pode comprometer os resultados estéticos e funcionais, assim como a estabilidade do tratamento.

Quanto à forma de fixação óssea para a contenção do procedimento cirúrgico, a fixação interna rígida tem apresentado melhores 
resultados $^{85,105,177,181}$, pois, os autores afirmam que quanto menor for a movimentação óssea após a cirurgia, menor também a recidiva após a finalização do tratamento. PROFFIT et al. ${ }^{177}$, em 1988, avaliaram 61 pacientes que realizaram a cirurgia tipo LeFort I para promover a impactação da maxila de $2 \mathrm{~mm}$, no mínimo. Observou-se a recidiva estatisticamente significante em somente 3 pacientes, o que confirma a grande estabilidade desse procedimento, após a correção da mordida aberta.

REITZIK et al $^{181}$, em 1990, realizaram um trabalho com 16 pacientes com mordida aberta anterior submetidos ao tratamento ortodôntico combinado ao cirúrgico. Concluíram que há grande estabilidade nos casos tratados cirurgicamente e sugerem a utilização da cirurgia ortognática como recurso necessário ao tratamento dos pacientes adultos que apresentam grande envolvimento esquelético na composição da má oclusão.

\subsubsection{Importância do Tratamento Fonoaudiológico}

Para aumentar a estabilidade do tratamento ortodôntico da mordida aberta anterior quando o mau posicionamento lingual persistir ao final da correção da má oclusão, torna-se necessária uma terapia funcional de reeducação muscular, realizada pelo fonoaudiólogo, concomitantemente ou após o término do tratamento ortodôntico ${ }^{146,170}$.

HUANG et al. ${ }^{87}$ em 1990, afirmaram que a língua exerce grande influência na recidiva do tratamento ortodôntico. Neste trabalho, os autores utilizavam grades palatinas para promover a correção da postura e função da língua, proporcionando uma oclusão mais estável ao final do tratamento. ALEXANDER ${ }^{1}$, em 1999, citou que a postura e função inadequadas da língua pode ser a maior causa da recidiva da mordida aberta anterior, pois sem a correção desse hábito, o paciente aumenta grandemente as chances de recidiva. $O$ autor relata que uma simples série de exercícios para a musculatura peribucal e língua podem ser a solução para maior estabilidade do tratamento ortodôntico. 
Observando a pequena quantidade das pesquisas existentes sobre a estabilidade do tratamento sem extração dentária da mordida aberta anterior na dentadura permanente, e nesses estudos, a utilização de amostras grandemente diversificadas, decidiu-se elaborar este trabalho, com o objetivo de avaliar a estabilidade de casos tratados ortodonticamente, sem extrações, na dentadura permanente, após cinco anos de sua conclusão. 


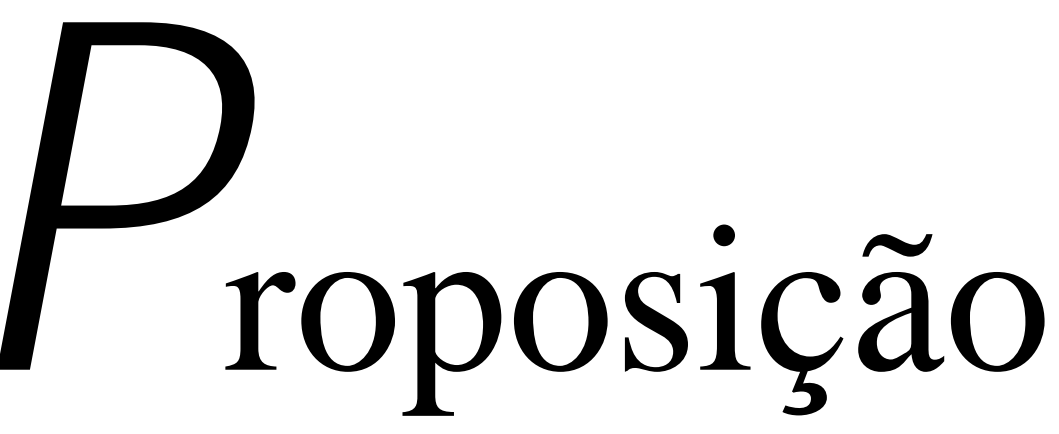




\section{PROPOSIÇÃO}

objetivo desse trabalho consistiu em avaliar a estabilidade dos
casos de mordida aberta anterior, tratados com aparelho ortodôntico fixo, sem extrações, na dentadura permanente, após 5 anos do término do tratamento. Adicionalmente, avaliou-se a recidiva "clinicamente significante". 

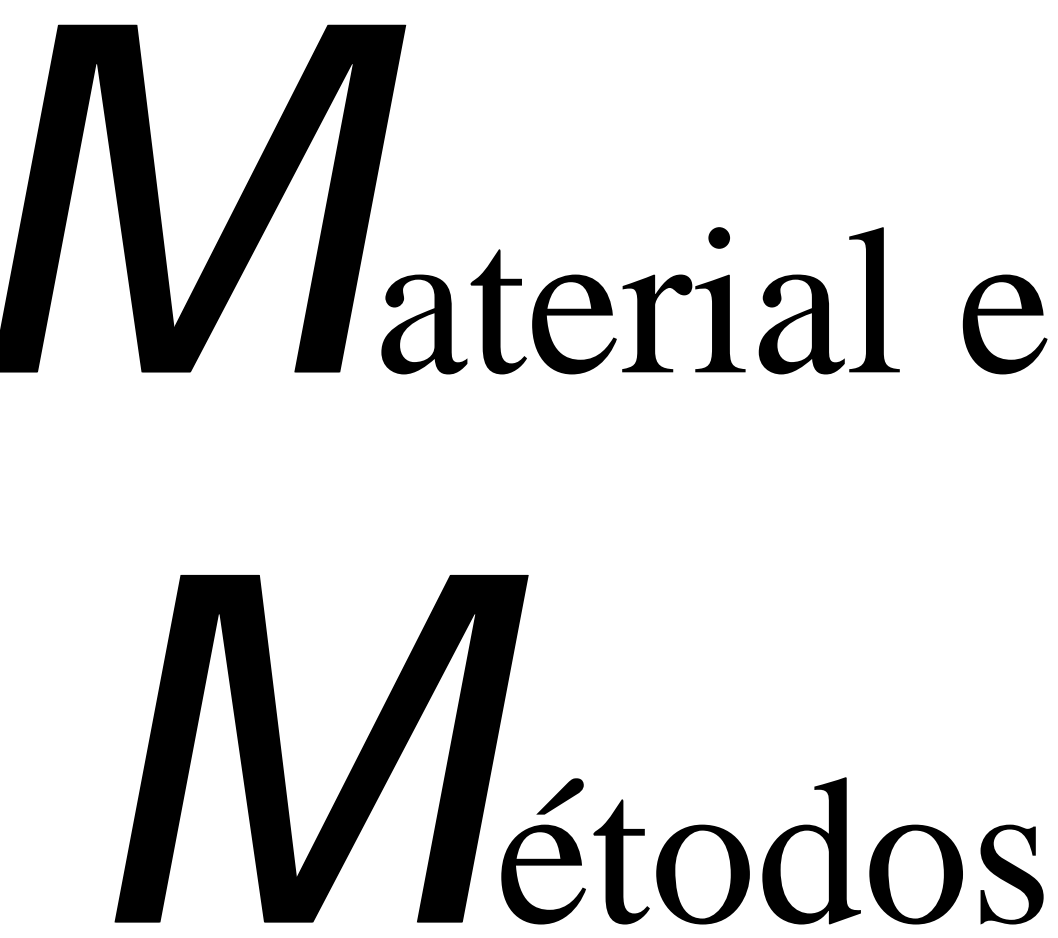


\section{MATERIAL E MÉTODOS}

presente estudo constituiu-se de três grupos: grupo experimental, grupo controle 1 e grupo controle 2.

\subsection{Amostra}

\subsubsection{Grupo Experimental}

Foram selecionados 21 pacientes, sendo 16 do gênero feminino e 5 do gênero masculino, dentre mais de 2000 tratados nos cursos de Pós-Graduação (Latu e Strictu sensu) da Disciplina de Ortodontia da Faculdade de Odontologia de Bauru - USP, para constituírem a amostra deste trabalho. Estes pacientes apresentavam os seguintes requisitos: mordida aberta anterior clinicamente maior ou igual a $1 \mathrm{~mm}$ e presença de todos os dentes permanentes, previamente ao tratamento; tratados sem extrações, com aparelhos fixos utilizando a técnica Edgewise; e que tenham apresentado, ao final do tratamento um trespasse vertical positivo de, no mínimo, $1 \mathrm{~mm}$.

TABELA 1 - Médias, desvios-padrão, máximo e mínimo das idades do grupo experimental no início, final e pós-tratamento.

\begin{tabular}{c|c|c|c|c}
\hline \multirow{2}{*}{ FASES } & \multicolumn{4}{|c}{ IDADE } \\
\cline { 2 - 5 } & Média & D.P. & Máximo & Mínimo \\
\hline INICIAL & 12,4 & 0,92 & 15,8 & 10,1 \\
FINAL & 14,8 & 1,37 & 19,2 & 12,1 \\
PÓS-TRATAMENTO & 19,9 & 2,03 & 26 & 17,8 \\
\hline
\end{tabular}




\subsubsection{Grupo Controle 1}

Com a finalidade de se verificar as características cefalométricas iniciais do Grupo Experimental, utilizou-se o Grupo Controle 1, que se constitui na amostra descrita no Atlas de Crescimento Craniofacial ${ }^{134}$ desenvolvido pelos professores da Faculdade de Odontologia de Bauru - USP. Essa amostra é composta por 18 pacientes do gênero feminino e serviu como parâmetro na comparação entre a fase inicial de tratamento do grupo experimental e a amostra descrita no Atlas de Crescimento para 12 anos de idade (TABELA 3 pg 61).

\subsubsection{Grupo Controle 2}

Com o intuito de diferenciar as alterações relacionadas à recidiva daquelas que decorrem do crescimento normal, avaliando, desta forma, a influência do crescimento na estabilidade do tratamento, foram selecionados 21 jovens, sendo 9 do gênero masculino e 12 do gênero feminino, com oclusão normal e idade média inicial de 14,6 anos e final de 19,6 anos - TABELA 9 pg 66 (compatível à fase de final de tratamento e 5 anos após o tratamento do grupo experimental, respectivamente). Este grupo também foi selecionado a partir da amostra longitudinal para estudos de crescimento da Disciplina de Ortodontia da Faculdade de Odontologia de Bauru-USP ${ }^{97}$, os quais apresentam as seguintes características:

- procedência: escolas secundárias de Bauru;

- leucodermas;

- filhos de pais brasileiros, descendentes de Mediterrâneos;

- portadores de oclusão normal, sem mutilações nos arcos dentários;

- nunca submetidos a tratamento ortodôntico. 
TABELA 2 - Médias, desvios-padrão, máximo e mínimo das idades dos pacientes do Grupo Controle 2, compatíveis com as fases final e 5 anos após tratamento.

\begin{tabular}{c|c|c|c|c}
\multirow{2}{*}{ FASES } & \multicolumn{4}{|c}{ IDADE } \\
\cline { 2 - 5 } & Média & D.P. & Máximo & Mínimo \\
\hline Inicial & 14,6 & 0,68 & 15,6 & 14,0 \\
Final & 19,6 & 1,03 & 22,6 & 18,3 \\
\hline
\end{tabular}

\subsection{Método}

Do grupo experimental foram obtidas três telerradiografias em norma lateral de cada paciente estudado. Estas foram realizadas anteriormente ao início do tratamento (T1), imediatamente após a conclusão do tratamento (T2) e, em média, 5 anos após o término do mesmo (T3), com o mínimo de 3 anos e 2 meses e o máximo de 10 anos e 4 meses. Os pacientes apresentaram média de 12,4 anos no início do tratamento, 14,8 anos ao final do tratamento e 19,9 anos ao final do último período estudado (TABELA 1). Denominou-se "fase" para as observações estáticas realizadas em T1, T2, e T3 e "período" para os intervalos de tempo entre T2 e T1 e entre T3 e T2.

Todas as telerradiografias da amostra foram realizadas em sete diferentes aparelhos, pois os períodos a serem estudados, por serem muito longos, não possibilitaram a obtenção das radiografias em apenas um aparelho. Para aumentar a confiabilidade dos resultados desse estudo, foi realizada a determinação da magnificação de cada aparelho. Todos os aparelhos foram regulados para uma exposição de $80 \mathrm{Kva}$ e $10 \mathrm{~mA}$ com uma distância focal de 1,52 metros e tempo de exposição de 1,3 segundos. A cabeça do paciente foi posicionada no cefalostato e este foi orientado para ficar com os lábios em posição de repouso e em máxima intercuspidação habitual.

O cálculo realizado para se obter a porcentagem de magnificação de cada aparelho cefalométrico é o seguinte:

$$
M=\frac{b-a}{a}
$$


sendo que:

$M=$ porcentagem de magnificação;

$\mathrm{a}=$ distância real entre as olivas do aparelho;

$\mathrm{b}=$ distância entre as olivas na imagem da telerradiografia.

Os diferentes tipos de aparelhos apresentaram porcentagens distintas de magnificação, que variou de $6 \%$ até $10,94 \%$.

\subsection{Traçados e Medição das Radiografias}

Os traçados cefalométricos foram realizados em folhas de papel ultraphan de 0,07mm de espessura e 17,5mm de largura e comprimento, adaptadas nas telerradiografias. O traçado anatômico e demarcação dos pontos de referência dentoesqueléticos foram efetuados manualmente pelo autor com lapiseira de $0,5 \mathrm{~mm}$, sobre um negatoscópio, em uma sala escurecida. Foram traçadas nas radiografias as estruturas anátomoradiográficas de interesse para a elaboração do cefalograma. O traçado anatômico e os pontos demarcados foram digitalizados em uma mesa digitalizadora Houston Instrument DT-11 ${ }^{\mathrm{a}}$, acoplada a um microcomputador Pentium III 450Mhz.

O programa utilizado para a medição das grandezas cefalométricas foi o Dentofacial Planner $7.0^{\mathrm{b}}$, efetuando-se por meio do mesmo, a correção da magnificação da imagem radiográfica.

\subsection{Traçado Anatômico}

Foram delimitadas as seguintes estruturas dentoesqueléticas:

- perfil do osso frontal e dos ossos nasais

- sela túrcica e meato acústico externo

\footnotetext{
${ }^{a}$ Houston Instruments, Austin, Texas, USA

${ }^{\mathrm{b}}$ Dentofacial Planner Software Inc., Toronto, Ontario, Canada
} 
- órbita, maxila e fissura pterigomaxilar

- ossos etimóide e esfenóide

- contorno da base e ramo da mandíbula e côndilo

- perfil mole

- incisivos centrais, segundos pré-molares e primeiros molares permanentes superiores e inferiores.

Para todas as estruturas bilaterais foi efetuado o traçado médio.

\subsection{Pontos de Referência (FIGURA 1)}

Os pontos de referência anatômicos foram demarcados seguindo as especificações de KROGMAN \& SASSOUNI ${ }^{112}$, RIOLO $^{188}$, MCNAMARA Jr $^{137}$, JACOBSON $^{93}$, e STEINER ${ }^{208}$ :

1. Glabela: o ponto mais anterior localizado no perfil mole, acima da órbita;

2. Nas sup': ponto localizado na metade da distância entre a glabela e o nasio';

3. Násio': o ponto mais posterior localizado no tecido mole acima da órbita;

4. Nas inf': ponto localizado no limite da junção entre o tecido mole acima da órbita e o dorso do nariz:

5. Nasal dors: ponto localizado na metade da distância entre o nasal e o pronasal:

6. Dorsal inf: ponto localizado na junção do dorso e ponta do nariz;

7. Nasal sup: ponto localizado superiormente à ponta do nariz;

8. Pronasal: o ponto mais anterior da ponta do nariz;

9. Nasal inf: ponto localizado inferiormente à ponta do nariz;

10. Columela: ponto localizado no limite interiormente ao nariz que representa o limite do ângulo naso-labial; 
11. Subnasal: ponto na junção da columela do nariz com o filtro do lábio superior;

12. Filtro: o ponto mais posterior localizado na concavidade do lábio superior;

13. LS: ponto localizado na junção pele-mucosa entre o lábio superior e o filtro;

14. LSm: ponto localizado no lábio superior entre o ponto Ls e o Estômio:

15. Estômio superior: o ponto mais inferior do vermelhão do lábio superior;

16. Estômio inferior: o ponto mais superior do vermelhão do lábio inferior;

17. Lim: ponto localizado no lábio inferior entre o ponto LI e o Estômio;

18. LI: ponto localizado na junção pele-mucosa entre o lábio inferior e a concavidade do queixo;

19. Sup inf: ponto localizado na metade da distância entre o LI e o Lmf;

20. Lmf: o ponto mais posterior na concavidade do queixo;

21. Inf Lmf: ponto localizado na metade da distância entre o Lmf e o Pogônio mole;

22. Pog ': projeção do ponto Pog no tecido mole;

23. Gn': projeção do ponto $\mathrm{Gn}$ no tecido mole;

24. Me': projeção do ponto Me no tecido mole;

25. Cervical: ponto localizado na junção da região submental e do pescoço.

26. S (sela): localizado no centro da sela túrcica;

27. N (nasio): junção do osso frontal e nasal, na sutura fronto-nasal;

28. Orbital m: o ponto localizado na metade da distância entre a borda superior e inferior da margem lateral da órbita.;

29. Or (orbital): o ponto mais inferior da margem orbital;

30. Pt: ponto mais póstero-superior da fossa pterigopalatina;

31. ENP (espinha nasal posterior): o limite posterior do assoalho nasal;

32. Sm1: ponto na face superior da maxila, próximo à espinha nasal posterior;

33. Sm2: ponto localizado na face superior da maxila pouco à frente do Sm1; 
34. Sm3: ponto localizado na face superior da maxila delimitando maxila posterior e anterior;

35. Sm4: ponto localizado entre o $\mathrm{Sm} 3$ e a espinha nasal anterior, atrás do Sm5;

36.Sm5: ponto na face superior da maxila localizado $3 \mathrm{~mm}$ posteriormente à espinha nasal anterior;

37. ENA (espinha nasal anterior): o limite anterior do assoalho nasal;

38. Sub-ENS: ponto localizado na face anterior da maxila $3 \mathrm{~mm}$ abaixo da espinha nasal anterior;

39. Ponto A: o ponto mais posterior da concavidade do limite anterior da maxila, entre a crista alveolar e a espinha nasal anterior;

40. IS ápice: a extremidade do ápice do incisivo central superior;

41. IS incisal: a extremidade da coroa do incisivo central superior;

42. MS ápice: ponto localizado na extremidade do ápice da raiz mésiovestibular do primeiro molar superior;

43. MS : a extremidade da cúspide mesial do primeiro molar superior;

44. MS distal: ponto localizado no contato proximal entre os primeiros e segundos molares superiores;

45. MI: a extremidade da cúspide mesial do primeiro molar inferior;

46. MI perp: ponto projetado a partir do ponto $\mathrm{MI}$ perpendicular ao plano oclusal, na altura do ápice da raiz mesial do molar inferior;

47. II incisal: a extremidade da coroa do incisivo central inferior;

48. II ápice: a extremidade do ápice do incisivo central inferior;

49. Ponto B: o ponto mais posterior da concavidade do limite anterior da mandíbula, entre a crista alveolar e o pogônio;

50. Agp: ponto localizado na metade da distância entre os pontos B e Pog;

51. Pog (Pogônio): o ponto mais anterior do osso basal da mandíbula;

52. Gn (Gnátio): ponto projetado no osso basal da manbíbula formado pela bissetriz dos pontos Pogônio e Mentoniano;

53. Me (Mentoniano): o ponto mais inferior do osso basal da mandíbula;

54. Pgp: ponto situado no meio da borda mais inferior da mandíbula;

55. Antegoníaco: ponto localizado mais superiormente na concavidade da borda inferior da mandíbula; 
56. Gônio inf: ponto localizado próximo ao Gônio na borda inferior da mandíbula;

57. Go (Gônio): ponto projetado no ângulo da mandíbula formado pela bissetriz das retas dos limites inferior e posterior da mandíbula;

58. Gônio post: ponto localizado próximo ao Gônio, no ramo da mandíbula;

59. Ramo post: ponto situado na metade da distância entre os pontos Go e $\mathrm{Ar}$;

60. Ar (Articular): ponto localizado na intersecção do ramo da mandíbula com a base do crânio;

61. Co (condílio): o ponto mais póstero-superior do côndilo;

62. Sigmóide: ponto mais inferior localizado na concavidade do processo sigmóide.

63. Ramo ant: ponto situado na metade da distância entre os pontos Go e Ar, na face anterior do ramo da mandíbula;

64. CR mand: ponto representando o centro de rotação da mandíbula, localizado arbitrariamente no centro do côndilo;

65. Po (Pório): ponto mais superior da margem do meato acústico externo;

66. Ba (básio): o ponto mais inferior da margem anterior do forame Magno;

67. SMPSM: a extremidade da cúspide do segundo pré-molar superior;

68. SMPMI: a extremidade da cúspide do segundo pré-molar inferior;

69. COPM: ponto localizado na metade da distância entre a cúspide do segundo pré-molar inferior e superior;

70. COM: ponto localizado na metade da distância entre as cúspides mesiais dos molares superiores e inferiores;

71. AO: ponto A projetado perpendicularmente ao plano oclusal funcional;

72. BO: ponto B projetado perpendicularmente ao plano oclusal funcional; 


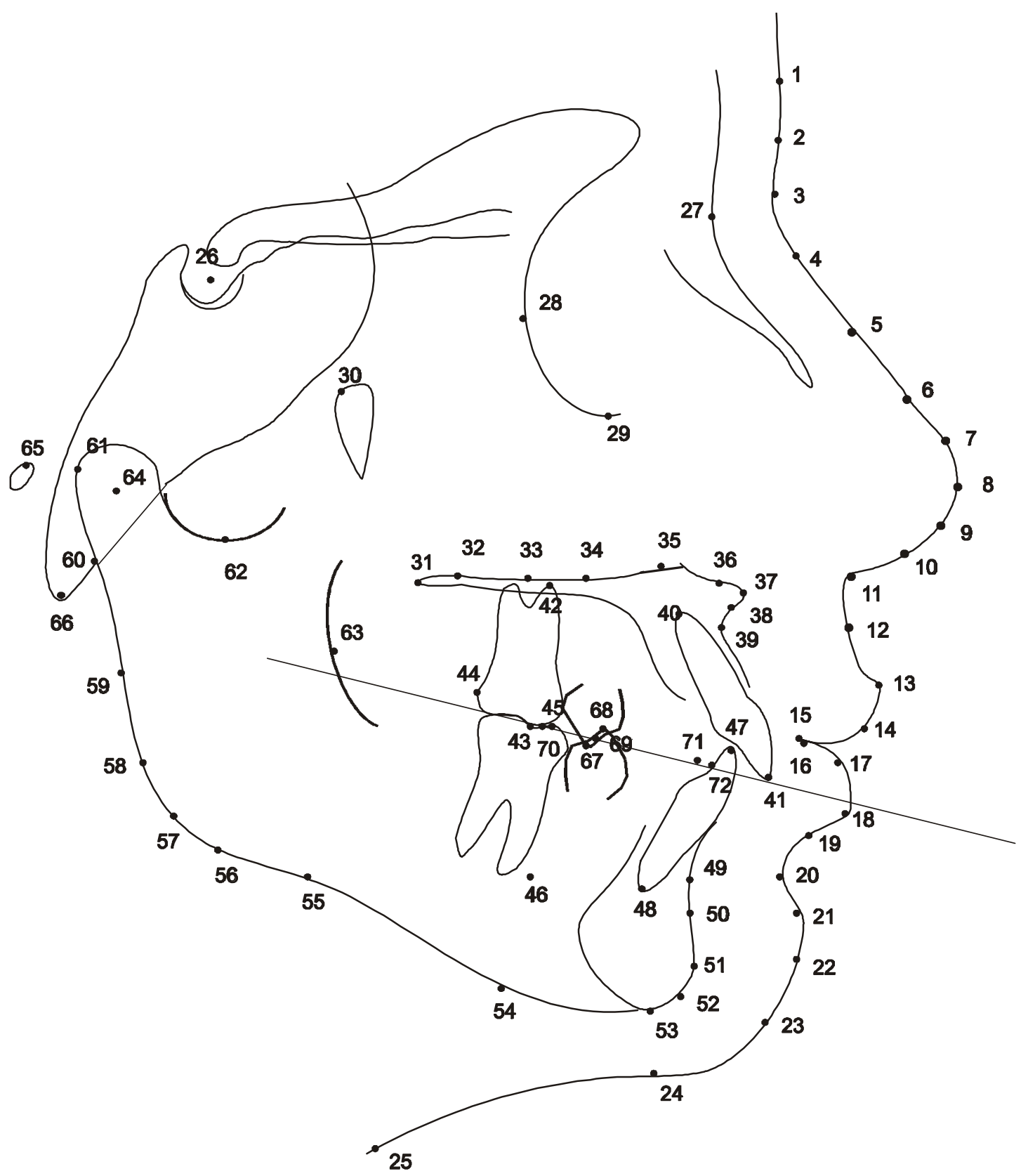

FIGURA 1 - Pontos de Referência do traçado cefalométrico 


\subsection{Linhas e Planos (FIGURA 2)}

\subsubsection{Horizontais}

A - $\quad$ Linha SN: do ponto Sela ao Násio;

B - $\quad \mathrm{FH}$ (plano horizontal de Francfort): do ponto Pório anatômico ao Orbitário;

C - $\quad$ PP (plano palatino): do ponto ENA ao ENP;

D - $\quad$ PO (plano oclusal funcional): linha que passa pelo contato oclusal dos molares e contato oclusal entre os pré-molares.

E - GoGn (plano mandibular): do ponto Gônio ao Gnátio;

F - GoMe (plano mandibular): do ponto Gônio ao Mentoniano.

\subsubsection{Verticais}

G - Linha NA: une o ponto Násio ao ponto A;

$\mathrm{H}$ - Linha NB: une o ponto Násio ao ponto B;

I - Linha BIS-AIS (longo eixo do incisivo superior): une os pontos correspondentes da borda incisal ao ápice dos incisivos centrais superiores;

J - Linha Bll-All (longo eixo do incisivo inferior): une os pontos correspondentes da borda incisal ao ápice dos incisivos centrais inferiores;

K - Linha N-perp: linha perpendicular ao plano horizontal de Francfort passando pelo ponto Násio. 


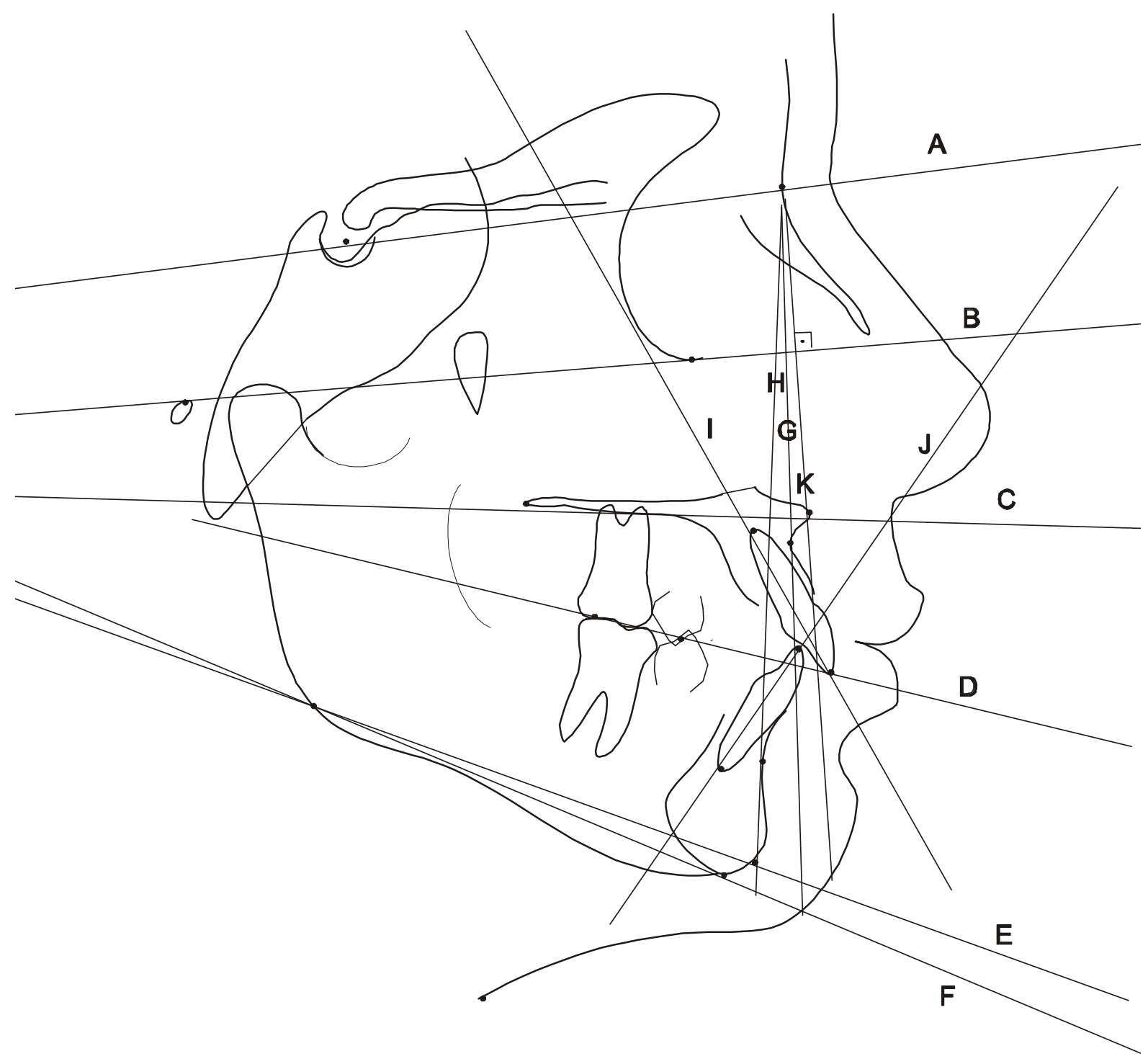

FIGURA 2 - Linhas e Planos 


\subsection{Grandezas Cefalométricas Esqueléticas (FIGURA 3)}

\subsubsection{Maxilares}

1 - SNA: ângulo formado pelas linhas SN e NA. Indica a relação sagital da maxila, em relação à base do crânio;

2 - Co-A: distância entre os pontos Condílio e A. Representa o comprimento efetivo da face média (maxila);

3 - A-Nperp: distância entre 0 ponto $A$ e a linha $N$ perpendicular ao plano de Francfort;

\subsubsection{Mandibulares}

4 - SNB: ângulo formado pelas linhas SN e NB. Indica a relação sagital da mandíbula, em relação à base do crânio;

5 - Co-Gn: distância entre os pontos Condílio e Gnátio. Define o comprimento efetivo mandibular;

6 - Go-Gn: distância entre os pontos Gônio e Gnátio. Avalia o comprimento do corpo madibular;

7 - Co-Go: distância entre os pontos Condílio e Gônio. Representa o comprimento do ramo mandibular;

8 - Co.GoMe: ângulo formado entre o ramo e o corpo mandibular;

9 - P-Nperp: distância entre o ponto $\mathrm{P}$ à linha $\mathrm{N}$ perpendicular ao plano de Francfort;

\subsubsection{Maxilomandibulares}

10 - ANB: ângulo entre as linhas NA e NB. Representa o grau de discrepância sagital entre a maxila e mandíbula;

11 - WITS: distância entre as projeções perpendiculares dos pontos $A$ e $B$ sobre o plano oclusal funcional. Define o relacionamento sagital entre a maxila e mandíbula; 
12 - Co-A/Co-Gn: proporção entre os comprimentos maxilar e mandibular. Avalia o crescimento diferencial da mandíbula em relação à maxila.

\subsubsection{Horizontais e Verticais}

13 - FMA: ângulo formado pelos planos horizontal de Francfort e mandibular (GoMe). Define basicamente a orientação do padrão de crescimento facial;

14 - SN.GoGn: ângulo formado pela linha $S N$ e o plano mandibular GoGn. Usando pontos cefalométricos diferentes, também define a orientação do padrão de crescimento facial;

15 - AFAI (ENA-Me): distância entre os pontos Espinha Nasal Anterior e Mentoniano. Indica a altura do terço inferior da face.

16 - SN.PP: ângulo formado entre a linha SN e o plano palatino.

17 - SN.PO: ângulo formado entre a linha SN e o plano oclusal funcional. 


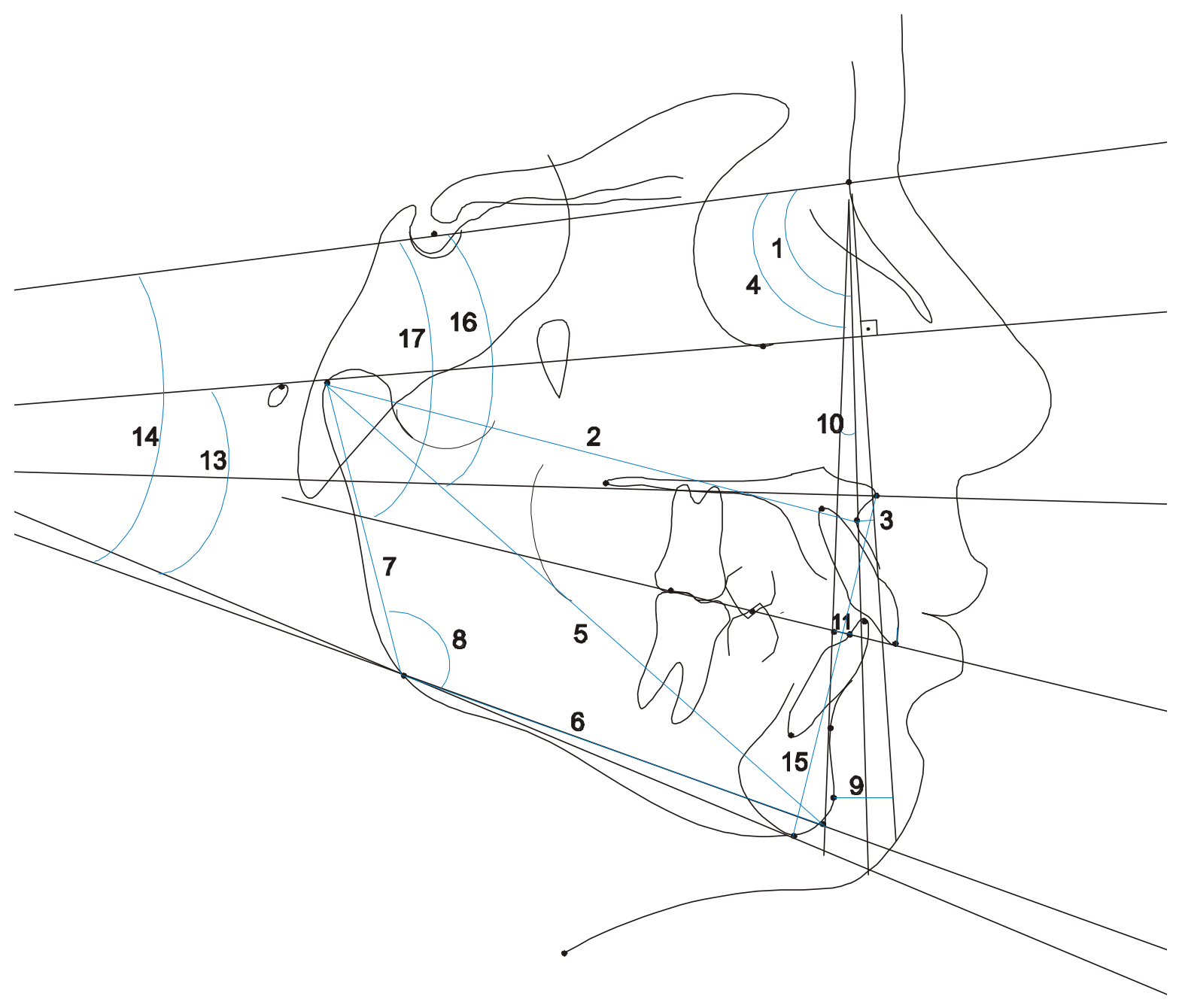

FIGURA 3 - Grandezas Cefalométricas Esqueléticas 


\subsection{Grandezas Cefalométricas Dentárias (FIGURA 4)}

\subsubsection{Superiores}

18 - IS.PP: ângulo entre o longo eixo do incisivo central superior e o plano palatino. Relaciona a inclinação do incisivo superior à maxila;

19 - IS.NA: ângulo entre o longo eixo do incisivo central superior e a linha NA. Define o grau de inclinação do incisivo central em relação à maxila e ao Násio;

20 - IS-NA: distância entre o ponto mais anterior da coroa do incisivo central superior e a linha NA. Relaciona a posição sagital do incisivo superior em relação à maxila e ao Násio;

21 - IS-PP: distância entre a borda incisal do incisivo central superior e o plano palatino. Determina o desenvolvimento vertical dos incisivos superiores;

22 - MS-PP: distância da cúspide mesial do primeiro molar superior ao plano palatino, medida perpendicularmente. Determina o desenvolvimento vertical dos molares superiores;

\subsubsection{Inferiores}

23 - II.NB: ângulo entre o longo eixo do incisivo inferior e a linha NB. Relaciona a inclinação deste dente com a mandíbula e o Násio;

24 - II-NB: distância entre o ponto mais anterior da coroa do incisivo central inferior e a linha NB. Relaciona a posição sagital do incisivo inferior em relação à mandíbula e ao Násio;

25 - II.PM: ângulo entre o longo eixo do incisivo central inferior e o plano mandibular. Relaciona a inclinação do incisivo inferior à mandíbula;

26 - II-PM: distância entre a borda incisal do incisivo central inferior e o plano mandibular. Determina o desenvolvimento vertical dos incisivos inferiores;

27 - MI-GoMe: distância da cúspide mesial do primeiro molar inferior ao plano mandibular medida perpendicularmente. Determina o desenvolvimento vertical dos molares inferiores; 


\subsubsection{Maxilomandibulares}

28 - TRES. V. (Trespasse vertical): distância entre as bordas incisais dos incisivos centrais superiores $\mathrm{e}$ inferiores medida perpendicularmente ao plano oclusal;

29 - TRES. H. (Trespasse horizontal): distância entre as bordas incisais dos incisivos centrais superiores e inferiores projetadas perpendicularmente no plano oclusal;

30 - REL. M. (Relação Molar): distância entre as cúspides mesiais dos primeiros molares superiores $e$ inferiores projetadas perpendicularmente no plano oclusal funcional. 


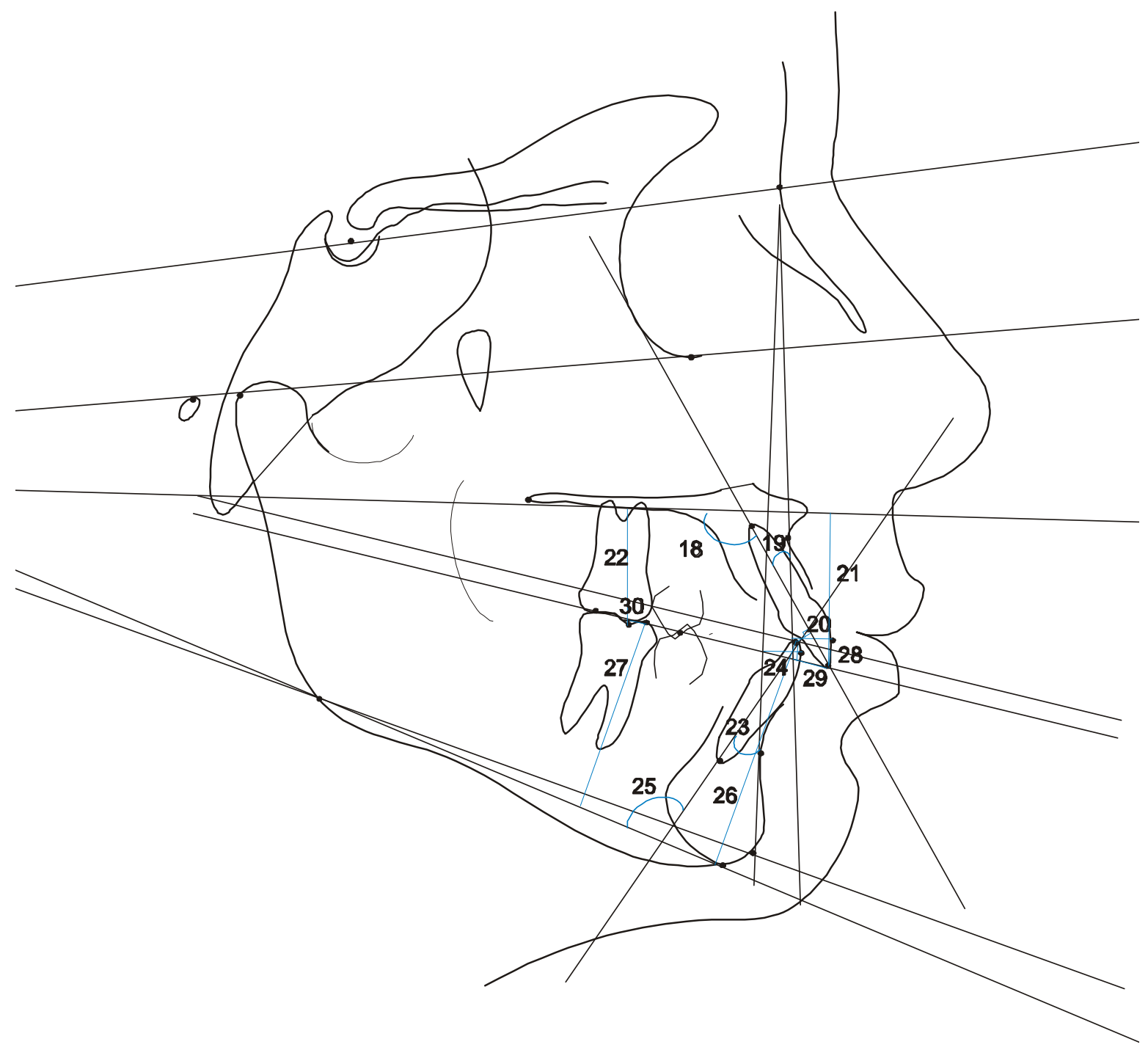

FIGURA 4 - Grandezas Cefalométricas Dentárias 


\subsection{Medição do Trespasse Vertical (figura 5)}

O trespasse vertical foi avaliado pela distância entre as bordas incisais dos incisivos centrais superiores e inferiores medida perpendicularmente ao plano oclusal.

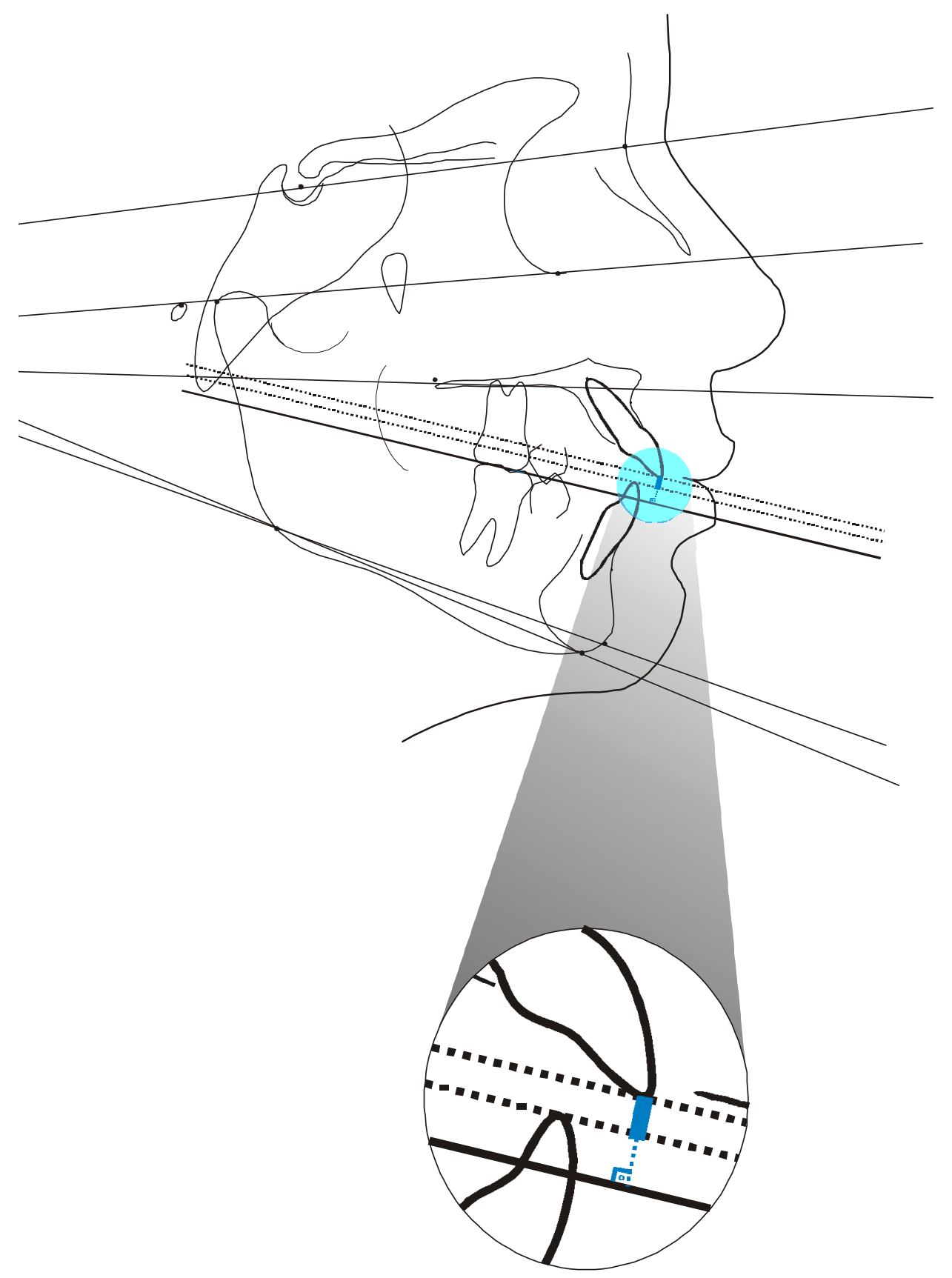

FIGURA 5 - Representação da forma de medição do trespasse vertical 


\subsection{Protocolo de Tratamento}

Os pacientes foram submetidos ao tratamento ortodôntico corretivo para o alinhamento e nivelamento dos dentes, visando a correção da mordida aberta anterior. Em alguns pacientes realizou-se a expansão rápida da maxila no intuito aliviar os apinhamentos dentários, melhorar a forma do arco e normalizar a relação vestíbulo-lingual entre os dentes posteriores. De um modo geral, utilizou-se bráquetes da técnica edgewise padrão com fios Nitinol ou de aço inoxidável com alças de nivelamento (na fase de alinhamento e nivelamento) e de aço inoxidável planos (na fase de finalização). Simultaneamente, utilizouse elásticos verticais na região anterior para auxiliar o fechamento da mordida aberta. Esta fase de tratamento durou, em média, 2,4 anos (TABELA 1). Após a finalização do tratamento, instalou-se a placa de Hawley no arco superior e realizou-se a colagem do $3 \times 3$ no arco inferior.

\subsection{Análise Estatística}

\subsubsection{Erro do Método}

Para a avaliação do erro intra-examinador foram traçadas, digitalizadas e medidas novamente 20 radiografias escolhidas ao acaso dentre as 63 existentes na amostra. A aplicação da fórmula proposta por DAHLBERG ${ }^{38}$ $\left(\mathrm{Se}^{2}=\right.$ somatória $\left.\mathrm{d}^{2} / 2 \mathrm{n}\right)$ permitiu estimar a ordem de grandeza dos erros casuais. A obtenção dos erros sistemáticos procedeu-se pela aplicação do teste $\mathrm{t}$ pareado de acordo com BAUMRIND \& FRANTZ ${ }^{13}$; GRAVELY \& BENZIES $^{74}$; HOUSTON ${ }^{86}$; e RICHARDSON ${ }^{184}$.

\subsubsection{Testes Estatísticos}

As características cefalométricas iniciais dos pacientes da amostra foram verificadas por meio do teste $t$ independente entre o grupo experimental na fase $\mathrm{T} 1$ e o grupo controle 1, que consiste na média descrita na população observada no Atlas de Crescimento Craniofacial da Faculdade de Odontologia de Bauru ${ }^{134}$ para adolescentes do gênero feminino aos 12 anos de idade. As 
características cefalométricas da amostra ao final do tratamento (T2) foram verificadas por meio do teste $t$ independente entre os pacientes da amostra em T2 e a fase inicial do grupo controle 2 (amostra de pacientes com oclusão normal aos 14 anos). As alterações apresentadas no período após o tratamento (T3-T2) foram verificadas por meio do teste $t$ independente para a amostra no período T3-T2 e o mesmo período no grupo controle 2 (amostra de pacientes com oclusão normal dos 14,6 aos 19,6 anos). Os resultados foram considerados significantes quando $p<0,05$.

Para a análise dos resultados obtidos com a medição das telerradiografias empregou-se o teste $t$ pareado entre as fases estudadas. Todas as medidas foram analisadas pelo programa statistica*. Os resultados foram considerados estatisticamente significantes para $p<0,05$. Após a avaliação da recidiva da mordida aberta anterior, realizada por meio da diferença da mensuração do trespasse vertical nas fases T3 e T2, foi utilizado o teste de "Pearson" para verificar a correlação existente entre a recidiva do trespasse vertical e a recidiva das outras medidas estudadas. O teste de "Pearson" também foi utilizado para verificar a existência da correlação da recidiva da mordida aberta anterior em relação à magnitude inicial da mordida aberta e à quantidade de correção realizada durante o tratamento ortodôntico.

Como meio de estabelecer-se parâmetros clínicos para a o assunto proposto, definiu-se a recidiva da mordida aberta anterior "clinicamente significante" quando houver qualquer trespasse vertical negativo entre os incisivos superiores e inferiores, na fase T3, ou seja, após 5 anos do término do tratamento. Essa análise foi representada em forma de porcentagem avaliando os pacientes que apresentaram a recidiva "clinicamente significante" em relação ao total da amostra estudada.

* Statistica for Windows - release 4.3B. - Copywright Statsoft, Inc. 1993. 


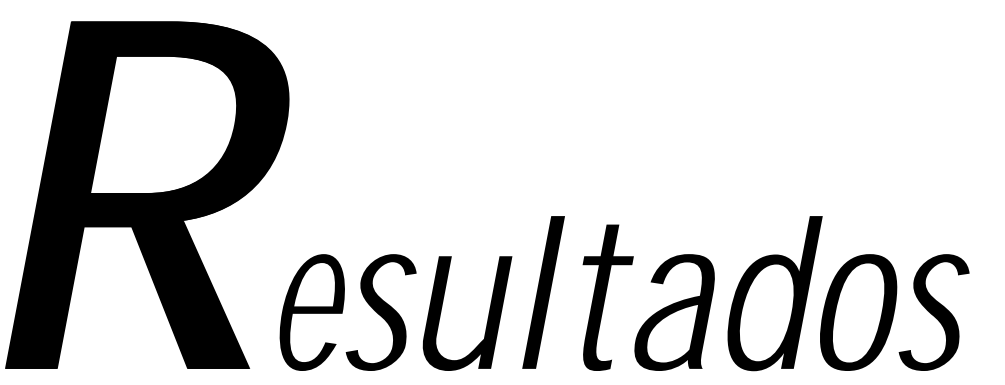




\section{RESULTADOS}

( $\mathrm{S}$ resultados estão apresentados nas tabelas seguintes. $\mathrm{Na}$ TABELA 3, estão dispostos os resultados da comparação dos pacientes do grupo experimental na fase inicial (T1) com a média da população descrita no Atlas de Crescimento Craniofacial da Faculdade de Odontologia de Bauru $^{133}$ (grupo controle 1) na idade de 12 anos. A TABELA 4 demonstra os resultados da comparação entre os pacientes do grupo experimental no final do tratamento (T2) e da fase inicial do grupo controle 2 (amostra de pacientes com oclusão normal aos 14,6 anos).

$\mathrm{Na}$ TABELA 5 estão demonstrados os resultados do erro intraexaminador. A TABELA 6 apresenta as médias reais para a variável que mensura o trespasse vertical (TRES. V.), nas três fases estudadas: T1, T2, T3. As TABELAS 7 e 8 retratam o resultado do teste $t$ pareado aplicado no período de tratamento (T2-T1) e após o término do tratamento (T3-T2), respectivamente. A TABELA 9 representa os resultados do teste $t$ independente entre o grupo experimental no período após o tratamento (T3-T2) e o grupo controle 2 no período equivalente (amostra de pacientes com oclusão normal no período dos 14,6 aos 19,6 anos).

A TABELA 10 evidencia a correlação entre a quantidade de recidiva do trespasse vertical (TRES. V. T3-T2) e as alterações das variáveis estudadas entre o final e 5 anos após o término do tratamento (T3-T2). A TABELA 11 descreve a correlação existente entre a magnitude inicial da mordida aberta anterior (TRES. V. T1) e a quantidade de correção efetuada pelo tratamento (TRES. V. T2-T1), em relação à quantidade de recidiva apresentada após 5 anos do término do tratamento (TRES. V. T3-T2). Finalmente, a TABELA 12 verifica a quantidade e a porcentagem dos casos que apresentaram uma "recidiva clinicamente significante". 
TABELA 3 - Resultados do teste $t$ independente entre as variáveis do grupo experimental no início do tratamento $(\mathrm{T} 1)$ e da média da população (grupo controle 1), descrita no Atlas de Crescimento Craniofacial $^{133}$, aos 12 anos.

\begin{tabular}{|c|c|c|c|c|c|}
\hline \multirow{2}{*}{ VARIÁVEIS } & \multicolumn{2}{|c|}{ INICIAL (T1) } & \multicolumn{2}{|c|}{ GRUPO CONTROLE } & \multirow[b]{2}{*}{$\mathrm{p}$} \\
\hline & Média & D. P. & Média & D. P. & \\
\hline \multicolumn{6}{|c|}{ COMPONENTE MAXILAR } \\
\hline SNA & 80,30 & 3,91 & 81,1 & 3,5 & 0,50 \\
\hline A-Nperp & $-0,12$ & 2,90 & $-1,1$ & 3,2 & 0,50 \\
\hline Co-A & 82,16 & 4,98 & 86,9 & 4,0 & 0,00 \\
\hline \multicolumn{6}{|c|}{ COMPONENTE MANDIBULAR } \\
\hline SNB & 77,44 & 3,63 & 78,9 & 3,1 & 0,17 \\
\hline P-Nperp & $-3,73$ & 6,09 & $-4,5$ & 3,0 & 0,62 \\
\hline Co-Go & 50,98 & 5,43 & 53,1 & 4,2 & 0,18 \\
\hline Go-Gn & 73,07 & 4,73 & 74,2 & 4,1 & 0,43 \\
\hline Co-Gn & 110,62 & 5,96 & 113,7 & 5,3 & 0,09 \\
\hline Co.GoMe & 128,36 & 6,40 & $-\ldots$ & --- & --- \\
\hline \multicolumn{6}{|c|}{ RELAÇÃO ENTRE MAXILA E MANDÍBULA } \\
\hline ANB & 2,87 & 2,32 & 2,2 & 2,4 & 0,38 \\
\hline Co-A/Co-Gn & 74,29 & 3,01 & --- & --- & --- \\
\hline WITS & $-1,94$ & 2,88 & --- & --- & --- \\
\hline \multicolumn{6}{|c|}{ PADRÃO DE CRESCIMENTO } \\
\hline FMA & 29,78 & 5,83 & 27,7 & 2,9 & 0,17 \\
\hline SN.PP & 7,46 & 2,33 & 9,3 & 3,4 & 0,06 \\
\hline SN.PO & 16,84 & 6,37 & 27,5 & 4,8 & 3,47 \\
\hline AFAl & 67,75 & 5,28 & 64,9 & 5,8 & 0,11 \\
\hline SN.GoGn & 36,94 & 5,66 & 33,2 & 5,0 & 0,03 \\
\hline \multicolumn{6}{|c|}{ COMPONENTE DENTOALVEOLAR SUPERIOR } \\
\hline IS.NA & 28,40 & 4,28 & 26,1 & 5,6 & 0,15 \\
\hline IS-NA & 5,98 & 1,89 & 4,6 & 1,7 & 0,02 \\
\hline IS.PP & 116,15 & 6,13 & 116,4 & 5,0 & 0,89 \\
\hline IS-PP & 26,51 & 2,62 & 26,9 & 3,0 & 0,67 \\
\hline MS-PP & 23,26 & 2,51 & 22,2 & 2,3 & 0,18 \\
\hline \multicolumn{6}{|c|}{ COMPONENTE DENTOALVEOLAR INFERIOR } \\
\hline II.NB & 28,25 & 6,64 & 26,8 & 6,3 & 0,49 \\
\hline II-NB & 5,45 & 2,21 & 4,7 & 3,0 & 0,37 \\
\hline II.PM & 91,43 & 7,76 & 92,4 & 6,6 & 0,67 \\
\hline II-PM & 38,26 & 2,93 & 40,0 & 3,5 & 0,09 \\
\hline MI-GoMe & 29,61 & 3,26 & 31,8 & 2,9 & 0,03 \\
\hline \multicolumn{6}{|c|}{ RELAÇÕES DENTÁRIAS } \\
\hline TRES. $\mathrm{H}$. & 4,43 & 2,60 & --- & --- & ---- \\
\hline TRES. V. & $-1,75$ & 0,66 & --- & --- & --- \\
\hline REL. M. & 0,06 & 0,36 & --- & --- & --- \\
\hline
\end{tabular}


TABELA 4 - Resultados do teste $t$ independente entre as variáveis do grupo experimental no final do tratamento (T2) e da fase inicial do grupo controle 2 (amostra de pacientes com oclusão normal aos 14,6 anos).

\begin{tabular}{|c|c|c|c|c|c|}
\hline \multirow[t]{2}{*}{ VARIÁVEIS } & \multicolumn{2}{|c|}{$\begin{array}{c}\text { FINAL DE } \\
\text { TRATAMENTO (T2) }\end{array}$} & \multicolumn{2}{|c|}{$\begin{array}{c}\text { GRUPO CONTROLE } \\
2\end{array}$} & \multirow[t]{2}{*}{$\mathrm{p}$} \\
\hline & & & Média & D. P. & \\
\hline \multicolumn{6}{|c|}{ COMPONENTE MAXILAR } \\
\hline SNA & 80,62 & 3,49 & 80,46 & 2,65 & 0,86 \\
\hline A-Nperp & $-0,10$ & 3,37 & $-2,00$ & 2,27 & 0,03 \\
\hline CoA & 83,00 & 5,10 & 85,18 & 4,18 & 0,13 \\
\hline \multicolumn{6}{|c|}{ COMPONENTE MANDIBULAR } \\
\hline SNB & 78,00 & 3,50 & 79,03 & 3,03 & 0,31 \\
\hline P-Nperp & $-3,08$ & 7,35 & $-4,06$ & 5,64 & 0,62 \\
\hline CoGo & 53,55 & 4,84 & 53,96 & 4,54 & 0,77 \\
\hline GoGn & 74,83 & 5,12 & 74,14 & 5,61 & 0,67 \\
\hline CoGn & 113,89 & 6,34 & 113,21 & 6,45 & 0,73 \\
\hline Co.GoMe & 127,03 & 6,19 & 125,59 & 5,44 & 0,42 \\
\hline \multicolumn{6}{|c|}{ RELAÇÁO ENTRE MAXILA E MANDÍBULA } \\
\hline ANB & 2,60 & 2,05 & 1,42 & 1,66 & 0,04 \\
\hline CoA/CoGn & 72,91 & 3,03 & 75,30 & 2,11 & 0,00 \\
\hline WITS & $-0,71$ & 2,46 & $-2,12$ & 2,64 & 0,08 \\
\hline \multicolumn{6}{|c|}{ PADRÃO DE CRESCIMENTO } \\
\hline FMA & 29,49 & 5,97 & 26,63 & 4,94 & 0,09 \\
\hline SN.PP & 7,23 & 2,24 & 8,90 & 3,24 & 0,06 \\
\hline SN.PO & 13,92 & 4,47 & 17,06 & 5,23 & 0,04 \\
\hline AFAl & 70,20 & 5,16 & 63,83 & 3,51 & 0,00 \\
\hline SN.GoGn & 36,43 & 5,36 & 32,28 & 4,45 & 0,00 \\
\hline \multicolumn{6}{|c|}{ COMPONENTE DENTOALVEOLAR SUPERIOR } \\
\hline IS.NA & 24,22 & 4,99 & 23,78 & 5,29 & 0,78 \\
\hline IS-NA & 5,30 & 1,87 & 4,66 & 1,91 & 0,28 \\
\hline IS.PP & 112,08 & 5,55 & 113,15 & 4,86 & 0,51 \\
\hline IS-PP & 29,33 & 2,64 & 27,45 & 2,52 & 0,02 \\
\hline MS-PP & 24,76 & 2,53 & 22,98 & 1,83 & 0,01 \\
\hline \multicolumn{6}{|c|}{ COMPONENTE DENTOALVEOLAR INFERIOR } \\
\hline II.NB & 27,13 & 5,54 & 23,41 & 4,08 & 0,01 \\
\hline II-NB & 6,04 & 2,08 & 3,71 & 1,68 & 0,00 \\
\hline II.PM & 90,32 & 6,56 & 90,46 & 4,68 & 0,13 \\
\hline II-PM & 40,97 & 2,74 & 37,82 & 1,92 & 0,00 \\
\hline $\mathrm{MI-GoMe}$ & 30,91 & 2,63 & 28,58 & 1,64 & 0,00 \\
\hline \multicolumn{6}{|c|}{ RELAÇÕES DENTÁRIAS } \\
\hline TRES. H. & 2,80 & 1,01 & 2,73 & 0,57 & 0,76 \\
\hline TRES. V. & 1,43 & 0,50 & 2,91 & 1,09 & 0,00 \\
\hline REL. M. & $-0,15$ & 0,49 & 1,80 & 0,72 & 0,00 \\
\hline
\end{tabular}


Resultados 63

TABELA 5 - Análise do erro intra-examinador. Apresentação dos erros casuais, das médias, dos desvios padrão e nível de significância estatística dos erros sistemáticos, entre os traçados repetidos.

\begin{tabular}{|c|c|c|c|c|c|c|c|}
\hline \multirow[b]{2}{*}{ VARIÁVEIS } & \multicolumn{2}{|c|}{ 1a MEDIÇÃO } & \multicolumn{2}{|c|}{$2^{\mathrm{a}}$ MEDIÇÃO } & \multirow[b]{2}{*}{ Dif. } & \multirow[b]{2}{*}{ Dahlber!ı } & \multirow[b]{2}{*}{$\mathrm{p}$} \\
\hline & MÉDIA & D. P. & MÉDIA & D. P. & & & \\
\hline \multicolumn{8}{|c|}{ COMPONENTE MAXILAR } \\
\hline SNA & 79,98 & 3,75 & 79,96 & 3,51 & 0,02 & 0,40 & 0,85 \\
\hline A-Nperp & $-0,84$ & 3,47 & $-0,78$ & 3,31 & $-0,06$ & 0,38 & 0,63 \\
\hline Co-A & 81,57 & 5,16 & 81,81 & 5,32 & $-0,23$ & 0,77 & 0,34 \\
\hline \multicolumn{8}{|c|}{ COMPONENTE MANDIBULAR } \\
\hline SNB & 76,86 & 3,59 & 76,76 & 3,44 & 0,10 & 0,36 & 0,37 \\
\hline P-Nperp & $-5,88$ & 6,66 & $-6,15$ & 6,51 & 0,27 & 0,58 & 0,15 \\
\hline Co-Go & 52,73 & 5,49 & 52,59 & 5,64 & 0,14 & 1,19 & 0,72 \\
\hline Go-Gn & 72,93 & 5,82 & 72,52 & 5,32 & 0,41 & 1,07 & 0,23 \\
\hline Co-Gn & 112,51 & 6,95 & 112,25 & 7,07 & 0,26 & 0,49 & 0,09 \\
\hline Co.GoMe & 129,60 & 6,62 & 130,02 & 6,39 & $-0,41$ & 0,97 & 0,23 \\
\hline \multicolumn{8}{|c|}{ RELAÇÃO ENTRE MAXILA E MANDÍBULA } \\
\hline ANB & 3,12 & 1,48 & 3,19 & 1,49 & $-0,07$ & 0,22 & 0,32 \\
\hline Co-A/Co-Gn & 72,52 & 2,49 & 72,91 & 2,45 & $-0,39$ & 0,64 & 0,05 \\
\hline WITS & $-1,16$ & 1,82 & $-1,38$ & 1,67 & 0,22 & 0,64 & 0,28 \\
\hline \multicolumn{8}{|c|}{ PADRÃO DE CRESCIMENTO } \\
\hline FMA & 32,33 & 6,28 & 32,22 & 6,46 & 0,11 & 0,64 & 0,60 \\
\hline SN.PP & 7,99 & 2,59 & 7,91 & 2,43 & 0,08 & 0,52 & 0,64 \\
\hline SN.PO & 16,31 & 6,10 & 17,95 & 5,80 & $-1,63$ & 2,39 & 0,02 \\
\hline AFAI & 70,94 & 5,62 & 71,35 & 5,62 & $-0,40$ & 0,56 & 0,02 \\
\hline SN.GoGn & 38,98 & 5,58 & 38,96 & 5,67 & 0,02 & 0,49 & 0,90 \\
\hline \multicolumn{8}{|c|}{ COMPONENTE DENTOALVEOLAR SUPERIOR } \\
\hline IS.NA & 25,79 & 4,49 & 25,57 & 4,20 & 0,21 & 0,74 & 0,37 \\
\hline IS-NA & 5,79 & 1,88 & 5,51 & 1,71 & 0,28 & 0,42 & 0,02 \\
\hline IS.PP & 113,74 & 5,55 & 113,44 & 5,38 & 0,30 & 0,77 & 0,23 \\
\hline IS-PP & 28,39 & 3,29 & 28,78 & 3,16 & $-0,39$ & 0,44 & 0,00 \\
\hline MS-PP & 24,49 & 3,00 & 24,65 & 3,05 & $-0,16$ & 0,27 & 0,06 \\
\hline \multicolumn{8}{|c|}{ COMPONENTE DENTOALVEOLAR INFERIOR } \\
\hline II.NB & 28,32 & 6,52 & 28,16 & 6,18 & 0,15 & 0,57 & 0,41 \\
\hline II-NB & 6,45 & 2,09 & 6,24 & 2,13 & 0,21 & 0,25 & 0,00 \\
\hline II.PM & 89,94 & 7,85 & 89,92 & 7,81 & 0,02 & 0,86 & 0,94 \\
\hline II-PM & 41,04 & 3,10 & 40,99 & 3,08 & 0,04 & 0,21 & 0,52 \\
\hline MI-GoMe & 31,27 & 2,67 & 31,42 & 2,76 & $-0,14$ & 0,31 & 0,14 \\
\hline \multicolumn{8}{|c|}{ RELAÇÕES DENTÁRIAS } \\
\hline TRES. $\mathrm{H}$. & 3,59 & 1,99 & 3,62 & 1,94 & $-0,03$ & 0,19 & 0,64 \\
\hline TRES. V. & $-0,14$ & 1,82 & 0,10 & 1,48 & $-0,24$ & 0,53 & 0,15 \\
\hline REL. M. & $-0,08$ & 0,41 & $-0,22$ & 0,39 & 0,13 & 0,42 & 0,33 \\
\hline
\end{tabular}


TABELA 6 - Médias reais e desvios-padrão do trespasse vertical (TRES. V.), nas três fases avaliadas.

\begin{tabular}{c|c|c|c|c}
\hline \multirow{2}{*}{ VARIÁVEIS } & \multicolumn{4}{|c}{ TRESPASSE VERTICAL } \\
\cline { 2 - 5 } & Média & Mínimo & Máximo & Desvio padrão \\
\hline TRES V1 (T1) & $-1,75$ & $-0,90$ & $-4,10$ & 0,66 \\
\hline TRES V2 (T2) & 1,43 & 0,40 & 2,50 & 0,50 \\
\hline TRES V3 (T3) & 0,07 & 1,20 & $-1,40$ & 0,62 \\
\hline
\end{tabular}

TABELA 7 - Resultado do teste $t$ pareado e médias reais das variáveis estudadas no período de tratamento (T2-T1).

\begin{tabular}{|c|c|c|c|c|c|c|}
\hline \multirow[t]{2}{*}{ VARIÁVEIS } & \multicolumn{2}{|c|}{$\begin{array}{c}\text { INÍCIO DO } \\
\text { TRATAMENTO (T1) }\end{array}$} & \multicolumn{2}{|c|}{$\begin{array}{c}\text { FINAL DO } \\
\text { TRATAMENTO (T2) }\end{array}$} & \multirow[t]{2}{*}{ Dif. } & \multirow[t]{2}{*}{$\mathrm{p}$} \\
\hline & MÉDIA & D. P. & MÉDIA & D. P. & & \\
\hline \multicolumn{7}{|c|}{ COMPONENTE MAXILAR } \\
\hline SNA & 80,30 & 3,91 & 80,62 & 3,49 & 0,32 & 0,38 \\
\hline A-Nperp & $-0,12$ & 2,90 & $-0,10$ & 3,37 & 0,01 & 0,96 \\
\hline Co-A & 82,16 & 4,98 & 83,00 & 5,10 & 0,83 & 0,08 \\
\hline \multicolumn{7}{|c|}{ COMPONENTE MANDIBULAR } \\
\hline SNB & 77,44 & 3,63 & 78,00 & 3,50 & 0,56 & 0,04 \\
\hline P-Nperp & $-3,73$ & 6,09 & $-3,08$ & 7,35 & 0,65 & 0,30 \\
\hline Co-Go & 50,98 & 5,43 & 53,55 & 4,84 & 2,56 & 0,00 \\
\hline Go-Gn & 73,07 & 4,73 & 74,83 & 5,12 & 1,76 & 0,01 \\
\hline Co-Gn & 110,62 & 5,96 & 113,89 & 6,34 & 3,27 & 0,00 \\
\hline Co.GoMe & 128,36 & 6,40 & 127,03 & 6,19 & $-1,32$ & 0,01 \\
\hline \multicolumn{7}{|c|}{ RELAÇÃO ENTRE MAXILA E MANDÍBULA } \\
\hline ANB & 2,87 & 2,32 & 2,60 & 2,05 & $-0,27$ & 0,39 \\
\hline Co-A/Co-Gn & 74,29 & 3,01 & 72,91 & 3,03 & $-1,37$ & 0,00 \\
\hline WITS & $-1,94$ & 2,88 & $-0,71$ & 2,46 & 1,22 & 0,02 \\
\hline \multicolumn{7}{|c|}{ PADRÃO DE CRESCIMENTO } \\
\hline FMA & 29,78 & 5,83 & 29,49 & 5,97 & $-0,29$ & 0,47 \\
\hline SN.PP & 7,46 & 2,33 & 7,23 & 2,24 & $-0,22$ & 0,51 \\
\hline SN.PO & 16,84 & 6,37 & 13,92 & 4,47 & $-2,91$ & 0,02 \\
\hline AFAl & 67,75 & 5,28 & 70,20 & 5,16 & 2,45 & 0,00 \\
\hline SN.GoGn & 36,94 & 5,66 & 36,43 & 5,36 & $-0,50$ & 0,21 \\
\hline \multicolumn{7}{|c|}{ COMPONENTE DENTOALVEOLAR SUPERIOR } \\
\hline IS.NA & 28,40 & 4,28 & 24,22 & 4,99 & $-4,17$ & 0,00 \\
\hline IS-NA & 5,98 & 1,89 & 5,30 & 1,87 & $-0,68$ & 0,16 \\
\hline IS.PP & 116,15 & 6,13 & 112,08 & 5,55 & $-4,07$ & 0,00 \\
\hline IS-PP & 26,51 & 2,62 & 29,33 & 2,64 & 2,81 & 0,00 \\
\hline MS-PP & 23,26 & 2,51 & 24,76 & 2,53 & 1,50 & 0,00 \\
\hline \multicolumn{7}{|c|}{ COMPONENTE DENTOALVEOLAR INFERIOR } \\
\hline II.NB & 28,25 & 6,64 & 27,13 & 5,54 & $-1,12$ & 0,30 \\
\hline II-NB & 5,45 & 2,21 & 6,04 & 2,08 & 0,59 & 0,10 \\
\hline II.PM & 91,43 & 7,76 & 90,32 & 6,56 & $-1,11$ & 0,31 \\
\hline II-PM & 38,26 & 2,93 & 40,97 & 2,74 & 2,70 & 0,00 \\
\hline MI-GoMe & 29,61 & 3,26 & 30,91 & 2,63 & 1,30 & 0,00 \\
\hline \multicolumn{7}{|c|}{ RELAÇÕES DENTÁRIAS } \\
\hline TRES. $\mathrm{H}$. & 4,43 & 2,60 & 2,80 & 1,01 & $-1,62$ & 0,00 \\
\hline TRES. V. & $-1,75$ & 0,66 & 1,43 & 0,50 & 3,19 & 0,00 \\
\hline REL. M. & 0,06 & 0,36 & $-0,15$ & 0,49 & $-0,21$ & 0,04 \\
\hline
\end{tabular}


TABELA 8 - Resultado do teste $t$ pareado e médias reais de todas as variáveis estudadas no período médio de 5 anos após o término do tratamento (T3-T2).

\begin{tabular}{|c|c|c|c|c|c|c|}
\hline \multirow[t]{2}{*}{ VARIÁVEIS } & \multicolumn{2}{|c|}{$\begin{array}{c}\text { FINAL DO } \\
\text { TRATAMENTO (T2 }\end{array}$} & \multicolumn{2}{|c|}{$\begin{array}{l}5 \text { ANOS APÓS O } \\
\text { TRATAMENTO (T3) }\end{array}$} & \multirow[t]{2}{*}{ Dif. } & \multirow[t]{2}{*}{$\mathrm{p}$} \\
\hline & MÉDIA & D. P. & MÉDIA & D. P. & & \\
\hline \multicolumn{7}{|c|}{ COMPONENTE MAXILAR } \\
\hline SNA & 80,62 & 3,49 & 81,41 & 3,57 & 0,78 & 0,05 \\
\hline A-Nperp & $-0,10$ & 3,37 & 0,26 & 3,02 & 0,36 & 0,42 \\
\hline Co-A & 83,00 & 5,10 & 83,50 & 5,57 & 0,51 & 0,21 \\
\hline \multicolumn{7}{|c|}{ COMPONENTE MANDIBULAR } \\
\hline SNB & 78,00 & 3,50 & 78,49 & 4,30 & 0,48 & 0,07 \\
\hline P-Nperp & $-3,08$ & 7,35 & $-2,84$ & 7,83 & 0,23 & 0,72 \\
\hline Co-Go & 53,55 & 4,84 & 55,01 & 6,06 & 1,46 & 0,04 \\
\hline Go-Gn & 74,83 & 5,12 & 75,43 & 4,99 & 0,59 & 0,21 \\
\hline Co-Gn & 113,89 & 6,34 & 115,01 & 7,12 & 1,12 & 0,01 \\
\hline Co.GoMe & 127,03 & 6,19 & 126,18 & 5,93 & $-0,84$ & 0,10 \\
\hline \multicolumn{7}{|c|}{ RELAÇẦO ENTRE MAXILA E MANDÍBULA } \\
\hline ANB & 2,60 & 2,05 & 2,93 & 2,12 & 0,33 & 0,24 \\
\hline Co-A/Co-Gn & 72,91 & 3,03 & 72,64 & 3,02 & $-0,27$ & 0,40 \\
\hline WITS & $-0,71$ & 2,46 & $-0,75$ & 2,79 &,- 03 & 0,90 \\
\hline \multicolumn{7}{|c|}{ PADRÃO DE CRESCIMENTO } \\
\hline FMA & 29,49 & 5,97 & 29,27 & 6,33 & $-0,21$ & 0,60 \\
\hline SN.PP & 7,23 & 2,24 & 6,76 & 2,60 & $-0,47$ & 0,15 \\
\hline SN.PO & 13,92 & 4,47 & 13,93 & 6,77 & 0,00 & 0,99 \\
\hline AFAl & 70,20 & 5,16 & 71,69 & 5,67 & 1,48 & 0,00 \\
\hline SN.GoGn & 36,43 & 5,36 & 35,41 & 6,55 & $-1,02$ & 0,02 \\
\hline \multicolumn{7}{|c|}{ COMPONENTE DENTOALVEOLAR SUPERIOR } \\
\hline IS.NA & 24,22 & 4,99 & 24,71 & 4,36 & 0,48 & 0,47 \\
\hline IS-NA & 5,30 & 1,87 & 5,22 & 1,91 & $-0,07$ & 0,85 \\
\hline IS.PP & 112,08 & 5,55 & 112,88 & 5,57 & 0,79 & 0,11 \\
\hline IS-PP & 29,33 & 2,64 & 29,19 & 2,93 & $-0,14$ & 0,56 \\
\hline MS-PP & 24,76 & 2,53 & 25,39 & 2,58 & 0,63 & 0,03 \\
\hline \multicolumn{7}{|c|}{ COMPONENTE DENTOALVEOLAR INFERIOR } \\
\hline II.NB & 27,13 & 5,54 & 28,57 & 6,74 & 1,44 & 0,07 \\
\hline II-NB & 6,04 & 2,08 & 6,53 & 2,36 & 0,49 & 0,00 \\
\hline II.PM & 90,32 & 6,56 & 91,93 & 8,15 & 1,61 & 0,05 \\
\hline II-PM & 40,97 & 2,74 & 41,31 & 2,79 &, 33 & 0,15 \\
\hline MI-GoMe & 30,91 & 2,63 & 31,91 & 3,06 & 1,00 & 0,00 \\
\hline \multicolumn{7}{|c|}{ RELAÇÕES DENTÁRIAS } \\
\hline TRES. $\mathrm{H}$. & 2,80 & 1,01 & 2,71 & 1,20 & $-0,09$ & 0,59 \\
\hline TRES. V. & 1,43 & 0,50 & 0,07 & 0,62 & $-1,36$ & 0,00 \\
\hline REL. M. & $-0,15$ & 0,49 & $-0,21$ & 0,43 & $-0,06$ & 0,69 \\
\hline
\end{tabular}


TABELA 9 - Resultados do teste $t$ independente entre as alterações das variáveis do grupo experimental no período após o tratamento (T3-T2) e do grupo controle 2 (amostra de pacientes com oclusão normal no período dos 14,6 aos 19,6 anos).

\begin{tabular}{|c|c|c|c|c|c|}
\hline \multirow[t]{2}{*}{ VARIÁVEIS } & \multicolumn{2}{|c|}{$\begin{array}{c}\text { PERÍODO APÓS } \\
\text { TRATAMENTO (T3-T2) }\end{array}$} & \multicolumn{2}{|c|}{$\begin{array}{c}\text { GRUPO CONTROLE } \\
2\end{array}$} & \multirow[t]{2}{*}{$p$} \\
\hline & Média & D. P. & Média & D. P. & \\
\hline \multicolumn{6}{|c|}{ COMPONENTE MAXILAR } \\
\hline SNA & 0,78 & 1,76 & 0,30 & 1,24 & 0,31 \\
\hline A-Nperp & 0,36 & 2,07 & $-0,38$ & 1,32 & 0,16 \\
\hline CoA & 0,50 & 1,81 & 1,70 & 2,14 & 0,05 \\
\hline \multicolumn{6}{|c|}{ COMPONENTE MANDIBULAR } \\
\hline SNB & 0,48 & 1,16 & 0,90 & 1,32 & 0,28 \\
\hline P-Nperp & 0,23 & 3,01 & 0,60 & 2,75 & 0,67 \\
\hline CoGo & 1,46 & 3,17 & 3,74 & 2,66 & 0,01 \\
\hline GoGn & 0,59 & 2,10 & 1,90 & 1,88 & 0,04 \\
\hline CoGn & 1,12 & 2,01 & 4,28 & 3,12 & 0,00 \\
\hline Co.GoMe & $-0,84$ & 2,29 & $-1,24$ & 1,84 & 0,53 \\
\hline \multicolumn{6}{|c|}{ RELAÇÃ̄O ENTRE MAXILA E MANDÍBULA } \\
\hline ANB & 0,33 & 1,28 & $-0,60$ & 0,95 & 0,01 \\
\hline CoA/CoGn & $-0,27$ & 1,46 & $-1,30$ & 1,00 & 0,01 \\
\hline WITS & $-0,03$ & 1,52 & 0,59 & 2,03 & 0,26 \\
\hline \multicolumn{6}{|c|}{ PADRÃO DE CRESCIMENTO } \\
\hline FMA & $-0,21$ & 1,87 & $-1,04$ & 1,62 & 0,13 \\
\hline SN.PP & $-0,47$ & 1,47 & $-0,69$ & 1,60 & 0,64 \\
\hline SN.PO & 0,00 & 5,54 & $-3,44$ & 3,99 & 0,02 \\
\hline AFAl & 1,48 & 1,69 & 2,43 & 2,30 & 0,13 \\
\hline SN.GoGn & $-1,02$ & 1,90 & $-1,64$ & 2,04 & 0,31 \\
\hline \multicolumn{6}{|c|}{ COMPONENTE DENTOALVEOLAR SUPERIOR } \\
\hline IS.NA & 0,48 & 3,05 & 0,57 & 2,28 & 0,91 \\
\hline IS-NA & $-0,07$ & 1,81 & 0,78 & 0,98 & 0,06 \\
\hline IS.PP & 0,79 & 2,21 & 0,19 & 2,08 & 0,37 \\
\hline IS-PP & $-0,14$ & 1,16 & 0,83 & 0,79 & 0,00 \\
\hline MS-PP & 0,63 & 1,27 & 1,90 & 1,31 & 0,00 \\
\hline \multicolumn{6}{|c|}{ COMPONENTE DENTOALVEOLAR INFERIOR } \\
\hline II.NB & 1,44 & 3,50 & $-0,04$ & 2,45 & 0,11 \\
\hline II-NB & 0,49 & 0,65 & 0,08 & 0,63 & 0,04 \\
\hline II.PM & 1,61 & 3,57 & 0,44 & 2,43 & 0,09 \\
\hline II-PM & 0,33 & 1,04 & 1,27 & 1,12 & 0,00 \\
\hline MI-GoMe & 1,00 & 0,99 & 1,38 & 1,57 & 0,34 \\
\hline \multicolumn{6}{|c|}{ RELAÇÖES DENTÁRIAS } \\
\hline TRES. $\mathrm{H}$. & $-0,09$ & 0,81 & $-0,08$ & 0,43 & 0,96 \\
\hline TRES. V. & $-1,36$ & 0,54 & $-0,31$ & 0,83 & 0,00 \\
\hline REL. M. & $-0,06$ & 0,70 & $-0,28$ & 1,06 & 0,43 \\
\hline
\end{tabular}


TABELA 10 - Análise da correlação entre a quantidade de recidiva do trespasse vertical (TRES. V.) e as alterações das variáveis estudadas, entre o final e 5 anos após o término do tratamento (T3-T2).

\begin{tabular}{|c|c|c|c|}
\hline \multicolumn{2}{|c|}{ VARIÁVEIS (T3-T2) } & $r$ & $p$ \\
\hline \multirow{29}{*}{ TRES. V. } & SNA & 0,25 & 0,27 \\
\hline & \begin{tabular}{|l|} 
A-Nperp \\
\end{tabular} & 0,02 & 0,90 \\
\hline & Co-A & 0,25 & 0,26 \\
\hline & SNB & 0,31 & 0,16 \\
\hline & P-Nperp & $-0,02$ & 0,90 \\
\hline & Co-Go & $-0,30$ & 0,17 \\
\hline & Co-Gn & 0,06 & 0,78 \\
\hline & Go-Gn & 0,16 & 0,32 \\
\hline & Co,Go,Me & $-0,15$ & 0,51 \\
\hline & ANB & 0,05 & 0,80 \\
\hline & Co-A/Co-Gn & 0,20 & 0,37 \\
\hline & WITS & 0,00 & 0,97 \\
\hline & FMA & 0,01 & 0,93 \\
\hline & SN,PP & $-0,27$ & 0,23 \\
\hline & SN,PO & $-0,01$ & 0,94 \\
\hline & AFAl & $-0,16$ & 0,46 \\
\hline & SN,GoGn & $-0,05$ & 0,82 \\
\hline & IS,NA & $-0,17$ & 0,44 \\
\hline & IS-NA & $-0,18$ & 0,43 \\
\hline & IS,PP & $-0,20$ & 0,36 \\
\hline & IS-PP & 0,04 & 0,85 \\
\hline & MS-PP &,- 017 & 0,45 \\
\hline & II,NB & $-0,27$ & 0,22 \\
\hline & II-NB & $-0,32$ & 0,15 \\
\hline & II,PM & $-0,27$ & 0,22 \\
\hline & II-PM & 0,06 & 0,78 \\
\hline & MI-GoMe & $-0,53$ & 0,01 \\
\hline & TRES. $\mathrm{H}$. & $-0,07$ & 0,73 \\
\hline & REL. M. & 0,15 & 0,50 \\
\hline
\end{tabular}


Tabela 11 - Análise da correlação existente da magnitude inicial da mordida aberta anterior (TRES. V. T1) e da quantidade de correção efetuada pelo tratamento (TRES. V. T2-T1) com relação à quantidade de recidiva apresentada após 5 anos do término do tratamento (TRES. V. T3-T2).

\begin{tabular}{c|l|c|c}
\hline \multicolumn{2}{c|}{ VARIÁVEIS } & $r$ & $p$ \\
\hline \multirow{2}{*}{ TRES. V. T3-T2 } & TRES. V. T2-T1 & $-0,09$ & 0,69 \\
\cline { 2 - 4 } & TRES. V. T1 & $-0,21$ & 0,35 \\
\hline
\end{tabular}

TABELA 12 - Quantidade dos pacientes estudados que apresentaram recidiva "Clinicamente significante" após 5 anos do término do tratamento.

\begin{tabular}{l|c|c|c}
\hline $\begin{array}{c}\text { PACIENTE } \\
\text { № }\end{array}$ & TRESP. V. & TRESP. V. & TRESP. V. \\
INICIAL (T1) & FINAL (T2) & 5 ANOS (T3) \\
\hline 1 & $-1,5$ & 1,3 & 0,4 \\
\hline 2 & $-1,2$ & 1,7 & 0,3 \\
\hline 3 & $-2,5$ & 1,6 & 0,2 \\
\hline 4 & $-1,7$ & 2,3 & 1 \\
\hline 5 & $-1,8$ & 2 & $-0,4$ \\
\hline 6 & $-1,1$ & 2,1 & 0,8 \\
\hline 7 & $-1,9$ & 1,3 & $-0,6$ \\
\hline 8 & $-1,5$ & 1,2 & 0,3 \\
\hline 9 & $-2,2$ & 1,5 & $-1,4$ \\
\hline 10 & $-1,8$ & 1,4 & $-0,4$ \\
\hline 11 & $-1,6$ & 1,4 & 0,4 \\
\hline 12 & -2 & 1,2 & 0,5 \\
\hline 13 & $-1,8$ & 1,2 & 0,1 \\
\hline 14 & $-0,9$ & 1,7 & 0,2 \\
\hline 15 & $-1,4$ & 0,8 & $-0,4$ \\
\hline 16 & -2 & 1 & $-0,4$ \\
\hline 17 & $-1,5$ & 2,5 & 1,2 \\
\hline 18 & $-4,1$ & 0,8 & $-0,7$ \\
\hline 19 & $-1,9$ & 1,2 & 0,6 \\
\hline 20 & $-1,4$ & 1,5 & 0,2 \\
\hline 21 & $-1,1$ & 0,4 & $-0,4$ \\
\hline
\end{tabular}

Recidiva "clinicamente significante" $=8$ pacientes $=38,1 \%$. 
$\mathbf{D}_{\text {scussão }}$ 


\section{DISCUSSÃO}

0 om o objetivo de facilitar a interpretação dos resultados obtidos neste trabalho, serão discutidos inicialmente os aspectos referentes à seleção da amostra e suas características cefalométricas. Logo após, serão tecidos comentários pertinentes à metodologia empregada, efetuando considerações sobre o erro intra-examinador e a forma de mensuração do trespasse vertical. Posteriormente, será realizada a interpretação das mensurações obtidas na análise das telerradiografias em norma lateral ao final do tratamento e, em média, 5 anos após o término do tratamento comparando-as com as alterações no grupo controle 2. Finalmente, serão realizadas considerações abordando os aspectos sobre a "recidiva clinicamente significante".

\subsection{A Amostra}

\subsubsection{Seleção da Amostra}

Considerando que a mordida aberta anterior é definida como a ausência de contato entre as bordas dos dentes anteriores superiores e inferiores medido no sentido vertical ${ }^{14,31,132,147,158,213,220,225}$, os pacientes desse trabalho deveriam apresentar um trespasse negativo, clinicamente observado, maior ou igual a $1 \mathrm{~mm}$ anteriormente ao tratamento ortodôntico. Devido às diferenças nas medições do trespasse vertical, observadas na literatura, um tópico sobre esse assunto será desenvolvido mais adiante.

A presença de todos os dentes permanentes irrompidos no início do tratamento constituiu-se em um requisito essencial para a seleção da amostra, visando assim, maior homogeneidade e a obtenção de resultados mais confiáveis. Vários são os trabalhos que preconizam o tratamento precoce da mordida aberta anterior, pois nessa época os resultados obtidos são mais estáveis ${ }^{62,71,79,83,87,166,202}$, quando comparados ao tratamento em pacientes adultos ou, mais especificamente, na dentadura permanente ${ }^{15,19,28,46,110,125,157}$. 
Baseando-se nessas afirmações, torna-se imprescindível a separação da amostra em tratamento precoce e tratamento realizado na dentadura permanente, quando são propostos estudos sobre a estabilidade do tratamento da mordida aberta anterior.

Outro requisito constituiu-se na realização do tratamento com aparelho ortodôntico fixo, técnica de edgewise, que é a técnica utilizada nessa instituição para a correção das más oclusões em pacientes na fase da dentadura permanente. A literatura mostra alguns autores que fizeram modificações na técnica de Edgewise original, conservando algumas características iniciais $^{28,50,108,109,113,140}$. Devido às inúmeras formas de tratamento descritas na literatura, esse assunto será discutido mais adiante.

A ausência de extrações dentárias ou mutilações nos arcos dentários se estabeleceu em outro critério para a seleção da amostra. Pacientes que apresentaram ao menos um desses fatores foram excluídos da pesquisa. Segundo CHANG \& $\mathrm{MOON}^{28}$, isso promove maior homogeneidade da amostra, visando assim, a exclusão dos efeitos que a extração dentária poderia proporcionar. A maioria dos trabalhos sobre a estabilidade da correção da mordida aberta anterior não se preocupa em dividir grupos experimentais de pacientes tratados com e sem extração dentária ${ }^{110,113,125}$, o que pode gerar resultados que não condizem com a realidade, uma vez que estudos recentes têm sugerido que o tratamento da mordida aberta anterior com extração dentária, pode proporcionar resultados mais estáveis em relação ao tratamento sem extração 28,167 .

Outro requisito fundamental era que os pacientes apresentassem um mínimo de 3 anos após o término do tratamento. A média do grupo acabou ficando em 5 anos. Essa característica foi um dos critérios para a seleção da amostra, pois alterações verticais podem ser observadas até cinco anos após a conclusão do tratamento, principalmente em pacientes que ainda apresentam crescimento $^{126}$. Sendo assim, presume-se que quanto maior for o período estudado após o tratamento ortodôntico, mais precisos e fidedignos serão os resultados encontrados. Baseados no fato de que os trabalhos que verificaram 
a estabilidade do tratamento da mordida aberta, estudam no máximo de 1 a 2 anos após o término do tratamento ${ }^{68,110,113}$, decidiu-se realizar esse trabalho avaliando pacientes que finalizaram o tratamento ortodôntico, em média, há 5 anos. Nesse contexto, o trabalho realizado por LOPEZ-GAVITO et al ${ }^{125}$, tornase alvo de extremo interesse, pois relata as mudanças ocorridas no tecido ósseo e dentário dos pacientes após um período mínimo de 9,6 anos do término do tratamento, e apesar de algumas diferenças na metodologia, os resultados obtidos mostraram-se muito semelhantes ao presente estudo.

Os trabalhos existentes na literatura não fazem distinção entre pacientes que apresentam má oclusão de Classe I ou Classe II no grupo experimental $^{46,50,53,87,103,110,113,125}$. Além disso, não enumeram que essa característica possa influenciar na estabilidade final do tratamento ortodôntico. $\mathrm{Na}$ época de avaliação dos casos de mordida aberta anterior para a seleção da amostra utilizada na pesquisa, foram selecionados 21 pacientes com Classe I e 1 paciente com Classe II que condiziam com todos os critérios estipulados inicialmente. Para minimizar ainda mais os fatores que podem influenciar direta ou indiretamente a recidiva após o tratamento dessa má oclusão, o paciente classificado como Classe II foi excluído da amostra, tornando-a mais homogênea, e provavelmente, não influenciando o resultado final da pesquisa.

Portanto, havendo muitos critérios para seleção da amostra, o número de pacientes restringiu-se a 21 , os quais foram selecionados dentre todo 0 acervo da Disciplina de Ortodontia da Faculdade de Odontologia de Bauru, que conta com mais de 2000 pacientes tratados. A quantidade de pacientes pode ser considerada menor do que o ideal de 30, por motivos estatísticos. Entretanto, considerando-se os diversos critérios restritivos para sua escolha, pode-se considerá-la satisfatória. Os motivos para esse número mais reduzido da amostra foram provocados pelos seguintes fatores: a maioria dos pacientes com mordida aberta anterior foi tratada com extrações dentárias por apresentarem grandes apinhamentos superiores e/ou inferiores, mordida aberta anterior moderada, ou Classe II e protrusão labial em conseqüência da protrusão dos incisivos, sendo excluídos da amostra; os casos mais acentuados foram indicados para tratamento com o auxílio da cirurgia 
ortognática; ausência da documentação necessária por falta de cooperação dos pacientes no período de controle após o término do tratamento por motivo de mudança de cidade ou mesmo, por qualquer outra impossibilidade; muitos pacientes foram tratados mais recentemente, sendo excluídos da amostra por não apresentarem tempo mínimo de 3 anos do término do tratamento.

Essa quantidade de pacientes estudados está em consonância com a literatura, que também mostra a dificuldade em se obter um grupo experimental homogêneo maior, pois a maioria dos trabalhos apresenta resultados de tratamentos de casos clínicos ${ }^{30,50,68,89,92,117,121,143,169}$ ou com amostras grandemente diversificadas ${ }^{87,108,110,113}$.

\subsubsection{Características Cefalométricas}

Com a intenção de caracterizar o grupo experimental cefalometricamente, no início, comparou-se as variáveis estudadas com um grupo controle, aos 12 anos (grupo controle 1), utilizado do Atlas de Crescimento Craniofacial de MARTINS et al. ${ }^{133}$. Nesse Atlas os dados não estão combinados quanto ao gênero. Portanto, optou-se pela comparação com o gênero feminino, pois a grande maioria dos pacientes da amostra desse trabalho era composta por esse gênero e apenas cinco pacientes eram do gênero masculino. Evidentemente que esse procedimento não é o ideal. Entretanto, permitirá um delineamento dos desvios principais que o grupo experimental apresenta em relação às características gerais de um grupo representativo da população, com certa reserva. Contudo, é obviamente melhor do que a ausência completa de um parâmetro de orientação.

O ideal nesse estudo seria a utilização de um grupo controle com mordida aberta anterior, sem tratamento, compatível com o experimental e acompanhado pelo mesmo período de tempo, seja durante, como após o tratamento. Entretanto, um grupo com essas características é muito difícil de ser encontrado porque razões éticas atuais não permitem o acompanhamento de casos com más oclusões, sem o devido tratamento. Como o objetivo principal dessa investigação consistia na avaliação da estabilidade do 
tratamento da mordida aberta, resolveu-se buscar um grupo de oclusão normal, em idade compatível ao experimental, avaliado longitudinalmente, no mesmo período de tempo. A comparação, nesse período, com um grupo de oclusão normal, parece mais sensata porque o grupo tratado deverá apresentar características mais próximas desse do que de outro com mordida aberta. Assim também se espera que as alterações conseqüentes sejam parecidas com um grupo com oclusão normal. Conseqüentemente, comparando-se as alterações dos dois grupos, será possível determinar se o grupo tratado está se comportando de maneira normal.

A utilização dos dados do Atlas ${ }^{133}$ para a comparação das alterações durante o tratamento ou após o período médio de 5 anos apresenta algumas limitações, como segue. $\mathrm{O}$ Atlas $^{133}$ consiste de uma avaliação longitudinotransversal do crescimento facial dos 6 aos 18 anos de idade, o que não é tão precisa quanto uma avaliação longitudinal pura, como o grupo experimental. Os gêneros não estão combinados e, portanto os dados se referem a cada um separadamente, como já mencionado. O mais importante, para se comparar entre os grupos, são as alterações ocorridas entre uma fase e outra, e isso não é possível porque os dados do Atlas consistem das médias obtidas dos indivíduos em cada faixa etária. Além disso, as idades são ligeiramente diferentes das idades médias de cada fase de observação, sendo necessário algum ajuste para que possam ser utilizadas.

Considerando-se as limitações acima descritas, foi observado que o grupo experimental, inicialmente, era composto por uma maxila sem discrepância ântero-posterior, mas que, apresentou-se significantemente menor em relação ao grupo controle 1. Esse menor tamanho talvez apenas reflita que o grupo experimental seja ligeiramente menor do que o controle ou provavelmente demonstre o predomínio de crescimento vertical sobre o horizontal, no grupo experimental ${ }^{28,46,49,110,125}$. Isso porque o tamanho mandibular no grupo controle também apresentou tendência de ser maior do que no experimental, enquanto que a AFAI demonstrou tendência de ser maior no grupo experimental, embora não estatisticamente significante. 
O aumento do ângulo goníaco é amplamente citado na literatura ${ }^{51,150,182,194,213}$ como característica dos pacientes com mordida aberta, por meio do aumento da ângulo Ar.GoMe. Esses autores utilizam a medida Ar.GoMe porque relatam que o ponto Condílio (Co) é muito difícil de ser visualizado e demarcado corretamente na telerradiografia. No entanto, utilizouse na presente pesquisa o ângulo Co.GoMe e os valores encontrados na sua medição são muito similares aos valores do ângulo Ar.GoMe e representam satisfatoriamente a mensuração do ângulo goníaco. Infelizmente, não houve possibilidade de comparação dessa variável com o Atlas de Crescimento ${ }^{133}$, pois esse, não apresenta registros dessa medida. $O$ aumento do ângulo goníaco, geralmente é associado, na literatura, com a redução no comprimento do ramo mandibular ${ }^{14,24,49,63,91,108,125,150,194,213}$, aqui descrito pela medida Co-Go e observado nessa amostra para alguns pacientes, mas não demonstrando significância estatística. De maneira geral, não foram verificadas diferenças significantes no componente mandibular em relação ao grupo controle 1 .

A relação entre a maxila e a mandíbula apresentou-se semelhante ao controle, visto que todos os pacientes eram Classe I. Alguns trabalhos relatam que a mandíbula posicionava-se retruída em relação à maxila, mas deve-se ressaltar que provavelmente essas características foram encontradas em pacientes Classe II, com padrão de crescimento extremamente vertical ${ }^{50,110,113}$. Em outros trabalhos, muitos foram tratados com o auxílio da cirurgia ortognática ${ }^{49,5349,53}$, já que apresentavam grandes discrepâncias esqueléticas.

De um modo geral, o padrão de crescimento do grupo experimental apresentou apenas ligeira diferença em relação ao controle. Esperava-se encontrar predominância de excesso vertical expressivo no grupo experimental, pois esse fator tem participação definitiva na rotação da mandíbula no sentido horário, proporcionando um aumento nos valores das medidas SN.GoGn e AFAl(altura facial ântero-inferior), o que torna os planos e linhas faciais divergentes em relação à base do crânio ${ }^{17,24,49,90,125,131,183,193,194,197,213,225}$, e conseqüentemente, propiciando a instalação da mordida aberta anterior. A única medida que se mostrou alterada em relação ao normal foi a SN.GoGn que estava significantemente aumentada. Essa característica está em consonância com 
diversos autores que afirmam que a causa desse aumento é a rotação da mandíbula no sentido horário ${ }^{63,107,149,150,182,194,213}$. De acordo com SUBTELNY \& SAKUDA $^{213}$, o aumento dessa medida está intimamente relacionado com o padrão de crescimento do paciente e na maioria das vezes, se o padrão for vertical, a mandíbula apresentará a tendência de girar no sentido horário e o paciente apresentará mordida aberta anterior. DENISON et $\mathrm{al}^{46}$ concorda com essa afirmação, embora saliente que mesmo que o paciente demonstre um padrão vertical, rotação mandibular e aumento da AFAl, ele pode não apresentar mordida aberta anterior.

Excetuando-se a variável SN.GoGn, nenhuma outra referente ao padrão de crescimento apresentou diferenças significantes em relação ao controle 1. Observa-se na literatura, que diversos autores, dentre eles, SUBTELNY \& SAKUDA $^{213}$, ENUNLU ${ }^{51}$ e FROST $^{63}$, não verificaram significância da medida SN.PP, embora essa característica tenha sido descrita por SASSOUNI \& NANDA $^{194}$ e NAHOUM ${ }^{149}$, que relatam o posicionamento mais superior da espinha nasal anterior, a localização mais inferior da espinha nasal posterior, ou ainda uma combinação entre as duas posições. Geralmente, uma das principais características pertencentes aos pacientes que apresentam mordida aberta anterior se constitui na altura facial ântero-inferior aumentada $8,63,77,147,149,150,182,194,195,197$. Neste estudo, a altura facial ânteroinferior (AFAI, ENA-Me) não se apresentou significantemente aumentada, 0 que demonstra a apenas suave predominância do padrão de crescimento vertical do grupo experimental.

Os componentes dentoalveolares superior e inferior apresentaram somente algumas diferenças significantes em relação ao controle. Apesar de grande parte da literatura mostrar valores significantes para a medida MSPP 17,63,90,131,183,193,195, esse estudo, em consonância com NAHOUM et. $\mathrm{al}^{150}$, não observou diferenças estatisticamente significantes no desenvolvimento dentoalveolar superior posterior. Por outro lado, aqueles estudos também mostram a normalidade do desenvolvimento dentoalveolar inferior. Nesse trabalho, não se observou essa característica, e sim, uma menor altura dentoalveolar póstero-inferior dos pacientes investigados (MI-GoMe). A 
protrusão dos incisivos superiores, definida pela medida IS-NA, estava aumentada, embora a inclinação desses dentes não estivesse alterada significantemente. Entretanto, houve uma tendência dos mesmos estarem mais vestibularizados, o que geralmente está relatado na literatura ${ }^{55,203}$.

De maneira geral, as características cefalométricas iniciais do grupo experimental apresentaram apenas uma pequena tendência de crescimento vertical, o que discorda um pouco da literatura que relata predominância mais forte desse padrão. Entretanto, deve-se lembrar que o grupo em estudo foi tratado sem extrações e que, portanto, apresentava mordidas abertas mais suaves que os trabalhos anteriores, em que foram incluídos casos sem e com extrações $^{110,113,125}$.

Da mesma forma que foram avaliadas as características cefalométricas do grupo experimental para o período inicial, decidiu-se verificar se essas características encontravam-se alteradas quando realizada a comparação da fase final do tratamento (T2) com a fase inicial do grupo controle 2 (indivíduos com oclusão normal na mesma faixa etária dos pacientes do grupo experimental na fase final de tratamento), para a verificação da compatibilidade entre os grupos.

Desse modo, verificou-se que os componentes maxilar e mandibular ao final do tratamento (T2) apresentam-se similarmente ao grupo controle 2 (TABELA 4), embora a relação entre a maxila e a mandíbula tenha se apresentado significantemente alterada. A variável ANB mostra valores maiores em comparação com o grupo controle 2, já pressupondo que exista uma rotação no sentido horário da mandíbula, o que poderá ser observado quando verificadas as variáveis pertinentes ao padrão de crescimento e desenvolvimento vertical dentoalveolar.

A avaliação do padrão de crescimento demonstra que o grupo experimental apresenta uma ligeira tendência ao maior desenvolvimento vertical, mesmo que menor, quando comparada a outros estudos $49,110,113,125$. Essa tendência é representada pelas variáveis AFAl e SN.GoGn, que 
apresentaram valores ligeiramente aumentados em comparação com o grupo controle 2.

De maneira geral, os componentes dentoalveolares superior e inferior apresentaram-se de forma aumentada quando comparados ao grupo controle 2. As variáveis que representam essa diferença nos dentes superiores são representadas por IS-PP e MS-PP e nos inferiores por II-PM e II-GoMe (TABELA 4). Provavelmente, essa diferença significante entre o grupo experimental e o grupo controle 2 seja conseqüência do maior padrão ligeiramente vertical exibido pelo primeiro.

A variável que verifica o trespasse vertical ao final do tratamento demonstrou-se significantemente menor quando comparada com o grupo controle 2. Isso provavelmente foi observado porque inicialmente essa variável apresentava-se com valores negativos, caracterizando a mordida aberta anterior, e mesmo obtendo o objetivo do final do tratamento ortodôntico, que era corrigir a má oclusão, seria muito otimismo esperar que essa variável atingisse valores similares aos descritos no grupo de pacientes com oclusão normal.

Apesar das diferenças cefalométricas apresentadas entre o grupo experimental e o grupo controle 2 na fase final do tratamento serem de grande relevância, os aspectos mais importantes são as alterações ocorridas em um determinado intervalo de tempo, como será realizado mais adiante, focalizando essencialmente as alterações ocorridas no período após o tratamento ortodôntico em comparação às alterações do grupo controle 2 no mesmo período.

\subsection{Metodologia}

O material de estudo consistiu de três telerradiografias em norma lateral para cada paciente estudado, as quais foram realizadas no início do tratamento (T1), imediatamente após a conclusão do tratamento (T2) e 5 anos após o término do tratamento, em média (T3). A análise das mudanças esqueléticas e 
dentárias ocorridas nos períodos estudados, por meio das telerradiografias em norma lateral é amplamente utilizada na literatura $28,50,87,110,113,125,167$, sendo a análise em modelos de gesso raramente utilizada, uma vez que muitos fatores externos podem influenciar na medição dos resultados. Verificou-se a existência somente de 1 trabalho na literatura que avaliou a mordida aberta por meio dos modelos de gesso ${ }^{157}$. Entretanto, a mensuração das medidas na telerradiografia também pode apresentar erros e conseqüentes resultados equivocados. Por esse motivo, procurou-se minimizar todas as variáveis que pudessem influir nos resultados obtidos nas telerradiografias com a realização dos testes para verificar o erro intra-examinador.

\subsubsection{Magnificação das Imagens Radiográficas}

As radiografias, nos diferentes períodos estudados, foram realizadas em diferentes locais e por diferentes aparelhos, pois, para a reunião da amostra, necessitou-se verificar as telerradiografias de todos os pacientes já tratados na instituição. Desse modo, foram verificadas as pastas dos pacientes que efetuaram o tratamento ortodôntico ao longo de mais de 28 anos e se torna perfeitamente aceitável, que estas tenham sido realizadas em diferentes centros de documentações da cidade por causa de períodos esporádicos de inutilização do aparelho de Rx da Faculdade. Adicionalmente, em meados de 1995, a Faculdade adquiriu outro aparelho de Rx em função da depreciação do anterior, implicando na alteração da magnificação da imagem radiográfica.

Por esses motivos, para que as medições das telerradiografias pudessem ser comparadas, necessitou-se informar ao programa cefalométrico o valor de magnificação de cada imagem radiográfica em função do aparelho de raio $\mathrm{X}^{28,46}$.

\subsubsection{Mensuração das Grandezas Cefalométricas}

A medição das grandezas cefalométricas foi realizada por meio de um microcomputador, pois, deste modo, é possível trabalhar com um maior 
número de dados em menor período de tempo. O método computadorizado também permitiu menor probabilidade de erros na obtenção dos valores das variáveis cefalométricas, assim como, na fase de mensuração dos resultados $^{184}$. O programa utilizado foi o Dentofacial Planner 7.0, que proporcionou a medição com precisão de $0,1 \mathrm{~mm}$ ou 0,1 grau. Diversos autores já utilizaram esse programa em pesquisas renomadas, assegurando assim, sua confiabilidade $16,21,27,94,95,96,97,165,171,207$.

\subsubsection{Medição do Trespasse Vertical}

Existem várias maneiras descritas na literatura para se realizar a mensuração do trespasse vertical. Alguns autores verificam essa medida por meio da distância linear desde a borda do incisivo inferior mais vestibularizado, acompanhando o seu longo eixo, até fazer contato com a estrutura de tecido duro oposta $6,125,167$. Essa forma de medição não parece ser a melhor para expressar o trespasse vertical, pois, em algumas situações pode apresentar erros. Exemplificando: um paciente que apresenta os incisivos inferiores verticalizados em sua base óssea e os incisivos superiores muito vestibularizados, não necessariamente apresentará má oclusão de mordida aberta anterior, mesmo que demonstre um grande trespasse vertical negativo entre os dentes mencionados. Talvez por isso, os autores impuseram como critério para a seleção de suas amostras, o mínimo de $3 \mathrm{~mm}$ de trespasse vertical negativo (FIG. 6).

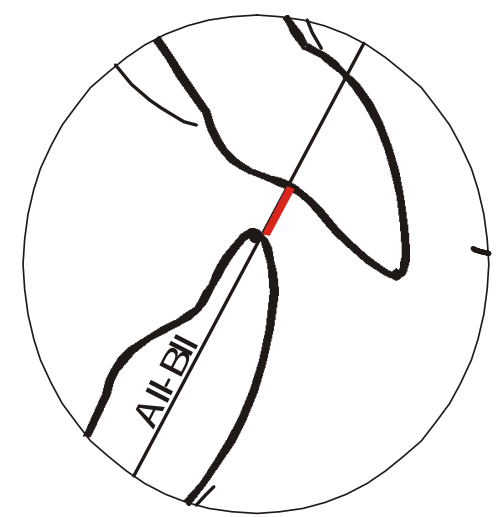

FIGURA 6: Representação da forma de medição do trespasse vertical baseando-se no longo eixo dos incisivos inferiores (All-BII). 
Outra forma de avaliação do trespasse vertical consiste em se medir a distância entre as bordas dos incisivos superiores e inferiores, perpendicularmente à linha N-Me ${ }^{46,87}$. Apesar dessa forma de mensuração da mordida aberta anterior constituir-se em uma forma aceitável de medição do trespasse vertical, pois os pontos cefalométricos utilizados são facilmente visualizados e proporcionam uma margem muito pequena de erro na sua demarcação, também pode apresentar erros que possibilitam a distorção dos resultados finais da pesquisa. Isso acontece porque a linha N-Me é formada pelos pontos cefalométricos $\mathrm{N}$ (Násio) e Me(Mentoniano), que são pontos posicionados a grande distância, em escala cefalométrica, da medida analisada(trespasse vertical). Isso proporciona maiores chances de ocorrer erros durante a medição do trespasse vertical, pois dessa forma o valor da medida analisada pode não corresponder à realidade. Esses pontos podem sofrer variações conforme o comprimento da base do crânio, padrão de crescimento cefálico e rotação da mandíbula, e sendo assim, quanto mais o paciente apresentar medidas que fogem ao normal, maior é a probabilidade de verificar-se erro na medição do trespasse vertical. Exemplificando, pode-se verificar em um paciente que apresenta comprimento da base do crânio aumentado e grande rotação da mandíbula no sentido horário, um valor linear para o trespasse vertical diferente da distância real observada no paciente. Em outras palavras, as alterações na inclinação da linha N-Me, interferirão na medição do trespasse vertical (FIG. 7).

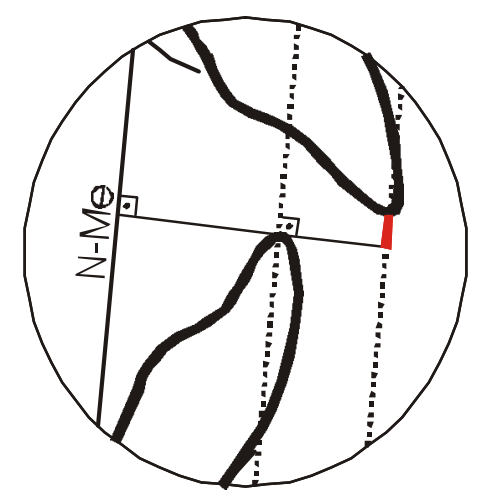

FIGURA 7: Representação da forma de medição do trespasse vertical baseando-se na linha N-Me. 
A forma de medição do trespasse vertical utilizada nessa pesquisa é certamente a mais utilizada pelos pesquisadores e indubitavelmente a que produz resultados mais consistentes com a realidade, pois verifica a distância entre as bordas dos incisivos superiores $e$ inferiores medidas perpendicularmente ao plano oclusal ${ }^{7,49,113,157}$ (FIG. 8). Essa forma de medição foi escolhida para mensurar o trespasse vertical nessa pesquisa, pois, quanto mais próximo está o ponto de referência em relação à variável, mais precisa será a avaliação. Percebe-se que ao utilizar o plano oclusal como parâmetro para avaliar o trespasse vertical procurou-se empregar um plano que sofresse as mesmas influências e variações que a medida a ser analisada, conseqüentemente proporcionando resultados mais compatíveis com a realidade (FIG. 8).

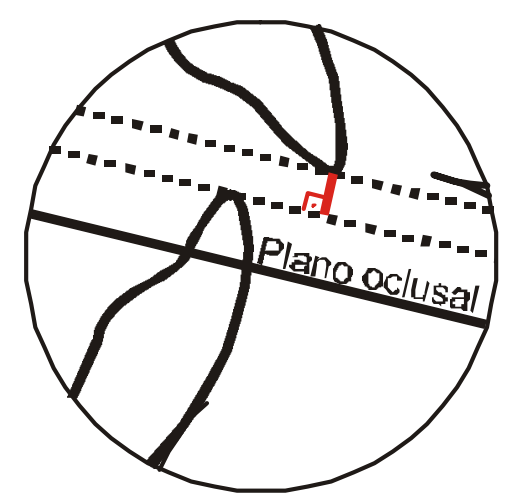

FIGURA 8: Representação da forma de medição do trespasse vertical baseando-se no plano oclusal funcional.

\subsubsection{Precisão da Metodologia}

Para que os resultados desse trabalho sejam confiáveis, procurou-se minimizar os erros dos métodos de mensuração empregados. Calculou-se a precisão do investigador pelos erros intra-examinador, casuais e sistemáticos.

O erro casual refere-se à dificuldade encontrada pelo examinador em identificar e definir certos pontos radiográficos utilizados nas medições cefalométricas ${ }^{86}$. A grande maioria dos erros casuais encontrados nas 
medidas verificadas nesse estudo estão em consonância com o trabalho realizado por KÜÇÜKKELES et al $^{113}$, que observou erros entre 0.13 e 0,76mm para as medidas lineares e 0,17 a 0,87 graus para as angulares. Foram encontradas apenas 3 medidas que variaram pouco mais de $1 \mathrm{~mm}$ ou $1 \mathrm{grau}$ : Co-Go, Go-Gn e SN.PO (TABELA 5).

$\mathrm{Na}$ medida SN.PO o erro casual se originou, provavelmente, na identificação e demarcação da média entre as cúspides dos primeiros molares permanentes e segundos pré-molares para a definição do plano oclusal. Isso ocorreu porque essas estruturas, quando observadas nas telerradiografias, ficam sujeitas a grandes sobreposições, por serem estruturas bilaterais, originando assim, grande dificuldade de visualização e, portanto, impossibilitando exatidão na demarcação. O erro casual nas medidas Go-Gn e Co-Go não gerou maior preocupação, pois, essas medidas apresentaram equilíbrio entre os valores sub e superestimados, verificado pelo teste $t$ pareado, não apresentando diferenças estatisticamente significantes, portanto, não afetando o erro sistemático.

Segundo HOUSTON ${ }^{86}$ o erro sistemático reflete uma falta de padronização do método, uma vez que o examinador tende a sub ou superestimar os valores de suas medições de maneira inconsciente, de modo a direcionar os resultados de acordo com as suas expectativas em relação às conclusões do estudo ${ }^{13,74,86,184}$. Dentre as 30 medidas realizadas, 5 apresentaram os erros sistemáticos. Foram elas: AFAI, IS-PP, IS-NA, II-NB e SN.PO. DENISON et $\mathrm{al}^{46}$, relataram em seu trabalho, que 2 dentre as 7 medidas analisadas, exibiram erro estatisticamente significante.

Baseando-se nessas afirmações e observando que a quantidade de variáveis que apresentou erros casuais ou sistemáticos é similar ou menor que as descritas na literatura, pode-se afirmar que os erros obtidos na verificação da precisão da metodologia desse estudo estão de acordo com a normalidade e promovem resultados transparentes e fidedignos. 


\subsection{Discussão dos resultados}

A comparação dos resultados encontrados neste trabalho em relação a outros presentes na literatura deve ser conduzida com cautela devido às diferentes técnicas de tratamento ortodôntico e métodos de medição do trespasse vertical ${ }^{46,49,87,110,125,157,167}$. Mesmo diante dessa variação, torna-se possível estabelecer parâmetros e avaliar a estabilidade do tratamento da mordida aberta anterior.

A estabilidade do tratamento da mordida aberta anterior realizado na dentadura permanente é pouco relatada na literatura ${ }^{28,87,110,125,157,167}$. Estudos afirmam que quando se promove o tratamento dessa má oclusão precocemente, ou seja, na dentadura decídua ou mista, obtém-se os melhores resultados com o mínimo de recidiva ${ }^{62,71,79,83,87,158,166,200,225}$. Já na dentadura permanente, não foi encontrada unanimidade em relação à estabilidade do tratamento da mordida aberta anterior. Alguns autores concluem que o tratamento apresenta recidiva significante ${ }^{46,113}$, enquanto outros apresentam resultados com grande estabilidade $87,103,110,125,167$.

O presente estudo apresentou recidiva estatisticamente significante da mordida aberta anterior, como pode ser observado na TABELA 8 e FIGURAS 9 e 11. Não só o trespasse vertical diminuiu significantemente no grupo experimental, como também essa diminuição foi estatisticamente maior do que o observado no grupo controle 2 (Tabela 9), demonstrando portanto uma alteração anormal dessa variável. Portanto, cabe agora identificar dentre as diversas outras variáveis quais as possíveis alterações que podem ter contribuído para a diminuição do trespasse vertical no período pós-tratamento. 


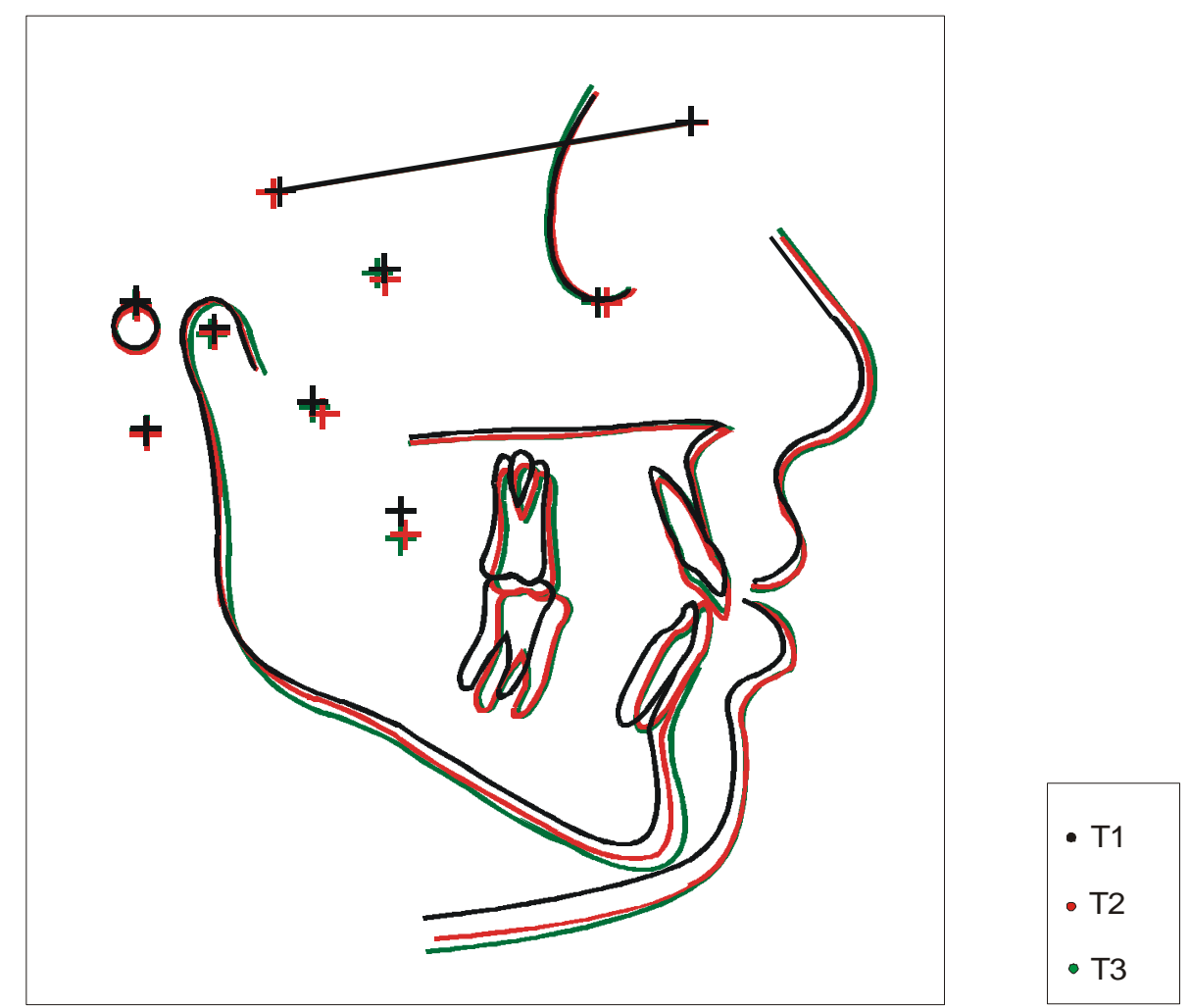

FIGURA 9: Sobreposição em BaN, centrado em CC, dos traçados cefalométricos médios nas fases: antes (T1), no final (T2) e após 5 anos do término do tratamento(T3). 


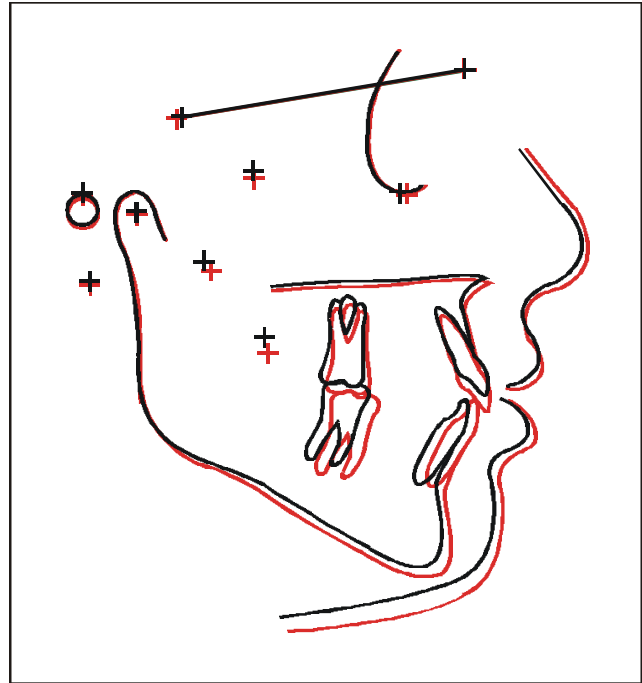

FIGURA 10 - Sobreposição em $\mathrm{BaN}$ centrado em CC, dos traçados cefalométricos médios nas fases inicial (T1) e final (T2).

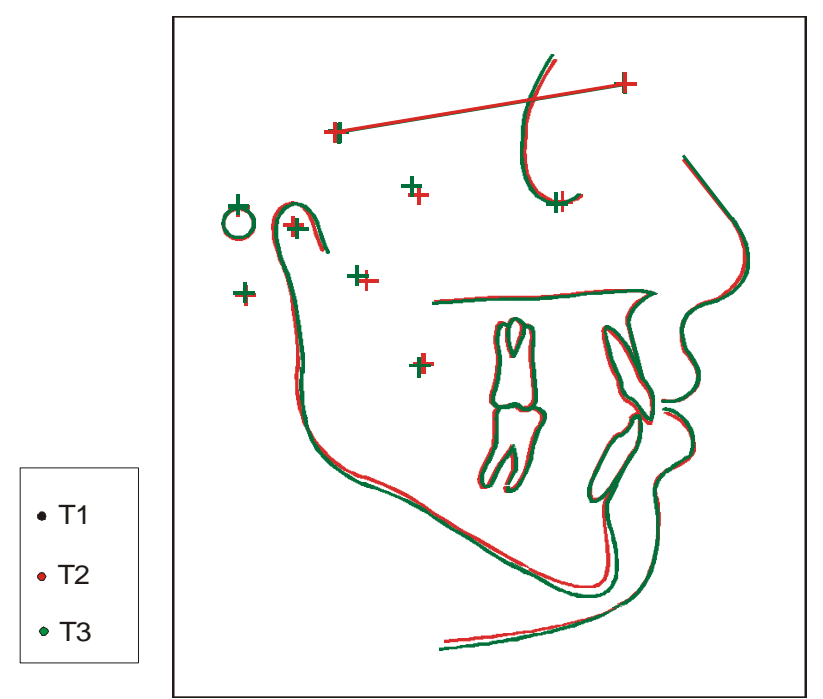

FIGURA 11 - Sobreposição em BaN centrado em CC, dos traçados cefalométricos médios nas fases final (T2) e após 5 anos do tratamento (T3).

As alterações no componente maxilar não parecem ter contribuído em nada para essa recidiva, uma vez que elas não foram estatisticamente significantes durante o tratamento, após 5 anos do término do mesmo, ou quando comparadas às alterações do grupo controle 2 (Tabelas 7, 8 e 9) (FIG. 12 e 13). 


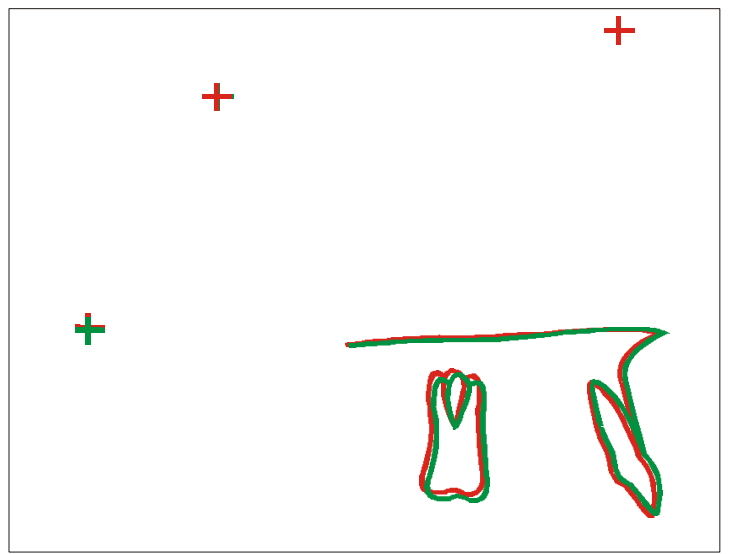

Figura 12 - Sobreposição em BaN centrado em $\mathrm{N}$ do traçado médio final (vermelho) e 5 anos após o tratamento (verde) do grupo experimental

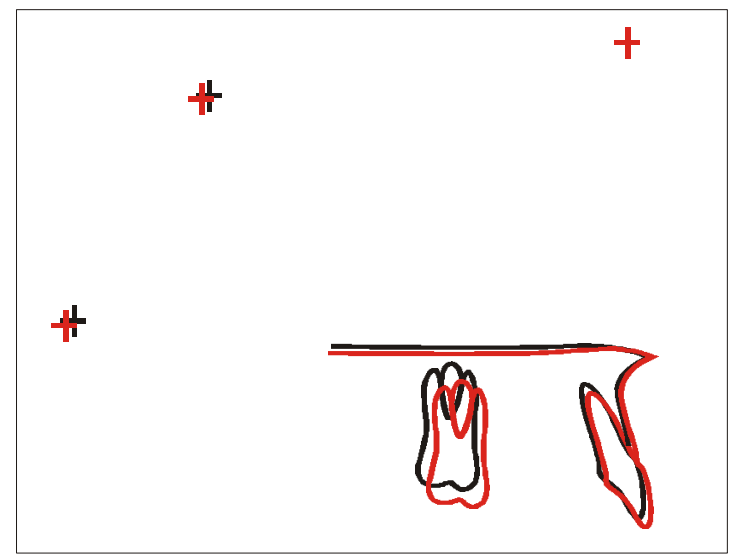

Figura 13 - Sobreposição em BaN centrado em $\mathrm{N}$ do traçado médio inicial (preto) e final (vermelho) do grupo controle 2

Observou-se algumas alterações significantes em relação ao componente mandibular no período de tratamento (T2-T1) e no período após o tratamento (T3-T2). As variáveis Co-Go, Go-Gn e Co-Gn, que representam o tamanho da mandíbula, apresentaram alterações estatisticamente significantemente nesses dois períodos, embora menores quando comparadas às alterações das mesmas variáveis no período (T3-T2) em relação às alterações normais observadas no grupo controle 2. Entretanto, uma vez que o tipo de tratamento empregado não é capaz de causar alterações no crescimento dessas estruturas, pode-se considerar que essas alterações consistiu apenas no resultado do crescimento intrínseco que esses pacientes apresentaram. É pouco provável que essas alterações estejam relacionadas com a recidiva da mordida aberta anterior observada. Além do mais, não houve correlação entre a recidiva do trespasse vertical e as alterações dessas variáveis no período de 5 anos pós-tratamento (TABELA 10). A literatura também não aponta essas alterações como responsáveis pela recidiva da mordida aberta. O fato das alterações terem sido menores do que no grupo controle pode ser explicado pela ligeira predominância de crescimento vertical 
do grupo experimental, que tende a apresentar menor quantidade de crescimento nessas estruturas ${ }^{110,113,125}$.

A relação entre a maxila e a mandíbula sofreu pequena alteração durante o tratamento, expressada pela avaliação "Wits", mas não sofreu alterações estatisticamente significantes no período após o tratamento, embora tenha sido observado alterações diferentes em relação às encontradas no grupo controle 2. A variável ANB obteve um aumento de 0,33 graus no grupo experimental enquanto o grupo com oclusão normal apresentou uma diminuição dessa variável de 0,60 graus. Essa diminuição pode ser explicada pela rotação em sentido horário da mandíbula após o tratamento, que dessa forma poderá realmente contribuir para a recidiva da mordida aberta e que será abordada mais adiante ${ }^{110,113,125}$.

O padrão de crescimento, durante o tratamento, sofreu aumento significante na AFAI e diminuição do ângulo SN.PO. O aumento da AFAl é normalmente esperado durante o tratamento ortodôntico. O ângulo SN.PO diminuiu provavelmente porque os incisivos inferiores foram extruidos, durante o fechamento da mordida. Após o tratamento, a AFAI continuou aumentando, mas dentro das alterações normais, uma vez que não apresentou diferença com o grupo controle. Já o ângulo SN.PO não apresentou a diminuição como o grupo controle, devido à recidiva da extrusão dos incisivos inferiores, que será abaixo discutida. Portanto, as alterações ocorridas no padrão de crescimento, em relação ao controle, são resultado de alterações desfavoráveis nas estruturas dentoalveolares e, portanto, secundárias em causar a recidiva da mordida aberta.

Um aspecto amplamente discutido na literatura e intimamente relacionado com a recidiva da mordida aberta anterior é o grande desenvolvimento vertical dos dentes posteriores durante 0 tratamento ortodôntico $6,44,63,91,114,186,197$. FROST ${ }^{63}$ enfatiza primordialmente a necessidade de redução da dimensão vertical posterior, ou ao menos, a prevenção da extrusão dos molares. 
Neste trabalho, o componente dentoalveolar superior, apresentou durante 0 tratamento ortodôntico (T2-T1), um desenvolvimento vertical estatisticamente significante dos molares superiores de $1,50 \mathrm{~mm}$ em média (TABELA 7). No período avaliado após o término do tratamento (T3-T2), houve um desenvolvimento vertical significante de $0,63 \mathrm{~mm}$, o que pode ser um fator que tenha contribuído para a rotação da mandíbula no sentido horário, aumentando a AFAl e somando-se aos fatores causadores da recidiva do tratamento (TABELA 8). Os incisivos superiores, no período de tratamento, também demonstraram desenvolvimento vertical estatisticamente significante, mas isso não foi observado no período após o tratamento. Quando comparados ao grupo controle 2 , as alterações dos molares e incisivos superiores foram menores. Isto é, no grupo experimental esses dentes apresentaram menor desenvolvimento vertical quando comparados aos indivíduos com oclusão normal. Em valores absolutos, os molares superiores apresentaram um aumento da variável MS-PP de $0,63 \mathrm{~mm}$, enquanto no grupo controle 2 obtiveram um aumento de 1,90mm (TABELA 9, FIG. 14), e os incisivos superiores mostraram uma diminuição real da variável IS-PP de $0,14 \mathrm{~mm}$, enquanto no grupo controle 2 esse desenvolvimento vertical foi um aumento de $0,83 \mathrm{~mm}$. Enquanto o menor desenvolvimento vertical dos molares superiores é um fator favorável para a estabilidade da correção da mordida aberta, o mesmo não se pode dizer do incisivo superior. Contudo, a tendência que se pode observar é que as estruturas que sofrem maior influência durante o tratamento apresentarão menores alterações no pós-tratamento. Algumas serão favoráveis enquanto que outras, não. 


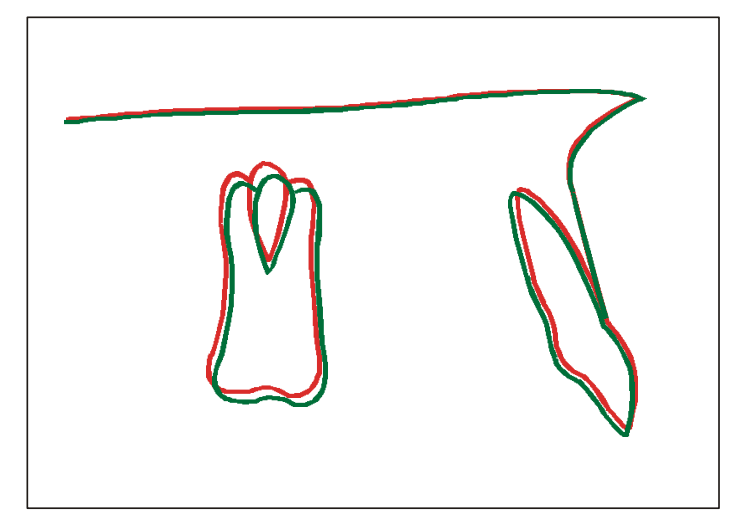

Figura 14 - Sobreposição (PP em ENA) do traçado médio final (vermelho) e 5 anos após o tratamento (verde) do grupo experimental.

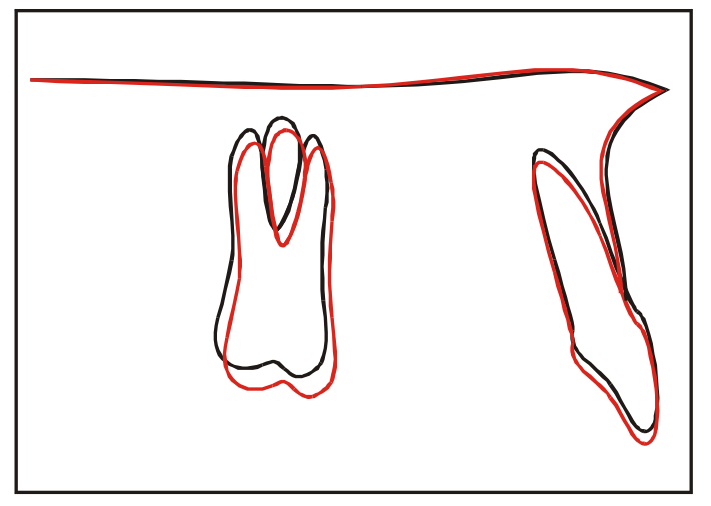

Figura 15 - Sobreposição (PP em ENA) do traçado médio inicial (preto) e final (vermelho) do grupo controle 2

Quanto ao componente dentoalveolar inferior, o mesmo relatado para os dentes superiores foi observado para os inferiores. O desenvolvimento vertical dos molares inferiores, representados pela variável MI-GoMe, foi significante no período de tratamento (T2-T1) e após o término do tratamento (T3-T2). Já os incisivos inferiores, do mesmo modo que os superiores, apresentaram significância estatística na alteração da variável II-PM somente na fase de tratamento. Quando comparadas ao grupo controle 2, somente 0 desenvolvimento vertical dos incisivos inferiores mostrou diferença estatisticamente significante, pois apresentou um aumento de 0,33mm e o grupo controle 2 mostrou aumento de 1,27mm (TABELA 9, FIG. 16 e 17). A variável que demonstra o desenvolvimento dos molares inferiores na amostra, embora tenha demonstrado valores menores que o grupo controle 2, não mostrou diferença estatisticamente significante. Isso demonstra mais um fator diretamente relacionado com a recidiva que é o menor desenvolvimento vertical dos incisivos inferiores, no período pós-tratamento, que contribuirá diretamente para a diminuição do trespasse vertical. Entretanto, apesar do desenvolvimento dos molares inferiores ser semelhante ao do grupo controle, eles apresentaram uma correlação significante com a recidiva da mordida 
aberta (TABELA 10). Portanto, dispositivos capazes de diminuir esse desenvolvimento vertical devem ser utilizados para garantir maior estabilidade da correção da mordida aberta.

Realmente, somente a alteração da variável MI-GoMe foi correlacionada à recidiva da mordida aberta anterior (TABELA 10). No período após o tratamento (T3-T2), essa medida aumentou $1 \mathrm{~mm}$, ou seja, o molar inferior sofreu um desenvolvimento vertical real estatisticamente significante em relação ao plano mandibular, mesmo que essa alteração não seja considerada estatisticamente significante quando comparada ao grupo controle 2 (TABELA 9, FIG. 16 e 17). KIM et al. ${ }^{110}$ afirmam que o grande desenvolvimento vertical dos dentes posteriores, aliado às alterações ocorridas nos incisivos, durante $e$ após o tratamento ortodôntico é a principal causa da recidiva da mordida aberta anterior, pois provoca a rotação horária da mandíbula. A maioria dos autores que estudaram a estabilidade do tratamento da mordida aberta anterior concorda com essa afirmação ${ }^{113,125}$.

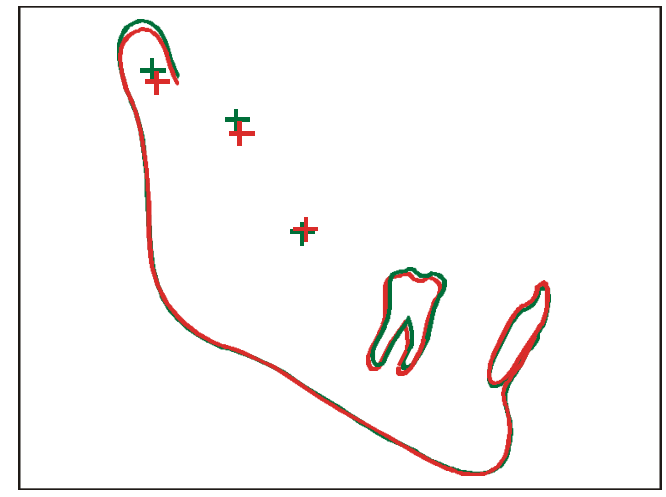

Figura 16 - Sobreposição no Plano mandibular do traçado médio final (vermelho) e 5 anos após o tratamento (verde) do grupo experimental

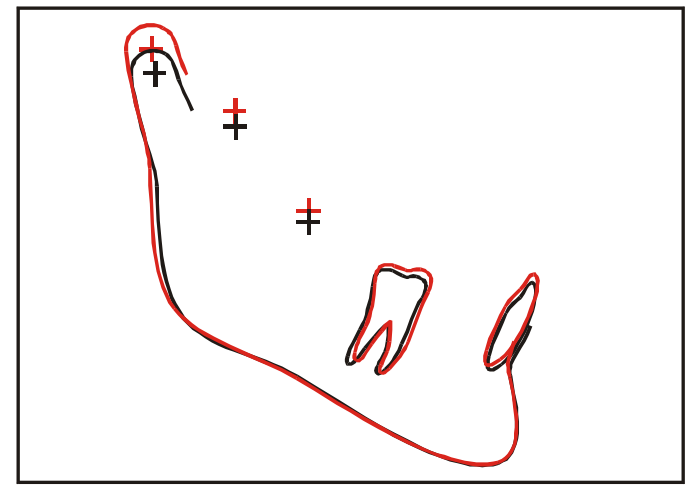

Figura 17 - Sobreposição no Plano mandibular do traçado médio inicial (preto) e final (vermelho) do grupo controle 2

Observando todas as alterações ocorridas nos componentes dentoalveolares superior e inferior após o término do tratamento, nota-se que, de maneira geral, essas foram menores que as alterações obtidas em 
pacientes da mesma idade, com oclusão normal no mesmo período de avaliação (grupo controle 2) (FIGURAS 16 e 17). Provavelmente isso ocorreu por causa das alterações advindas do período de tratamento ortodôntico, que foram resultantes da mecanoterapia empregada na correção. Segundo alguns autores $^{43,60,164,221,228}$, há um aumento das alterações na época de tratamento e uma desaceleração dessas mudanças após o término do mesmo.

A variável que representa o trespasse vertical sofreu alteração significante em todos os períodos estudados. No período de tratamento, a alteração é óbvia, pois um requisito principal para a constituição do grupo experimental era que seus pacientes apresentassem mordida aberta anterior e tivessem finalizado o período de tratamento com a má oclusão corrigida. No período após o tratamento (T3-T2), essa variável apresentou alterações significantes, de forma que, resultou uma recidiva estatisticamente significante do tratamento da mordida aberta anterior. Quando comparada com o grupo controle 1 (TABELA 1), a variável obviamente mostra-se aumentada, pois inicialmente, os pacientes da amostra apresentavam mordida aberta anterior. Quando comparada ao grupo controle 2, o trespasse vertical da amostra apresenta-se diminuído de $1,36 \mathrm{~mm}$, enquanto essa variável no grupo controle 2 apresenta diminuição de 0,31mm (TABELA 9). Esse resultado também se mostra bastante óbvio, visto que existiu uma recidiva estatisticamente significante da variável TRES. V. no período T3-T2, o que não se pode esperar dessa variável nos pacientes com oclusão normal.

KIM et al $^{110}$, assim como outros autores ${ }^{49,113}$, salientam a importância de um grupo controle no período após o tratamento, pois sua ausência se constitui em uma limitação do estudo porque põe em dúvida se o desenvolvimento vertical dos dentes superiores e inferiores pode ser considerado normal.

Vários autores descrevem técnicas para o tratamento da mordida aberta anterio $^{50,108,223}$. A técnica MEAW (Multiloop Edgewise Archwire Therapy), preconizada por $\mathrm{KIM}^{108}$ em 1987, é conhecida na literatura por apresentar resultados estáveis ${ }^{28,68,110,143}$. Todavia, esses trabalhos apresentam algumas limitações que podem influenciar seus resultados finais, como: ausência de 
distinção entre pacientes tratados com e sem extrações dentárias ${ }^{110}$; apresentações apenas de casos clínicos isolados ${ }^{68,143}$; e tempo insuficiente, de no máximo 2 anos após o término do tratamento para a avaliação da estabilidade $^{28,110}$. KIM et $\mathrm{al}^{110}$, dividem sua amostra em 2 grupos: com crescimento e adulto. Relata que na época de tratamento, as alterações dentoalveolares no grupo de pacientes com crescimento são similares às alterações no grupo de pacientes adultos. Os molares inferiores não apresentaram desenvolvimento vertical estatisticamente significante, ao passo que, os molares superiores sofreram intrusão real de $0,66 \mathrm{~mm}$. Segundo os autores, esses resultados só foram possíveis mediante a realização do tratamento com a técnica $M E A W^{108}$, que se baseia na utilização de fios de aço com alças nos espaços interproximais, reversão e acentuação da curva de Spee, e utilização concomitantemente de elásticos verticais na região anterior $^{108}$.

CHANG \& MOON ${ }^{28}$, relatou resultados semelhantes ao trabalho de KIM et $\mathrm{al}^{110}$ utilizando a técnica MEAW ${ }^{108}$, sendo que em seu trabalho, os molares inferiores apresentaram intrusão significante ao longo do tratamento ortodôntico. Segundo o autor, esse resultado deveu-se à grande força de intrusão sofrida pelos molares por causa da acentuação e reversão da curva de Spee e utilização dos elásticos intermaxilares na região anterior.

Resultados opostos foram verificados nessa pesquisa, sendo que no período de tratamento, tanto os molares superiores, quanto os inferiores apresentaram um desenvolvimento vertical estatisticamente significante (TABELA 7). Isso ocorreu provavelmente porque normalmente não se utiliza a sistemática de acentuar e reverter a curva de Spee, com utilização simultânea de elásticos anteriores, como na técnica MEAW ${ }^{108}$. É compreensível que isso possa proporcionar esses resultados, entretanto a necessidade das diversas alças utilizadas nos espaços interproximais é questionável. Tanto é que outros autores, utilizando fios de Nitinol sem alças ${ }^{50,113}$, relataram resultados semelhantes. A sistemática utilizada nos pacientes avaliados consiste basicamente na utilização de elásticos verticais intermaxilares em arcos planos, ou seja, sem acentuação e reversão da curva de Spee. 
ENACAR et $a^{50}$ modificaram a técnica do MEAW ${ }^{108}$ utilizando arcos de Nitinol .016" X .022" com curvas reversa, acentuada e elásticos verticais na região de caninos. Argumentavam que a modificação proporcionava maior simplicidade no tratamento, melhorava a higienização, não produzia irritações nos tecidos bucais e resultava em maior agilidade e rapidez no tempo clínico. Os autores que utilizaram fios de NiTi para promoverem a correção da mordida aberta anterior ${ }^{50,113,223}$, demonstraram resultados similares aos apresentados pela técnica do $M E A W^{108}$, com suave extrusão dos dentes posteriores durante o período de tratamento, que não foi estatisticamente significante.

Nesse estudo, os resultados no período de tratamento (T2-T1) indicaram que a correção da mordida aberta anterior foi possível devido à extrusão e verticalização dos incisivos superiores e extrusão dos inferiores verificados pelas medidas IS.PP, IS-PP e II-PM (TABELA 7), as quais foram estatisticamente significantes e estão em consonância com a maioria dos autores ${ }^{28,50,55,68,110,113,125,203}$. Essas alterações, principalmente quando associadas, podem influenciar na estabilidade da correção da mordida aberta.

O tratamento cirúrgico da mordida aberta anterior tornou-se uma opção viável para pacientes com grande envolvimento esquelético na composição da má oclusão. Embora a maioria dos autores descreva resultados estáveis do tratamento, DENISON et al ${ }^{46}$ relatam recidivas estatisticamente significantes em $42,9 \%$ de uma amostra de 28 pacientes.

Observou-se, na literatura, que existem vários tipos de procedimentos cirúrgicos associados ao tratamento ortodôntico para a correção da mordida aberta anterior. Vários estudos relatam que procedimentos cirúrgicos realizados no ramo mandibular são grandemente instáveis ${ }^{53,138,173}$. Já BELL ${ }^{14}$, comprova a estabilidade do tratamento da mordida aberta realizando a cirurgia apenas nos segmentos anteriores das bases ósseas. Entretanto, salienta que esses procedimentos são indicados somente para pacientes com grandes mordidas abertas anteriores e envolvimento esquelético. ELLIS et $\mathrm{al}^{49}$, sugerem que a cirurgia realizada conjuntamente na maxila e na mandíbula 
promove os melhores resultados em relação à estabilidade do tratamento da mordida aberta associada à Classe II.

\subsection{ESTABILIDADE CLÍNICA}

Como forma de tornar a visualização dos resultados desse trabalho mais próxima da realidade do ortodontista decidiu-se avaliar a recidiva "clinicamente significante" da mordida aberta anterior. Essa forma de avaliação, proposta por alguns autores ${ }^{46,125,167}$,foi utilizada nesse estudo por se constituir em um meio de avaliação do real objetivo do tratamento da mordida aberta que é a obtenção e manutenção, a longo prazo, do trespasse vertical positivo.

A recidiva observada nesse estudo reflete apenas se as alterações que ocorreram no trespasse vertical entre o final do tratamento e 5 anos após, são estatisticamente significantes, mas não demonstram se os pacientes voltaram a apresentar mordida aberta, após esse período. Também não demonstram a porcentagem de pacientes que apresentaram novamente a manifestação de um trespasse negativo. Exemplificando: supondo a existência de dois pacientes que apresentam mordida aberta anterior. O primeiro com $6 \mathrm{~mm}$ de trespasse negativo e o segundo com $2 \mathrm{~mm}$, inicialmente ao tratamento ortodôntico. Após a correção, verifica-se que o primeiro paciente obteve um trespasse positivo de $4 \mathrm{~mm}$ e o segundo de $1 \mathrm{~mm}$. No período após 5 anos do tratamento, verificou-se a presença de $0,5 \mathrm{~mm}$ de trespasse positivo no primeiro paciente e $1 \mathrm{~mm}$ de trespasse negativo no segundo, ou seja, mordida aberta. Desse exemplo pode-se verificar que embora tenha ocorrido maior recidiva do tratamento no primeiro paciente $(3,5 \mathrm{~mm})$, foi o segundo paciente, com recidiva de $1,5 \mathrm{~mm}$, que apresentou novamente mordida aberta anterior, esteticamente desfavorável.

Dessa forma, verificou-se que 8 pacientes apresentaram recidiva "clinicamente significante" do tratamento ortodôntico, ou seja, trespasse vertical negativo na fase T3 (TABELA 8). Portanto, apenas $61,9 \%$ dos pacientes do grupo experimental mostraram estabilidade da correção da mordida aberta anterior após 5 anos, em média, do término do tratamento. Os modelos de 
Disasxão 96

todos os pacientes que compuseram a amostra desse estudo encontram-se na FIGURA 14 para melhor ilustrar os resultados obtidos. Os primeiros 13 casos são os com "estabilidade clinicamente significante" e os últimos 8 , com "recidiva clinicamente significante".
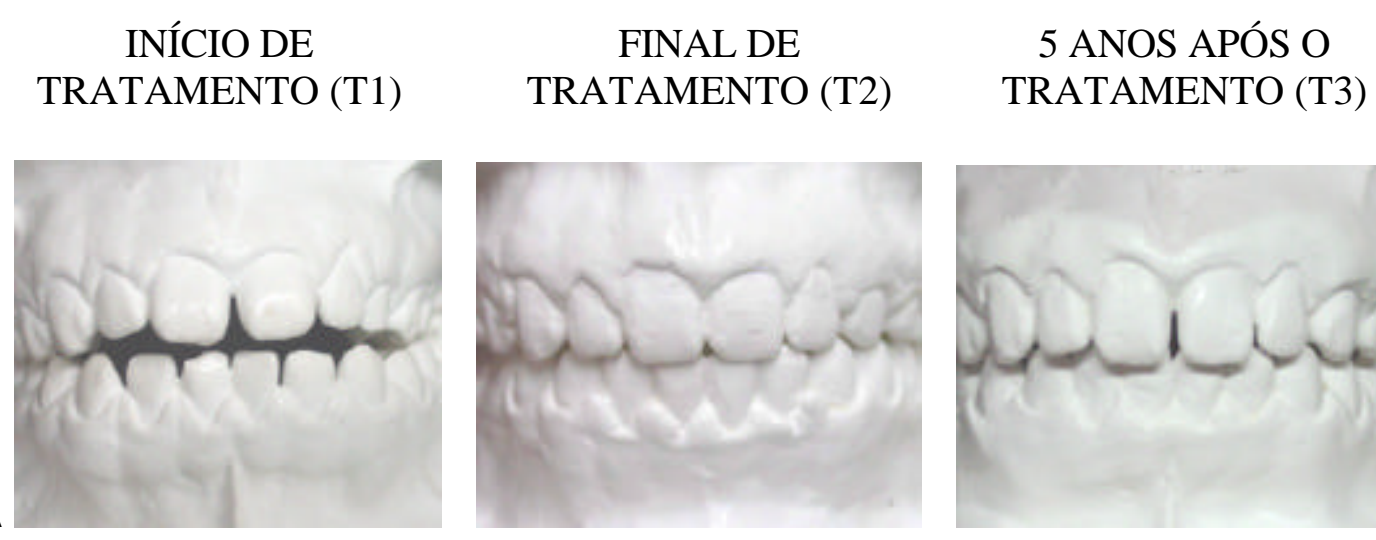

A
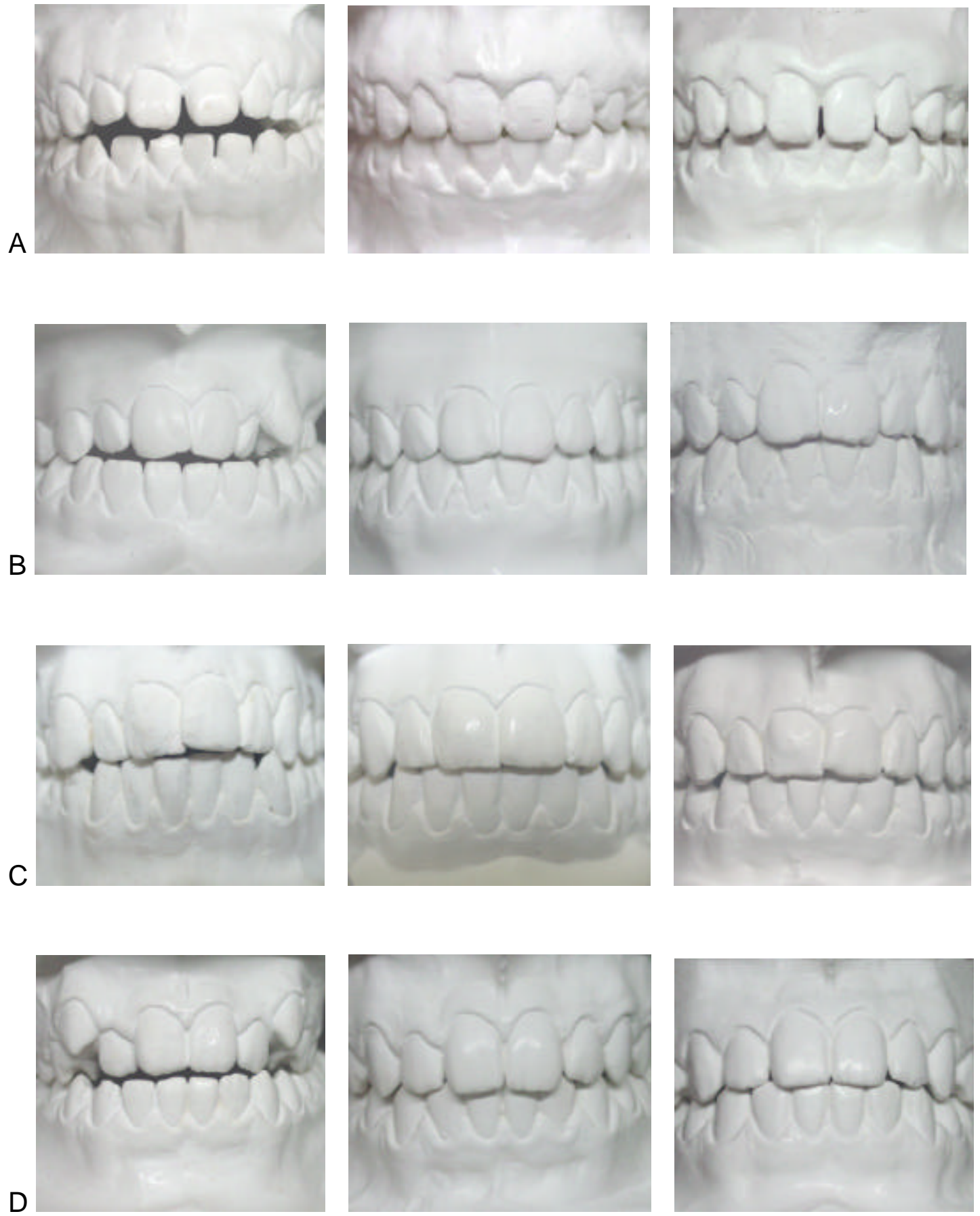
Disaseão 97
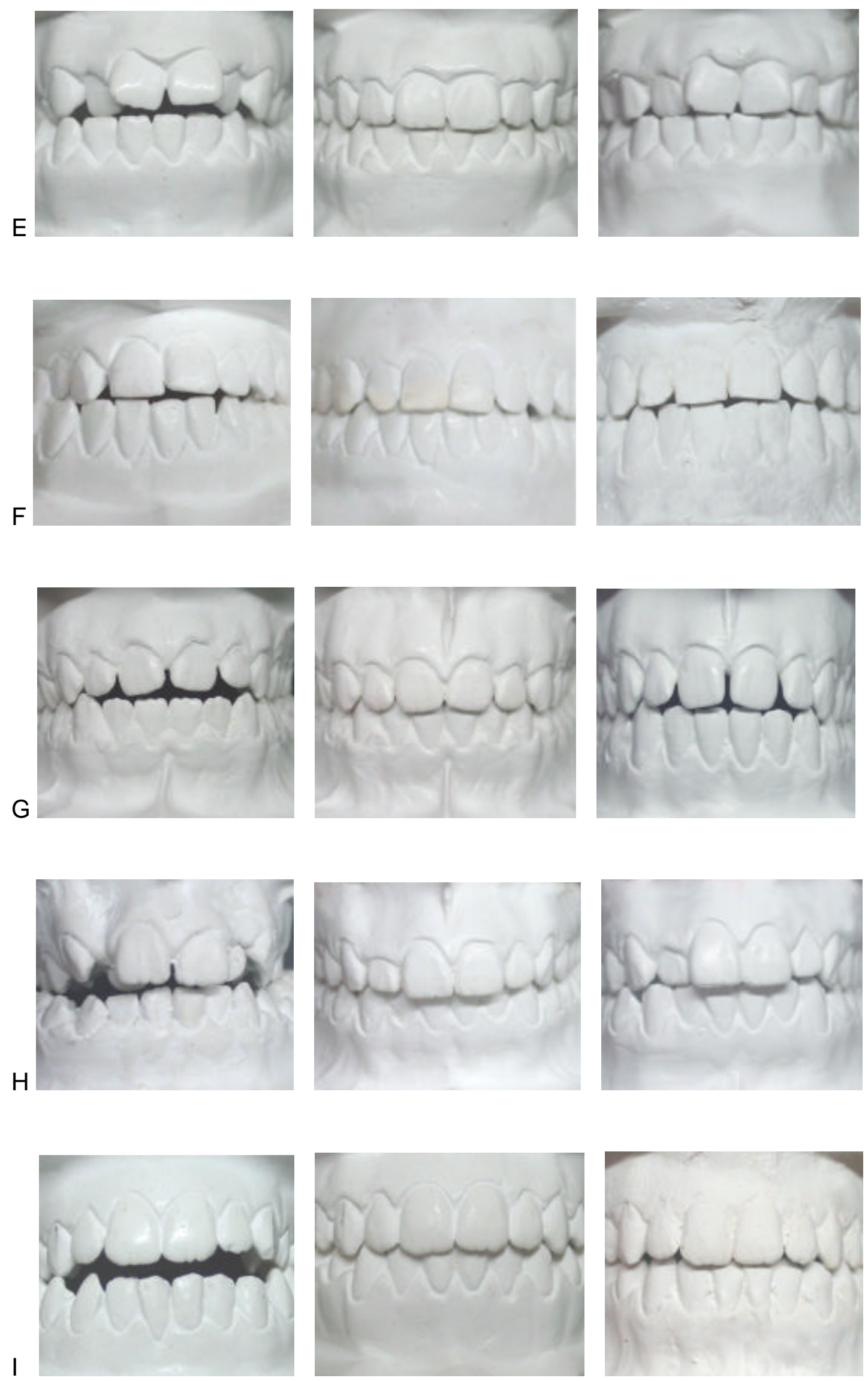
Disasxão 98
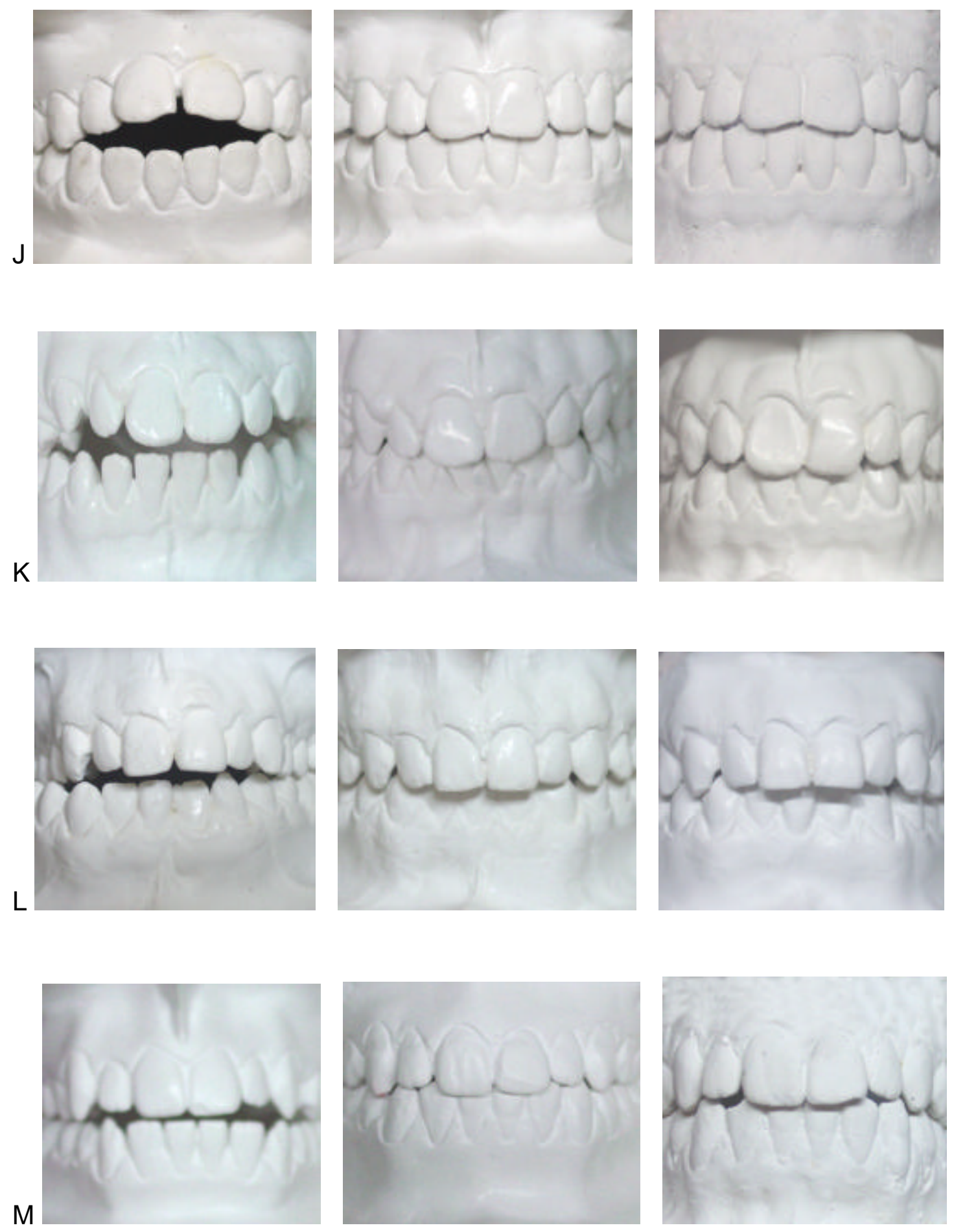
Disaxsão 99
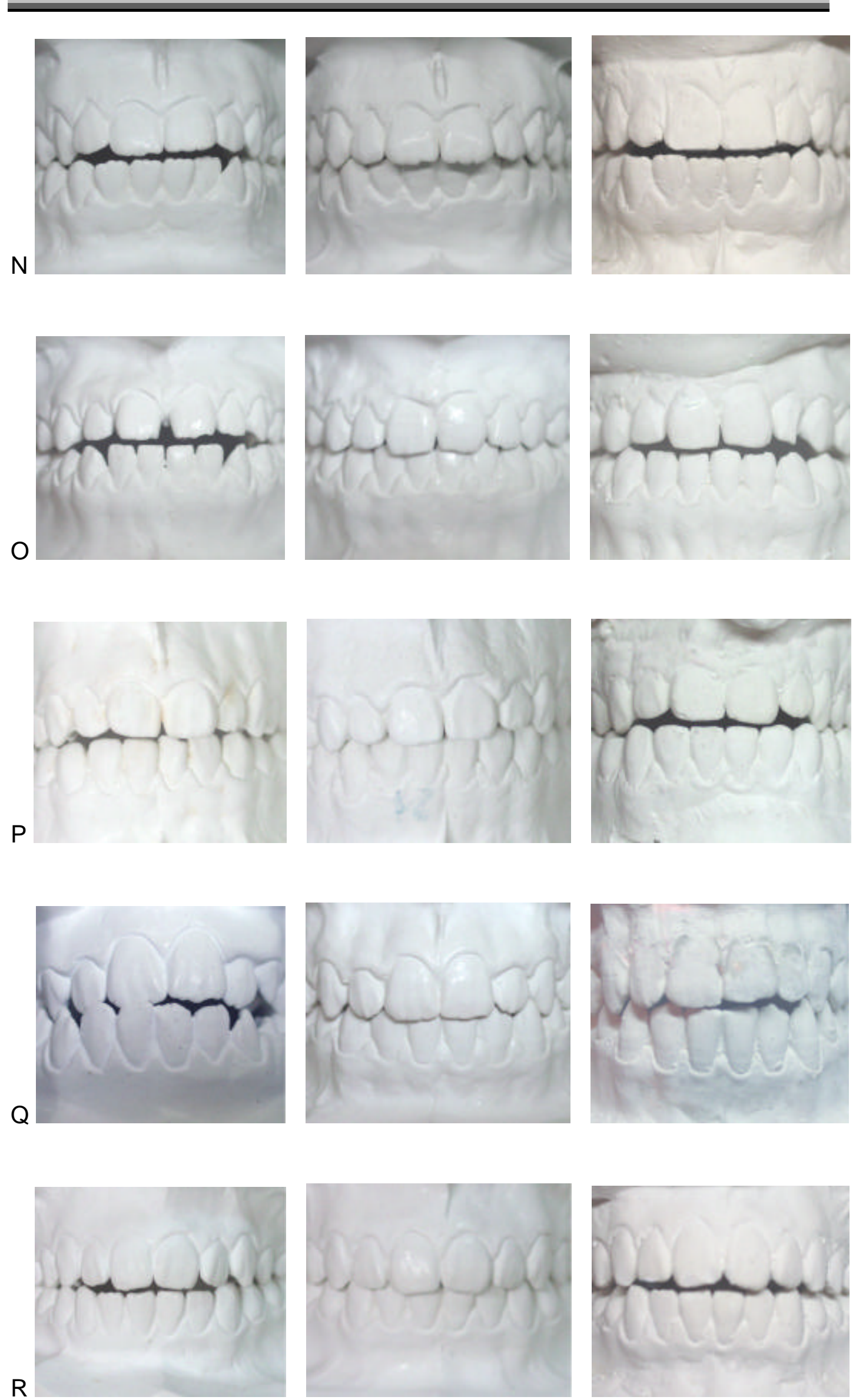

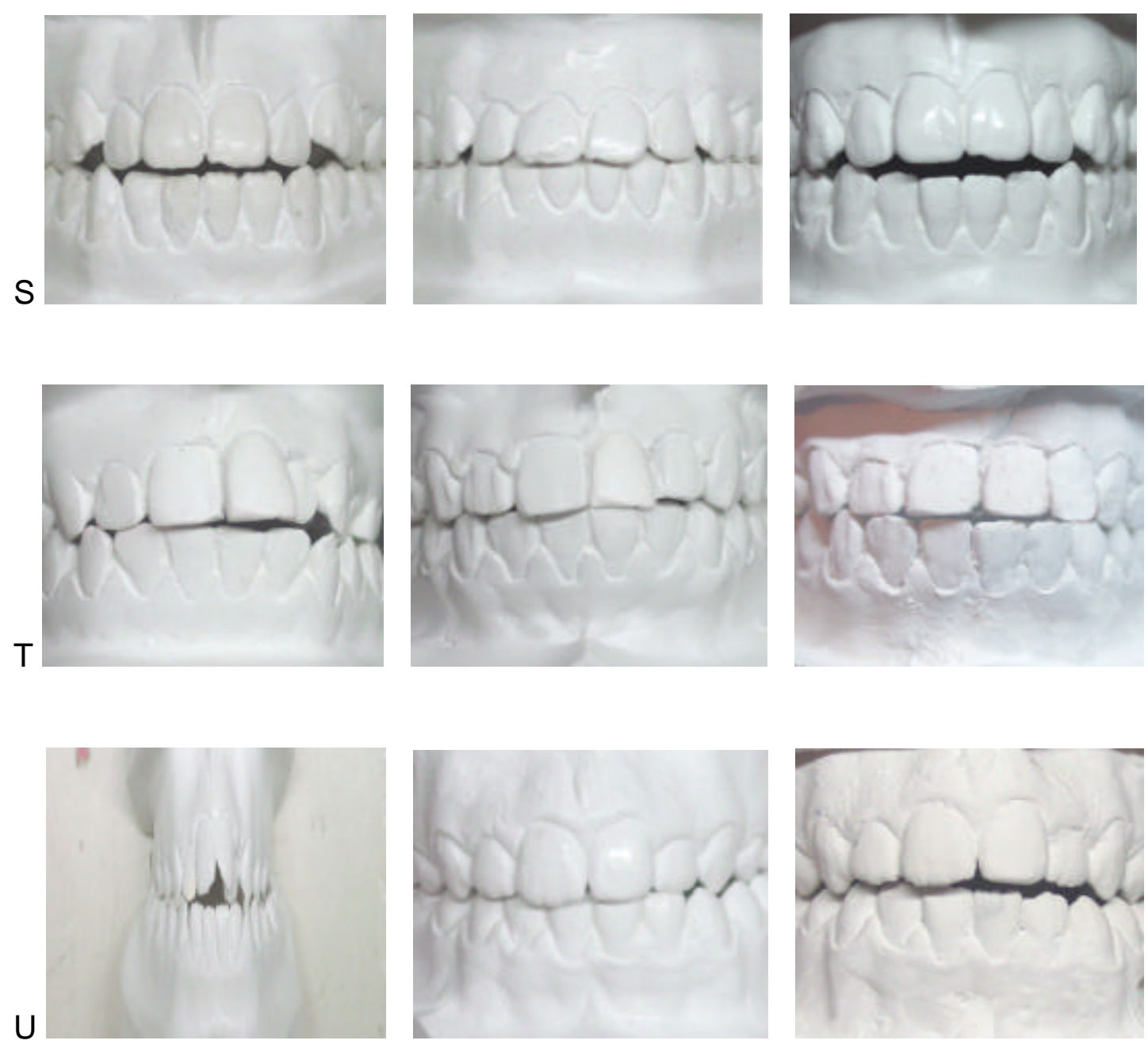

FIGURA 18: Representação dos casos nas fases antes (T1), final (T2) e após 5 anos do tratamento (T3). Primeiramente os casos com estabilidade (de $A$ à $M$ ) e em seguida os casos com recidiva "clinicamente significante" ( de $\mathrm{N}$ à $\mathrm{U}$ ).

Alguns autores também propuseram uma avaliação da recidiva da mordida aberta anterior analisada clinicamente, embora utilizassem como parâmetro para mensuração do trespasse vertical, a distância entre as bordas incisais dos dentes anteriores, medida no prolongamento do longo eixo dos incisivos inferiores até tocar tecido duro oposto, como descrito anteriormente nesse mesmo capítulo. LOPEZ-GAVITO et $\mathrm{al}^{125}$, avaliaram a recidiva 
"clinicamente significante" após 10 anos do final do tratamento e verificaram que $65 \%$ dos pacientes estudados apresentavam estabilidade ao tratamento ortodôntico. PARRA ${ }^{167}$ estudou o tratamento de 20 pacientes e observou que $70 \%$ dos pacientes apresentaram estabilidade do tratamento ortodôntico, 5 anos após contenção. Após essa análise, a autora dividiu sua amostra em casos com e sem extração verificando que 63\% dos casos tratados sem extração e $75 \%$ dos casos tratados com extração apresentaram estabilidade. Apesar desses estudos apresentarem uma forma de medição do trespasse vertical diferente da efetuada no presente trabalho, é possível verificar que a quantidade de estabilidade é bastante semelhante ao obtido nessa investigação.

DENISON et $\mathrm{al}^{46}$, avaliaram a recidiva "clinicamente significante" do tratamento da mordida aberta anterior realizada cirurgicamente. Verificou que $21,4 \%$ dos pacientes tratados com cirurgia apresentaram novamente trespasse negativo entre os dentes anteriores, 1 ano após o término do tratamento. Os autores indicam que a causa da recidiva resume-se às alterações dentoalveolares. Do mesmo modo que o presente estudo, esses autores propõem a definição de "recidiva clinicamente significante" quando existir o trespasse negativo no período após a correção (T3). PROFFIT et al $^{177}$, em 1988, verificaram que dos 61 pacientes tratados com o reposicionamento superior da maxila, apenas 3 apresentaram recidiva, o que significa uma estabilidade de 95\%. Em seu trabalho, HAYMOND et $\mathrm{al}^{81}$ verificaram a estabilidade do tratamento de 38 pacientes submetidos aos procedimentos cirúrgicos. Os pacientes utilizaram fixação interna rígida e apresentaram estabilidade em $85 \%$ dos casos após 1 a 5 anos do término do tratamento. É importante salientar que, provavelmente, os pacientes que se submeteram ao tratamento cirúrgico, apresentassem grandes discrepâncias esqueléticas e dentárias, além de um padrão vertical mais acentuado, quando comparados aos valores da amostra desse estudo. Isso pode proporcionar maior tendência à recidiva do tratamento.

Observando esses estudos, percebe-se que embora a correção cirúrgica da mordida aberta anterior apresente alguns casos com recidiva, esse tipo de 
tratamento tem apresentado melhores resultados quando comparado às compensações dentárias efetuadas somente pela correção ortodôntica.

Provavelmente, um dos fatores que mais influenciam nos resultados finais da pesquisa sobre a estabilidade do tratamento da mordida aberta anterior, seja a ausência da distinção entre pacientes tratados com e sem extrações dentárias. CHANG \& MOON ${ }^{28}$, em seu trabalho, já haviam atentado para os efeitos que a extração dentária poderia promover na estabilidade do tratamento. KIM et $\mathrm{al}^{110}$ relataram que as extrações dentárias poderiam influenciar na estabilidade do tratamento da mordida aberta. No entanto, em sua amostra as extrações foram realizadas no intuito somente de correção dos apinhamentos, e não para promover maior estabilidade ao tratamento. Em sua pesquisa, PARRA ${ }^{167}$ dividiu os grupos tratados com e sem extrações dentárias obtendo resultados semelhantes ao presente trabalho. Portanto, especula-se que o tratamento com extrações dentárias em pacientes com mordida aberta anterior seja mais estável, a longo prazo, em comparação ao tratamento sem extrações.

\subsection{Considerações Clínicas}

Os resultados obtidos demonstram a expectativa de estabilidade da correção de mordidas abertas semelhantes a esse estudo para que o profissional possa planejar o tratamento e informar o paciente sobre esses aspectos. Concomitantemente, permitirá ao clínico desenvolver aparelhos de contenção que possam limitar os fatores potenciais que causam a recidiva e assim aumentar a porcentagem de sucesso desse tipo de tratamento.

\subsection{Sugestão para Futuros Estudos}

1) Comparação da estabilidade do tratamento da mordida aberta anterior realizado com e sem extração. 
Disaxxãa 03 


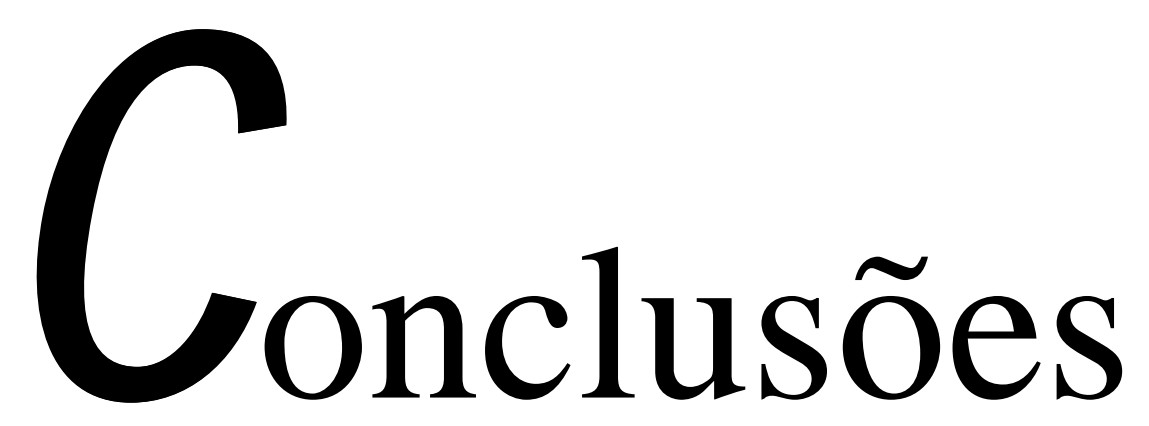




\section{CONCLUSÕES}

Baseando-se nos resultados obtidos nesse trabalho e de acordo com a metodologia utilizada para a avaliação da estabilidade do tratamento sem extração da mordida aberta anterior, na dentadura permanente, 5 anos após o término do tratamento, julgou-se lícito concluir que:

1. Houve recidiva estatisticamente significante da correção da mordida aberta anterior.

2. Os principais fatores que contribuíram para a recidiva foram o menor desenvolvimento vertical dos incisivos superiores e inferiores, e o desenvolvimento vertical dos dentes póstero-inferiores no período póstratamento.

3. Não há correlação entre a magnitude inicial e a quantidade de correção da mordida aberta anterior com a recidiva do tratamento ortodôntico.

4. Houve uma estabilidade "clinicamente significante" em $61,9 \%$ dos casos. 

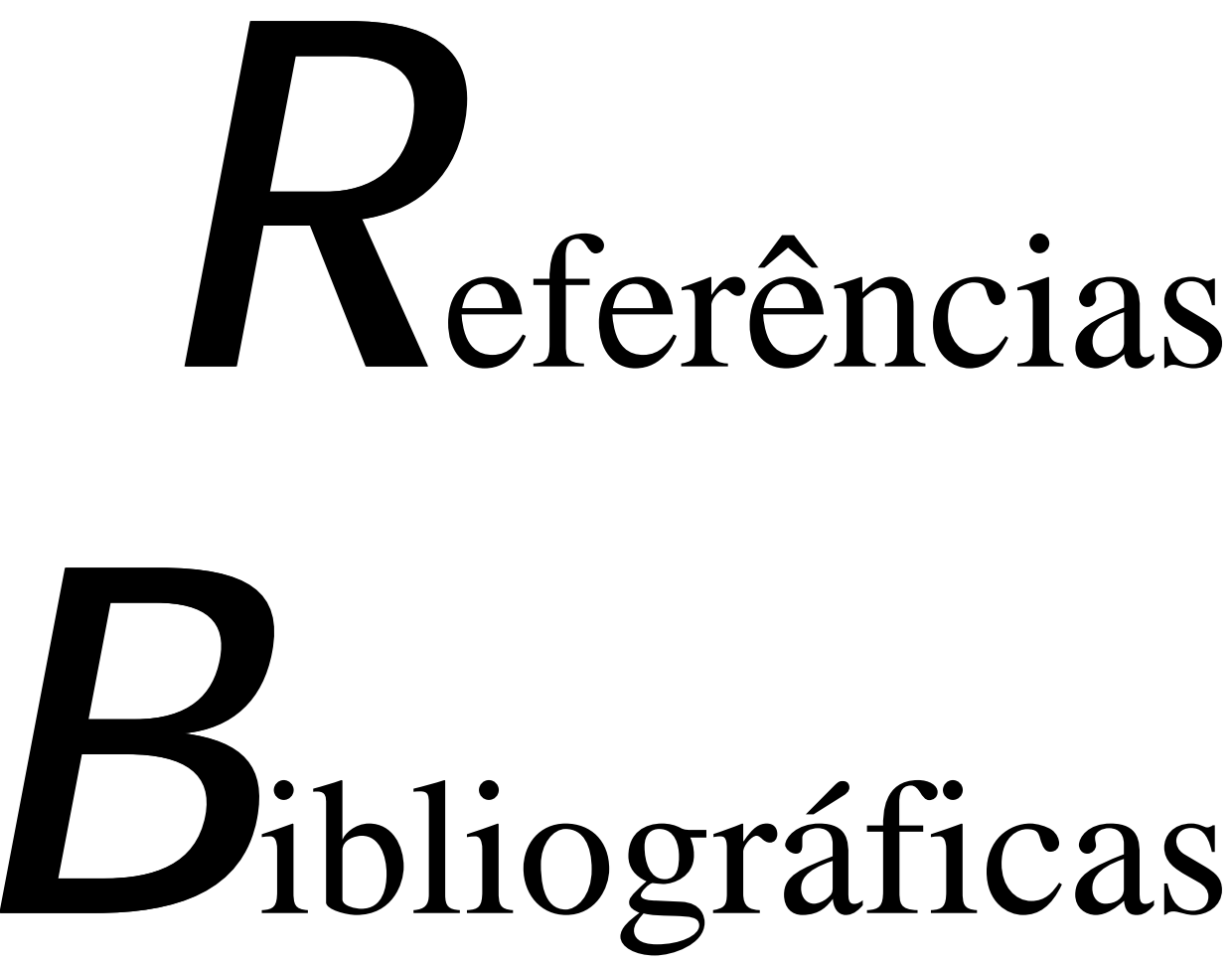


\section{REFERÊNCIAS BIBLIOGRÁFICAS*}

1. ALEXANDER, C. D. Open bite, dental alveolar protrusion, Class I malocclusion: a successful treatment result. Am. J. Orthod. v.116, n.5, p.494-500, nov. 1999.

2. ALEXANDER, C. D. The role of occlusal forces in openbite treatment. J. Clin. Orthod. v.34, n.1, p.23-9, jan. 2000.

3. ALMEIDA, M. F. Aleitamento materno: acima de tudo um ato de amor. Pediatria Moderna. v.29, n.5, p.637-43, ago 1995.

4. ALTUNA, G.; WOODSIDE, D. G. Response of the midface to treatment with increased vertical occlusal forces: treatment and posttreatment effects in monkeys. Angle Orthod. v.55, n.3, p.251-63, jul. 1985.

5. ANDERSEN, W. S. The relationship of the tongue thrust syndrome to maturation and other factors. Am. J. Orthod. v.49, n.4, p.264-75, apr. 1963.

6. ARAT, M. ISERI, H. Orthodontic and orthopedic approach in the treatment of skeletal open bite. Europ. J. Orthod. v.14, p.207-15, 1992.

7. ARPORNMAEKLONG, P. et. al. Anterior open bite malocclusion stability of maxillary reposicioning using rigid internal fixation. Austr. Orthod. J. v.16, n.2, p.69-81, Jul. 2000.

8. ARVYSTAS, M. G. Treatment of skeletal anterior open bite deformity. Am. J. Orthod. v.72, n.2, p.147-64, 1977.

\footnotetext{
* Normas recomendadas para uso no âmbito da Universidade de São Paulo, com base no documento "Referências Bibliográficas: exemplos" emanado do Conselho Supervisor do Sistema Integrado de Bibliotecas da USP, em reunião dia 20 de setembro de 1990
} 
9. ATKINSON, S. R. Open bite malocclusion. Am. J. Orthod. v.52, n.12, p.877-86, dec. 1966.

10. BADELL, M. C. An evaluation of extraoral combined high-pull traction and cervical traction to the maxilla. Am. J. Orthod. v.69, p.431-46, 1976.

11. BARBRE, R. E.; SINCLAIR, P. M. A cephalometric evaluation of anterior open bite correction with the magnetic active vertical corretor. Angle Orthod. v.61, p.93-102, 1991.

12. BARRER, H. G. Limitations in orthodontics. Am. J. Orthod. v.65, n.6, p.612-25, jun. 1974.

13. BAUMIRIND, S.; FRANTZ, R. The reability of hesd film measurements. Amer. J. Orthod. v.60, n.2, p.111-27, aug. 1971.

14. BELL, W. H. Correction of skeletal types of anterior open bite. J. Oral Surg. v.29, n.10, p.706-14, 1971.

15. BIEN, S. M. et alli. Open bite prolems in adults. Brit. Dent. J. v.98, n.8, p.280-5, apr. 1955.

16. BISHARA, S. E.; TREDER, J. E.; JAKOBSEN, J. R. Facial and dental changes in adulthood. Amer. J. Orthod. Dentofac. Orthop. v.106, n.2, p.175-86, Aug. 1994.

17. BJÖRK, A. Prediction of mandibular growth rotation. Am. J. Orthod. v.55, p.585-99, 1969.

18. BLACK, B. et al. Hábitos bucais nocivos. Soc. Paul. Ortod. v.23, n.2, p.40-4, 1990. 
19. BLAKE, M.; BIBBY, K. Retention and stability: A review of the literature. Am. J. Orthod. Dentofac. Orthop. v.114, p.229-306, sep. 1998.

20. BOWDEN, B. D. A longitudinal study of the effects of digit and dummy sucking. Am. J. Orthod. v.52, n.12, p.887-901, dec. 1966.

21. BRAUN, S. Achieving improved visualizations of the temporomandibular joint condyle and fossa in the sagittal cephalogram and a pilot study of their relationships in habitual occlusion. Amer. J. Orthod. Dentofac. Orthop. v.109, n.6, p.635-8, Jun. 1996.

22. BREITNER, C. Fuether investigations of bone changes exsulting from experimental orthodontic treatment. Am. J. Orthod. Dentofac. Orthop. v.27, p.605-32, 1941.

23. CALISTI, L. J. P. et al. Correlation between malocclusion, oral habits, and socio-economic level of preschool children. J. Dent. Res. v.39, p.4504, may/jun. 1960.

24. CANGIALOSI, T. J. Skeletal morphologic featurs of anterior open bite. Am. J. Orthod. v.85, p.28-36, jan. 1984.

25. CARVALHO, A. B. R. et al. Crescimento de crianças alimentadas com leite materno exclusivo. Jornal de Pediatria. v.68, n.9, p.329-33, 1992.

26. CASE, C. S. A practical treatise on the technics and principles of dental orthopedia and prosthetic correction of cleft palate. Chicago, Case, 1921, 486 p.

27. CASSIDY, D. W. et al. A comparison of surgery and orthodontics in "borderline" adults with Class II, division 1 malocclusions. Amer. J. Orthod. Dentofac. Orthop. v.104, n.5, p.455-70, Nov. 1993. 
28. CHANG, Y.; MOON, S. C. Cephalometric evaluation of the anterior open bite treatment. Am. J. Orthod. v.115, n.1, p.29-38, jan. 1999.

29. CHASE, W. R. Imperative early treatment of anterior open bite. General Dentistry. p.307-9, aug. 1993.

30. $\mathrm{CHO}, \mathrm{H}$. C. Patient with severe skeletal Class III malocclusion and severe open bite treated by orthodontics and orthognathic surgery - a case report. Am. J. Orthod. Dentofac. Orthop. v.110, n.3, p.155-62, aug. 1996.

31. CHRISTENSEN, J.; FIELDS, H. Odontopediatria da infância à adolescência. Hábitos bucais. 2. ed., São Paulo, Artes Médicas, 1996, p.401-7.

32. CLEALL, J. F. Deglutition: a study of form and function. Am. J. Orthod. v.51, n.8, p.566-94, aug. 1965.

33. CLEMENS, C. Prevalência de mordida aberta anterior em escolares de São Paulo. 1977. Tese - Universidade Federaol do Rio Grande do Sul.

34. COELI, B. M.; TOLEDO, O. A. Hábitos bucais de sucção: aspectos relacionados com a etiologia e tratamento. Rev. Odontoped. v.3, n.1, p.43-51, 1994.

35. COMMERFORD, M. et al. Sucking habits in the breast-fed versus non breast-fed child. J. Res. Orofacial Muscle Imbal. v.88, p.18-19, 1977.

36. COMPOSTELA, E. A. Mordida aberta. Ortodonc. clin. v.3, n.6, p.97-114, nov. 1952. 
37. COSTA, M. C. O. et al. Aleitamento materno: causas de demame e justificativa para amamentar. Jornal de Pediatria. v.69, n.3, p.177-8, 1993.

38. DAHLBERG, G. Statisticl methods for medical and biological students. New York, Interscience, 1940,

39. DALPONT, G. L'osteotomia retromolare per la correzione della progenia. Minerva Shir. v.18, p.1138, 1959.

40. DAWSON, P. E. In: Evaluation, diagnosis and treatment of occlusal problems. Solving anterior open bites problems. St. Louis, The C. V. Mosby, 1974, p.322-30.

41. De COSTER, L. Open bite. Dent. Rec. v.55, n.4, p.185-206, apr. 1935.

42. De MICHELIS, S. B.; HERTEL, A. Considerazioni eziopatogenetiche diagnostiche e terapeutiche sul "morso aperto". Minerva Stomat. v.16, n.9, p.567-80, sep. 1967.

43. DE VINCENZO, J. P. Changes in mandibular length before, during and after succesful orthopedic correction of Class II malocclusions, using a functional appliance. Am. J. Orthod. Dentofac. Orthop. v.100, n.2, p.274-85, sep. 1991.

44. DELLINGER, E. L. A clinical assesment of the active vertical corretor: a nonsurgical alternative for skeletalopen bite treatment. Am. J. Orthod. Dentofac. Orthop. v.89, p.428-36, 1986.

45. DELLINGER, E. L. A. Tratamento com o Corretor Vertical Ativo - Um acompanhamento prolongado da mordida aberta por intrusão dos dentes posteriores. Rev. Dental Press de Ortod. e Ortop. Facial. v.2, 
n.2, p.35-43, mar./abr. 1997.

46. DENISON, T. F.; KOKICH, V. G.; SHAPIRO, P. A. Stability of maxillary surgery in openbite versus nonopenbite malocclusions. The Angle Orthod. n.1, p.5-10, 1989.

47. DERMAUT, L. R. Skeletal and dento-alveolar changes as result of headgear activator therapy related to different vertical growth patterns. Europ. J. Orthod. v.14, n.2, p.140-46, 1992.

48. DUNG, J. D.; SMITH, R.J. Cephalometric and clinical diagnoses of open bite tendency. Am. J. Orthod. v.94, p.484-90, dec. 1988.

49. ElLiS, E.; McNAMARA, JR.; LAWRENCE, T. M. Components of adult Class II open-bite malocclusion. J. Oral Maxillofacial Surg. v.43, p.92$105,1985$.

50. ENACAR, A.; UGUR, T.; TORUGLU, S. A method for correction of open bite. J. Clin. Orthod. v.30, n.1, p.43-8, jan. 1996.

51. ENUNLU, N. Palatal and mandibular plane variations in openbite cases with varying aetiology. Trans. Europ. Orthod. Soc. p.165-71, 1974.

52. EPKER, B. N.; FISH, L. C. The surgical-orthodontic correction of class III skeletal open-bite. Am. J. Orthod. v.73, n.6, p.601-18, jun. 1978.

53. EPKER, B. N.; FISH, L. C. Surgical-orthodontic correction of open-bite deformity. Am. J. Orthod. v.71, n.3, p.278-99, mar. 1977.

54. ESTRIPEAUT, L. E.; HENRIQUES, J. F. C.; ALMEIDA, R. R. Hábito de sucção digital e má oclusão: relato de um caso clínico. Rev. Odont. USP. v.3, n.2, p.371-6, 1989. 
55. EVERDí, N. et al. Cephalometric evaluation of crib therapy for cases of mixed dentition (open bite). J. Nihon Univ. Sch. Dent. v.34, p.131-6, 1992.

56. FALTIN, C. O.; FALTIN JUNIOR, K. Bionator de Balters. Rev. Dental Press de Ortod. e Ortop. Facial. v.3, n.6, p.70-95, nov./dez. 1998.

57. FERRE, J. C. Treitement des beances frontales anterioures a l'aide de la methode de Ricketts. (A propos de deux cas). Acta Stomat. Belg. v.72, n.4, p.619-28, 1975.

58. FERREIRA, S. H. et al. Estudo da prevalência da mordida aberta anterior em crianças de zero a cinco anos de idade nas creches minicipais de Bento Gonçalves - RS. J. Bras. Odontop.Odontol. do Bebê. v.4, n.17, p.jan./fev., 2001.

59. FISCHER, H. Finger, tongue and lip habits in children. Dent. Survey. v.12, p.35-7, 1969.

60. FRANCHI, L.; BACCETTI, T.; McNAMARA JUNIOR, J. A. Treatment and posttreatment effects of acrylic aplint herbst appliance therapy. Amer. J. Orthod. Dentofac. Orthop. v.115, n.4, p.429-38, apr. 1999.

61. FRANKEL, R.; The functional matrix and its pratical importance in orthodontics. Transactions of European Orthodontic Society. p.20718, mar 1969.

62. FRANKEL, R.; FRANKEL, C. A. Functional approach to treatment of skeletal open bite. Am. J. Orthod. v.84, n.1, p.54-68, jul. 1983.

63. FROST, D. E., et al. Cephalometric diagnosis and surgical orthodontic correction of apertognathia. Am. J. Orthod. v.78, p.657-69, 1980. 
64. FUKUTA, O. et al. Damage to the primary dentition resulting from thumb and finger (digit) sucking. J. Dent. Child. p.403-7, 1996.

65. GESHATER, M. M. The proper perspective of open bite. Angle Orthod. v.42, n.3, p.263-72, jul. 1972.

66. GILE, R. A. A longitudinal cephalometric evaluation of orthodontically treated anterior openbite cases. 1972. University of Washington Master's Tesis.

67. GIRON, M. C. C. Fundamentos psicológicos da prática odontológica. p.144 p., 1988.

68. GOTO, S. et al. Case report: nonsirurgical treatment of an adult with severe anterior open bite. The Angle Orthod. v.4, n.64, p.311-18, 1994.

69. GRABER, T. M. The finger-sucking habit and associated problems. J. Dent. Child. v.25, p.145-51, 1958.

70. GRABER, T. M. Thumb and finger-sucking. Am. J. Orthod. v.45, n.4, p.258-64, apr. 1959.

71. GRABER, T. M. Orthodontics. Principles and practice. $2^{\circ}$ ed., W. B. Saunders Company, 1966, p.cap. 3, 6.

72. GRABER, T. M.; RAKOSI, T; PETROVIC, A. In: Dentofacial orthopedics with functional appliances. The bionator - a modified activator. Saint Louis, Mosby, 1985,

73. GRABER, T. M.; NEUMANN, B. Aparelhos ortodônticos removíveis. 2. ed., São Paulo, Panamericana, 1987. 
74. GRAVELY, J. F.; BENZIES, P. M. The clinical significance of tracing error in cephalometry. Brit. J. Orthod. v.1, p.95-111, 1974.

75. HANNA, J. C. Breast feeding versus bootle feeding in relation to oral habits. J. Dent. Child. v.34, p.243-49, 1967.

76. HANSON, M. L.; ADRIANOPOULOS, M. V. The tongue thrust and malocclusion - a longitudinal study. Int. J. Orthod. v.20, p.9-18, 1982.

77. HAPAK, F. M. Cephalometric appraisal of the open bite case. The Angle Orthod. v.34, n.1, p.65-72, jan. 1964.

78. HARVOLD, E.P. Primate experiments on oral respiration. Amer. $\mathbf{J}$. Orthod. v.79, p.359-72, apr. 1981.

79. HARYETT, R. D. et al. Chronic thumb sucking: the psychological effects and relative effectiveness of various methods of treatment. Am. J. Orthod. v.53, p.559-85, 1967.

80. HAYDAR, B.; ENACAR, A. Functional regulator therapy in treatment of skeletal open-bite. J. Nihon Univ. Sch. Dent. v.34, p.278-87, 1992.

81. HAYMOND, C. S. et. al. Plate internal fixation. One to five year follow-up. Int. J. Oral Maxollofac. Surg. v.20, n.5, p.223-7, 1991.

82. HELLMAN. Openbite. Int. J. Orthod. v.17, n.5, p.421-44, may 1931.

83. HENRIQUES, J. F. C. Mordida aberta anterior: a importância da abordagem multidisciplinar e considerações sobre etiologia, diagnóstico e tratamento. Apresentação de um caso clínico. Rev. Dental Press de Ortod. e Ortop. Facial. v.5, n.3, p.29-36, maio/jun. 2000. 
84. HONZIK, M. P.; McKEE, J. P. The sex difference in thumb-sucking. J. Pediatr. v.61, p.726-32, nov. 1962.

85. HORI, M. et al. Two cases of skeletal open bite treated by sagittal splitting osteotomy of the mandibular ramus. J. Nihon Univ. Sch. Dent. v.33, n.1, p.1-12, mar. 1991.

86. HOUSTON, W. J. B. The analysis of errors in orthodontic measurements. Amer. J. Orthod. v.83, n.5, p.382-90, may 1983.

87. HUANG, G. J., et al. Stability of anterior open bite treated with crib therapy. Angle Orthod. n.1, p.17-26, 1990.

88. HULLIHEN, S.P. Case of elongation of under jaw and distortion of face and neck, caused by burn, successfully treated. AM. J. Dent. Sci. v.9, p.157, 1849.

89. INSOFT, M. D. et. al. The nonsurgical treatment of a Class II open bite malocclusion. Am. J. Orthod. Dentofac. Orthop. v.110, n.6, p.598605, 1996.

90. ISAACSON, J. R. et. al. Extreme variation in skeletal and dental relations. Angle Orthod. v.41, p.219-29, 1971.

91. ISCAN, H. N.; AKKAYA, S.; KORALP, E. The effects of the spring-loaded posterior bite-block on the maxilofacial morphology. Europ. J. Orthod. v.14, n.1, p.54-60, feb 1992.

92. JACKSON, A. F. Open bite. Report of a case. Amer. J. Orthod. v.37, n.8, p.623-8, aug. 1951. 
93. JACOBSON, A. The wits appraisal of jaws disharmony. Am. J. Orthod. v.67, n.2, p.125-38, feb. 1975.

94. JANSON, G. R. P.; METAXAS, A.; WOODSIDE, D. G. Variation in maxillary and mandibular molar and incisor vertical dimension in 12year-old subjects with excess, normal and short lower anterior face height. Amer. J. Orthod. Dentofac. Orthop. v.106, n.4, p.409-18, Oct. 1994.

95. JANSON, G. R. P. et. al. Cephalometric evaluation of the eruption guidance in class II, division 1 treatment. J. Clin. Orthod. v.31, n.5, p.299-306, may. 1997.

96. JANSON, G. R. P. et. al. Eruption guidance appliance effects in the treatment of Class II, division 1 malocclusions. Amer. J. Orthod. Dentofac. Orthop. v.117, n.2, p.119-29, Feb. 2000.

97. JANSON, G. R. P. Three-dimensional evaluation of skeletal and dental assymetries in Class II subdivision malocclusions. Am. J. Orthod. Dentofac. Orthop. v.119, n.4, p.406-18, 2001.

98. JARABAK, J. R.; FIZZEL, J. A. Aparatologia del arco de canto com alambres delgados.Tecnica y Tratamiento. Buenos Aires, Mundi, 1975, v.1. 612.

99. JATKOWITZ, A. Open bite associated with a tongue habits. Case report. Am. J. Orthod. Oral Surg. v.27, n.1, p.30-40, jan. 1941.

100. JENNINGS, R. E. At what age should thumbsucking be treated? Dent. Abst. v.14, p.73-4, 1969. 
101. JOHNSON, E. D.; LARSON, B. E. Thumb-sucking: literature review. J. Dent. Child. p.385-91, nov./dec. 1993.

102. JORDON, M. E. Treitement des dents des enfants. Paris, Semaine Dentaire, 1926, 222 p.

103. JUSTUS, R. Tratamiento de la mordida abierta anterior: un estudio cefalométrico y clinico. ADM. v.6, n.1, p.17-40, nov./dic. 1976.

104. KALRA, R.; BURSTONE, C.; NANDA, R. Effects of a fixed magnetic appliance on the dentofacial complex. Am. J. Orthod. Dentofac. Orthop. v.95, n.6, p.467-78, jun. 1989.

105. KASSISICH, S. et al. Orthosurgical correction of a Class II open bite, with previous first premolar extractions without follow-up orthodontic treatment. Am. J. Orthod. v.112, n.6, p.589-95, 1997.

106. KILIARIDIS, S. et al. Anterior open bite treatment with magnets: an experimental nongrowing baboons. Am. J. Orthod. v.100, p.393-400, 1991.

107. KIM, Y. H. Overbite depth indicator with particular reference to anterior open-bite. Am. J. Orthod. v.65, p.586-611, 1974.

108. KIM, Y. H. Anterior open bite and its treatment with Multiloop Edgewise Archwire. Angle Orthod. n.4, p.290-321, 1987.

109. KIM, Y. H. Treatment of malocclusions by means multiloop edgewise archwire technic. J. Assoc. Orthod. Repub. China. v.7, p.62-72, 1995.

110. KIM, Y. H. et. al. Stability of anterior openbite correction with multiloop edgewise archwire therapy: a cephalometric follow-up study. Am. J. 
Orthod. Dentofac. Orthop. v.118, p.43-54, 2000.

111. KLEIN, E. T. The thumb-sucking habit: meaningful or empty. Amer. J. Orthod. v.59, p.283-9, 1971.

112. KROGMAN, W. N.; SASSOUNI, V. A. A syllabus in roentgenographic cephalometry. Philadelphia, Philadelphia Center for Research in Child Growth, 1957, p.45-103.

113. KÜÇÜKKELES, N. et al. Cephalometric evaluation of open bite treatment with $\mathrm{NiTi}$ arch wires and anterior elastics. Am. J. Orthod. v.116, n.5, p.555-62, nov. 1999.

114. KUHN, R. J. Control of anterior vertical dimension and proper selection of extraoral anchorage. Angle Orthod. v.38, p.340-9, 1968.

115. KUSTER, R.; INGERVALL, B. The effects of treatment of skeletal open bite with two types of bite-blocks. Europ. J. Orthod. v.14, p.489-99, 1992.

116. LAGERSTROM, L. O. et al. Dental and skeletal contributions to occlusal correction in patients treated with the high-pull headgear/activator combination. Am. J. Orthod. v.97, p.495-504, 1990.

117. LEE, B. W. Case report: treatment of anterior open bite tongue thrust and associated temporo-mandibular join symptoms. Austr. Orthod. J. p.246-9, mar. 1993.

118. LEGOVIC, M.; OSTRIC, L. The effects of feeding methods on the growth of the jaws in infants. J. Dent. Child. v.58, n.3, p.253-5, may/jun. 1991. 
119. LEVITAS, T. C. Examine the habit-evaluate the treatment. J. Dent. Child. v.37, p.122-3, 1970.

120. LEWIS, S. J. Thumb-sucking: a cause of malocclusion in the deciduous teeth. J. Amer. Dent. Ass. v.17, p.1060-73, jun. 1930.

121. LIEBERMAN, M. A.; GAZIT, E. Correction of class I skeletal open bite malocclusion. Angle Orthod. v.48, n.3, p.206-9, 1978.

122. LINDER-ARONSON, S. et al. Mandibular growth direction following adenoidectomy. Am. J. Orthod. v.89, p.273-83, apr. 1986.

123. LINDER-ARONSON, S. Adenoids - their effect on mode of breathing and nasal air flow and their relationship to caracteristics of the facial skeleton and dentition. Acta Otolaringol. Suppl. p.265, 1990.

124. LINO, A. P. Deglutição atípica: proposição de uma terapêutica. Ortodontia. v.6, n.1-2, p.9-14, 1973.

125. LOPEZ-GAVITO, G. et al. Anterior openbite malocclusion. A longitudinal 10-year postretention evaluation of orthodontically treated patients. Am. J. Orthod. v.87, p.175-86, mar. 1985.

126. LOWE, A. A.; JOHNSON, W.D. Tongue and jaw muscle activity in response to mandibular rotations in a sample of open-bite subjects. Am. J. Orthod. v.76, p.565-76, 1978.

127. LUBOWITZ, A. H. Open bite malocclusion. Dent. Items Interest. v.60, n.8, p.737-45, aug. 1938.

128. LUNDSTROM, M. A.; WOODSIDE, C. C. A comparision of various facial and occlusal characteristics in mature individual with vertical and horizontal growth direction expressed at the chin. Europ. J. Orthod. 
v.3, n.4, p.227-35, 1981.

129. MAHALSKI, P. A.; STANTON, W. R. The relationship between digit sucking and behavior problems: a longitudinal study over 10 years. J. Child. Psychol. Psychiat. v.33, n.5, p.913-23, 1992.

130. MARESCA, C. A.; FERES, M. A. In: Petrelli, Ortodontia para fonoaudiologia. Habitos viciosos bucais. Curitiba, Lovise, cap 10, 1992, p.164-76.

131. MARTINA, R.; LAINO, A.; MICHELOTTI, A. Class I malocclusion with severe open bite skeletal pattern treatment. Am. J. Orthod. v.97, n.5, p.363-73, 1990.

132. MARTINS, D. R. et al. Mordida aberta anterior:. Odontomaster. v.1, n.5, p.105-33, 1994.

133. MARTINS, D. R. et. al. Atlas de crescimento craniofacial. 1ํ Edição, Bauru, Editora Santos, 1998, 280p.

134. MARTINS FILHO, J. Como e porquê amamentar. 2. ed., São Paulo, Sarvier, 1987, 220 p.

135. MASSLER, M.; CHOPRA, B. The palatal crib for the correction of oral habits. J. Dent. Child. v.17, p.1-6, second quarter 1950.

136. McNAMARA JR., J. A. An experimental study of induced vertical dimension in the growing face. Am. J. Orthod. v.71, n.4, p.382-95, apr. 1977.

137. McNAMARA JR., J. A. A method of cephalometric analysis. In: McNAMARA J. A. JR.; RIBBENS, K. A.; HOWE, R. P. Clinical alteration of the growing face. Monograph 14. Craniofacial Growth 
Series, Center for Human Growth and Development. The University of Michigan, Ann Arbor, 1983,

138. McNEIL, W. R. et. al. Skeletal relapse during intermaxillary fixation. J. Oral Surg. v.31, p.212, 1973.

139. MERVILLE, L. C.; DINER, P. A. Long face: new propolsals for taxonomy, diagnosis and treatment. J. Craniomaxillofac. Surg. v.15, n.2, p.8493, 1987.

140. MESTRE, J. C. Reporte de um caso tratado con la retrotecnica (Mestre) y con la tecnica (Kim). Rev. Iberoamericana de Ortodoncia. v.15, p.3948, 1996.

141. MEYERS, A.; HERTZBERG, J. Bootle-feeding and malocclusion: Is there an association? Am. J. Orthod. Dentofac. Orthop. v.93, n.2, p.14952, feb. 1988.

142. MILORI, S. A. et al. Remoção dos hábitos bucais de sucção de polegar e chupeta. Rev. Gaucha Odontol. v.43, n.5, p.284-8, 1995.

143. MIYAJIMA, K.; LIZUKA, T. Treatment mechanics in a Class III open bite malocclusion with Tip Edge technique. Am. J. Orthod. Dentofac. Orthop. v.110, n.1, p.1-7, july 1996.

144. MIZRAHI, E. A review of anterior open bite. Br. J. Orthod. v.5, p.21-7, 1978.

145. MOSS, M. L. The functional matrix. In: KRAUS, B. S. \& RIEDEL, R. A. Vistas in Orthodontics. Philadelgia, Lea \& Febiger, 1962, p.85-97. 
146. MOYERS, R.E. In: Ortodontia. Etiologia da má oclusão. 4 ed., Rio de Janeiro, 1991, p.131-4.

147. MOYERS, R.E. Handbook of orthodontics for the student and general practioner. 3 ed, Chicago Year Book, 1973, p.442.

148. NAGAHARA, K. et al. Orthodontic tratment of an open bite patient with oral-facial-digital syndrome. Am. J. Orthod. Dentofac. Orthop. v.110, n.2, p.137-44, 1996.

149. NAHOUM, H. I. Vertical proportions and palatal plane in anterior open-bite. Am. J. Orthod. v.59, n.3, p.273-82, mar. 1971.

150. NAHOUM, H. I.; HOROWITZ, S.L.; BENEDICTO, E.A. Varieties of anterior openbites. Am. J. Orthod. v.61, n.5, p.486-92, may 1972.

151. NAHOUM, H. I. Anterior open bite: a cephalometric analysis and suggest treatment procedures. Am. J. Orthod. v.67, n.5, p.513-21, may. 1975.

152. NAHOUM, H. I. Vertical proportions : a guide for prognosis and treatment in anterior open bite. Am. J. Orthod. v.72, n.2, p.128-46, aug. 1977.

153. NANDA, R. S. et al. Effect of oral habits on the occlusion in preschool children. J. Dent. Child. v.39, p.449-52, nov./dec. 1972.

154. NANDA, S. K. Patterns of vertical growth in the face. Am. J. Orthod. v.93, n.2, p.103-16, feb. 1988.

155. NANDA, S. K. Growth patterns in subject with long and short faces. Am. J. Orthod. v.98, n.3, p.247-58, sep. 1990.

156. NANDA, S. K. Considerations of dentofacial growth in long-term retention and stability: is active retention needed? Am. J. Orthod. v.101, n.4, 
p.297-302, apr. 1992.

157. NEMETH, R. B.; ISAACSON, R. J. Vertical anterior relapse. Am. J. Orthod. v.65, n.6, jun. 1974.

158. NGAN, P.; FIELDS, H. W. Open bite: a review of etiology and management. Pediatric Dentistry. v.19, n.2, p.91-8, 1997.

159. NIELSEN, H. Vertical malocclusions: etiology, development, diagnosis and some aspects of treatment. Angle Orthod. v.61, p.247-60, 1991.

160. OBWEGESER, $\mathrm{H}$. The surgical correction of mandibular prognathism with consideration of genioplasty. Oral Surg. Oral Med. Oral Pathol. v.10, p.677, 1957.

161. OGAARD, B. et al. The effect of sucking habits, cohort, sex, intercanine arch widths, and breast or bootle feeding on posterior crossbite in Norwegian and Swedish 3-year-old children. Am. J. Orthod. Dentofac. Orthop. v.106, n.2, p.106-61, aug. 1994.

162. ORSINI, R. H. et al. Class I open bite: a case report. Am. J. Orthod. v.99, n.2, p.100-6, Feb. 1991.

163. OZAWA, T. et al. Controle vertical em ortodontia. Ortodontia. v.31, n.2, p.81-90, 1998.

164. PANCHERZ, H.; HANSEN, K. Occlusal changes during and after Herbst treatment: a cephalometric investigation. Europ. J. Orthod. v.8, n.4, p.215-28, nov. 1986.

165. PANCHERZ, H. The nature of Class II relapse after Herbst appliance treatment: a cephalometric long-term investigation. Amer. J. Orthod. 
v.100, n.3, p.220-33, Sep. 1991.

166. PARKER, J. H. The interception of the open bite in the early growth period. Angle Orthod. v.41, n.1, p.24-44, jan. 1971.

167. PARRA, N. L. S. Mordida aberta anterior. Estudo de pacientes tratados ortodonticamente e cinco anos após contenção. (HYPERLINK http://www.odontologia.com.br/artigos). p.1-14, abr. 2000.

168. PEARSON, L. E. Vertical control in treatment of patients having backwardrotation growth tendencies. Angle Orthod. v.48, p.131-40, 1978.

169. PEARSON, L. E. Treatment of a severe openbite excessive vertical pattern with an ecletic non-surgical approach. The Angle Orthod. n.1, p.71-6, 1991.

170. PETRELLI, E. Ortodontia para fonoaudiologia. Curitiba, Lovise, 1992, caps. 9, 10, 11.

171. POLLARD, L. E.; MAMANDRAS, A. H. Male postpubertal facial growth in Class II malocclusions. Amer. J. Orthod. Dentofac. Orthop. v.108, n.1, p.62-8, Jul. 1995.

172. POPOVICH, F.; THOMPSON, G.W. Thumb and finger-sucking: its relation to malocclusion. Am. J. Orthod. v.63, n.2, p.148-55, feb. 1973.

173. POULTON, D. R.; WARE, W. H. Surgical-orthodontic treatment of severe mandibular retrusion. Am. J. Orthod. v.59, p.244, 1971.

174. PROFFIT, W. R.; NORTON, L. A. The tongue and oral morphology: influences of tongue activity during speech and swallowing. ASHA Reports. n.5, p.106-15, 1970. 
175. PROFFIT, W. R.; MASON, R. M. Myofunctional therapy for tonguethrusting: background and recommendations. J.A.D.A. v.90, p.403-11, 1975.

176. PROFFIT, W. R. The equilibrium theory revisited: factors influencing position teeth. Angle Orthod. v.48, n.3, p.175-86, jul. 1978.

177. PROFFIT, W. R.; PHILLIPS, C.; TURVEY, T. A. Stability following superior repositioning of the maxilla. Am. J. Orthod. Dentofac. Orthop. v.94, p.184-200, 1988.

178. PROFFIT, W. R. Contempory Orthodontics. 2.ed., Mosby Year Book, 1993.

179. PROSTERMAN, B. et. al. The use of implants for orthodontic correction of an open bite. Am. J. Orthod. v.107, n.3, p.245-50, mar. 1995.

180. REIN, B. Treatment of anterior open bite malocclusions. Int. J. Orthod. v.7, n.1, p.27-34, mar. 1969.

181. REITZIK, M. et al. The surgical treatment of skeletal anterior open bite deformities with rigid internal fixation in the mandible. Am. J. Orthod. v.97, n.1, p.52-7, jan. 1990.

182. RICHARDSON, A. Skeletal factors in anterior openbite and deep overbite. Am. J. Orthod. v.56, n.2, p.114-27, aug. 1969.

183. RICHARDSON, A. R. Dento-alveolar factors in anterior open bite and deep over bite. Dent. Pract. Dent. Rec. v.21, p.53-7, 1970.

184. RICHARDSON, A. A comparision of traditional and computadorized method of cephalometric analysis. Europ. J. Orthod. v.3, p.15-20, 
1981.

185. RICHARDSON, A. R. A classification of open bites. Europ. J. Orthod. v.3, p.289-96, 1981.

186. RICKETTS, R. M. The influence of orthodontic treatment on facial growth and development. Angle Orthod. v.30, p.103-33, 1960.

187. RIEDEL, R. A. In: GRABER, T. M.; SWAIN, B. F. Current orthodontic concepts and techniques. philadelphia, 1969, p.875-918.

188. RIOLO, M. L. An Atlas of Craniofacial Growth. Cephalometric standards from the University School Growth Study. The University of Michigan, Ann Arbor, Center for Human Growth and Development., 1974, p.1-8.

189. ROGERS, A. P. Open bite cases involving tongue habits. Int. J. Orthod. v.13, p.837-44, 1927.

190. SABRI, R. Nonsurgical correction of a skeletal class II. division I, malocclusion with bilateral crossbite and anterior open bite. Am. J. Orthod. v.114, p.189-94, 1998.

191. SAFIRSTEIN, G. R.; BURTON, D. J. Open bite - a case report. Am. J. Orthod. p.47-55, jan. 1983.

192. SANTOS, E. C. A. et al. Hábito de sucção digital: etiologia, tratamento e apresentação de um caso clínico. Rev. Paran. de Ortod. v.12, n.1-2, p.21-9, 1991.

193. SARVER, D. M.; WEISSMAN, S. M. Nonsurgical treatment of open bite in nongrowing patients. Am. J. Orthod. v.108, n.6, p.651-9, 1995. 
194. SASSOUNI, V.; NANDA, S. Analysis of dentofacial vertical proportions. Am. J. Orthod. v.50, n.11, p.801-23, 1964.

195. SASSOUNI, V. A classification of skeletal facial types. Am. J. Orthod. v.55, n.2, p.109-23, feb. 1969.

196. SCHENDEL, S. A. et al. The long face syndrome: vertical maxilary excess. Am. J. Orthod. v.70, n.4, p.398-408, oct. 1976.

197. SCHUDY, F. F. The rotation of the mandible resulting from growth: its implications in orthodontic treatment. Angle Orthod. v.35, n.1, p.36-50, jan. 1965.

198. SEGOVIA, M. L. Interrelaciones entre la odontoestomatologia y la fonoaudiologia. Buenos Aires, Editorial Médica Panamenricana, 1977.

199. SERRA NEGRA, et al. Estudo da associação entre aleitamento, hábitos bucais e maloclusões. Rev. Odont. USP. v.11, n.2, p.79-86, abr./jun. 1997.

200. SILVA FILHO, O. G. et al. Sucção digital. Abordagem multidisciplinar: ortodontia $\mathrm{x}$ psicologia $\mathrm{x}$ fonoaudiologia. Estomat. Cult. v.16, n.2, p.44-52, 1986.

201. SILVA FILHO, O.G.; FREITAS, S. F.; CAVASSAN, A. O. Hábitos de sucção: elementos passíveis de intervenção. Estomat. Cult. v.16, n.4, p.61-71, 1986.

202. SILVA FILHO, O. G.; GONÇALVES, R. M. G.; MAIA, F. A. Sucking habits: clinical managements in dentistry. J. Clin. Pediat. Dent. v.15, n.3, p.137-56, 1991. 
203. SILVA FILHO, O. G. et al. Efeitos terapêuticos suscitados pelo uso da grade palatina: um estudo cefalométrico. Rev. Soc. Par. Ortod. v.1, n.1, p.9-15, nov./dez. 1995.

204. SIM, J. M.; FINN, S. B. In: Odontologia Pediátrica. Hábitos bucales infantiles. 4. ed., México, D. F. Interamericana, 1982, p.326-8.

205. SKINAZI, G. et al. A psychological approach to thumbsucking. J. Clin. Orthod. v.34, n.8, p.478-81, aug. 2000.

206. SPEIDEL, T. M.; ISAACSON, R. J.; WORMS, F. W. Tongue thrust therapy and anterior dental open bite. Am. J. Orthod. v.62, n.3, p.287-95, sep. 1972.

207. STAGGERS, J. A. Vertical changes following first premolar extractions. Amer. J. Orthod. Dentofac. Orthop. v.105, n.1, p.19-24, Jan. 1994.

208. STEINER, C. L. In: KRAUS, B.; RIEDEL, R. Vistas in orthodontics. Cephalometrics as a clinical tool. Philadelphia, Lea \& Fabiger, 1962, p.131-61.

209. STOCKLI, P. W.; TEUSCHER, U. M. Orthodontics current principles and techniques. GRABER, T. M. Combined activator headgear ortopedics. St. Louis, Mosby Yearbook inc., 1985, p.405-83.

210. STRANG, R. H. W. Factors associated with sucessful orthodontic treatment. Am. J. Orthod. v.38, n.10, p.790-800, oct. 1952.

211. StRANG, R. H. W. Tratado de ortodoncia. 3. ed., Buenos Aires, Bibliográfica Argentina, 1957.

212. STRAUB, W. Malfunction of the tongue. Part I. The abnormal swallowng habit: it causes, efects and results in reaction to orthodontic and 
speech therapy. Am. J. Orthod. v.46, p.404-24, 1960.

213. SUBTELNY, J. D.; SAKUDA, M. Open bite: diagnosis and treatment. Am. J. Orthod. v.50, n.5, p.337-58, may. 1964.

214. SUBTELNY, J. D.; SUBTELNY. Oral habits: studies in form, function and therapy. Angle Orthod. v.43, n.4, p.347-83, oct. 1973.

215. SUGUINO, R. et al. Utilização e confecção do "Bite Block". Rev. Dental Press de Ortod. e Ortop. Facial. v.2, n.1, p.89-116, jan./fev. 1997.

216. SWINEHART, E. W. A clinical study of openbite. Am. J. Orthod. Oral Surg. v.28, p.18-34, jan. 1942.

217. TEIXEIRA, S. Hábitos bucais deletérios: sucção prolongada. Rev. Ciência-saúde. v.13, n.12, p.152-61, jan./jun. 1994.

218. TRAISMAN, A.S.; TRAISMAN, H. S. Thumb and finger sucking: a study of 2.650 infants and children. J. Pediatr. v.52, p.566-72, 1958.

219. TULLEY, W. J. A clinical appraisal of tongue-thrusting. Am. J. Orthod. v.55, p.640-50, 1969.

220. VAN DER LINDEN, F. P. G. M. Ortodontia - Desenvolvimento da dentição. São Paulo, Editora Santos, 1986.

221. VARGERVIK, K.; HARVOLD, E. P. Response to activator treatment in Class II malocclusion. Amer. J. Orthod. v.88, n.3, p.242-51, sep. 1985.

222. VATTEONE, A. L. et al. Mordida abierta: formas clinicas y tratamiento. Rev. Circ. Argent. v.32, n.2, p.17-22, may 1969. 
223. VIAZIS, A. D. Correction of open bite with elastics and rectangular NiTi wires. J. Clin. Orthod. v.25, n.11, p.697-8, 1991.

224. WALTER, L. R. F. et al. In: Odontologia para o bebê. Educação odontológica: necessidades nutritivas. Londrina, Artes Médicas, 1986, p.83-4.

225. WATSON, W. G. Openbite: a multifactorial event. Am. J. Orthod. v.80, n.4, p.443-6, oct. 1981.

226. WEINBACH, J. R.; SMITH, R. J. Cephalometric changes during treatment with the open bite bionator. Am. J. Orthod. v.101, n.4, p.367-74, Apr. 1992.

227. WOODS, M. G.; NANDA, R. S. Intrusion of posterior teeth with magnets: an experiment in nongrowing baboons. Am. J. Orthod. Dentofac. Orthop. v.100, p.393-400, 1991.

228. WOODSIDE, D. G. Do functional appliance have an orthopedic effect? /editorial/. Am. J. Orthod. Dentofac. Orthop. v.113, n.1, p.11-4, Jan. 1998.

229. WORMS, F. W.; MESKIN, L.H.; ISAACSON, R.J. Openbite. Am. J. Orthod. v.59, n.6, p.589-95, jun. 1971.

230. YASHIRO, K.; TAKADA, K. Tongue muscle activity after orthodontic treatment of anterior openbite: a case report. Am. J. Orthod. v.115, n.6, p.600-6, jun. 1999. 


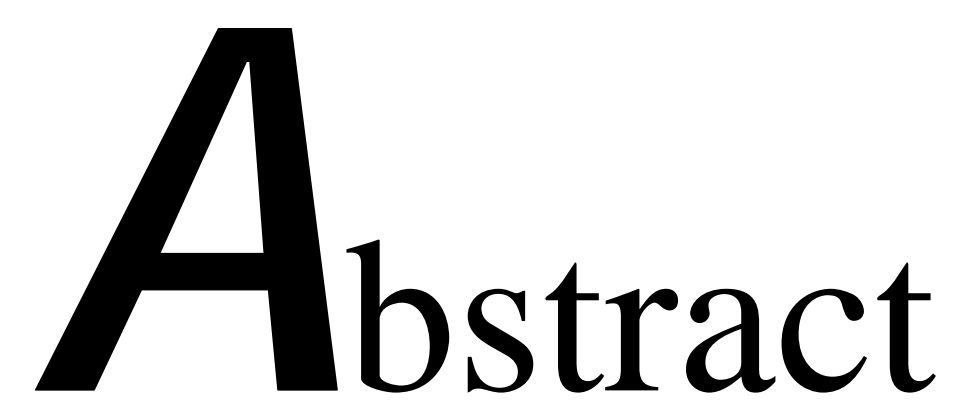




\section{ABSTRACT}

Stability of anterior open bite non-extraction treatment in the permanent dentition

The purpose of this study was to cephalometrically evaluate the longterm stability of anterior open bite non-extraction treatment in the permanent dentition after a mean period of 5 years. The experimental group consisted of 21 patients who had undergone orthodontic treatment with fixed appliances from whom cephalometric headplates were obtained at the pretreatment (T1), posttreatment (T2) and postretention (T3) stages. Two control groups were employed. The first, with a compatible age to the experimental group before treatment, was used only to characterize it. The second control group, with normal occlusion, was longitudinally followed, in a time period compatible to the posttretention period and was used for comparison of the changes between them, during this period. The differences between the observation stages in the experimental group were analyzed with paired tests and the postretention changes were compared to the changes of the second control group with independent t tests. Results demonstrated a statistically significant relapse of the open bite at the end of the postretention period. The primary factors that contributed for the relapse were the smaller vertical development of the maxillary and mandibular incisors in the postretention period. However, 61,9\% of the sample presented a "clinically stable" open bite correction. Neither the pretreatment anterior open bite amount or the magnitude of correction were associated with the long-term stability of the final treatment results. 


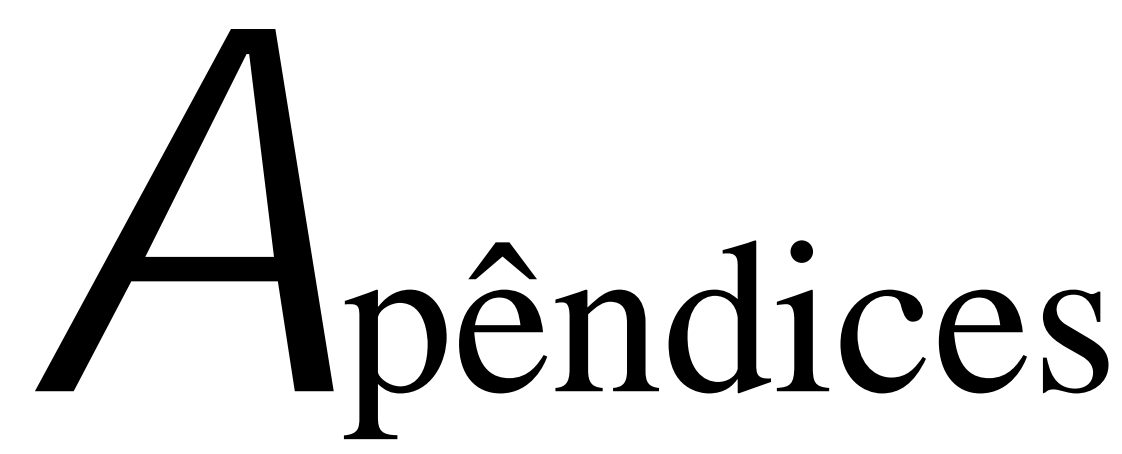




\section{APÊNDICES}

TABELA A-1 e B-1. Características dos pacientes que compõem o grupo experimental e o grupo controle 2 respectivamente.

TABELA A-1: Grupo experimental

\begin{tabular}{|c|c|c|c|c|c|c|c|}
\hline Paciente & numero & grupo & sexo & Idade inic. & idade final & $\begin{array}{l}\text { Idade pós- } \\
\text { trat. }\end{array}$ & procedência \\
\hline A.C.S. & 1 & 2 & $\mathrm{~F}$ & 12,1 & 14,7 & 20,8 & especialização \\
\hline A.O.M. & 2 & 2 & $\mathrm{~F}$ & 10,8 & 12,9 & 18,7 & especialização \\
\hline A.B.M. & 3 & 2 & $\mathrm{~F}$ & 15,1 & 19,2 & 22,4 & especialização \\
\hline B.F.B. & 4 & 2 & $M$ & 11,1 & 13,9 & 17,8 & especialização \\
\hline C.F.B. & 5 & 2 & $F$ & 12,7 & 14,9 & 18,5 & especialização \\
\hline C.V.C. & 6 & 2 & $\mathrm{~F}$ & 11 & 12,1 & 18,4 & especialização \\
\hline D.P.A. & 7 & 2 & M & 14,7 & 16,6 & 20,3 & especialização \\
\hline D.S.A. & 8 & 2 & $\mathrm{~F}$ & 11,1 & 14,1 & 19,5 & especialização \\
\hline E.A.S.Q. & 9 & 2 & $\mathrm{~F}$ & 13,9 & 15,6 & 26 & especialização \\
\hline F.M.B. & 10 & 2 & $F$ & 12,2 & 14,7 & 18,7 & especialização \\
\hline F.G. & 11 & 2 & $\mathrm{~F}$ & 11,9 & 14,1 & 18,6 & especialização \\
\hline J.L. & 12 & 2 & $F$ & 15,8 & 17,1 & 22,1 & pós-graduação \\
\hline J.C.C. & 13 & 2 & $\mathrm{~F}$ & 12,2 & 14,8 & 19,5 & especialização \\
\hline K.E.S. & 14 & 2 & $\mathrm{~F}$ & 11,7 & 13,5 & 18,7 & especialização \\
\hline L.M.D. & 15 & 2 & $M$ & 13,4 & 15,7 & 20,7 & especialização \\
\hline M.B.B. & 16 & 2 & M & 12,4 & 14,8 & 21,2 & especialização \\
\hline M.M.V & 17 & 2 & $\mathrm{~F}$ & 10,1 & 13,3 & 19,6 & especialização \\
\hline M.C.F. & 18 & 2 & $\mathrm{~F}$ & 11,5 & 13,5 & 18,2 & especialização \\
\hline R.B. & 19 & 2 & M & 13,7 & 15,6 & 22,3 & especialização \\
\hline T.A.L. & 20 & 2 & $\mathrm{~F}$ & 13,1 & 15 & 19,5 & especialização \\
\hline V.O. & 21 & 2 & $\mathrm{~F}$ & 11,2 & 13,8 & 18,1 & especialização \\
\hline
\end{tabular}

TABELA B-1: Grupo controle 2

\begin{tabular}{|c|c|c|c|c|c|c|}
\hline Paciente & numero & grupo & sexo & idade inicial & idade final & procedência \\
\hline A.B.C. & 1 & 1 & M & 14,1 & 18,9 & $\mathrm{CCB}^{*}$ \\
\hline A.C. & 2 & 1 & M & 14 & 18,9 & CCB \\
\hline A.L.T.E. & 3 & 1 & M & 15,6 & 18,4 & CCB \\
\hline A.R & 4 & 1 & M & 15,5 & 18,3 & CCB \\
\hline D.R. & 5 & 1 & $F$ & 14,5 & 18,6 & CCB \\
\hline D.S. & 6 & 1 & $F$ & 14,9 & 19,1 & CCB \\
\hline G.M. & 7 & 1 & $F$ & 14,4 & 18,5 & CCB \\
\hline J.A. & 8 & 1 & M & 14,4 & 20 & СCB \\
\hline J.R.N. & 9 & 1 & $M$ & 14,9 & 21 & CCB \\
\hline L.M. & 10 & 1 & $F$ & 14,6 & 21 & CCB \\
\hline L.C.D. & 11 & 1 & M & 15 & 19,2 & CCB \\
\hline M.L.P. & 12 & 1 & $F$ & 14,9 & 19 & CCB \\
\hline M.Q. & 13 & 1 & M & 14,7 & 22,6 & CCB \\
\hline M.A.S. & 14 & 1 & $F$ & 15 & 19,2 & CCB \\
\hline M.C.T & 15 & 1 & $F$ & 14,6 & 19,3 & CCB \\
\hline M.E.T. & 16 & 1 & $F$ & 14,9 & 20 & CCB \\
\hline M.I.C. & 17 & 1 & $F$ & 14,9 & 19,9 & ССВ \\
\hline M.P. & 18 & 1 & $F$ & 14,8 & 20 & CCB \\
\hline P.S. & 19 & 1 & $F$ & 14,7 & 19,5 & CCB \\
\hline R.A. & 20 & 1 & $M$ & 14,2 & 19 & ССВ \\
\hline R.A.P. & 21 & 1 & $\mathrm{~F}$ & 14 & 21,8 & ССВ \\
\hline
\end{tabular}

\footnotetext{
* Centro de Crescimento da Faculdade de Odontologia de Bauru - USP
} 
As TABELAS A-2 à A-16 e B-2 à $B-11$ representam os valores individuais de cada variável para os pacientes do grupo experimental e do grupo controle 2 respectivamente.

TABELA A-2: Grupo experimental

\begin{tabular}{|c|c|c|c|c|c|c|c|c|c|c|}
\hline paciente & & & & SNA & SNA & & & & & \\
\hline & SNA 1 & SNA 2 & SNA 3 & $2-1$ & $3-2$ & SNB 1 & SNB 2 & SNB 3 & SNB 2-1 & $\begin{array}{r}\text { SNB 3- } \\
-0\end{array}$ \\
\hline A.C.S. & 79,1 & 78,7 & 78,2 & $-0,4$ & $-0,5$ & 75,4 & 75,7 & 75,1 & 0,3 & -0 \\
\hline A.O.M. & 78 & 75 & 73,7 & -3 & $-1,3$ & 74,1 & 74,2 & 73,3 & 0,1 & \\
\hline A.B.M. & 84,9 & 84,8 & 86 & $-0,1$ & 1,2 & 80,9 & 80,3 & 81,6 & $-0,6$ & \\
\hline B.F.B. & 86,4 & 86,4 & 85,3 & 0 & $-1,1$ & 81 & 82,7 & 83,7 & 1,7 & \\
\hline C.F.B. & 82,8 & 82,9 & 85,4 & 0,1 & 2,5 & 78,3 & 80 & 82 & 1,7 & \\
\hline C.V.C. & 80,7 & 79,1 & 79 & $-1,6$ & $-0,1$ & 75,8 & 74,7 & 73,8 & $-1,1$ & \\
\hline D.P.A. & 81,5 & 80,7 & 81,9 & $-0,8$ & 1,2 & 78,6 & 79,5 & 79,8 & 0,9 & \\
\hline 8-D.S.A. & 73,2 & 75,7 & 81,3 & 2,5 & 5,6 & 77,3 & 79,3 & 81,5 & 2 & \\
\hline 9-E.A.S.Q. & 79,8 & 81,8 & 78,8 & 2 & -3 & 74,8 & 76 & 73,7 & 1,2 & \\
\hline 10-F.M.B. & 84,9 & 84,9 & 85,9 & 0 & 1 & 80,8 & 81,1 & 82,4 & 0,3 & \\
\hline -F.G. & 85,5 & 84,3 & 84,9 & $-1,2$ & 0,6 & 83,2 & 83,8 & 84,6 & 0,6 & \\
\hline 2-J.L. & 81,7 & 83,5 & 83 & 1,8 & $-0,5$ & 79,5 & 81,1 & 81,5 & 1,6 & \\
\hline 3-J.C.C. & 79,2 & 80,1 & 81,5 & 0,9 & 1,4 & 75,7 & 74,4 & 74,1 & $-1,3$ & \\
\hline 14-K.E.S. & 76,6 & 77,4 & 77,2 & 0,8 & $-0,2$ & 74,1 & 75,2 & 74,5 & 1,1 & \\
\hline 15-L.M.D. & 79,5 & 78,4 & 80 & $-1,1$ & 1,6 & 75,4 & 75,5 & 76 & 0,1 & \\
\hline 6-M.B.B. & 78,8 & 80,3 & 82,2 & 1,5 & 1,9 & 75,9 & 77,3 & 77,2 & 1,4 & \\
\hline 7-M.M.V & 76,3 & 76,5 & 79,2 & 0,2 & 2,7 & 72,8 & 72,6 & 73,4 & $-0,2$ & \\
\hline 8-M.C.F. & 82 & 81,2 & 82,7 & $-0,8$ & 1,5 & 77,2 & 78,1 & 79,6 & 0,9 & \\
\hline R.B. & 71,5 & 76,3 & 76 & 4,8 & $-0,3$ & 70,9 & 74,1 & 74,5 & 3,2 & \\
\hline T.A.L. & 84,6 & 86,2 & 86,8 & 1,6 & 0,6 & 86,3 & 85,1 & 87,4 & $-1,2$ & \\
\hline O. & 79,4 & 79 & 80,7 & $-0,4$ & 1,7 & 78,3 & 77,5 & 78,6 & $-0,8$ & \\
\hline
\end{tabular}

TABELA B-2: Grupo controle 2

\begin{tabular}{lccccccccc}
\multicolumn{1}{c}{ paciente } & SNA 2 & SNA 3 & SNA3-2 & Co-A 2 & Co-A 3 & Co-A 3-2 & A-Nperp 2 & A-Nperp 3 & 3-2 \\
1-A.B.C. & 76,6 & 78,7 & 2,1 & 80,6 & 85,2 & 4,6 & $-3,8$ & $-5,6$ & $-1,8$ \\
2-A.C. & 76,4 & 77,3 & 0,9 & 79,9 & 84,2 & 4,3 & -8 & $-7,6$ & 0,4 \\
3-A.L.T.E. & 82,7 & 83,4 & 0,7 & 87,8 & 90,8 & 3 & $-3,6$ & $-4,2$ & $-0,6$ \\
4-A.R & 81,4 & 81,2 & $-0,2$ & 90,1 & 92,2 & 2,1 & $-1,7$ & $-0,9$ & 0,8 \\
5-D.R. & 80,8 & 80,1 & $-0,7$ & 86,8 & 87,8 & 1 & $-0,9$ & 0 & 0,9 \\
6-D.S. & 76,3 & 74 & $-2,3$ & 86,2 & 83,7 & $-2,5$ & $-4,4$ & $-6,2$ & $-1,8$ \\
7-G.M. & 81,6 & 81,8 & 0,2 & 87,8 & 88,8 & 1 & $-1,7$ & $-1,8$ & $-0,1$ \\
8-J.A. & 83,3 & 81,6 & $-1,7$ & 91,1 & 92,9 & 1,8 & 1,5 & $-2,1$ & $-3,6$ \\
9-J.R.N. & 83,7 & 82,6 & $-1,1$ & 93 & 93,7 & 0,7 & $-1,6$ & $-4,6$ & -3 \\
10-L.M. & 79,7 & 79,8 & 0,1 & 85,3 & 86,9 & 1,6 & 0,5 & 0,6 & 0,1 \\
11-L.C.D. & 83,5 & 84,2 & 0,7 & 81,2 & 82,8 & 1,6 & $-1,3$ & $-0,9$ & 0,4 \\
12-M.L.P. & 82,8 & 83,9 & 1,1 & 80,1 & 76,8 & $-3,3$ & $-1,5$ & $-1,6$ & $-0,1$ \\
13-M.Q. & 83,4 & 85,1 & 1,7 & 82,3 & 83,3 & 1 & $-3,1$ & $-3,4$ & $-0,3$ \\
14-M.A.S. & 78,2 & 78,5 & 0,3 & 87,2 & 92 & 4,8 & $-3,1$ & $-2,7$ & 0,4 \\
15-M.C.T & 77,2 & 78,9 & 1,7 & 83,2 & 84 & 0,8 & 2,5 & 1,8 & $-0,7$ \\
16-M.E.T. & 82,2 & 82,2 & 0 & 83,3 & 83,8 & 0,5 & 0,8 & 1,3 & 0,5 \\
17-M.I.C. & 79,3 & 79,8 & 0,5 & 88,6 & 91,4 & 2,8 & $-3,1$ & $-4,9$ & $-1,8$ \\
18-M.P. & 83,7 & 86,7 & 3 & 84,9 & 84,1 & $-0,8$ & $-3,2$ & $-3,5$ & $-0,3$ \\
19-P.S. & 79,2 & 79,6 & 0,4 & 81,4 & 85,4 & 4 & $-1,2$ & $-0,8$ & 0,4 \\
20-R.A. & 80,4 & 79,9 & $-0,5$ & 90,1 & 93,4 & 3,3 & $-1,8$ & 0 & 1,8 \\
21-R.A.P. & 77,3 & 76,9 & $-0,4$ & 78 & 81,4 & 3,4 & $-3,3$ & -3 & 0,3
\end{tabular}


TABELA A-3: Grupo experimental

\begin{tabular}{|c|c|c|c|c|c|c|c|c|c|c|}
\hline pacientes & ANB 1 & ANB 2 & ANB 3 & $\begin{array}{c}\text { ANB } \\
2-1\end{array}$ & $\begin{array}{c}\text { ANB } \\
3-2\end{array}$ & Co-Gn 1 & Co-Gn 2 & Co-Gn 3 & $\begin{array}{c}\text { Co-Gn } \\
2-1\end{array}$ & $\begin{array}{c}\text { Co-Gn } \\
3-2\end{array}$ \\
\hline 1-A.C.S. & 3,8 & 3,1 & 3,1 & $-0,7$ & 0 & 110,5 & 114,5 & 113,4 & 4 & $-1,1$ \\
\hline 2-A.O.M. & 3,9 & 0,8 & 0,4 & $-3,1$ & $-0,4$ & 108,4 & 113,4 & 114,5 & 5 & 1,1 \\
\hline 3-A.B.M. & 4 & 4,4 & 4,4 & 0,4 & 0 & 111 & 110,3 & 111,2 & $-0,7$ & 0,9 \\
\hline 4-B.F.B. & 5,4 & 3,7 & 1,6 & $-1,7$ & $-2,1$ & 115,4 & 118,2 & 127 & 2,8 & 8,8 \\
\hline 5-C.F.B. & 4,5 & 3 & 3,4 & $-1,5$ & 0,4 & 107,4 & 112,3 & 112,2 & 4,9 & $-0,1$ \\
\hline 6-C.V.C. & 4,9 & 4,4 & 5,2 & $-0,5$ & 0,8 & 101,5 & 106,8 & 106,4 & 5,3 & $-0,4$ \\
\hline 7-D.P.A. & 2,9 & 1,1 & 2,1 & $-1,8$ & 1 & 125,9 & 130,2 & 132,4 & 4,3 & 2,2 \\
\hline 8-D.S.A. & $-4,1$ & $-3,7$ & $-0,2$ & 0,4 & 3,5 & 111,2 & 113,8 & 113,9 & 2,6 & 0,1 \\
\hline 9-E.A.S.Q. & 5,1 & 5,7 & 5,2 & 0,6 & $-0,5$ & 115,6 & 116,5 & 116,6 & 0,9 & 0,1 \\
\hline 10-F.M.B. & 4,2 & 3,8 & 3,5 & $-0,4$ & $-0,3$ & 107,1 & 108,2 & 109,1 & 1,1 & 0,9 \\
\hline 11-F.G. & 2,3 & 0,5 & 0,4 & $-1,8$ & $-0,1$ & 107,7 & 111,2 & 113,3 & 3,5 & 2,1 \\
\hline 12-J.L. & 2,2 & 2,3 & 1,6 & 0,1 & $-0,7$ & 112,5 & 113,3 & 114,5 & 0,8 & 1,2 \\
\hline 13-J.C.C. & 3,5 & 5,7 & 7,4 & 2,2 & 1,7 & 104,6 & 106 & 104,8 & 1,4 & $-1,2$ \\
\hline 14-K.E.S. & 2,5 & 2,2 & 2,7 & $-0,3$ & 0,5 & 105,8 & 111,1 & 112,6 & 5,3 & 1,5 \\
\hline 15-L.M.D. & 4,1 & 2,9 & 4,1 & $-1,2$ & 1,2 & 114,6 & 125,5 & 126,4 & 10,9 & 0,9 \\
\hline 16-M.B.B. & 2,9 & 3 & 4,9 & 0,1 & 1,9 & 119,4 & 121,4 & 121,6 & 2 & 0,2 \\
\hline 17-M.M.V & 3,5 & 4 & 5,9 & 0,5 & 1,9 & 100,5 & 103,5 & 105,2 & 3 & 1,7 \\
\hline 18-M.C.F. & 4,8 & 3,1 & 3,1 & $-1,7$ & 0 & 107,4 & 110,2 & 111,1 & 2,8 & 0,9 \\
\hline 19-R.B. & 0,6 & 2,1 & 1,5 & 1,5 & $-0,6$ & 114,3 & 117,1 & 119,6 & 2,8 & 2,5 \\
\hline 20-T.A.L. & $-1,7$ & 1,1 & $-0,7$ & 2,8 & $-1,8$ & 114,8 & 116,8 & 117,3 & 2 & 0,5 \\
\hline 21-V.O. & 1,1 & 1,5 & 2,1 & 0,4 & 0,6 & 107,5 & 111,5 & 112,3 & 4 & 0,8 \\
\hline
\end{tabular}

TABELA B-3: Grupo controle 2

\begin{tabular}{lccccccccc}
\multicolumn{1}{c}{ pacientes } & SNB 2 & SNB 3 & SNB 3-2 & CoGn 2 & Co-Gn 3 & 3-2 & Go-Gn 2 & Go-Gn 3 & Go-Gn \\
1-A.B.C. & 73,9 & 75,9 & 2 & 109,6 & 118 & 8,4 & 66,9 & 70,9 & 4 \\
2-A.C. & 75,9 & 77,9 & 2 & 106,7 & 116,4 & 9,7 & 69,6 & 73,7 & 4,1 \\
3-A.L.T.E. & 83,6 & 86,4 & 2,8 & 118,1 & 126,5 & 8,4 & 74,3 & 78,1 & 3,8 \\
4-A.R & 79,9 & 81,6 & 1,7 & 123,9 & 131,4 & 7,5 & 79,5 & 81,4 & 1,9 \\
5-D.R. & 79,6 & 79,8 & 0,2 & 115,3 & 118,4 & 3,1 & 77 & 80 & 3 \\
6-D.S. & 75,7 & 75,7 & 0 & 112,2 & 112,7 & 0,5 & 69,6 & 69,7 & 0,1 \\
7-G.M. & 80,1 & 80,9 & 0,8 & 113,7 & 117 & 3,3 & 72 & 74,3 & 2,3 \\
8-J.A. & 80,6 & 80,3 & $-0,3$ & 119,8 & 125,2 & 5,4 & 79,3 & 84,2 & 4,9 \\
9-J.R.N. & 81,4 & 81,8 & 0,4 & 122,8 & 125 & 2,2 & 81,8 & 81,8 & 0 \\
10-L.M. & 80 & 79,5 & $-0,5$ & 115,3 & 116,6 & 1,3 & 72,8 & 73,1 & 0,3 \\
11-L.C.D. & 82,1 & 81,1 & -1 & 110,4 & 114,4 & 4 & 65,7 & 70,3 & 4,6 \\
12-M.L.P. & 81,3 & 82,1 & 0,8 & 106,7 & 105,1 & $-1,6$ & 70,9 & 69,8 & $-1,1$ \\
13-M.Q. & 79 & 81,7 & 2,7 & 110,5 & 113,2 & 2,7 & 75,7 & 75,7 & 0 \\
14-M.A.S. & 79,2 & 79,7 & 0,5 & 121,9 & 130,4 & 8,5 & 77,4 & 81,5 & 4,1 \\
15-M.C.T & 75,7 & 77,4 & 1,7 & 107,3 & 111,7 & 4,4 & 72,5 & 74,8 & 2,3 \\
16-M.E.T. & 81,1 & 80,9 & $-0,2$ & 113,5 & 116 & 2,5 & 74,2 & 75,1 & 0,9 \\
17-M.I.C. & 80,3 & 81,1 & 0,8 & 119,2 & 120,8 & 1,6 & 84,2 & 83,8 & $-0,4$ \\
18-M.P. & 84,2 & 88,3 & 4,1 & 114,8 & 115,4 & 0,6 & 80,9 & 81,4 & 0,5 \\
19-P.S. & 77 & 78,5 & 1,5 & 103,7 & 111,2 & 7,5 & 68,5 & 71 & 2,5 \\
20-R.A. & 75,8 & 75,4 & $-0,4$ & 113 & 117,9 & 4,9 & 80 & 79,8 & $-0,2$ \\
21-R.A.P. & 73,4 & 72,7 & $-0,7$ & 99,2 & 104,3 & 5,1 & 64,2 & 66,5 & 2,3
\end{tabular}


TABELA A-4: Grupo experimental

\begin{tabular}{|c|c|c|c|c|c|c|c|c|c|c|}
\hline & & & & Co-A & o-A & - A-Npe & & & & A-Nperp \\
\hline pacientes & Co-A 1 & Co-A 2 & Co-A 3 & $2-1$ & 2 & 1 & 2 & 3 & $2-1$ & \\
\hline 1-A.C.S. & 79,4 & 79,8 & 79,4 & 0,4 & $-0,4$ & $-2,3$ & $-3,4$ & $-2,2$ & $-1,2$ & 1,2 \\
\hline 2-A.O.M. & 83,4 & 78,6 & 82,3 & $-4,8$ & 3,7 & $-0,6$ & $-4,3$ & $-5,6$ & 1,3 & $-1,3$ \\
\hline 3-A.B.M. & 80,5 & 82,2 & 81 & 1,7 & $-1,2$ & 2 & 3 & 3,7 & $-0,7$ & 0,7 \\
\hline 4-B.F.B. & 92,1 & 91,9 & 95,3 & $-0,2$ & 3,4 & 4,1 & 3,9 & 2,6 & 1,3 & $-1,3$ \\
\hline 5-C.F.B. & 83,8 & 85,1 & 83,5 & 1,3 & $-1,6$ & 0,2 & 1 & 1,9 & $-0,9$ & 0,9 \\
\hline 6-C.V.C. & 80 & 80,7 & 78,4 & 0,7 & $-2,3$ & 1 & $-0,2$ & 0,5 & $-0,7$ & 0,7 \\
\hline 7-D.P.A. & 91 & 91,8 & 93,3 & 0,8 & 1,5 & 0,6 & $-2,7$ & 1,7 & $-4,4$ & 4,4 \\
\hline 8-D.S.A. & 81,5 & 82,3 & 85,6 & 0,8 & 3,3 & $-2,6$ & $-1,9$ & 2,7 & $-4,6$ & 4,6 \\
\hline 9-E.A.S.Q. & 86,1 & 87 & 86,1 & 0,9 & $-0,9$ & 1,6 & 3,7 & 1,6 & 2,1 & $-2,1$ \\
\hline 10-F.M.B. & 85 & 84 & 84,8 & -1 & 0,8 & 3,4 & 3,6 & 3,2 & 0,4 & $-0,4$ \\
\hline 11-F.G. & 75,4 & 76 & 77,3 & 0,6 & 1,3 & 2,5 & 1,8 & 0,4 & 1,4 & $-1,4$ \\
\hline 12-J.L. & 83,5 & 80,5 & 82,4 & -3 & 1,9 & 1,4 & 4,3 & 0,9 & 3,4 & $-3,4$ \\
\hline 13-J.C.C. & 78,8 & 82,6 & 82,3 & 3,8 & $-0,3$ & $-2,9$ & $-2,1$ & $-1,2$ & $-0,9$ & 0,9 \\
\hline 14-K.E.S. & 76,3 & 77,7 & 77,1 & 1,4 & $-0,6$ & $-4,9$ & -4 & -3 & -1 & 1 \\
\hline 15-L.M.D. & 84,5 & 88,9 & 88,5 & 4,4 & $-0,4$ & -1 & 1,3 & $-0,4$ & 1,7 & $-1,7$ \\
\hline 16-M.B.B. & 89,1 & 90,6 & 92,5 & 1,5 & 1,9 & $-0,8$ & $-0,5$ & 2,3 & $-2,8$ & 2,8 \\
\hline 17-M.M.V & 71,4 & 72,2 & 73,9 & 0,8 & 1,7 & $-5,4$ & $-7,6$ & $-5,8$ & $-1,8$ & 1,8 \\
\hline 18-M.C.F. & 82,8 & 82,8 & 83,5 & 0 & 0,7 & 1,7 & $-0,4$ & 1,8 & $-2,2$ & 2,2 \\
\hline 19-R.B. & 81,2 & 85,7 & 87,2 & 4,5 & 1,5 & $-5,5$ & $-3,2$ & $-4,9$ & 1,7 & $-1,7$ \\
\hline 20-T.A.L. & 80,8 & 82,1 & 79,6 & 1,3 & $-2,5$ & 3,8 & 4,8 & 4,8 & 0 & 0 \\
\hline 21-V.O. & 78,8 & 80,5 & 79,7 & 1,7 & $-0,8$ & 1,1 & 0,7 & 0,5 & 0,2 & $-0,2$ \\
\hline
\end{tabular}

TABELA B-4: Grupo controle 2

\begin{tabular}{|c|c|c|c|c|c|c|c|c|c|}
\hline pacientes & $\begin{array}{c}\text { Co-Go } \\
2\end{array}$ & Co-Go 3 & $\begin{array}{c}\text { Co-Go } 3- \\
2\end{array}$ & P-Nperp 2 & P-Nperp 3 & $\begin{array}{l}\text { P-nperp 3- } \\
2\end{array}$ & $\begin{array}{c}\text { CoGoMe } \\
2\end{array}$ & CoGoMe3 & $\begin{array}{c}\text { CoGoMe3 } \\
-2\end{array}$ \\
\hline 1-A.B.C. & 57,5 & 66,6 & 9,1 & $-9,6$ & $-13,3$ & $-3,7$ & 124,9 & 119,7 & $-5,2$ \\
\hline 2-A.C. & 47,8 & 55,1 & 7,3 & $-13,9$ & $-10,2$ & 3,7 & 132 & 130,7 & $-1,3$ \\
\hline 3-A.L.T.E. & 52,8 & 59,7 & 6,9 & $-4,8$ & $-2,6$ & 2,2 & 137,3 & 134,4 & $-2,9$ \\
\hline 4-A.R & 58,4 & 65 & 6,6 & $-4,7$ & 1 & 5,7 & 128,9 & 128,8 & $-0,1$ \\
\hline 5-D.R. & 57,9 & 59,2 & 1,3 & 0,2 & 3,3 & 3,1 & 119 & 117,5 & $-1,5$ \\
\hline 6-D.S. & 55,6 & 56,8 & 1,2 & $-7,9$ & $-7,2$ & 0,7 & 129,3 & 128,7 & $-0,6$ \\
\hline 7-G.M. & 56,4 & 58,8 & 2,4 & -4 & $-3,2$ & 0,8 & 126,1 & 124,9 & $-1,2$ \\
\hline 8-J.A. & 57,2 & 59 & 1,8 & 0,4 & $-3,6$ & -4 & 123,7 & 122,6 & $-1,1$ \\
\hline 9-J.R.N. & 55,9 & 58,8 & 2,9 & -2 & $-5,2$ & $-3,2$ & 126,1 & 126 & $-0,1$ \\
\hline 10-L.M. & 60,2 & 60,1 & $-0,1$ & 4,6 & 3,9 & $-0,7$ & 122,6 & 124,5 & 1,9 \\
\hline 11-L.C.D. & 58,1 & 59,5 & 1,4 & $-3,6$ & $-6,3$ & $-2,7$ & 127,5 & 124,5 & -3 \\
\hline 12-M.L.P. & 48,6 & 49,5 & 0,9 & $-2,9$ & $-3,2$ & $-0,3$ & 126,8 & 124 & $-2,8$ \\
\hline 13-M.Q. & 46,7 & 50 & 3,3 & $-13,3$ & $-11,4$ & 1,9 & 128,6 & 129,1 & 0,5 \\
\hline 14-M.A.S. & 57,6 & 64,3 & 6,7 & 1 & 3,8 & 2,8 & 130,4 & 128,2 & $-2,2$ \\
\hline 15-M.C.T & 49,5 & 54,6 & 5,1 & 3,7 & 3,4 & $-0,3$ & 124,7 & 120,3 & $-4,4$ \\
\hline 16-M.E.T. & 55,3 & 57,4 & 2,1 & 1,2 & 1,8 & 0,6 & 124,3 & 123,8 & $-0,5$ \\
\hline 17-M.I.C. & 59,4 & 61 & 1,6 & 1,2 & $-1,5$ & $-2,7$ & 111,9 & 113,2 & 1,3 \\
\hline 18-M.P. & 52,7 & 55,1 & 2,4 & $-1,5$ & $-0,2$ & 1,3 & 118,6 & 115,7 & $-2,9$ \\
\hline 19-P.S. & 47,6 & 54,4 & 6,8 & $-4,6$ & $-1,4$ & 3,2 & 127,4 & 126 & $-1,4$ \\
\hline 20-R.A. & 51,2 & 57,2 & 6 & $-11,7$ & $-7,3$ & 4,4 & 118,9 & 119,3 & 0,4 \\
\hline 21-R.A.P. & 46,8 & 49,7 & 2,9 & $-13,2$ & $-13,2$ & 0 & 128,5 & 129,4 & 0,9 \\
\hline
\end{tabular}


TABELA A-5: grupo experimental

\begin{tabular}{|c|c|c|c|c|c|c|c|c|c|c|}
\hline pacientes & $\begin{array}{c}\text { Go-Gn } \\
1\end{array}$ & $\begin{array}{c}\text { Go-Gn } \\
2\end{array}$ & $\begin{array}{c}\text { Go-Gn } \\
3\end{array}$ & $\begin{array}{c}\text { Go-Gn } \\
2-1\end{array}$ & $\begin{array}{c}\text { Go-Gn } \\
3-2\end{array}$ & Co-Go 1 & Co-Go 2 & $\begin{array}{c}\text { Co-Go } \\
3\end{array}$ & $\begin{array}{c}\text { Co-Go } \\
1\end{array}$ & $\begin{array}{c}\text { Co-Go } \\
2\end{array}$ \\
\hline 1-A.C.S. & 72,3 & 69,9 & 70,7 & $-2,4$ & 0,8 & 49,1 & 56,9 & 55,5 & 7,8 & $-1,4$ \\
\hline 2-A.O.M. & 73,5 & 75,3 & 77,9 & 1,8 & 2,6 & 46,5 & 52,3 & 48,7 & 5,8 & $-3,6$ \\
\hline 3-A.B.M. & 71,1 & 66,3 & 68,9 & $-4,8$ & 2,6 & 53,7 & 57,7 & 57,3 & 4 & $-0,4$ \\
\hline 4-B.F.B. & 76 & 81,5 & 83 & 5,5 & 1,5 & 52,4 & 52,6 & 62,1 & 0,2 & 9,5 \\
\hline 5-C.F.B. & 71,2 & 74,4 & 73,4 & 3,2 & -1 & 51,1 & 54 & 58,4 & 2,9 & 4,4 \\
\hline 6-C.V.C. & 67,6 & 69,4 & 71,6 & 1,8 & 2,2 & 40,4 & 44,8 & 43,7 & 4,4 & $-1,1$ \\
\hline 7-D.P.A. & 87,5 & 84,3 & 84,1 & $-3,2$ & $-0,2$ & 54,5 & 61,8 & 67,5 & 7,3 & 5,7 \\
\hline 8-D.S.A. & 77 & 76,7 & 78,9 & $-0,3$ & 2,2 & 47,3 & 50,5 & 48,9 & 3,2 & $-1,6$ \\
\hline 9-E.A.S.Q. & 74,2 & 78,6 & 73,9 & 4,4 & $-4,7$ & 59,9 & 55,5 & 60,1 & $-4,4$ & 4,6 \\
\hline 10-F.M.B. & 71 & 74,4 & 74,6 & 3,4 & 0,2 & 53,3 & 52,5 & 53,1 & $-0,8$ & 0,6 \\
\hline 11-F.G. & 72,8 & 76,2 & 76,4 & 3,4 & 0,2 & 52 & 53,7 & 56,3 & 1,7 & 2,6 \\
\hline 12-J.L. & 72,8 & 74,8 & 71,9 & 2 & $-2,9$ & 51,3 & 51,9 & 55,8 & 0,6 & 3,9 \\
\hline 13-J.C.C. & 71,6 & 71,5 & 70 & $-0,1$ & $-1,5$ & 48,7 & 49,4 & 51,2 & 0,7 & 1,8 \\
\hline 14-K.E.S. & 65,7 & 67,1 & 70,2 & 1,4 & 3,1 & 47,9 & 52,9 & 51,9 & 5 & -1 \\
\hline 15-L.M.D. & 77,9 & 84,2 & 86 & 6,3 & 1,8 & 53,2 & 60,2 & 60,3 & 7 & 0,1 \\
\hline 16-M.B.B. & 78 & 79,1 & 80,1 & 1,1 & 1 & 63,8 & 64,3 & 63,7 & 0,5 & $-0,6$ \\
\hline 17-M.M.V & 65,6 & 68,5 & 68,4 & 2,9 & $-0,1$ & 42,4 & 44,1 & 45 & 1,7 & 0,9 \\
\hline 18-M.C.F. & 69,6 & 73,2 & 77,1 & 3,6 & 3,9 & 49,7 & 52,8 & 51,2 & 3,1 & $-1,6$ \\
\hline 19-R.B. & 72,9 & 76,4 & 76,6 & 3,5 & 0,2 & 54 & 53,7 & 58,5 & $-0,3$ & 4,8 \\
\hline 20-T.A.L. & 72,8 & 78,2 & 76,6 & 5,4 & $-1,6$ & 55,3 & 52,3 & 55,7 & -3 & 3,4 \\
\hline 21-V.O. & 73,4 & 71,6 & 73,8 & $-1,8$ & 2,2 & 44,2 & 50,7 & 50,4 & 6,5 & $-0,3$ \\
\hline
\end{tabular}

TABELA B-5: Grupo controle 2

$\begin{array}{lccccccccc}\text { pacientes } & \text { ANB 2 } & \text { ANB 3 } & \text { ANB 3-2 } & \text { CoA/CoGn 2 CoA/CoGn3 } & 3-2 & \text { FMA 2 } & \text { FMA 3 } & \text { FMA } \\ \text { 1-A.B.C. } & 2,7 & 2,8 & 0,1 & 73,5 & 72,2 & -1,3 & 28,6 & 26,5 & -2,1 \\ \text { 2-A.C. } & 0,6 & -0,6 & -1,2 & 74,9 & 72,3 & -2,6 & 34,9 & 31 & -3,9 \\ \text { 3-A.L.T.E. } & -1 & -2,9 & -1,9 & 74,4 & 71,8 & -2,6 & 31 & 29,6 & -1,4 \\ \text { 4-A.R } & 1,4 & -0,4 & -1,8 & 72,7 & 70,2 & -2,5 & 29,9 & 27 & -2,9 \\ \text { 5-D.R. } & 1,1 & 0,3 & -0,8 & 75,3 & 74,1 & -1,2 & 21,4 & 19,7 & -1,7 \\ \text { 6-D.S. } & 0,7 & -1,7 & -2,4 & 76,8 & 74,3 & -2,5 & 28,3 & 27,2 & -1,1 \\ \text { 7-G.M. } & 1,5 & 1 & -0,5 & 77,2 & 75,9 & -1,3 & 24,6 & 24,5 & -0,1 \\ \text { 8-J.A. } & 2,7 & 1,2 & -1,5 & 76,1 & 74,2 & -1,9 & 24,7 & 26,5 & 1,8 \\ \text { 9-J.R.N. } & 2,3 & 0,8 & -1,5 & 75,7 & 74,9 & -0,8 & 25,2 & 25,6 & 0,4 \\ \text { 10-L.M. } & -0,3 & 0,2 & 0,5 & 74 & 74,5 & 0,5 & 20,1 & 20,3 & 0,2 \\ \text { 11-L.C.D. } & 1,5 & 3 & 1,5 & 73,6 & 72,3 & -1,3 & 25,8 & 27,6 & 1,8 \\ \text { 12-M.L.P. } & 1,5 & 1,8 & 0,3 & 75,1 & 73 & -2,1 & 27,4 & 27,5 & 0,1 \\ \text { 13-M.Q. } & 4,4 & 3,4 & -1 & 74,4 & 73,6 & -0,8 & 36,3 & 34,5 & -1,8 \\ \text { 14-M.A.S. } & -1 & -1,2 & -0,2 & 71,6 & 70,6 & -1 & 25,7 & 23,8 & -1,9 \\ \text { 15-M.C.T } & 1,5 & 1,5 & 0 & 77,5 & 75,2 & -2,3 & 20,4 & 20,2 & -0,2 \\ \text { 16-M.E.T. } & 1,2 & 1,3 & 0,1 & 73,4 & 72,2 & -1,2 & 26,7 & 26,4 & -0,3 \\ \text { 17-M.I.C. } & -1 & -1,3 & -0,3 & 74,3 & 75,6 & 1,3 & 16,2 & 15,9 & -0,3 \\ \text { 18-M.P. } & -0,5 & -1,6 & -1,1 & 74 & 72,9 & -1,1 & 24,1 & 22,5 & -1,6 \\ \text { 19-P.S. } & 2,2 & 1 & -1,2 & 78,5 & 76,8 & -1,7 & 25,5 & 22,3 & -3,2 \\ \text { 20-R.A. } & 4,6 & 4,5 & -0,1 & 79,7 & 79,3 & -0,4 & 28,9 & 25 & -3,9 \\ \text { 21-R.A.P. } & 3,9 & 4,2 & 0,3 & 78,7 & 78 & -0,7 & 33,6 & 33,8 & 0,2\end{array}$


TABELA A-6: Grupo Experimental

\begin{tabular}{|c|c|c|c|c|c|c|c|c|c|c|}
\hline pacientes & $\begin{array}{l}\text { CoGo } \\
\text { Me } 1\end{array}$ & $\begin{array}{l}\text { CoGo } \\
\text { Me } 2\end{array}$ & $\begin{array}{l}\text { CoGo } \\
\text { Me } 3\end{array}$ & $\begin{array}{l}\text { CoGo } \\
\text { Me } 2-1\end{array}$ & $\begin{array}{l}\text { CoGo } \\
\text { Me 3-2 }\end{array}$ & $\begin{array}{c}\text { CoA/Co } \\
\text { Gn } 1\end{array}$ & $\begin{array}{c}\mathrm{CoA} / \mathrm{Co} \\
\text { Gn } 2\end{array}$ & $\begin{array}{c}\text { CoA/Co } \\
\text { Gn } 3\end{array}$ & $\begin{array}{c}\text { CoA/Co } \\
\text { Gn 2-1 }\end{array}$ & $\begin{array}{c}\text { CoA/Co } \\
\text { Gn 3-2 }\end{array}$ \\
\hline 1-A.C.S. & 132,9 & 131,9 & 130,9 & -1 & -1 & 71,9 & 69,7 & 70 & $-2,2$ & 0,3 \\
\hline 2-A.O.M. & 130,1 & 126,6 & 131,1 & $-3,5$ & 4,5 & 76,9 & 69,3 & 71,9 & $-7,6$ & 2,6 \\
\hline 3-A.B.M. & 128,3 & 128,3 & 126,5 & 0 & $-1,8$ & 72,5 & 74,5 & 72,8 & 2 & $-1,7$ \\
\hline 4-B.F.B. & 129,9 & 124,6 & 123,6 & $-5,3$ & -1 & 79,8 & 77,8 & 75 & -2 & $-2,8$ \\
\hline 5-C.F.B. & 124,4 & 123,3 & 119,4 & $-1,1$ & $-3,9$ & 78 & 75,7 & 74,5 & $-2,3$ & $-1,2$ \\
\hline 6-C.V.C. & 140,8 & 140,4 & 135,1 & $-0,4$ & $-5,3$ & 78,8 & 75,6 & 73,7 & $-3,2$ & $-1,9$ \\
\hline 7-D.P.A. & 126,2 & 127,9 & 124,4 & 1,7 & $-3,5$ & 72,3 & 70,5 & 70,5 & $-1,8$ & 0 \\
\hline 8-D.S.A. & 127,5 & 127,3 & 126,7 & $-0,2$ & $-0,6$ & 73,3 & 72,3 & 75,1 & -1 & 2,8 \\
\hline 9-E.A.S.Q. & 121,8 & 121,1 & 123,6 & $-0,7$ & 2,5 & 74,5 & 74,7 & 73,9 & 0,2 & $-0,8$ \\
\hline 10-F.M.B. & 120,6 & 117,6 & 118,5 & -3 & 0,9 & 79,4 & 77,7 & 77,7 & $-1,7$ & 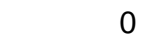 \\
\hline 11-F.G. & 121,3 & 119,6 & 119,6 & $-1,7$ & 0 & 70 & 68,4 & 68,2 & $-1,6$ & $-0,2$ \\
\hline 12-J.L. & 131,8 & 128,4 & 129,2 & $-3,4$ & 0,8 & 74,2 & 71 & 72 & $-3,2$ & 1 \\
\hline 13-J.C.C. & 121,5 & 124,1 & 121,4 & 2,6 & $-2,7$ & 75,4 & 77,9 & 78,5 & 2,5 & 0,6 \\
\hline 14-K.E.S. & 138,8 & 137,7 & 136 & $-1,1$ & $-1,7$ & 72,1 & 69,9 & 68,5 & $-2,2$ & $-1,4$ \\
\hline 15-L.M.D. & 122,6 & 121,3 & 120,7 & $-1,3$ & $-0,6$ & 73,7 & 70,9 & 70 & $-2,8$ & $-0,9$ \\
\hline 16-M.В.В. & 116,6 & 117,8 & 117,9 & 1,2 & 0,1 & 74,6 & 74,7 & 76,1 & 0,1 & 1,4 \\
\hline 17-M.M.V & 138,3 & 135 & 137,4 & $-3,3$ & 2,4 & 71 & 69,8 & 70,2 & $-1,2$ & 0,4 \\
\hline 18-M.C.F. & 129,8 & 123,5 & 120,8 & $-6,3$ & $-2,7$ & 77 & 75,1 & 75,1 & $-1,9$ & 0 \\
\hline 19-R.B. & 130,5 & 129,9 & 127,8 & $-0,6$ & $-2,1$ & 71 & 73,2 & 72,9 & 2,2 & $-0,3$ \\
\hline 20-T.A.L. & 129 & 128,4 & 128 & $-0,6$ & $-0,4$ & 70,4 & 70,3 & 67,9 & $-0,1$ & $-2,4$ \\
\hline 21-V.O. & 132,9 & 133 & 131,3 & 0,1 & $-1,7$ & 73,3 & 72,2 & 71 & $-1,1$ & $-1,2$ \\
\hline
\end{tabular}

TABELA B-6: Grupo controle 2

\begin{tabular}{lccccccccc} 
& SN.GoGn & SN.GoGn & SN.GoGn & \multicolumn{7}{c}{ SN.PP } & & AFAI \\
pacientes & 2 & 3 & $3-2$ & SN.PP 2 & SN.PP 3 & $3-2$ & AFAI2 & AFAI 3 & $3-2$ \\
1-A.B.C. & 36,7 & 31,2 & $-5,5$ & 9,8 & 7,2 & $-2,6$ & 65,8 & 73,9 & 8,1 \\
2-A.C. & 38,3 & 34,2 & $-4,1$ & 10,4 & 9,2 & $-1,2$ & 64,9 & 69,8 & 4,9 \\
3-A.L.T.E. & 33,3 & 30,3 & -3 & 10,5 & 9,2 & $-1,3$ & 62,6 & 66,2 & 3,6 \\
4-A.R & 35,3 & 33,4 & $-1,9$ & 4,7 & 4,6 & $-0,1$ & 73,7 & 78,1 & 4,4 \\
5-D.R. & 27,4 & 27,7 & 0,3 & 4,1 & 5 & 0,9 & 66,9 & 68,5 & 1,6 \\
6-D.S. & 35,2 & 33,9 & $-1,3$ & 13,3 & 12,4 & $-0,9$ & 62,4 & 62,5 & 0,1 \\
7-G.M. & 29 & 28,4 & $-0,6$ & 6,3 & 5,6 & $-0,7$ & 62,9 & 64,3 & 1,4 \\
8-J.A. & 31 & 31,1 & 0,1 & 6,5 & 7,6 & 1,1 & 67,6 & 72,7 & 5,1 \\
9-J.R.N. & 28,8 & 27,4 & $-1,4$ & 8,5 & 8,8 & 0,3 & 64,5 & 65,9 & 1,4 \\
10-L.M. & 28,2 & 28,6 & 0,4 & 9,5 & 10,6 & 1,1 & 60,1 & 60,2 & 0,1 \\
11-L.C.D. & 29,4 & 31,6 & 2,2 & 8,3 & 9 & 0,7 & 63,8 & 69,5 & 5,7 \\
12-M.L.P. & 31,6 & 30,4 & $-1,2$ & 8,4 & 5,7 & $-2,7$ & 59,7 & 60,3 & 0,6 \\
13-M.Q. & 38,5 & 34,1 & $-4,4$ & 9,3 & 5,7 & $-3,6$ & 67 & 68,7 & 1,7 \\
14-M.A.S. & 32,7 & 31 & $-1,7$ & 7,9 & 7,8 & $-0,1$ & 66,8 & 70,7 & 3,9 \\
15-M.C.T & 33,2 & 31,5 & $-1,7$ & 10,3 & 7,8 & $-2,5$ & 58,6 & 60,6 & 2 \\
16-M.E.T. & 32,8 & 33,3 & 0,5 & 10 & 10,2 & 0,2 & 63,9 & 65,3 & 1,4 \\
17-M.I.C. & 22,8 & 20,1 & $-2,7$ & 7,7 & 8,5 & 0,8 & 59,3 & 58,2 & $-1,1$ \\
18-M.P. & 25,3 & 20,2 & $-5,1$ & 3 & $-1,1$ & $-4,1$ & 62,1 & 63,2 & 1,1 \\
19-P.S. & 33,1 & 30,2 & $-2,9$ & 7,3 & 6,1 & $-1,2$ & 61,8 & 64,7 & 2,9 \\
20-R.A. & 35,2 & 33,6 & $-1,6$ & 15,6 & 16,6 & 1 & 65,3 & 64,7 & $-0,6$ \\
21-R.A.P. & 40,1 & 41,1 & 1 & 15,5 & 15,9 & 0,4 & 60,8 & 63,7 & 2,9
\end{tabular}


TABELA A-7: Grupo experimental

$\begin{array}{lrrrrrrrrrr}\text { pacientes } & \text { FMA 1 } & \text { FMA 2 } & \text { FMA 3 } & \text { FMA 2-1 } & \text { FMA 3-2 } & \text { AFAI 1 } & \text { AFAI 2 } & \text { AFAI 3 } & \text { AFAI 2-1 } & 3-2 \\ \text { 1-A.C.S. } & 37,7 & 35,8 & 34,7 & -1,9 & -1,1 & 74,1 & 74,6 & 76,6 & 0,5 & 2 \\ \text { 2-A.O.M. } & 30,2 & 32,5 & 33,6 & 2,3 & 1,1 & 67,7 & 72,9 & 75,7 & 5,2 & 2,8 \\ \text { 3-A.B.M. } & 31,6 & 28,2 & 28,4 & -3,4 & 0,2 & 71,1 & 71,3 & 70,3 & 0,2 & -1 \\ \text { 4-B.F.B. } & 27,1 & 25,9 & 24,2 & -1,2 & -1,7 & 64,3 & 65,9 & 71,3 & 1,6 & 5,4 \\ \text { 5-C.F.B. } & 28,4 & 26,2 & 24,7 & -2,2 & -1,5 & 62,1 & 64,4 & 64,1 & 2,3 & -0,3 \\ \text { 6-C.V.C. } & 36,5 & 37 & 38,3 & 0,5 & 1,3 & 67,5 & 71,6 & 75,5 & 4,1 & 3,9 \\ \text { 7-D.P.A. } & 31,8 & 31,9 & 26,6 & 0,1 & -5,3 & 79,4 & 81 & 81,7 & 1,6 & 0,7 \\ \text { 8-D.S.A. } & 22,1 & 22,2 & 21,4 & 0,1 & -0,8 & 58,2 & 61,5 & 62 & 3,3 & 0,5 \\ \text { 9-E.A.S.Q. } & 27,5 & 28,7 & 29,7 & 1,2 & 1 & 75,4 & 75,2 & 79,1 & -0,2 & 3,9 \\ \text { 10-F.M.B. } & 20,2 & 20,4 & 20,7 & 0,2 & 0,3 & 62,7 & 63,1 & 63,3 & 0,4 & 0,2 \\ \text { 11-F.G. } & 26 & 24,8 & 26,5 & -1,2 & 1,7 & 64 & 66,6 & 66,6 & 2,6 & 0 \\ \text { 12-J.L. } & 29,1 & 28,3 & 27,8 & -0,8 & -0,5 & 70,2 & 67,6 & 70 & -2,6 & 2,4 \\ \text { 13-J.C.C. } & 32 & 33,4 & 33 & 1,4 & -0,4 & 69,9 & 71,9 & 71,7 & 2 & -0,2 \\ \text { 14-K.E.S. } & 38,4 & 36,2 & 36,8 & -2,2 & 0,6 & 70,8 & 73,8 & 76,2 & 3 & 2,4 \\ \text { 15-L.M.D. } & 24,7 & 22,7 & 25,2 & -2 & 2,5 & 67,8 & 78 & 79,5 & 10,2 & 1,5 \\ \text { 16-M.B.B. } & 21,5 & 22,7 & 22,3 & 1,2 & -0,4 & 68 & 72,9 & 73,7 & 4,9 & 0,8 \\ \text { 17-M.M.V } & 42,7 & 45,5 & 46,2 & 2,8 & 0,7 & 63,4 & 67,6 & 69,4 & 4,2 & 1,8 \\ \text { 18-M.C.F. } & 31,3 & 29,2 & 26,8 & -2,1 & -2,4 & 61,8 & 64,2 & 64 & 2,4 & -0,2 \\ \text { 19-R.B. } & 30,1 & 29,3 & 28,1 & -0,8 & -1,2 & 74,1 & 74,1 & 74 & 0 & -0,1 \\ \text { 20-T.A.L. } & 23,9 & 27,2 & 25,3 & 3,3 & -1,9 & 62,9 & 65,6 & 67 & 2,7 & 1,4 \\ \text { 21-V.O. } & 32,6 & 31,2 & 34,5 & -1,4 & 3,3 & 67,4 & 70,6 & 73,8 & 3,2 & 3,2\end{array}$

TABELA B-7: Grupo controle

$\begin{array}{lccccccccc}\text { pacientes } & \text { IS.PP2 } & \text { IS.PP3 } & \text { IS.PP3-2 } & \text { IS.NA2 } & \text { IS.NA3 } & \text { IS.NA3-2 } & \text { IS-NA2 } & \text { IS-NA3 } & \text { IS-NA3-2 } \\ \text { 1-A.B.C. } & 112,5 & 112,6 & 0,1 & 26,1 & 26,7 & 0,6 & 4,7 & 4,4 & -0,3 \\ \text { 2-A.C. } & 115 & 112,7 & -2,3 & 28,1 & 26,3 & -1,8 & 6,3 & 8,1 & 1,8 \\ \text { 3-A.L.T.E. } & 124 & 126,3 & 2,3 & 30,8 & 33,7 & 2,9 & 8,7 & 9,7 & 1 \\ \text { 4-A.R } & 104,6 & 107,3 & 2,7 & 18,6 & 21,5 & 2,9 & 3,2 & 4,8 & 1,6 \\ \text { 5-D.R. } & 114,9 & 115 & 0,1 & 30 & 29,8 & -0,2 & 6,3 & 6,8 & 0,5 \\ \text { 6-D.S. } & 119,8 & 119 & -0,8 & 30,1 & 32,6 & 2,5 & 7,2 & 10 & 2,8 \\ \text { 7-G.M. } & 111,5 & 111,4 & -0,1 & 23,6 & 24 & 0,4 & 4,9 & 6,5 & 1,6 \\ \text { 8-J.A. } & 109,4 & 108,6 & -0,8 & 19,6 & 19,4 & -0,2 & 3,2 & 4,5 & 1,3 \\ \text { 9-J.R.N. } & 120 & 120,4 & 0,4 & 27,8 & 28,9 & 1,1 & 3,4 & 4,6 & 1,2 \\ \text { 10-L.M. } & 113,7 & 113,5 & -0,2 & 24,6 & 23,1 & -1,5 & 5,3 & 5,7 & 0,4 \\ \text { 11-L.C.D. } & 111,4 & 110,3 & -1,1 & 19,6 & 17 & -2,6 & 4 & 2,3 & -1,7 \\ \text { 12-M.L.P. } & 111,2 & 110 & -1,2 & 20,1 & 20,5 & 0,4 & 3,2 & 4 & 0,8 \\ \text { 13-M.Q. } & 112,1 & 113,2 & 1,1 & 19,4 & 22,4 & 3 & 4,9 & 6,2 & 1,3 \\ \text { 14-M.A.S. } & 109,6 & 113,9 & 4,3 & 23,4 & 27,7 & 4,3 & 6,1 & 7,3 & 1,2 \\ \text { 15-M.C.T } & 104,4 & 104,8 & 0,4 & 16,9 & 18,1 & 1,2 & 2,1 & 3,1 & 1 \\ \text { 16-M.E.T. } & 114,7 & 114,3 & -0,4 & 22,4 & 22 & -0,4 & 4,6 & 4,4 & -0,2 \\ \text { 17-M.I.C. } & 116,3 & 118,7 & 2,4 & 29,4 & 30,4 & 1 & 5,6 & 5,7 & 0,1 \\ \text { 18-M.P. } & 117,8 & 116 & -1,8 & 31 & 30,4 & -0,6 & 5,6 & 6,4 & 0,8 \\ \text { 19-P.S. } & 114,2 & 117,8 & 3,6 & 27,7 & 32 & 4,3 & 6,1 & 7,9 & 1,8 \\ \text { 20-R.A. } & 111,8 & 112,1 & 0,3 & 15,8 & 15,6 & -0,2 & 2,1 & 1,8 & -0,3 \\ \text { 21-R.A.P. } & 107,3 & 102,4 & -4,9 & 14,5 & 9,5 & -5 & 0,5 & 0,3 & -0,2\end{array}$


TABELA A-8: Grupo experimental pacientes ISPP 1 ISPP 2 ISPP 3 ISPP 2-1 ISPP 3-2 IS-PP 1 IS-PP 2 IS-PP 3

$\begin{array}{lrrrrrrrrrr}\text { 1-A.C.S. } & 113,7 & 110,2 & 110,6 & -3,5 & 0,4 & 29,1 & 32,2 & 32,3 & 3,1 & 0,1 \\ \text { 2-A.O.M. } & 104,2 & 100,7 & 102 & -3,5 & 1,3 & 28,1 & 32,2 & 33,8 & 4,1 & 1,6 \\ \text { 3-A.B.M. } & 115,8 & 113,4 & 111,5 & -2,4 & -1,9 & 28,8 & 31,9 & 29,4 & 3,1 & -2,5 \\ \text { 4-B.F.B. } & 121,4 & 114,8 & 110,4 & -6,6 & -4,4 & 26,1 & 29 & 30,5 & 2,9 & 1,5 \\ \text { 5-C.F.B. } & 118,3 & 116,6 & 122,1 & -1,7 & 5,5 & 23,7 & 26,4 & 24,6 & 2,7 & -1,8 \\ \text { 6-C.V.C. } & 116,9 & 109,9 & 108,4 & -7 & -1,5 & 27,7 & 30,4 & 31 & 2,7 & 0,6 \\ \text { 7-D.P.A. } & 114,9 & 115,5 & 115,6 & 0,6 & 0,1 & 30,1 & 31,5 & 31,7 & 1,4 & 0,2 \\ \text { 8-D.S.A. } & 117,7 & 117,5 & 117,5 & -0,2 & 0 & 22,6 & 26,8 & 26,4 & 4,2 & -0,4 \\ \text { 9-E.A.S.Q. } & 115 & 111,3 & 113,3 & -3,7 & 2 & 30 & 32 & 32,4 & 2 & 0,4 \\ \text { 10-F.M.B. } & 129,2 & 123,9 & 123 & -5,3 & -0,9 & 23,6 & 25,5 & 25 & 1,9 & -0,5 \\ \text { 11-F.G. } & 111 & 115,9 & 119,6 & 4,9 & 3,7 & 25,3 & 27,1 & 26,1 & 1,8 & -1 \\ \text { 12-J.L. } & 118,7 & 118,2 & 121 & -0,5 & 2,8 & 28,6 & 27,7 & 29,6 & -0,9 & 1,9 \\ \text { 13-J.C.C. } & 110,2 & 100,5 & 104 & -9,7 & 3,5 & 27,1 & 28,7 & 28 & 1,6 & -0,7 \\ \text { 14-K.E.S. } & 108,8 & 111,1 & 112,5 & 2,3 & 1,4 & 28,3 & 31,6 & 32,2 & 3,3 & 0,6 \\ \text { 15-L.M.D. } & 116 & 107,4 & 110,6 & -8,6 & 3,2 & 26,5 & 33,3 & 32,1 & 6,8 & -1,2 \\ \text { 16-M.B.B. } & 115,9 & 111,7 & 111,6 & -4,2 & -0,1 & 25,6 & 30,7 & 29,4 & 5,1 & -1,3 \\ \text { 17-M.M.V } & 114,2 & 106,7 & 106,8 & -7,5 & 0,1 & 23,4 & 26,8 & 26,6 & 3,4 & -0,2 \\ \text { 18-M.C.F. } & 126,5 & 116,1 & 115,3 & -10,4 & -0,8 & 20,9 & 24,9 & 24,2 & 4 & -0,7 \\ \text { 19-R.B. } & 114,2 & 112,7 & 112,9 & -1,5 & 0,2 & 28,8 & 30,4 & 29,1 & 1,6 & -1,3 \\ \text { 20-T.A.L. } & 127 & 111,3 & 112,7 & -15,7 & 1,4 & 24,2 & 25,8 & 26,8 & 1,6 & 1 \\ \text { 21-V.O. } & 109,7 & 108,4 & 109,1 & -1,3 & 0,7 & 28,4 & 31,2 & 31,8 & 2,8 & 0,6\end{array}$

\section{TABELA B-8: Grupo controle 2}

\begin{tabular}{lccccccccc}
\multicolumn{1}{c}{ pacientes } & IS-PP2 & IS-PP3 & IS-PP3-2 & II.NB2 & II.NB3 & II.NB3-2 & II-NB2 & II-NB3 & II-NB3-2 \\
1-A.B.C. & 28,8 & 30,8 & 2 & 25 & 24,6 & $-0,4$ & 4,9 & 5,5 & 0,6 \\
2-A.C. & 29,1 & 30,5 & 1,4 & 27,5 & 22,3 & $-5,2$ & 4,2 & 3,9 & $-0,3$ \\
3-A.L.T.E. & 23,2 & 24,4 & 1,2 & 22,9 & 22 & $-0,9$ & 4,4 & 3,4 & -1 \\
4-A.R & 33,3 & 34,6 & 1,3 & 22,8 & 18 & $-4,8$ & 3,3 & 2,4 & $-0,9$ \\
5-D.R. & 30,4 & 30,8 & 0,4 & 29,1 & 27,8 & $-1,3$ & 5,2 & 4,8 & $-0,4$ \\
6-D.S. & 28,2 & 28,8 & 0,6 & 24,3 & 26,9 & 2,6 & 4,2 & 4,4 & 0,2 \\
7-G.M. & 28,6 & 29,1 & 0,5 & 23,2 & 24,9 & 1,7 & 3,8 & 5,1 & 1,3 \\
8-J.A. & 29,1 & 31,4 & 2,3 & 19 & 21,1 & 2,1 & 2,7 & 2,8 & 0,1 \\
9-J.R.N. & 24,9 & 25,3 & 0,4 & 25,5 & 24,4 & $-1,1$ & 3,6 & 3,1 & $-0,5$ \\
10-L.M. & 25,2 & 25,6 & 0,4 & 22,2 & 24,1 & 1,9 & 2,3 & 2,7 & 0,4 \\
11-L.C.D. & 29,7 & 31,1 & 1,4 & 15,5 & 20,3 & 4,8 & 2,5 & 3,2 & 0,7 \\
12-M.L.P. & 25 & 24,8 & $-0,2$ & 20,8 & 23 & 2,2 & 2,6 & 3,8 & 1,2 \\
13-M.Q. & 28,7 & 28,7 & 0 & 31,2 & 30,9 & $-0,3$ & 8,5 & 8,9 & 0,4 \\
14-M.A.S. & 29,7 & 30,4 & 0,7 & 22,6 & 21,8 & $-0,8$ & 2,3 & 2,6 & 0,3 \\
15-M.C.T & 25,4 & 26,5 & 1,1 & 19,3 & 21,5 & 2,2 & 1,5 & 2,2 & 0,7 \\
16-M.E.T. & 28 & 29,2 & 1,2 & 22,1 & 21,9 & $-0,2$ & 4 & 3,5 & $-0,5$ \\
17-M.I.C. & 23,2 & 22,3 & $-0,9$ & 17,3 & 19,2 & 1,9 & 1,1 & 0,6 & $-0,5$ \\
18-M.P. & 26,1 & 26,3 & 0,2 & 22 & 20,2 & $-1,8$ & 2,6 & 2,2 & $-0,4$ \\
19-P.S. & 27,7 & 29,3 & 1,6 & 27,8 & 27,1 & $-0,7$ & 5,3 & 5,6 & 0,3 \\
20-R.A. & 25,8 & 26 & 0,2 & 30,1 & 27,3 & $-2,8$ & 6 & 5,6 & $-0,4$ \\
21-R.A.P. & 26,5 & 28,3 & 1,8 & 21,6 & 21,6 & 0 & 3,1 & 3,5 & 0,4
\end{tabular}


TABELA A-9: Grupo experimental

pacientes ISNA 1 ISNA 2 ISNA 3 ISNA 2-1 ISNA 3-2 IS-NA 1 IS-NA 2 IS-NA 3 IS-NA 2-1 3-2

$\begin{array}{lrrrrrrrrrr}\text { 1-A.C.S. } & 26,3 & 20,8 & 21,8 & -5,5 & 1 & 4,5 & 4,8 & 5,3 & 0,3 & 0,5 \\ \text { 2-A.O.M. } & 21,3 & 20,4 & 23,1 & -0,9 & 2,7 & 5,6 & 5,8 & 7,4 & 0,2 & 1,6 \\ \text { 3-A.B.M. } & 27,3 & 25,1 & 22,4 & -2,2 & -2,7 & 6 & 5,4 & 5 & -0,6 & -0,4 \\ \text { 4-B.F.B. } & 30,2 & 23,5 & 21,8 & -6,7 & -1,7 & 7,8 & 3,5 & 6,1 & -4,3 & 2,6 \\ \text { 5-C.F.B. } & 28,7 & 25,7 & 27,8 & -3 & 2,1 & 5,4 & 5,3 & 6 & -0,1 & 0,7 \\ \text { 6-C.V.C. } & 30,1 & 25,6 & 23,4 & -4,5 & -2,2 & 6,1 & 5,9 & 5,5 & -0,2 & -0,4 \\ \text { 7-D.P.A. } & 26,7 & 28,5 & 27,9 & 1,8 & -0,6 & 5,8 & 7,4 & 5,2 & 1,6 & -2,2 \\ \text { 8-D.S.A. } & 34,3 & 35,4 & 30,4 & 1,1 & -5 & 6,7 & 8,8 & 4,5 & 2,1 & -4,3 \\ \text { 9-E.A.S.Q. } & 24,5 & 19,5 & 22,8 & -5 & 3,3 & 4,3 & 3,2 & 5,1 & -1,1 & 1,9 \\ \text { 10-F.M.B. } & 35,9 & 32,7 & 30,9 & -3,2 & -1,8 & 8 & 8,1 & 7,7 & 0,1 & -0,4 \\ \text { 11-F.G. } & 20,7 & 27,3 & 30,7 & 6,6 & 3,4 & 1,3 & 4,3 & 5,1 & 3 & 0,8 \\ \text { 12-J.L. } & 27,9 & 23,2 & 30,9 & -4,7 & 7,7 & 6,8 & 5,4 & 8,5 & -1,4 & 3,1 \\ \text { 13-J.C.C. } & 23,2 & 12,6 & 14,5 & -10,6 & 1,9 & 4,7 & 1,4 & 0,4 & -3,3 & -1 \\ \text { 14-K.E.S. } & 26,4 & 25,8 & 27,7 & -0,6 & 1,9 & 6,3 & 7,4 & 7,5 & 1,1 & 0,1 \\ \text { 15-L.M.D. } & 30,1 & 23,6 & 26,4 & -6,5 & 2,8 & 5,6 & 4,7 & 4,5 & -0,9 & -0,2 \\ \text { 16-M.B.B. } & 26,5 & 23,7 & 22,5 & -2,8 & -1,2 & 5,7 & 5 & 2,5 & -0,7 & -2,5 \\ \text { 17-M.M.V } & 28,3 & 21,1 & 19,2 & -7,2 & -1,9 & 5,1 & 5 & 3,6 & -0,1 & -1,4 \\ \text { 18-M.C.F. } & 32,7 & 24,4 & 20,9 & -8,3 & -3,5 & 5,3 & 3,5 & 2,3 & -1,8 & -1,2 \\ \text { 19-R.B. } & 35,1 & 28,6 & 28 & -6,5 & -0,6 & 11,6 & 6 & 5,6 & -5,6 & -0,4 \\ \text { 20-T.A.L. } & 34 & 17 & 21,5 & -17 & 4,5 & 7 & 2,7 & 5,3 & -4,3 & 2,6 \\ \text { 21-V.O. } & 26,2 & 24,3 & 24,4 & -1,9 & 0,1 & 6,1 & 7,7 & 6,7 & 1,6 & -1\end{array}$

TABELA B-9: Grupo controle 2

\begin{tabular}{|c|c|c|c|c|c|c|c|c|c|}
\hline paciente & II-GoMe 2 & II-GoMe 3 & $\begin{array}{c}\text { II-GoMe } \\
3-2\end{array}$ & $\begin{array}{c}\text { MI-GoMe } \\
2\end{array}$ & $\begin{array}{c}\text { MI-GoMe } \\
3\end{array}$ & $\begin{array}{c}\text { MI-GoMe } \\
3-2\end{array}$ & SN.PO 2 & SN.PO 3 & $\begin{array}{c}\text { SN.PO } \\
3-2\end{array}$ \\
\hline 1-A.B.C. & 38,6 & 43,1 & 4,5 & 28,8 & 34,7 & 5,9 & 19,9 & 14,1 & $-5,8$ \\
\hline 2-A.C. & 37,8 & 40,5 & 2,7 & 29,5 & 32,1 & 2,6 & 29,2 & 16,7 & $-12,5$ \\
\hline 3-A.L.T.E. & 39,6 & 41,2 & 1,6 & 29,8 & 30,9 & 1,1 & 12,7 & 13,7 & 1 \\
\hline 4-A.R & 39,8 & 42 & 2,2 & 30,4 & 32,7 & 2,3 & 13,1 & 13,5 & 0,4 \\
\hline 5-D.R. & 38,3 & 38,6 & 0,3 & 28 & 29,1 & 1,1 & 16,7 & 15,5 & $-1,2$ \\
\hline 6-D.S. & 37,6 & 37,7 & 0,1 & 26,5 & 25,5 & -1 & 21 & 13,8 & $-7,2$ \\
\hline 7-G.M. & 37,5 & 38 & 0,5 & 28,7 & 29,8 & 1,1 & 18,2 & 16 & $-2,2$ \\
\hline 8-J.A. & 41,9 & 43,4 & 1,5 & 29,1 & 32,4 & 3,3 & 6,5 & 11,2 & 4,7 \\
\hline 9-J.R.N. & 39,3 & 40 & 0,7 & 29,3 & 30,9 & 1,6 & 17,8 & 10,2 & $-7,6$ \\
\hline 10-L.M. & 35,8 & 35,7 & $-0,1$ & 27,4 & 27,5 & 0,1 & 12,7 & 9,7 & -3 \\
\hline 11-L.C.D. & 36,7 & 38,7 & 2 & 28,6 & 30,1 & 1,5 & 16,8 & 19,3 & 2,5 \\
\hline 12-M.L.P. & 35 & 36,1 & 1,1 & 26,5 & 26,6 & 0,1 & 14,9 & 10 & $-4,9$ \\
\hline 13-M.Q. & 39,7 & 40,7 & 1 & 28,8 & 30,4 & 1,6 & 19,9 & 12,4 & $-7,5$ \\
\hline 14-M.A.S. & 38,1 & 40,5 & 2,4 & 28,4 & 31 & 2,6 & 12,9 & 7,6 & $-5,3$ \\
\hline 15-М.С.Т & 34,8 & 35,4 & 0,6 & 26,6 & 27,5 & 0,9 & 20,7 & 14,5 & $-6,2$ \\
\hline 16-M.E.T. & 37,7 & 38,1 & 0,4 & 28,8 & 29,2 & 0,4 & 18 & 16,8 & $-1,2$ \\
\hline 17-M.I.C. & 36,9 & 37,6 & 0,7 & 30,2 & 31,1 & 0,9 & 11,5 & 6 & $-5,5$ \\
\hline 18-M.P. & 36 & 36,8 & 0,8 & 27,8 & 28,6 & 0,8 & 11,9 & 6,3 & $-5,6$ \\
\hline 19-P.S. & 36 & 38,3 & 2,3 & 27,4 & 30 & 2,6 & 18,6 & 15,7 & $-2,9$ \\
\hline 20-R.A. & 41,1 & 41 & $-0,1$ & 33,4 & 31,8 & $-1,6$ & 18,1 & 18,3 & 0,2 \\
\hline 21-R.A.P. & 36,1 & 37,7 & 1,6 & 26,3 & 27,5 & 1,2 & 27,3 & 24,8 & $-2,5$ \\
\hline
\end{tabular}


TABELA A-10: Grupo experimental

$\begin{array}{lrrrrrrrrrr}\text { pacientes } & \text { IINB 1 } & \text { IINB 2 } & \text { IINB 3 } & \text { IINB 2-1 } & \text { IINB 3-2 } & \text { II-NB 1 } & \text { II-NB 2 } & \text { II-NB 3 } & \text { II-NB 2-1 } & \text { II-NB 3-2 } \\ \text { 1-A.C.S. } & 30 & 31,1 & 31,6 & 1,1 & 0,5 & 5,9 & 7,3 & 7,9 & 1,4 & 0,6 \\ \text { 2-A.O.M. } & 29,3 & 20,9 & 27 & -8,4 & 6,1 & 5 & 4,1 & 5,6 & -0,9 & 1,5 \\ \text { 3-A.B.M. } & 36,4 & 34,6 & 40,1 & -1,8 & 5,5 & 8 & 8,5 & 9 & 0,5 & 0,5 \\ \text { 4-B.F.B. } & 36,2 & 31,9 & 28,8 & -4,3 & -3,1 & 7,5 & 5,4 & 5,8 & -2,1 & 0,4 \\ \text { 5-C.F.B. } & 35,1 & 28,1 & 36,5 & -7 & 8,4 & 6,3 & 6,5 & 7,7 & 0,2 & 1,2 \\ \text { 6-C.V.C. } & 31,1 & 29,1 & 30,5 & -2 & 1,4 & 5,2 & 7,7 & 7,4 & 2,5 & -0,3 \\ \text { 7-D.P.A. } & 27,9 & 25,7 & 23,3 & -2,2 & -2,4 & 6,4 & 6,4 & 5,8 & 0 & -0,6 \\ \text { 8-D.S.A. } & 18,9 & 23,1 & 19,7 & 4,2 & -3,4 & 0,6 & 2,5 & 2,1 & 1,9 & -0,4 \\ \text { 9-E.A.S.Q. } & 32,1 & 33,6 & 34,6 & 1,5 & 1 & 7 & 7,5 & 8,1 & 0,5 & 0,6 \\ \text { 10-F.M.B. } & 35,3 & 31,3 & 39 & -4 & 7,7 & 8,1 & 9,6 & 10,9 & 1,5 & 1,3 \\ \text { 11-F.G. } & 22,7 & 18,7 & 21,1 & -4 & 2,4 & 2 & 2,8 & 3,2 & 0,8 & 0,4 \\ \text { 12-J.L. } & 30,2 & 33,3 & 32,8 & 3,1 & -0,5 & 6,4 & 7,8 & 8,8 & 1,4 & 1 \\ \text { 13-J.C.C. } & 32,1 & 30,8 & 34,9 & -1,3 & 4,1 & 6,2 & 6,2 & 7,4 & 0 & 1,2 \\ \text { 14-K.E.S. } & 20,6 & 31,1 & 28,7 & 10,5 & -2,4 & 4,2 & 6,9 & 7,4 & 2,7 & 0,5 \\ \text { 15-L.M.D. } & 19,2 & 24 & 23,4 & 4,8 & -0,6 & 2,1 & 5,3 & 5,8 & 3,2 & 0,5 \\ \text { 16-M.B.B. } & 28,1 & 26,7 & 27,9 & -1,4 & 1,2 & 6,6 & 7,1 & 7,6 & 0,5 & 0,5 \\ \text { 17-M.M.V } & 23,8 & 27,1 & 28 & 3,3 & 0,9 & 5,3 & 7,2 & 8,1 & 1,9 & 0,9 \\ \text { 18-M.C.F. } & 39,3 & 29,7 & 28,2 & -9,6 & -1,5 & 8,2 & 5,4 & 4,5 & -2,8 & -0,9 \\ \text { 19-R.B. } & 15,1 & 16,9 & 20,3 & 1,8 & 3,4 & 2 & 3,2 & 2,9 & 1,2 & -0,3 \\ \text { 20-T.A.L. } & 22,2 & 15,3 & 13,3 & -6,9 & -2 & 4,2 & 2 & 2,6 & -2,2 & 0,6 \\ \text { 21-V.O. } & 27,8 & 26,8 & 30,4 & -1 & 3,6 & 7,3 & 7,5 & 8,6 & 0,2 & 1,1\end{array}$

TABELA B-10: Grupo controle 2

Rel.molar

$\begin{array}{lccccccccc}\text { pacientes } & \text { Rel.molar 2 Rel.molar 3 } & 3-2 & \text { Wits 2 } & \text { Wits 3 } & \text { Wits 3-2 } & \text { TH 2 } & \text { TH 3 } & \text { TH 3-2 } \\ \text { 1-A.B.C. } & 1,6 & 1,8 & 0,2 & 0,7 & 3,3 & 2,6 & 3,2 & 2,9 & -0,3 \\ \text { 2-A.C. } & 2,1 & 3 & 0,9 & -7,1 & -3,6 & 3,5 & 2,3 & 2,9 & 0,6 \\ \text { 3-A.L.T.E. } & 2,8 & 3,6 & 0,8 & -5,3 & -9,3 & -4 & 2,9 & 2,2 & -0,7 \\ \text { 4-A.R } & 0,7 & 1,8 & 1,1 & -1,6 & -3,4 & -1,8 & 1,9 & 1,8 & -0,1 \\ \text { 5-D.R. } & 1,3 & 1 & -0,3 & -2,6 & -2,4 & 0,2 & 2,6 & 2,4 & -0,2 \\ \text { 6-D.S. } & 2,8 & 2,2 & -0,6 & -3,4 & -1,9 & 1,5 & 3,6 & 2,9 & -0,7 \\ \text { 7-G.M. } & 1,4 & 1,3 & -0,1 & -4,5 & -3,6 & 0,9 & 2,9 & 2,5 & -0,4 \\ \text { 8-J.A. } & 1,9 & 3,5 & 1,6 & 5 & 0,7 & -4,3 & 4,1 & 3,3 & -0,8 \\ \text { 9-J.R.N. } & 2,1 & 1 & -1,1 & -2,9 & 0 & 2,9 & 2,8 & 2,4 & -0,4 \\ \text { 10-L.M. } & 1,9 & 0,1 & -1,8 & -0,9 & 0,3 & 1,2 & 2,6 & 3,3 & 0,7 \\ \text { 11-L.C.D. } & 2,6 & 1,6 & -1 & -4,2 & -4,2 & 0 & 3,3 & 3,2 & -0,1 \\ \text { 12-M.L.P. } & 2,3 & 0,8 & -1,5 & -2,3 & -0,4 & 1,9 & 2,4 & 2,3 & -0,1 \\ \text { 13-M.Q. } & 1,2 & 1 & -0,2 & -1,2 & 0 & 1,2 & 2,4 & 1,8 & -0,6 \\ \text { 14-M.A.S. } & 1,4 & 1,3 & -0,1 & -1,2 & -0,6 & 0,6 & 2,2 & 2,7 & 0,5 \\ \text { 15-M.C.T } & 2,4 & 1,6 & -0,8 & -2,1 & 0,7 & 2,8 & 2,7 & 2,9 & 0,2 \\ \text { 16-M.E.T. } & 1,8 & 0,4 & -1,4 & -3,5 & -3,5 & 0 & 2,2 & 2,7 & 0,5 \\ \text { 17-M.I.C. } & 2,7 & 0,7 & -2 & -2,1 & -0,1 & 2 & 3,1 & 3,2 & 0,1 \\ \text { 18-M.P. } & 2,3 & 3,4 & 1,1 & -3,9 & -3,5 & 0,4 & 2,3 & 2,2 & -0,1 \\ \text { 19-P.S. } & 0,8 & 1,5 & 0,7 & -1,5 & -1,9 & -0,4 & 3,5 & 3,6 & 0,1 \\ \text { 20-R.A. } & 1,6 & 0 & -1,6 & 2,8 & 2,3 & -0,5 & 2,5 & 2,5 & 0 \\ \text { 21-R.A.P. } & 0,1 & 0,3 & 0,2 & -2,8 & -1,1 & 1,7 & 1,9 & 1,9 & 0\end{array}$


TABELA A-11: Grupo experimental

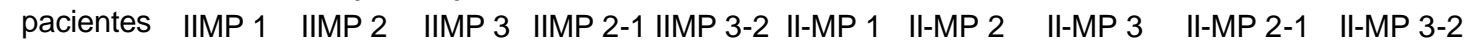

$\begin{array}{lrrrrrrrrrr}\text { 1-A.C.S. } & 88,4 & 91,7 & 92,2 & 3,3 & 0,5 & 40,1 & 42,1 & 43,2 & 2 & 1,1 \\ \text { 2-A.O.M. } & 93,7 & 83,8 & 89,7 & -9,9 & 5,9 & 37,3 & 40,1 & 40,2 & 2,8 & 0,1 \\ \text { 3-A.B.M. } & 96,6 & 97,7 & 102,1 & 1,1 & 4,4 & 39,7 & 41,7 & 42 & 2 & 0,3 \\ \text { 4-B.F.B. } & 100 & 95,7 & 93,7 & -4,3 & -2 & 37,5 & 38,9 & 42 & 1,4 & 3,1 \\ \text { 5-C.F.B. } & 100,9 & 94 & 103,3 & -6,9 & 9,3 & 36,3 & 39,3 & 39,4 & 3 & 0,1 \\ \text { 6-C.V.C. } & 88,3 & 86,7 & 86,9 & -1,6 & 0,2 & 36,6 & 41,7 & 42,3 & 5,1 & 0,6 \\ \text { 7-D.P.A. } & 88,3 & 87,5 & 87,3 & -0,8 & -0,2 & 45,9 & 49,4 & 47,9 & 3,5 & -1,5 \\ \text { 8-D.S.A. } & 85,7 & 89,4 & 85,1 & 3,7 & -4,3 & 32,5 & 35,1 & 33,9 & 2,6 & -1,2 \\ \text { 9-E.A.S.Q. } & 98,1 & 97 & 98,5 & -1,1 & 1,5 & 42,2 & 44,1 & 44,8 & 1,9 & 0,7 \\ \text { 10-F.M.B. } & 105,4 & 100,8 & 108,1 & -4,6 & 7,3 & 37,7 & 39,8 & 39,5 & 2,1 & -0,3 \\ \text { 11-F.G. } & 86,2 & 82,4 & 84,6 & -3,8 & 2,2 & 34,6 & 38,8 & 39,1 & 4,2 & 0,3 \\ \text { 12-J.L. } & 91,7 & 92,5 & 95,6 & 0,8 & 3,1 & 39,8 & 42,2 & 42 & 2,4 & -0,2 \\ \text { 13-J.C.C. } & 96,8 & 95,2 & 100,5 & -1,6 & 5,3 & 40,7 & 42,4 & 42,2 & 1,7 & -0,2 \\ \text { 14-K.E.S. } & 80,1 & 91,2 & 87,8 & 11,1 & -3,4 & 38,2 & 41,8 & 42,2 & 3,6 & 0,4 \\ \text { 15-L.M.D. } & 89,7 & 92,9 & 92,6 & 3,2 & -0,3 & 35,3 & 41,4 & 42,2 & 6,1 & 0,8 \\ \text { 16-M.B.B. } & 100,3 & 97,5 & 98,4 & -2,8 & 0,9 & 40,5 & 42,4 & 43,1 & 1,9 & 0,7 \\ \text { 17-M.M.V } & 80,1 & 83,3 & 83,7 & 3,2 & 0,4 & 35,5 & 40,4 & 40,7 & 4,9 & 0,3 \\ \text { 18-M.C.F. } & 101 & 94,1 & 92,6 & -6,9 & -1,5 & 37,7 & 39,6 & 39,5 & 1,9 & -0,1 \\ \text { 19-R.B. } & 81,2 & 82,9 & 88,3 & 1,7 & 5,4 & 40,3 & 41,4 & 41,5 & 1,1 & 0,1 \\ \text { 20-T.A.L. } & 82,7 & 74,2 & 72,2 & -8,5 & -2 & 36,5 & 37,9 & 37,3 & 1,4 & -0,6 \\ \text { 21-V.O. } & 85 & 86,3 & 87,5 & 1,3 & 1,2 & 38,7 & 40 & 42,6 & 1,3 & 2,6\end{array}$

TABELA B-11: Grupo Controle 2

$\begin{array}{lccccccccc}\text { pacientes } & \text { TV 2 } & \text { TV 3 } & \text { TV 3-2 } & \text { MS-PP 2 } & \text { MS-PP 3 } & \text { MS-PP 3-2 } & \text { II.PM 2 } & \text { II.PM 3 } & \text { II.PM 3-2 } \\ \text { 1-A.B.C. } & 3 & 1 & -2 & 23,2 & 27,6 & 4,4 & 92,8 & 96 & 3,2 \\ \text { 2-A.C. } & 3,6 & 3,5 & -0,1 & 21,1 & 24,7 & 3,6 & 91,3 & 88,3 & -3 \\ \text { 3-A.L.T.E. } & 2 & 1,6 & -0,4 & 21,2 & 23,3 & 2,1 & 84,6 & 83,8 & -0,8 \\ \text { 4-A.R } & 1,5 & 0,9 & -0,6 & 26,6 & 30 & 3,4 & 86 & 81,5 & -4,5 \\ \text { 5-D.R. } & 2,3 & 1,8 & -0,5 & 25,4 & 26,1 & 0,7 & 99,8 & 98,4 & -1,4 \\ \text { 6-D.S. } & 3,9 & 4,2 & 0,3 & 25,2 & 27,1 & 1,9 & 91,1 & 94,1 & 3 \\ \text { 7-G.M. } & 3,5 & 2,8 & -0,7 & 23,3 & 23,8 & 0,5 & 92 & 93,3 & 1,3 \\ \text { 8-J.A. } & 5,2 & 4,1 & -1,1 & 25,2 & 26,8 & 1,6 & 85,5 & 87,9 & 2,4 \\ \text { 9-J.R.N. } & 2,3 & 2 & -0,3 & 21,7 & 22,8 & 1,1 & 95,3 & 91,5 & -3,8 \\ \text { 10-L.M. } & 1,7 & 1,9 & 0,2 & 23,6 & 24,3 & 0,7 & 94,2 & 94,1 & -0,1 \\ \text { 11-L.C.D. } & 4,9 & 2,8 & -2,1 & 24,1 & 28,6 & 4,5 & 82,5 & 86,6 & 4,1 \\ \text { 12-M.L.P. } & 2,6 & 2,3 & -0,3 & 21,4 & 22,1 & 0,7 & 86,4 & 89,1 & 2,7 \\ \text { 13-M.Q. } & 2,1 & 0,8 & -1,3 & 24,1 & 25,4 & 1,3 & 92,4 & 93,4 & 1 \\ \text { 14-M.A.S. } & 3,8 & 3,5 & -0,3 & 25,3 & 26,9 & 1,6 & 89 & 89,2 & 0,2 \\ \text { 15-M.C.T } & 3,7 & 3,3 & -0,4 & 19,7 & 22,4 & 2,7 & 87,8 & 90,9 & 3,1 \\ \text { 16-M.E.T. } & 3 & 3,2 & 0,2 & 22,8 & 24,3 & 1,5 & 85,8 & 85,4 & -0,4 \\ \text { 17-M.I.C. } & 2,5 & 3,4 & 0,9 & 21,1 & 20,8 & -0,3 & 93,4 & 97 & 3,6 \\ \text { 18-M.P. } & 1,3 & 1 & -0,3 & 22,3 & 23,5 & 1,2 & 90,8 & 90 & -0,8 \\ \text { 19-P.S. } & 1,5 & 2,5 & 1 & 22,3 & 24,4 & 2,1 & 95,9 & 96,6 & 0,7 \\ \text { 20-R.A. } & 2,8 & 3 & 0,2 & 21,3 & 24,7 & 3,4 & 97,5 & 96,8 & -0,7 \\ \text { 21-R.A.P. } & 4 & 5 & 1 & 21,8 & 23,1 & 1,3 & 85,6 & 85,2 & -0,4\end{array}$


TABELA A-12: Grupo experimental Wits Wits Wits Wits Wits

\begin{tabular}{|c|c|c|c|c|c|c|c|c|c|c|}
\hline pacientes & $\begin{array}{c}\text { Wits } \\
1\end{array}$ & $\begin{array}{l}\text { Wits } \\
2\end{array}$ & $\begin{array}{c}\text { Wits } \\
3\end{array}$ & $\begin{array}{l}\text { Wits } \\
2-1\end{array}$ & $\begin{array}{l}\text { Wits } \\
3-2\end{array}$ & $\begin{array}{c}\text { SN,GoGn } \\
1\end{array}$ & $\begin{array}{c}\text { SN,GoGn } \\
2\end{array}$ & $\begin{array}{c}\text { SN,GoGn } \\
3\end{array}$ & $\begin{array}{c}\text { SN,GoGn } \\
2-1\end{array}$ & $\begin{array}{c}\text { SN,GoGn } \\
3-2\end{array}$ \\
\hline 1-A.C.S. & 0,7 & -1 & $-1,8$ & $-1,7$ & $-0,8$ & 43,4 & 40,7 & 40,9 & $-2,7$ & 0,2 \\
\hline 2-A.O.M. & $-2,3$ & 0,2 & $-1,3$ & 2,5 & $-1,5$ & 39,2 & 40,8 & 40,8 & 1,6 & \\
\hline 3-A.B.M. & $-2,2$ & $-1,5$ & $-0,9$ & 0,7 & 0,6 & 35,8 & 33,8 & 33,4 & -2 & $-0,4$ \\
\hline 4-B.F.B. & 1,3 & $-0,7$ & $-1,6$ & -2 & $-0,9$ & 32,2 & 30,9 & 29,3 & $-1,3$ & $-1,6$ \\
\hline 5-C.F.B. & $-1,1$ & 0,6 & $-1,7$ & 1,7 & $-2,3$ & 33,5 & 32,2 & 28 & $-1,3$ & $-4,2$ \\
\hline 6-C.V.C. & $-1,4$ & $-1,6$ & 1,5 & $-0,2$ & 3,1 & 44,7 & 44,7 & 47,7 & 0 & \\
\hline 7-D.P.A. & 1,7 & $-1,6$ & $-0,9$ & $-3,3$ & 0,7 & 38 & 36 & 33,1 & -2 & -2, \\
\hline 8-D.S.A. & $-7,1$ & $-5,6$ & $-2,4$ & 1,5 & 3,2 & 33,6 & 32,9 & 30,8 & $-0,7$ & -2 \\
\hline 9-E.A.S.Q. & $-1,8$ & $-0,4$ & $-0,4$ & 1,4 & 0 & 36,1 & 38,9 & 39,3 & 2,8 & 0 \\
\hline 10-F.M.B. & $-0,7$ & 1,2 & 0,8 & 1,9 & $-0,4$ & 27 & 27,8 & 26,3 & 0,8 & $-1,5$ \\
\hline 11-F.G. & $-2,8$ & $-2,9$ & $-1,8$ & $-0,1$ & 1,1 & 30,4 & 29,4 & 28,9 & -1 & $-0,5$ \\
\hline 12-J.L. & $-7,3$ & $-5,7$ & $-8,4$ & 1,6 & $-2,7$ & 36,5 & 37,1 & 33,5 & 0,6 & $-3,6$ \\
\hline 13-J.C.C. & -5 & 3 & 2,3 & 8 & $-0,7$ & 37,8 & 38,4 & 37,8 & 0,6 & $-0,6$ \\
\hline 14-K.E.S. & $-2,4$ & $-0,4$ & $-1,3$ & 2 & $-0,9$ & 44,6 & 42,2 & 44,3 & $-2,4$ & 2 , \\
\hline 15-L.M.D. & 3,1 & 3,1 & 4,7 & 0 & 1,6 & 32,2 & 34,1 & 32,7 & 1,9 & -1 \\
\hline 16-M.B.B. & 2,2 & 3,2 & 4 & 1 & 0,8 & 29,8 & 29,5 & 29,3 & $-0,3$ & -0, \\
\hline 17-M.M.V & $-1,6$ & -2 & $-1,5$ & $-0,4$ & 0,5 & 48,5 & 48,6 & 48,7 & 0,1 & 0 , \\
\hline 18-M.C.F. & $-3,4$ & $-1,4$ & $-3,1$ & 2 & $-1,7$ & 38,9 & 35,3 & 33,8 & $-3,6$ & -1 \\
\hline 19-R.B. & $-1,1$ & 2,4 & 2,2 & 3,5 & $-0,2$ & 40,5 & 37,4 & 33,7 & $-3,1$ & $-3,7$ \\
\hline 20-T.A.L. & $-6,4$ & $-2,7$ & $-3,3$ & 3,7 & $-0,6$ & 31 & 33,5 & 29,8 & 2,5 & -3 \\
\hline 21-V.O. & $-3,2$ & $-1,3$ & -1 & 1,9 & 0,3 & 42,1 & 41 & 41,6 & $-1,1$ & 0 , \\
\hline
\end{tabular}


TABELA A-13: Grupo experimental

pacientes Pg-Nperp Pg-Nperp Pg-Nperp Pg-Nperp 2- Pg-Nperp SN.PP SN.PP

1-A.C.S.

$\begin{array}{rrrr}-10 & -10,5 & -8,3 & -0,5\end{array}$

2-A.O.M.

$-6,3 \quad-8,4 \quad-10,7$

$-0,5$

3-2

SN.PP 1

N.PP 2 SN.P

$\begin{array}{lll} & 2-1 & 3-2\end{array}$

3-A.B.M.

$-3,2 \quad-1,7 \quad-0,2$

$-2,1$

$-2,3$

5

5,3

$10,7 \quad 2,4$

0

4-B.F.B.

$-0,4$

1,5

1,5

3,7

$5,2 \quad 0,3$

$-0,1$

5-C.F.B.

$-5,9$

24,5

2,4

2,5

4,8

3,6

$\begin{array}{lll}3,2 & -0,1 & -0,4\end{array}$

6-C.V.C.

$-6,6 \quad-7,6 \quad-9,1$

1,3

6,8

4,9

$3,3 \quad 0,1 \quad-1,6$

7-D.P.A.

$-2,6$

$-6,1$

$-1$

$-1,5$

6,1

7,9

$\begin{array}{lll}9 & 1,1 & 1,1\end{array}$

8-D.S.A.

4,4

6,3

0,8

6,9

6,7

$\begin{array}{lll}6 & -0,9 & 0,8\end{array}$

9-E.A.S.Q.

$-5,5$

$-3,7$

8,1

1,9

10-F.M.B.

11-F.G.

12-J.L.

$-0,1$

$-6,6$

1,8

$-2,9$

10,3

6,3

$\begin{array}{lll}5,8 & -0,4 & -0,5\end{array}$

1,8

$-0,6$

10,7

6,4

$\begin{array}{lll}5,7 & -3,9 & -0,7\end{array}$

$\begin{array}{llll}4,1 & 6,3 & 3,7 & 2,2\end{array}$

$-2,6$

8,4

10

$11,7 \quad-0,7$

1,7

$0,2 \quad 5,2 \quad 0,8$

13-J.C.C.

$-11,2$

$-4,4$

$4,8 \quad 4,3$

$\begin{array}{rrr}6,2 & -2 & -0,2\end{array}$

14-K.E.S.

$-13,7$

$-14,2 \quad-15,2$

$\begin{array}{lll}4 & -0,5 & -0,3\end{array}$

15-L.M.D.

$-1,3$

$-9,9$

$-8,4$

$\begin{array}{lll}-1 & 7,8 & 7,9\end{array}$

$1,5 \quad 5,9 \quad 7,9$

$-4,1 \quad 6,3 \quad 5,4$

$2,2 \quad 10,5 \quad 7,6$

$\begin{array}{lll}-0,3 & 9,6 & 9,1\end{array}$

17-M.M.V

$-3,3 \quad-3,5 \quad-1,3$

$\begin{array}{lll}-14 & -19,8 & -20,1\end{array}$

18-M.C.F.

19-R.B.

$\begin{array}{lll}-5,7 & -5,4 & -1,2\end{array}$

$4,2 \quad 11,8$

10,6

$-2,1 \quad 7,6$

7,8

$\begin{array}{lll}7 & 2,4 & -4,5\end{array}$

20-T.A.L.

$11,1 \quad 9,8 \quad 14,6$

4,8

8,4

8,1

$\begin{array}{lll}8 & 0,1 & 0,1\end{array}$

$\begin{array}{lll}7,6 & 2 & -0,3\end{array}$

$\begin{array}{lll}4,2 & -0,9 & -1,2\end{array}$

$\begin{array}{lll}7 & -2,9 & -0,6\end{array}$

$\begin{array}{lll}8,4 & -0,5 & -0,7\end{array}$

$\begin{array}{lll}11,7 & -1,2 & 1,1\end{array}$

$\begin{array}{llll}-0,9 & -1,2 & -3,4 & -0,3\end{array}$

$-2,2 \quad 4,1$

$8,9 \quad 0,2 \quad 1,1$

$4,4 \quad-0,3 \quad-3,7$

21-V.O.

$-0,3$

5,1

$4,1 \quad 1$

$-1$ 
TABELA A-14: Grupo experimental SN,OP SN,OP SN,OP SN,OP SN,OP

\begin{tabular}{|c|c|c|c|c|c|c|c|c|c|c|}
\hline pacientes & 1 & 2 & 3 & $2-1$ & $3-2$ & TH 1 & $\mathrm{TH} 2$ & TH 3 & TH 2-1 & TH 3-2 \\
\hline 1-A.C.S. & 14,9 & 13,2 & 18,4 & $-1,7$ & 5,2 & 3,9 & 1,8 & 1,8 & $-2,1$ & 0 \\
\hline 2-A.O.M. & 26,6 & 8,3 & 14,5 & $-18,3$ & 6,2 & 5,7 & 2,7 & 2,4 & -3 & $-0,3$ \\
\hline 3-A.B.M. & 16,9 & 10,1 & 8,9 & $-6,8$ & $-1,2$ & 3,3 & 2,8 & 1,8 & $-0,5$ & -1 \\
\hline 4-B.F.B. & 11,8 & 12,6 & 11,5 & 0,8 & $-1,1$ & 7,3 & 3,2 & 2,6 & $-4,1$ & $-0,6$ \\
\hline 5-C.F.B. & 15,5 & 14,8 & 16 & $-0,7$ & 1,2 & 5,3 & 2,9 & 2,9 & $-2,4$ & 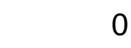 \\
\hline 6-C.V.C. & 21,6 & 19 & 16,8 & $-2,6$ & $-2,2$ & 7 & 3,8 & 4,9 & $-3,2$ & 1,1 \\
\hline 7-D.P.A. & 9,1 & 11,7 & 15,9 & 2,6 & 4,2 & 3,7 & 2,6 & 2,6 & $-1,1$ & 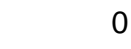 \\
\hline 8-D.S.A. & 20 & 14,6 & 10,7 & $-5,4$ & $-3,9$ & 1,2 & 1,9 & 2,2 & 0,7 & 0,3 \\
\hline 9-E.A.S.Q. & 22,3 & 23,9 & 14,6 & 1,6 & $-9,3$ & 4,7 & 4,1 & 4,7 & $-0,6$ & 0,6 \\
\hline 10-F.M.B. & 2,7 & 9,8 & 9,4 & 7,1 & $-0,4$ & 5 & 3,3 & 1,1 & $-1,7$ & $-2,2$ \\
\hline 11-F.G. & 13,1 & 8,6 & 2,5 & $-4,5$ & $-6,1$ & 2,2 & 2,2 & 2,3 & 0 & 0,1 \\
\hline 12-J.L. & 18,9 & 15,3 & 20,8 & $-3,6$ & 5,5 & 3,2 & 0,7 & 1,7 & $-2,5$ & 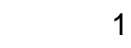 \\
\hline 13-J.C.C. & 23 & 15,1 & 19,6 & $-7,9$ & 4,5 & 3,4 & 2,7 & 2,9 & $-0,7$ & 0,2 \\
\hline 14-K.E.S. & 23,8 & 15,1 & 25,3 & $-8,7$ & 10,2 & 5,6 & 3,3 & 3,9 & $-2,3$ & 0,6 \\
\hline 15-L.M.D. & 17,7 & 10,1 & 3,8 & $-7,6$ & $-6,3$ & 9,1 & 3,7 & 4,6 & $-5,4$ & 0,9 \\
\hline 16-M.В.B. & 10,4 & 12,4 & 14,1 & 2 & 1,7 & 3,3 & 2,2 & 2 & $-1,1$ & $-0,2$ \\
\hline 17-M.M.V & 24,1 & 20,9 & 30 & $-3,2$ & 9,1 & 4,6 & 2,8 & 3,3 & $-1,8$ & 0,5 \\
\hline 18-M.C.F. & 26 & 22 & 14 & -4 & -8 & 3,3 & 2,2 & 1,8 & $-1,1$ & $-0,4$ \\
\hline 19-R.B. & 11 & 10,6 & 10,2 & $-0,4$ & $-0,4$ & 10,7 & 5,7 & 4,7 & -5 & -1 \\
\hline 20-T.A.L. & 10,9 & 8,8 & 4 & $-2,1$ & $-4,8$ & 0,5 & 2,2 & 1,9 & 1,7 & $-0,3$ \\
\hline 21-V.O. & 13,5 & 15,6 & 11,6 & 2,1 & -4 & 0,2 & 2,2 & 0,9 & 2 & $-1,3$ \\
\hline
\end{tabular}


TABELA A-15: Grupo experimental

\begin{tabular}{|c|c|c|c|c|c|c|c|c|c|c|}
\hline pacientes & TV 1 & TV 2 & TV 3 & TV 2-1 & TV 3-2 & ${ }_{1}^{\text {Rel molar }}$ & $\begin{array}{c}\text { Rel molar } \\
2\end{array}$ & $\begin{array}{c}\text { Rel molar } \\
3\end{array}$ & $\begin{array}{c}\text { Rel molar } \\
2-1\end{array}$ & $\begin{array}{c}\text { Rel molar } \\
3-2\end{array}$ \\
\hline 1-A.C.S. & $-1,5$ & 1,3 & 0,4 & 2,8 & $-0,9$ & 0,4 & $-0,2$ & $-0,4$ & $-0,6$ & $-0,2$ \\
\hline 2-A.O.M. & $-1,2$ & 1,7 & 0,3 & 2,9 & $-1,4$ & $-0,2$ & 0,1 & $-0,1$ & 0,3 & $-0,2$ \\
\hline 3-A.B.M. & $-2,5$ & 1,6 & 0,2 & 4,1 & $-1,4$ & $-0,4$ & -1 & 0,8 & $-0,6$ & 1,8 \\
\hline 4-B.F.B. & $-1,7$ & 2,3 & 1 & 4 & $-1,3$ & 0,4 & 0,4 & 0,1 & 0 & $-0,3$ \\
\hline 5-C.F.B. & $-1,8$ & 2 & $-0,4$ & 3,8 & $-2,4$ & $-0,1$ & 0 & $-0,2$ & 0,1 & $-0,2$ \\
\hline 6-C.V.C. & $-1,1$ & 2,1 & 0,8 & 3,2 & $-1,3$ & $-0,4$ & $-0,5$ & 0 & $-0,1$ & 0,5 \\
\hline 7-D.P.A. & $-1,9$ & 1,3 & $-0,6$ & 3,2 & $-1,9$ & $-0,1$ & $-0,9$ & $-0,4$ & $-0,8$ & 0,5 \\
\hline 8-D.S.A. & $-1,5$ & 1,2 & 0,3 & 2,7 & $-0,9$ & $-0,1$ & $-0,6$ & -1 & $-0,5$ & $-0,4$ \\
\hline 9-E.A.S.Q. & $-2,2$ & 1,5 & $-1,4$ & 3,7 & $-2,9$ & $-0,1$ & $-0,4$ & $-0,1$ & $-0,3$ & 0,3 \\
\hline 10-F.M.B. & $-1,8$ & 1,4 & $-0,4$ & 3,2 & $-1,8$ & 0 & $-0,1$ & $-0,4$ & $-0,1$ & $-0,3$ \\
\hline 11-F.G. & $-1,6$ & 1,4 & 0,4 & 3 & -1 & $-0,5$ & 0,4 & $-0,6$ & 0,9 & -1 \\
\hline 12-J.L. & -2 & 1,2 & 0,5 & 3,2 & $-0,7$ & 1 & 0,1 & $-0,3$ & $-0,9$ & $-0,4$ \\
\hline 13-J.C.C. & $-1,8$ & 1,2 & 0,1 & 3 & $-1,1$ & $-0,1$ & $-0,4$ & $-0,2$ & $-0,3$ & 0,2 \\
\hline 14-K.E.S. & $-0,9$ & 1,7 & 0,2 & 2,6 & $-1,5$ & 0,2 & 0,1 & $-1,3$ & $-0,1$ & $-1,4$ \\
\hline 15-L.M.D. & $-1,4$ & 0,8 & $-0,4$ & 2,2 & $-1,2$ & $-0,3$ & $-0,3$ & $-0,3$ & 0 & 0 \\
\hline 16-M.B.B. & -2 & 1 & $-0,4$ & 3 & $-1,4$ & 0,2 & $-0,9$ & $-0,2$ & $-1,1$ & 0,7 \\
\hline 17-M.M.V & $-1,5$ & 2,5 & 1,2 & 4 & $-1,3$ & $-0,1$ & $-0,2$ & $-0,1$ & $-0,1$ & 0,1 \\
\hline 18-M.C.F. & $-4,1$ & 0,8 & $-0,7$ & 4,9 & $-1,5$ & 0,4 & $-0,4$ & 0,3 & $-0,8$ & 0,7 \\
\hline 19-R.B. & $-1,9$ & 1,2 & 0,6 & 3,1 & $-0,6$ & 0,6 & 1 & $-0,1$ & 0,4 & $-1,1$ \\
\hline 20-T.A.L. & $-1,4$ & 1,5 & 0,2 & 2,9 & $-1,3$ & 0,2 & 0,3 & 0,3 & 0,1 & 0 \\
\hline 21-V.O. & $-1,1$ & 0,4 & $-0,4$ & 1,5 & $-0,8$ & 0,3 & 0,2 & $-0,4$ & $-0,1$ & $-0,6$ \\
\hline
\end{tabular}


Apêndices

TABELA A-16: Grupo experimental

MS-PP MS-PP MI-GoMe MI-GoMe MI-GoMe Ml-GoMe Ml-GoMe

\begin{tabular}{|c|c|c|c|c|c|c|c|c|c|c|}
\hline & & & & & & & & & & \\
\hline 1-A.C.S. & 25,1 & 26,6 & 27,4 & 1,5 & 0,8 & 29 & 31,5 & 32,9 & 2,5 & 1,4 \\
\hline 2-A.O.M. & 21,2 & 24,9 & 27,7 & 3,7 & 2,8 & 28,7 & 29,7 & 30,4 & 1 & 0,7 \\
\hline 3-A.B.M. & 25,5 & 26,7 & 24,2 & 1,2 & $-2,5$ & 30,6 & 30,6 & 31,9 & 0 & 1,3 \\
\hline 4-B.F.B. & 20,7 & 22,8 & 25,4 & 2,1 & 2,6 & 28,7 & 30,6 & 33,5 & 1,9 & 2,9 \\
\hline 5-C.F.B. & 20,4 & 22,3 & 22,7 & 1,9 & 0,4 & 29,5 & 30,1 & 32,4 & 0,6 & 2,3 \\
\hline 6-C.V.C. & 21,9 & 22,2 & 24,9 & 0,3 & 2,7 & 26,1 & 29,5 & 29,9 & 3,4 & 0,4 \\
\hline 7-D.P.A. & 28,7 & 29 & 30,1 & 0,3 & 1,1 & 33,9 & 36,3 & 37,1 & 2,4 & 0,8 \\
\hline 8-D.S.A. & 21,6 & 23,4 & 23,2 & 1,8 & $-0,2$ & 24,4 & 25,5 & 24,7 & 1,1 & $-0,8$ \\
\hline 9-E.A.S.Q. & 26,3 & 26,6 & 28,8 & 0,3 & 2,2 & 36 & 34,7 & 37,2 & $-1,3$ & 2,5 \\
\hline 10-F.M.B. & 24,8 & 23,7 & 23,8 & $-1,1$ & 0,1 & 28 & 28,8 & 29,8 & 0,8 & 1 \\
\hline 11-F.G. & 22,9 & 25 & 25,5 & 2,1 & 0,5 & 26,7 & 28,8 & 28,1 & 2,1 & $-0,7$ \\
\hline 12-J.L. & 25,5 & 24,4 & 24,5 & $-1,1$ & 0,1 & 32,9 & 32,8 & 35,1 & $-0,1$ & 2,3 \\
\hline 13-J.C.C. & 22,5 & 23,5 & 22,7 & 1 & $-0,8$ & 34,5 & 34,6 & 35,6 & 0,1 & 1 \\
\hline 14-K.E.S. & 22,3 & 26,1 & 26,3 & 3,8 & 0,2 & 30,4 & 31,2 & 32,5 & 0,8 & 1,3 \\
\hline 15-L.M.D. & 23,7 & 29,6 & 30,3 & 5,9 & 0,7 & 28,1 & 31,1 & 31,4 & 3 & 0,3 \\
\hline 16-M.B.B. & 26,2 & 27,6 & 26,7 & 1,4 & $-0,9$ & 32,8 & 33,3 & 34,5 & 0,5 & 1,2 \\
\hline 17-M.M.V & 19,5 & 19,4 & 20,3 & $-0,1$ & 0,9 & 27,1 & 29,4 & 30,5 & 2,3 & 1,1 \\
\hline 18-M.C.F. & 19,1 & 21 & 21,9 & 1,9 & 0,9 & 29,4 & 32 & 31,8 & 2,6 & $-0,2$ \\
\hline 19-R.B. & 24,7 & 26,3 & 26,2 & 1,6 & $-0,1$ & 33,5 & 33,3 & 33,1 & $-0,2$ & $-0,2$ \\
\hline 20-T.A.L. & 24,3 & 24,2 & 24,7 & $-0,1$ & 0,5 & 26,9 & 27,3 & 28,8 & 0,4 & 1,5 \\
\hline 21-V.O. & 21,6 & 24,7 & 26 & 3,1 & 1,3 & 24,7 & 28,2 & 29,1 & 3,5 & 0,9 \\
\hline
\end{tabular}

